\title{
Using evidence of multiple study designs in systematic reviews
}

Citation for published version (APA):

Peinemann, F. (2015). Using evidence of multiple study designs in systematic reviews. [Doctoral Thesis, Maastricht University]. Datawyse / Universitaire Pers Maastricht. https://doi.org/10.26481/dis.20150611fp

Document status and date:

Published: 01/01/2015

DOI:

10.26481/dis.20150611fp

Document Version:

Publisher's PDF, also known as Version of record

\section{Please check the document version of this publication:}

- A submitted manuscript is the version of the article upon submission and before peer-review. There can be important differences between the submitted version and the official published version of record.

People interested in the research are advised to contact the author for the final version of the publication, or visit the DOI to the publisher's website.

- The final author version and the galley proof are versions of the publication after peer review.

- The final published version features the final layout of the paper including the volume, issue and page numbers.

Link to publication

\footnotetext{
General rights rights.

- You may freely distribute the URL identifying the publication in the public portal. please follow below link for the End User Agreement:

www.umlib.nl/taverne-license

Take down policy

If you believe that this document breaches copyright please contact us at:

repository@maastrichtuniversity.nl

providing details and we will investigate your claim.
}

Copyright and moral rights for the publications made accessible in the public portal are retained by the authors and/or other copyright owners and it is a condition of accessing publications that users recognise and abide by the legal requirements associated with these

- Users may download and print one copy of any publication from the public portal for the purpose of private study or research.

- You may not further distribute the material or use it for any profit-making activity or commercial gain

If the publication is distributed under the terms of Article $25 \mathrm{fa}$ of the Dutch Copyright Act, indicated by the "Taverne" license above, 


\section{Using evidence of multiple study designs in systematic reviews}

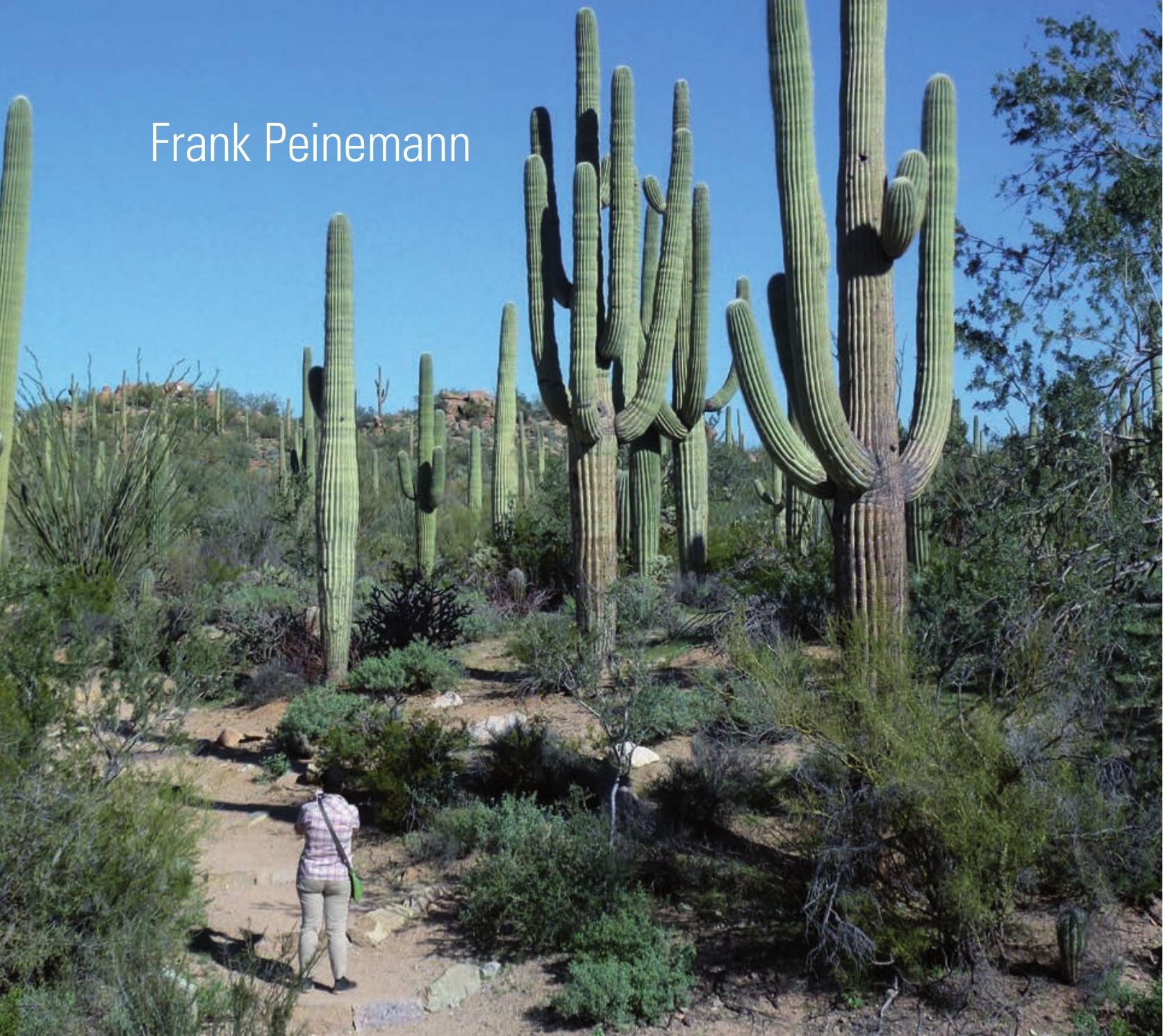


Production: Datawyse | Universitaire Pers Maastricht

Cover design: Deborah Stijnen

Copyright (C) Frank Peinemann, Maastricht 2015

ISBN 9789461593924

All rights reserved. No part of this thesis may be reproduced or transmitted in any form or by any means, electronic or mechanical, including photocopying, recording or any information storage or retrieval system, without permission in writing from the author, or, when appropriate, from the publishers of the publications.

The research presented in this thesis was conducted at the School for Public Health and Primary Care (CAPHRI), Department of Family Medicine, Maastricht University. CAPHRI participates in the Netherlands School of Primary Care Research (CaRe), acknowledged by the Royal Dutch Academy of Science (KNAW). CAPHRI was classified as 'excellent' by the external evaluation committee of leading international experts that reviewed CAPHRI in December 2010. 


\title{
Using evidence of multiple study designs in systematic reviews
}

\begin{abstract}
PROEFSCHRIFT
ter verkrijging van de graad van doctor aan de Universiteit Maastricht, op gezag van de Rector Magnificus, Prof.dr. L.L.G. Soete, volgens het besluit van het College van Decanen, in het openbaar te verdedigen op donderdag 11 juni 2015 om 14:00 uur
\end{abstract}

door

Frank Peinemann

Geboren op 27 december 1959 te Northeim

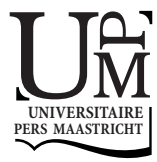




\section{Promotores}

Prof.dr. J.M.P. Kleijnen

\section{Copromotores}

Prof.dr. T. van der Weijden

\section{Beoordelingscommissie}

Prof.dr. M.P.A. Zeegers (voorzitter)

Prof.dr. R.A. de Bie

Prof.dr. C.D. Dirksen

Dr. R.J.P. Scholten, Dutch Cochrane Centre, Utrecht

Prof.dr. M.W. van Tulder, Vrije Universiteit Amsterdam 


\section{Table of contents}

CHAPTER 1 General introduction

CHAPTER 2 Using multiple types of studies in systematic reviews of health care interventions - a systematic review

CHAPTER 3 Autologous hematopoietic stem cell transplantation following high dose chemotherapy for non-rhabdomyosarcoma soft tissue sarcomas. 41

CHAPTER 4 First-line matched related donor hematopoietic stem cell transplantation compared to immunosuppressive therapy in acquired severe aplastic anemia

CHAPTER 5 Permanent interstitial low-dose-rate brachytherapy for patients with localised prostate cancer: a systematic review of randomised and nonrandomised controlled clinical trials

CHAPTER 6 Negative-pressure wound therapy: Systematic review of randomized controlled trials

CHAPTER 7 Development of an algorithm to provide awareness in choosing study designs for inclusion in systematic reviews of health care interventions - a method study

CHAPTER 8 General discussion 195

Summary 209

Valorisation

Curriculum vitae 219

Publications 221 



\section{CHAPTER 1}

\section{General introduction}



In this chapter a description is given of the main characteristics of systematic reviews such as the aim and definition of a systematic literature review and the principles of developing a structured research question. A crucial part of a systematic review is to limit the inclusion criteria with regard to the study design. Subsequently, important issues of study designs are described such as explanatory and pragmatic study designs, the evaluation of adverse events, practical or ethical concerns that may arise with certain study designs, and the so-called hierarchy of evidence. Finally, the aim of the research project and the outline of this thesis are addressed.

\section{Aim of a systematic review}

Systematic reviews of health care interventions aim to summarize evidence in a systematic and transparent manner and by doing so to generate new knowledge that can help people make decisions relevant to health [1,2]. According to the Centre for Reviews and 'Dissemination's guidance for undertaking reviews in health care, systematic reviews aim to identify, evaluate and summarise the findings of all relevant individual studies, thereby making the available evidence more accessible to decisionmakers [3]. According to the Medical Research Council, the evaluation of complex interventions such as change of behavior or prevention is also within the scope of systematic review of interventions [4].

\section{Definition of a systematic review}

A meaningful definition of a systematic review is given in the Cochrane Handbook for systematic reviews of interventions [5], quote:

A systematic review attempts to collate all empirical evidence that fits pre-specified eligibility criteria in order to answer a specific research question. It uses explicit, systematic methods that are selected with a view to minimizing bias, thus providing more reliable findings from which conclusions can be drawn and decisions made. The key characteristics of a systematic review are:

- a clearly stated set of objectives with pre-defined eligibility criteria for studies;

- an explicit, reproducible methodology;

- a systematic search that attempts to identify all studies that would meet the eligibility criteria;

- an assessment of the validity of the findings of the included studies, for example through the assessment of risk of bias; and

- a systematic presentation, and synthesis, of the characteristics and findings of the included studies. 
Ideally, the pre-specified eligibility criteria and the planned methodological approaches are published in a protocol beforehand. The Cochrane Collaboration, for example, requires the publication of a protocol as an initial step in conducting a Cochrane systematic review. Moher 2013 addressed the problem of duplicate systematic reviews [6]. PROSPERO an international prospective register of systematic reviews [7] aims to avoid unplanned duplication by also providing information about other ongoing systematic reviews. Waugh 2013 enumerated potential barriers that may contest the effectiveness of PROSPERO [8]. For instance, people might use the published information to speed up their own secret review of the same topic or may copy the ideas. Progress may be hampered if the authors who registered their plans lose interest while this refrains others from writing a review on the same topic. The Cochrane Collaboration requests registration of all of their systematic reviews and thereafter rejects inquiries addressing the same topic. For example, the Cochrane Skin Group (CSG) accepted the title 'Balneophototherapy for chronic plaque type psoriasis' in 2006 [9]. In 2013, the authors withdraw their application after being unable to develop a protocol and the Cochrane Sking Group posted an announcement wanting authors to form a new group [10]. During this 7-year time period other persons interested in preparing this review were prevented from doing so.

In a systematic review, the applied search strategy and the assessment of studies as well as the analysis of results have to match the procedures pre-determined in the protocol. Authors should avoid deviations from the protocol or carefully explain the reasons.

There may be some difficulties to separate systematic reviews from nonsystematic reviews. First, some use the expression 'narrative review' to denote nonsystematic reviews. Popay 2006 explains the ambiguous nature of the term 'narrative' [11]. 'Narrative' means storytelling and 'narrative review' is used as a phrase by some to describe more traditional literature reviews that are neither systematic nor transparent. However, a 'narrative synthesis' is an integral part of a systematic review using words and text to summarize the findings/results. According to the Cochrane Handbook, analysis of included studies in a systematic review may be 'narrative' or quantitative and a 'narrative synthesis' may use subjective rather than statistical methods where meta-analysis may be either not feasible or not sensible [12]. Thus, 'narrative review' may be a misnomer and 'nonsystematic review' should be the preferred term.

Second, both publication types 'narrative and nonsystematic review' may appear comprehensive at a first glance. However, they are profoundly different. In a nonsystematic review, an expert provides a broad overview of relevant information about a particular field [13]. In general, it lacks methodological information about how and where the included publications were searched and how they were selected and it lacks the reasons why some studies were given more emphasis than others. An appraisal of the risk of bias and a quantitative summary of the literature is often absent [14]. The most distinctive characteristics that are present in a systematic review and 
that are not present in a nonsystematic review may be a study protocol, an analysis plan, a literature search strategy, and a description of the selection of suitable studies in accordance with prospectively defined inclusion and exclusion criteria [15]. It is important to know whether a conclusion or recommendation concerning the benefit of a health care intervention is based on data summarized in a systematic or a nonsystematic review. The systematic review of randomized controlled trials (RCTs) is regarded as the highest level of evidence available if confined to effects of interventions [16]. Some systematic reviews, called overviews of reviews (umbrella reviews), are designed to compile evidence from multiple systematic reviews without evaluating primary studies [17]. In a previous paper, we applied the following minimal inclusion criteria to distinguish systematic reviews from nonsystematic reviews: The authors were required to report multiple literature sources including at least MEDLINE and The Cochrane Library and had to report the search strategy including the search date [18]. Difficulties in separating systematic from nonsystematic reviews may happen with experts in evidence-based medicine exemplified by an evidence report in which the experts classified 10 reviews as systematic although nine of those were in fact nonsystematic [19].

\section{Developing a research question}

Preparing a systematic review of interventions begins with a health care question to clarify which intervention provides more benefit and less harm to patients than an alternative. The starting point and fundamental component of a systematic review of health care interventions is a structured clinical question that should include four essential constituents, that is, the type of participants $(P)$, intervention (I), comparator (C), and outcome (O) commonly denoted as PICO $[3,20]$. These four items can be supplemented by timing $(\mathrm{T})$ and setting $(\mathrm{S})$, two other important features of a systematic review, to create the so-called PICOTS typology [21]. A further extension embraces the study design (SD) to complete all major items of a search strategy (PICOTS-SD) [22]. PICOTS-SD also leads to a clear and comprehensive definition of the inclusion criteria relevant to a systematic review.

\section{Explanatory and pragmatic study designs}

A systematic review may evaluate benefit and harm of a health care intervention in the context of 'efficacy' and 'effectiveness' [23]. Both terms sound similar but may be easily mixed up. Therefore, we adopt the terms 'explanatory study design' and 'pragmatic study design' in the present thesis instead [24]. Explanatory study designs address the question whether the intervention of interest can work in principle in the ideal study setting (RCT) and typically provides a conclusion for an average patient only [25]. Con- 
ducting an RCT can mean the exclusion of female gender, persons beyond a certain age, patients not treated in primary care hospitals, outpatient treatment, participants with co-morbidities, and an allocation to treatment groups by discretion of the medical doctor. In some situations RCTs are not feasible, for example, due to ethical concerns or strong patients' preferences and the results may not be applicable to everyday practice [26]. Pragmatic study designs aim to show that interventions will work under every day circumstances, for example, in a general practice [27]. As pragmatic study designs consider a variety of patients' characteristics, the conclusions based on the results may typically apply for certain subgroups of patients. The reporting of the range of applicability should always accompany the reporting of the estimated effect. Some authors criticized that many public commissioners provide predominantly funding for explanatory study designs research [27]. To accommodate the evaluation of various research questions concerning explanatory study designs and pragmatic study designs, the inclusion of more than one study design appears to be necessary. If multiple study designs are included in a systematic review then they should be well selected and customized to provide answers to the questions of interest. Efficiency, also known as costeffectiveness, addresses the question whether the intervention of interest is value for money and should be paid for. The costs are usually not the issue of systematic reviews but of health technology assessments.

\section{Adverse events}

Concerning medical interventions such as surgery, drugs, or behavioural counselling, adverse events can be crucial for their legal approval or their restriction to particular indications. The detection of severe adverse events may give rise to their discontinuation and removal from the market. The comprehensive detection of adverse events may need a long-term observation of a large number of participants and an experimental research design could become a costly and unsuccessful enterprise.

\section{Practical or ethical concerns}

A practical concern may arise when the low number of patients with a specific rare disease such as acquired severe aplastic anemia makes it difficult to conduct an RCT. An ethical con-cern may arise with the treatment of certain severe diseases such as random allocation to a new experimental treatment in patients with pancreatic cancer. Another ethical concern may arise if a short-time survival is expected to differ between test and control intervention. 


\section{Hierarchy of evidence}

There appears to be some variation in the hierarchy among some authors and institutions issuing evidence-based guidelines or systematic reviews. All agree that RCTs have the highest level of evidence with respect to minimising risk of bias. The prospective nonrandomized controlled clinical trial (CCT) has an experimental design and its internal validity should be regarded lower than a randomized trial but higher than an observational study. Prospective cohort studies have a potential for a lower risk of bias than retrospective cohort studies because they have lower risk of measurement bias and confounding [28]. In cohort studies groups are defined by exposure whereas in case-control studies groups are defined by disease status. Both points are acknowledged in the hiearchy of evidence by some but not all authors. Case series and case reports are descriptions of one or more individual cases. Some authors combine these two designs in one category while others place case series in a higher level. The Centre for Evidence-Based Medicine (CEBM), the National Institute of Health and Care Excellence (NICE), and the Centre for Reviews and Dissemination (CRD) $[3,29,30]$ are some of major institutions that propose study design classification trees. A critical study characteristic is the concurrent versus the historical control group. Concurrent means that the participants in the test and in the control group are treated and followed within the same observation period. Historical means that the participants were treated and followed in a different observation period introducing potential bias that results, for example, from different study conditions due to medical progress. Another critical study characteristic is the allocation of participants to the test or control arm by random and concealed allocation versus by discretion of the study investigator. Single-arm studies such as case series and case reports cannot provide information whether the test intervention works better than a control intervention. Another single-arm study design is called the within group comparison which has also been referred to as before and after study in a previous CRD report.

A considerable proportion of researchers appears dichotomized to either accept only the randomized design for scientific evidence on health care interventions or to also accept designs without randomization as sufficient [31]. A 'hierarchy of evidence' was established that clearly downgrades designs other than randomized studies regardless of the type of outcome evaluated [16]. Some authors questioned this hierarchy $[32,33]$. Advantages and disadvantages of various designs have been reported repeatedly and some authors support the integration of multiple study designs with respect to the outcome of interest [31]. The selection of study design is dependent on the research question such as the intended effect under ideal or under daily health care conditions, the adverse event, or the health-related quality of life or costs of (the implementation of) an intervention. The effects of drug therapy, medical device therapy, or the treatment of life-threatening rare diseases may be best evaluated by different study designs. The limitations of exclusively using data from RCTs to evaluate 
whether an intervention might work have been discussed [26]. The number of study participants may be too low to detect certain severe adverse events especially if the events are rare. Therefore, RCTs may not be appropriate to estimate the incidence of rare but important adverse events. Study designs that incorporate the data of a large number of participants of interest such as case control studies, case series, registry analyses, or cross-section or qualitative analyses may complement the information on severe adverse events.

\section{Aim of the research project}

The aim of this thesis is to investigate the advantages and disadvantages of using various study designs to answer specific clinical research questions within systematic reviews and to develop and pilot test an algorithm to guide systematic reviewers in their decision to choose appropriate study designs.

We will discuss the following research questions in this thesis:

1. What is known in the published literature about the pros and cons of integration of multiple study types in systematic reviews?

2. What can be learnt from conducting systematic reviews about topics that may require the inclusion of multiple study designs, assuming that more than one study design may be essential to gather sufficient data for answering the objectives of the review.

3. What is the preferred content and format of a straightforward algorithm for integration of various study designs in a systematic review, that incorporates major study characteristics as decision points and that allows consideration of practical concerns?

4. Can the algorithm hold its promise as a useful guide for choosing appropriate study designs by testing its feasibility and applying it to existing systematic reviews?

\section{Outline of this thesis}

Chapter 2 includes the main method paper 'Using multiple types of studies in systematic reviews of health care interventions - a systematic review' that answers research question 1. It contains the search strategy for literature retrieval about the characteristics of various study designs and recommendations for integrating them in systematic reviews of health care interventions. The specific abilities of individual study designs to answer particular research questions are presented. The data from studies are summarized that evaluated whether the effects reported in RCTs might have a direction or magnitude that vary in general from those in nonrandomized trials. 
Chapter 3 to chapter 6 include papers of systematic reviews on various health care interventions that answer research question 2 . All systematic reviews concern nonmedicinal treatment. Two systematic reviews address hematopoietic stem cell transplantation in two distinct rare and severe diseases with scarce comparative studies. One systematic review concentrates on patient-centered outcomes in a low-risk stage of a frequent malignant disease. Another systematic review on a surgical intervention relies on RCTs only, but faces the need to compensate data on adverse events by other study designs.

Chapter 7 includes the method manuscript 'Development of an algorithm to provide awareness in choosing study designs for inclusion in systematic reviews of health care interventions - a method study' that answers research question 3. In this chapter, the construction of an algorithm is described as well as the reasoning for choosing specific decision points. It is also explained that the algorithm needs the consideration of practical or ethical concerns and the need to switch the design chosen at first sight to provide a sufficiently pragmatic and flexible tool that is fit for application in the real world. The manuscript also answers the research question 4 . The practical application of the algorithm is described and it is tested whether the potential usefulness of the algorithm can be confirmed in principle by applying it to the four systematic reviews of health care interventions reported in chapters 3 to 6.

Chapter 8 accommodates the general discussion of this thesis. It contains the summary of the main findings, its strengths and limitations. It also contains the consideration of agreements and disagreements expressed in other studies or reviews. The concepts of evidence-based medicine and best available evidence are crucial for interpreting the findings. Therefore, a separate section was introduced to connect these concepts with the results of the thesis. Finally, conclusions and recommendations for decision makers and further research are drawn. 


\section{References}

1. Liberati A, Altman DG, Tetzlaff J, Mulrow C, Gotzsche PC, loannidis JP et al. The PRISMA statement for reporting systematic reviews and meta-analyses of studies that evaluate health care interventions: explanation and elaboration. PLoS Medicine. 2009;6(7):e1000100.

2. Khan KS, Kunz R, Kleijnen J, Antes G. Five steps to conducting a systematic review. Journal of the Royal Society of Medicine. 2003;96(3):118-21.

3. Systematic reviews. CRD's guidance for undertaking reviews in health care. York: Centre for Reviews and Dissemination, University of York; 2009.

4. Developing and evaluating complex interventions: new guidance. London: Medical Research Council; 2008.

5. Green S, Higgins JPT, Alderson P, Clarke M, Mulrow CD, Oxman AD. Chapter 1: Introduction. In: Higgins JPT, Green S (editors). Cochrane Handbook for Systematic Reviews of Interventions Version 5.1.0 [updated March 2011]. The Cochrane Collaboration; 2011.

6. Moher D. The problem of duplicate systematic reviews. BMJ. 2013;347:f5040.

7. International prospective register of systematic reviews (PROSPERO). York: Centre for Reviews and Dissemination; 2014.

8. Waugh N. Misgivings about PROSPERO in solving the problem of duplicate systematic reviews. BMJ. 2013;347:f5496.

9. Cochrane Skin Group. Balneophototherapy for chronic plaque type psoriasis. Cochrane authors are currently working on this review. No abstract is available at this time. Primary Review Group: Skin Group. Authors: Markus Follmann, Stefan Lange, Sandra Janatzek, Stefanie Thomas, Guido Skipka, Susanne H Ebrahim. Created: Wednesday, November 29, 2006. Internet access date: 11 May 2014.

10. Cochrane Skin Group. Vacant titles. The titles on this page - stalled unpublished or published protocols are not going through our usual title voting process as they are already registered, but they are in need of new teams. The Skin Group is still looking for new teams for the following registered titles: Balneophototherapy for chronic plaque type psoriasis. 4 people have expressed interest in this title, including one consumer. Internet access date: 11 May 2014.

11. Popay J, Roberts H, Sowden A, Petticrew M, Arai L, Rodgers M et al. Guidance on the conduct of narrative synthesis in systematic reviews. Swindon: Economic and Social Research Council; 2006.

12. Deeks JJ, Higgins JPT, Altman DG. Chapter 9: Analysing data and undertaking meta-analyses. In: Higgins JPT, Green S (editors). Cochrane Handbook for Systematic Reviews of Interventions Version 5.1.0 [updated March 2011]. The Cochrane Collaboration; 2011.

13. Cipriani A, Geddes J. Comparison of systematic and narrative reviews: the example of the atypical antipsychotics. Epidemiologia e Psichiatria Sociale. 2003;12(3):146-53.

14. Garg AX, Hackam D, Tonelli M. Systematic review and meta-analysis: when one study is just not enough. Clinical Journal of the American Society of Nephrology. 2008;3(1):253-60.

15. Ressing M, Blettner M, Klug SJ. Systematic literature reviews and meta-analyses: part 6 of a series on evaluation of scientific publications. Deutsches Arzteblatt International. 2009;106(27):456-63.

16. Levels of evidence. Oxford: Centre of Evidence-Based Medicine (CEBM); 2009.

17. Becker LA, Oxman AD. Chapter 22: Overviews of reviews. In: Higgins JPT, Green S (editors). Cochrane Handbook for Systematic Reviews of Interventions Version 5.1.0 (updated March 2011). The Cochrane Collaboration; 2011.

18. Peinemann F, McGauran N, Sauerland S, Lange S. Disagreement in primary study selection between systematic reviews on negative pressure wound therapy. BMC Medical Research Methodology 2008;8:41.

19. Institut fur Qualiat und Wirtschaftlichkeit. Rapid Report N06-02 [in German]: ANHANG B: Liste der gescreenten systematischen Ubersichten. In: Vakuum-versiegelungstherapie von Wunden. Koln: Institut fur Qualiat und Wirtschaftlichkeit; 2007. 
20. Guyatt GH, Oxman AD, Kunz R, Atkins D, Brozek J, Vist G, et al. GRADE guidelines: 2. Framing the question and deciding on important outcomes. Journal of Clinical Epidemiology. 2011;64(4):395-400.

21. Agency for Healthcare Research and Quality. Chapter 1: Introduction. In: Methods Guide for Medical Test Reviews. AHRQ Publication No. 12-EC017. June 2012. Rockville: Agency for Healthcare Research and Quality; 2012.

22. White CM, Ip S, McPheeters M, Carey TS, Chou R, Lohr KN et al. Using existing systematic reviews to replace de novo processes in conducting Comparative Effectiveness Reviews [posted September 2009]. In: Methods Guide for Comparative Effectiveness Reviews. Rockville: Agency for Healthcare Research and Quality; 2009.

23. Haynes B. Can it work? Does it work? Is it worth it? The testing of health care interventions is evolving. BMJ. 1999;319(7211):652-653.

24. Thorpe KE, Zwarenstein M, Oxman AD, Treweek S, Furberg CD, Altman DG et al. A pragmaticexplanatory continuum indicator summary (PRECIS): a tool to help trial designers. Journal of Clinical Epidemiology. 2009;62(5):464-75.

25. Djulbegovic B, Paul A. From efficacy to effectiveness in the face of uncertainty: indication creep and prevention creep. Journal of the American Medical Association. 2011;305(19):2005-6.

26. Victora CG, Habicht JP, Bryce J. Evidence-based public health: moving beyond randomized trials. American Journal of Public Health. 2004;94:400-5.

27. Djulbegovic M, Djulbegovic B. Implications of the principle of question propagation for comparativeeffectiveness and "data mining" research. Journal of the American Medical Association. 2011;305(3):298-9.

28. Campbell PG, Malone J, Yadla S, Chitale R, Nasser R, Maltenfort MG, et al. Comparison of ICD-9-based, retrospective, and prospective assessments of perioperative complications: assessment of accuracy in reporting. Journal of Neurosurgery: Spine 2011;14(1):16-22.

29. Study designs. Oxford: Centre of Evidence-Based Medicine (CEBM); 2013.

30. Reviewing and grading the evidence. In: Guideline Development Methods. London: National Institute for Health and Care Excellence; 2005.

31. Vandenbroucke JP. Observational research, randomised trials, and two views of medical science. PLoS Medicine. 2008;5(3):e67.

32. Concato J, Peduzzi P, Huang GD, O'Leary TJ, Kupersmith J. Comparative effectiveness research: what kind of studies do we need? Journal of Investigative Medicine. 2010;58(6):764-9.

33. Hoppe DJ, Schemitsch EH, Morshed S, Tornetta P, 3rd, Bhandari M. Hierarchy of evidence: where observational studies fit in and why we need them. The Journal of Bone and Joint Surgery: American Volume. 2009;91 Suppl 3:2-9. 



\section{CHAPTER 2}

Using multiple types of studies in systematic reviews of health care interventions a systematic review

Peinemann F, Tushabe DA, Kleijnen J. Using Multiple Types of Studies in Systematic Reviews of Health Care Interventions - A Systematic Review. PLoS One. 2013;8(12):e85035. 


\begin{abstract}
Background A systematic review may evaluate different aspects of a health care intervention. To accommodate the evaluation of various research questions, the inclusion of more than one study design may be necessary. One aim of this study is to find and describe articles on methodological issues concerning the incorporation of multiple types of study designs in systematic reviews on health care interventions. Another aim is to evaluate methods studies that have assessed whether reported effects differ by study types.
\end{abstract}

Methods and findings We searched PubMed, the Cochrane Database of Systematic Reviews, and the Cochrane Methodology Register on 31 March 2012 and identified 42 articles that reported on the integration of single or multiple study designs in systematic reviews. We summarized the contents of the articles qualitatively and assessed theoretical and empirical evidence. We found that many examples of reviews incorporating multiple types of studies exist and that every study design can serve a specific purpose. The clinical questions of a systematic review determine the types of design that are necessary or sufficient to provide the best possible answers. In a second independent search, we identified 49 studies, 31 systematic reviews and 18 trials that compared the effect sizes between randomized and nonrandomized controlled trials, which were statistically different in $35 \%$, and not different in $53 \%$. Twelve percent of studies reported both, different and non-different effect sizes.

Conclusions Different study designs addressing the same question yielded varying results, with differences in about half of all examples. The risk of presenting uncertain results without knowing for sure the direction and magnitude of the effect holds true for both nonrandomized and randomized controlled trials. The integration of multiple study designs in systematic reviews is required if patients should be informed on the many facets of patient relevant issues of health care interventions. 


\section{Introduction}

A systematic review may evaluate different aspects of a health care intervention such efficacy, effectiveness, and adverse events [1]. To accommodate the evaluation of various research questions such as efficacy or effectiveness and outcomes such as survival or severe adverse events, the inclusion of more than one study design appears to be necessary. If multiple study designs are included in a systematic review they should be well selected and customized to answer to the questions of interest. Efficacy addresses the question whether the intervention of interest can work in the ideal study setting (randomized controlled trial) and typically provides a conclusion for an average patient only [2]. In some situations, RCTs are not feasible due to ethical concerns or due to strong patients' preferences and the results may not be applicable to everyday practice [3]. Some nonrandomized studies are designed to evaluate effectiveness and may show that interventions will work under every day circumstances, for example in a general practice [4]. Effectiveness typically provides a conclusion for a subgroup of patients that can be applied to individual patients. Adverse events can be crucial for approval, the restriction of application to particular indications, or the discontinuation of drugs or other interventions. The comprehensive detection of adverse events may need a long-term observation of a large number of participants and an experimental research design could become a costly and unsuccessful enterprise. It appears that many public commissioners provide predominantly funding for efficacy research [4].

A considerable proportion of researchers appears dichotomized to either require the randomized design for scientific evidence on health care interventions or to also accept designs without randomization as sufficient [5]. A 'hierarchy of evidence' was established that clearly downgrades designs other than randomized studies regardless of the type of outcome evaluated [6]. Some authors questioned this hierarchy $[7,8]$. Advantages and disadvantages of various designs have been reported repeatedly and some authors support the integration of multiple study designs with respect to the outcome of interest [5]. We did not find a report that systematically summarized methods papers about usefulness and complexity of integrating various designs in one systematic review. Therefore, we wanted to collect experiences, recommendations, and evidence based on clinical study data reported by others to infer whether one design is superior to others or not and whether alternative or more practical designs could complement or even replace a seemingly favorable design. One aim of this study is to find and describe articles on methodological issues concerning the incorporation of multiple types of study designs in systematic reviews on health care interventions. Another aim is to evaluate methods studies that have assessed whether reported effects differ by study types. Finally, we aimed to identify and summarize qualitative evidence sufficient enough to guide finding and integrating the right research design for answering various clinical questions within systematic reviews of health care interventions. 


\section{Methods}

While preparing this systematic review, we endorsed the PRISMA statement, adhered to its principles and conformed to its checklist (Table S1; online at doi: 10.1371/journal.pone.0085035).

\section{Inclusion criteria}

We included articles reporting on how to integrate different study designs in systematic reviews of health care interventions. We did not include articles merely describing advantages and disadvantages of various designs. We also included articles reporting different results of a particular outcome that depend on the type of design such as in a comparison of a randomized vs. a nonrandomized controlled design. Since we concentrated on the reporting of various study designs, we did not specify on the type of participants, interventions, comparisons, outcomes.

\section{Search strategy}

We searched PubMed, the Cochrane Database of Systematic Reviews, and the Cochrane Methodology Register on 31 March 2012. The search strategy is detailed in Table 1. Terms and syntax used for the search in PubMed were also used for the Cochrane Libarary. The MeSH term "Randomized Controlled Trials as Topic"[MeSH] aims to specifically identify RCTs [9] while the MeSH term "Epidemiologic Studies"[Mesh] comprises nonrandomized study designs [10]. We combined terms of the controlled vocabulary MeSH with text words. We searched PubMed and the Related citations function in PubMed tool to find some pertinent articles that appeared to represent the topic of the present revew. We adopted candidate text words reported by those articles in the title or the abstract to build a search strategy for nonrandomized or observational studies [11-13].

\section{Study selection}

We imported the bibliographic data of the search results into an EndNote X4 database. Two reviewers assessed independently title and/or abstract whether randomized controlled trials and nonrandomized studies were addressed at the same time in any type of article. Disagreements were resolved by discussion. Full texts were ordered if we agreed on potentially relevant references and if disagreements could not be resolved. The full text papers were assessed to see whether the methodology of how to integrate specific study designs in systematic reviews was addressed. We also marked studies that compared the results of randomized controlled trials and nonrandomized 
studies on the same clinical topic to estimate possible effect size differences between the two design categories.

Table 1. Search strategy

\begin{tabular}{ll}
\hline No & Term \\
\hline 1 & "Randomized Controlled Trials as Topic"[Mesh] \\
2 & randomized controlled[tiab] \\
3 & randomised controlled[tiab] \\
4 & randomization[tiab] \\
5 & randomisation[tiab] \\
6 & random allocation[tiab] \\
7 & "Epidemiologic studies"[Mesh] non random*[tiab] \\
8 & nonrandom*[tiab] \\
9 & non-random*[tiab] \\
10 & observational[tiab] \\
11 & quasi-experiment*[tiab] \\
12 & quasi experiment*[tiab] \\
13 & or/1-6 \\
14 & or/7-12 \\
15 & and/13-14 \\
\hline
\end{tabular}

Searching PubMed, Cochrane database of systematic reviews, and the Cochrane database of methods studies on 31 March 2012.

Abbreviations and symbols. *: The asterisk represents truncation to find all terms that begin with a given text string; [Mesh]: Search field tag provided by PubMed for the search in Medical Subject Headings (MeSH) terms; [tiab]: Search field tag provided by PubMed for the search in the title and/or in the abstract

\section{Data collection, analysis, and synthesis}

We summarized the identified statements in a descriptive manner and did not quantitatively pool any data. We worked with 2 types of reviews, systematic reviews and other reviews. The systematic review category included Cochrane systematic reviews, other systematic reviews not issued by Cochrane, and health technology assessments. The other review category included non-systematic reviews, editorials, comments, and letters. We based the rationale to include non-systematic type papers on the following reflections. We wanted to build a comprehensive review of available methods papers. We wanted to acknowledge experience-based thoughts and reasonings and we wanted to include rationales and recommendations with respect to integrate various designs in systematic reviews that have been developed by others. We did not expect a large number of systematic reviews and we apprehended a limited scope of topics if we would have confined the data collection to systematic reviews only. Nevertheless, we stratified the results presentation by the two review types. 
We identified 16 separately reported clinical fields and we used one additional category for articles that combined two or more clinical fields. The 17 categories were:

- Acupuncture: Intervention regarding acupuncture type of complementary and alternative medicine)

- Cardiology: Interventional procedures to reopen coronary arteries as opposed to surgical interventions

- Genetics: Genetic diseases and rare diseases

- HRT: Hormone replacement therapy for women

- Mental: Intervention to treat a mental disease such as depression

- Nephrology: Intevention regarding renal disease

- Nutrition: Influence of food on health

- Orthopedics: Intervention regarding orthopedic disease

- Palliation: Intervention regarding palliative treatment

- Pediatrics: Intervention regarding children

- Pharma: Drugs to treat patients

- Pregnancy: Intervention regarding pregnant women

- Social: Complex social interventions

- Surgery: Surgical intervention regarding various diseases

- Tele: Intervention regarding telehealth issues

- Transplant: Autologous or allogeneic transplantation of organs

- Various: Two or more different clinical fields

We created 8 distinct categories for classifying the type of study design:

- RCT: Randomized controlled trial

- NRCT: Nonrandomized controlled trial: prospective comparative trial with allocation of patients by physician

- Cohort study: Prospective or retrospective observational study with a control group without allocation of patients by physician, start is intervention

- CCS: Case-control study: retrospective study, start is events

- Regist: Registry of data from patients with particular diseases or interventions

- Admin: Administrative databases such as data from health care providers

- Survey: Survey or audit as well as postmarketing analysis Cases: Single case or case series

We identified a considerable number of different methodological topics relevant for the integration of various study designs in systematic reviews. As some of the topics were similar, we assigned these topics to 15 methodological categories. All major issues such as validity, applicability, and confounding were addressed in the papers.

- Adherence: Patients may adhere to the prescription or may not take drugs or doses as wanted 
- Adverse events: Patients may experience unwanted effects or events that are associated with the intervention

- Applicability: Results may not be generalized to patients that have different characteristics than the study population

- Case load: The number of patients with a particular disease or intervention admitted to a hospital or treated by a physician

- Confounding: A known or unknown factor that is associated with the intervention and influences the outcome

- Exclusions: Certain patients are excluded from the recruitment such as elderly, pregnant women, children, patients with comorbidities

- Heterogeneity: Patients within one treatment group differ in baseline characteristics such as severity of disease

- Long term: Follow up more than 12 months after the intervention

- Participation: Eligible individuals who did not participate in trials

- Pathophysiol: Pathophysiological issues such as bacterial cause or various genetic constitution

- Preferences: Patients and physicians may have preferences about what treatment is best

- Rare disease: Rare diseases may not be represented in clinical trials and rare adverse events may not be detected by small studies

- Specialisation: The level of education and experience of a physician may influence the outcome

- Survival: Proportion of patients that sustain a specific wanted status after a certain time period

- Validity: To measure what should be measured; minimizing uncertainty and systematic error; dealing with selection bias

\section{Results}

\section{Search results}

We included 42 articles that report about the integration of study designs in systematic reviews (Figure 1) [5,7,8,14-52]. In the first step of the study selection process, we retrieved 6994 records from electronic databases including 6141 citations from PubMed and 803 citations from the Cochrane Library. The Cochrane Library citations were made of 188 systematic reviews and 526 methods studies. After excluding 6555 records not relevant to the topic of interest or duplicates, we assessed the fulltexts of 439 different articles. After a first screening process, we excluded 355 articles and after a repeated screening of the remaining potentially relevant fulltexts, we excluded another 42 articles. The reasons for exclusion are shown in Figure 1. 


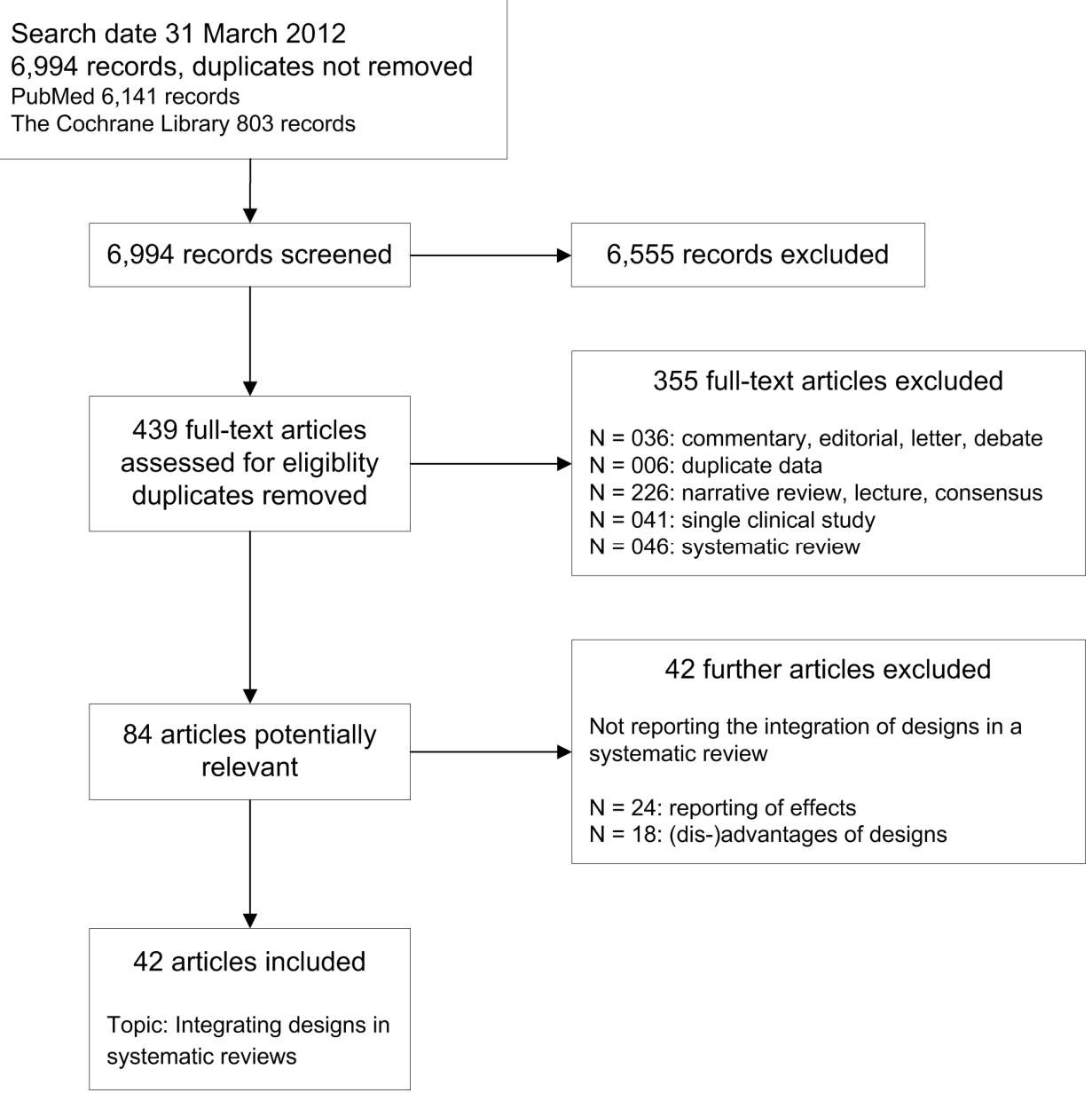

Figure 1. Literature retrieval and study selection.

\section{Characteristics of included articles}

The characteristics of included articles are shown in Table 2 and Table 3. We identified 8 systematic reviews [14,17-20,33,34,38] and 34 non-systematic reviews including editorials, comments, or letters. The articles containing concepts relevant to our research question were published between 1995 and 2012. Most of the articles were published between 2005 and 2012: 73\% (31 of 42) of all reviews, 62\% (5 of 8) systematic reviews and $76 \%$ (26 of 34 ) non-systematic reviews (Table 2 ). The systematic reviews covered 4 of 16 distinct clinical field categories with 5 of 8 reviews reporting on surgery and with 1 review reporting on acupuncture, cardiology, and various clinical fields, respectively (Table 2 ). 
Table 2. Characteristics of included articles

\begin{tabular}{|c|c|c|c|c|c|c|c|c|c|c|c|}
\hline \multirow[t]{2}{*}{ Author } & \multirow[t]{2}{*}{ Year } & \multirow[t]{2}{*}{ Ref } & \multirow[t]{2}{*}{ Field } & \multicolumn{8}{|c|}{ Type of design } \\
\hline & & & & $\mathrm{RCT}$ & NRCT & Cohort & CCS & Regist & Admin & Survey & Cases \\
\hline \multicolumn{12}{|l|}{ Systematic review } \\
\hline Archampong & 2012 & {$[14]$} & Surgery & & 1 & 1 & 1 & 1 & & 1 & \\
\hline Britton & 1998 & {$[17]$} & Surgery & 1 & 1 & & & & & & \\
\hline Chambers & 2009 & [18] & Cardiology & 1 & 1 & & & & & & 1 \\
\hline Chambers & 2010 & [19] & Surgery & 1 & & & & 1 & & & \\
\hline Chou & 2010 & {$[20]$} & Surgery & 1 & 1 & 1 & 1 & 1 & 1 & 1 & 1 \\
\hline Lewsey & 2000 & [33] & Surgery & 1 & & & & & 1 & & \\
\hline Linde & 2002 & {$[34]$} & Acupuncture & 1 & 1 & 1 & 1 & & & 1 & 1 \\
\hline Norris & 2005 & [38] & Various & & 1 & 1 & 1 & & & & 1 \\
\hline \multicolumn{12}{|c|}{ Non-systematic review } \\
\hline Atkins & 2007 & {$[15]$} & Surgery & 1 & 1 & 1 & 1 & 1 & 1 & 1 & \\
\hline Black & 1996 & {$[16]$} & Various & & & 1 & 1 & & & & \\
\hline Chumbler & 2008 & {$[21]$} & Tele & 1 & 1 & 1 & & & & & 1 \\
\hline Concato (Comp) & 2010 & [7] & Surgery & 1 & 1 & 1 & & & 1 & & \\
\hline Concato (Observ) & 2010 & [22] & Various & 1 & 1 & 1 & 1 & & & & \\
\hline Essock & 2003 & [23] & Mental & 1 & 1 & & & & & & \\
\hline Fletcher & 2002 & {$[24]$} & Various & 1 & 1 & 1 & 1 & & & & \\
\hline Fletcher & 2009 & {$[25]$} & HRT & 1 & 1 & 1 & & & & & \\
\hline Gale & 2009 & {$[26]$} & Transplant & 1 & & & & 1 & & & \\
\hline Grzeskowiak & 2012 & {$[27]$} & Pregnancy & & & 1 & 1 & 1 & 1 & & 1 \\
\hline Hadley & 2009 & {$[61]$} & Palliation & 1 & & 1 & & 1 & & 1 & \\
\hline Hartling & 2005 & {$[29]$} & Surgery & & 1 & 1 & 1 & & & & 1 \\
\hline Hodgson & 2007 & {$[30]$} & Mental & 1 & & 1 & & & & & \\
\hline Hoppe & 2009 & [8] & Orthopedics & 1 & & 1 & 1 & & & & 1 \\
\hline Horn & 2010 & [31] & Various & 1 & 1 & & & & & & \\
\hline Kovesdy & 2012 & [32] & Nephrology & 1 & & 1 & & & & & \\
\hline McCarthy & 2008 & [35] & Surgery & 1 & 1 & 1 & & & & & 1 \\
\hline Mercer & 2007 & {$[36]$} & Various & 1 & 1 & & & & & & 1 \\
\hline Mitchell & 1995 & {$[37]$} & Pediatrics & 1 & & & & & & & \\
\hline Norris & 2011 & [39] & Various & & 1 & 1 & 1 & 1 & & & 1 \\
\hline Ogilvie & 2005 & {$[40]$} & Social & 1 & 1 & 1 & 1 & & & & 1 \\
\hline Olivier & 2006 & {$[41]$} & Pharma & 1 & 1 & 1 & 1 & 1 & 1 & & 1 \\
\hline Reeves & 2005 & {$[42]$} & Nutrition & 1 & & 1 & 1 & & & & \\
\hline Rosendaal & 2001 & {$[43]$} & Cardiology & 1 & & & 1 & & & & \\
\hline Sharma & 2012 & {$[44]$} & Social & 1 & & 1 & & & & & \\
\hline Shrier & 2007 & {$[45]$} & Various & 1 & & 1 & & & & & \\
\hline Silverman & 2009 & {$[46]$} & Pharma & 1 & & 1 & 1 & & 1 & & \\
\hline Vandenbroucke & 1998 & {$[47]$} & Various & 1 & & & 1 & & & & \\
\hline Vandenbroucke & 2004 & {$[48]$} & Various & 1 & & & 1 & & & & \\
\hline Vandenbroucke & 2008 & {$[5]$} & Various & 1 & & & 1 & & & & \\
\hline Vandenbroucke & 2009 & [49] & HRT & 1 & & 1 & & & & & \\
\hline Vandenbroucke & 2011 & {$[50]$} & Various & 1 & 1 & & & & & & \\
\hline Wilcken & 2001 & {$[51]$} & Genetics & 1 & & 1 & & 1 & & & \\
\hline Zlowodzki & 2006 & [52] & Various & 1 & 1 & 1 & 1 & & & & 1 \\
\hline Frequency & & & & 36 & 22 & 28 & 21 & 10 & 7 & 5 & 14 \\
\hline
\end{tabular}


Legend: Type of review. Systematic review (first 8 papers): Cochrane Systematic Review (Archampong 2012), Health Technology Assessment of National Health Service in UK (Britton 1998), other systematic reviews not issued by Cochrane or HTA (Chambers 2009, Chambers 2010, Chou 2010, Lewsey 2000, Linde 2002, Norris 2005). Nonsystematic review (rest of 34 papers): narrative review or editorial or comment or letter.

Field. Acupuncture: Intervention regarding acupuncture type of complementary and alternative medicine; Cardiology: Interventional procedures to reopen coronary arteries as opposed to surgical interventions; Genetics: Genetic diseases and rare diseases; HRT: Hormone replacement therapy for women; Mental: Intervention to treat a mental disease such as depression; Nephrology: Intevention regarding renal disease; Nutrition: Influence of food on health; Orthopedics: Intervention regarding orthopedic disease; Palliation: Intervention regarding palliative treatment; Pediatrics: Intervention regarding children; Pharma: Drugs to treat patients; Pregnancy: Intervention regarding pregnant women; Social: Complex social interventions; Surgery: Surgical intervention regarding various diseases; Tele: Intervention regarding telehealth issues; Transplant: Autologous or allogeneic transplantation of organs; Various: Two or more different clinical fields Type of design. RCT: Randomized controlled trial; NRCT: Nonrandomized controlled trial: prospective comparative trial with allocation of patients by physician; Cohor: Prospective or retrospective observational study without allocation of patients by physician, start is intervention; CCS: Case-control study: retrospective study, start is events; Regist: Registry of data from patients with particular diseases or interventions; Admin: Administrative databases such as data from health care providers; Survey: Survey or audit or postmarketing analysis; Cases: Single case or case series

Other abbreviations. Ref: reference

Table 3. Outcomes of included articles

\begin{tabular}{|c|c|c|c|c|c|c|c|c|c|c|c|c|c|c|c|c|c|}
\hline \multirow[t]{2}{*}{ Authors } & \multirow[t]{2}{*}{ Year } & \multirow[t]{2}{*}{ Ref } & \multicolumn{15}{|c|}{ Outcomes addressed } \\
\hline & & & 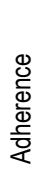 & 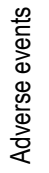 & 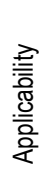 & 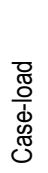 & 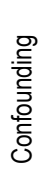 & 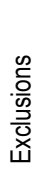 & 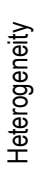 & $\begin{array}{l}\frac{E}{\Phi} \\
\stackrel{5}{0} \\
\stackrel{\Xi}{0}\end{array}$ & 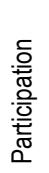 & 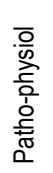 & 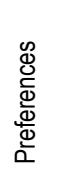 & 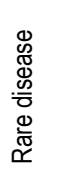 & 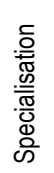 & 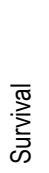 & 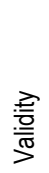 \\
\hline \multicolumn{18}{|l|}{ Systematic review } \\
\hline Archampong & 2012 & [14] & & & & 1 & & & & & & & & & 1 & 1 & \\
\hline Britton & 1998 & [17] & & & 1 & & 1 & 1 & 1 & 1 & 1 & & 1 & & & & \\
\hline Chambers & 2009 & [18] & & 1 & 1 & & & & & 1 & & & & & & & \\
\hline Chambers & 2010 & [19] & & 1 & & & & & & & & & & & & 1 & \\
\hline Chou & 2010 & {$[20]$} & 1 & 1 & 1 & & & & 1 & 1 & & & & & & & 1 \\
\hline Lewsey & 2000 & [33] & & & 1 & & & & & & & & & & & & 1 \\
\hline Linde & 2002 & [34] & & 1 & 1 & & & & & 1 & & & & & & & \\
\hline Norris & 2005 & [38] & & & 1 & & 1 & & & & & & & & & & 1 \\
\hline \multicolumn{18}{|c|}{ Non-systematic review } \\
\hline Atkins & 2007 & [15] & & 1 & 1 & & & & 1 & & & & & & & & \\
\hline Black & 1996 & {$[16]$} & 1 & 1 & 1 & & & & & 1 & 1 & & 1 & 1 & & & 1 \\
\hline Chumbler & 2008 & {$[21]$} & & & & & & & & & & & & & & & 1 \\
\hline Concato (Comp) & 2010 & [7] & & & 1 & & & & & & & & & & & & 1 \\
\hline Concato (Observ) & 2010 & [22] & & & & & 1 & & & & & & & & & & 1 \\
\hline Essock & 2003 & [23] & & & 1 & & 1 & & & 1 & & & 1 & & & & 1 \\
\hline Fletcher & 2002 & [24] & & & 1 & & 1 & & & & & & & & & & 1 \\
\hline Fletcher & 2009 & [25] & & & & & 1 & & & & & & & & & & 1 \\
\hline Gale & 2009 & {$[26]$} & & & 1 & & 1 & & & & 1 & & & & & & 1 \\
\hline Grzeskowiak & 2012 & {$[27]$} & & 1 & & & 1 & & & & & & & & & & 1 \\
\hline Hadley & 2009 & {$[61]$} & & 1 & & & & & 1 & & & & & & & & \\
\hline Hartling & 2005 & [29] & & 1 & 1 & & & & & 1 & & & & & & & \\
\hline Hodgson & 2007 & {$[30]$} & & 1 & 1 & & & 1 & & 1 & 1 & & & & & & 1 \\
\hline Hoppe & 2009 & [8] & & & 1 & & 1 & & & 1 & 1 & & 1 & & & & 1 \\
\hline
\end{tabular}




\begin{tabular}{|c|c|c|c|c|c|c|c|c|c|c|c|c|c|c|c|c|c|}
\hline \multirow[t]{2}{*}{ Authors } & \multirow[t]{2}{*}{ Year } & \multirow[t]{2}{*}{ Ref } & \multicolumn{15}{|c|}{ Outcomes addressed } \\
\hline & & & 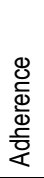 & 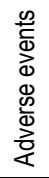 & 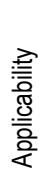 & $\begin{array}{l}\text { ్ㅠ } \\
\text { 응 } \\
\text { d } \\
\mathbb{J} \\
\mathbb{J}\end{array}$ & $\begin{array}{l}\text { 옹 } \\
\text { 음 } \\
\text { 음 } \\
\text { 임 }\end{array}$ & 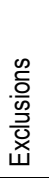 & 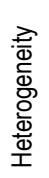 & 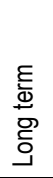 & 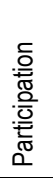 & 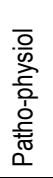 & 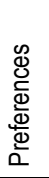 & 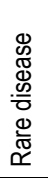 & 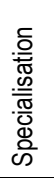 & 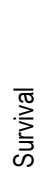 & 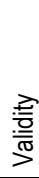 \\
\hline Horn & 2010 & [31] & & & 1 & & & & & & & & & & & & 1 \\
\hline Kovesdy & 2012 & {$[32]$} & 1 & & 1 & & 1 & & 1 & 1 & & & & & & & 1 \\
\hline McCarthy & 2008 & {$[35]$} & & & & & 1 & & & & & & & & & & 1 \\
\hline Mercer & 2007 & {$[36]$} & & & 1 & & & & & & & & & & & & 1 \\
\hline Mitchell & 1995 & [37] & & 1 & & & 1 & & & & & & & & & & \\
\hline Norris & 2011 & [39] & & & 1 & & 1 & & 1 & 1 & & & 1 & & & & 1 \\
\hline Ogilvie & 2005 & [40] & & & 1 & & & 1 & & & & & & & & & 1 \\
\hline Olivier & 2006 & [41] & & 1 & & & & & & 1 & & & & & & & \\
\hline Reeves & 2005 & {$[42]$} & & & & & 1 & & & & & & & & & & 1 \\
\hline Rosendaal & 2001 & [43] & & & & & 1 & & & & & & & & & & 1 \\
\hline Sharma & 2012 & [44] & & & & & & & & & & 1 & & & & & \\
\hline Shrier & 2007 & {$[45]$} & & & & & 1 & & & & & & & & & & 1 \\
\hline Silverman & 2009 & {$[46]$} & 1 & & 1 & & & & & 1 & & & & & & & 1 \\
\hline Vandenbroucke & 1998 & {$[47]$} & & 1 & & & 1 & & & & & 1 & & & & & 1 \\
\hline Vandenbroucke & 2004 & [48] & & 1 & & & 1 & & & & & & & & & & 1 \\
\hline Vandenbroucke & 2008 & {$[5]$} & & 1 & & & 1 & & & 1 & & & & & & & 1 \\
\hline Vandenbroucke & 2009 & [49] & & 1 & & & 1 & 1 & & & & & & & & & 1 \\
\hline Vandenbroucke & 2011 & {$[50]$} & & 1 & & & & & & & & & & & & & 1 \\
\hline Wilcken & 2001 & {$[51]$} & & 1 & & & & & & 1 & & & & 1 & & & \\
\hline Zlowodzki & 2006 & [52] & & & & & 1 & & & & & & & & & & 1 \\
\hline Frequency & & & 4 & 18 & 21 & 1 & 21 & 4 & 6 & 15 & 5 & 2 & 5 & 2 & 1 & 2 & 30 \\
\hline
\end{tabular}

Legend. Outcomes addressed. Adherence: Patients may adhere to the prescription or may not take drugs or doses as wanted; Adverse events: Patients may experience unwanted effects or events that are associated with the intervention; Applicability: Results may not be generalized to patients that have different characteristics than the study population; Case load: The number of patients with a particular disease or intervention admitted to a hospital or treated by a physician; Confounding: A known or unknown factor that is associated with the intervention and influences the outcome; Exclusions: Certain patients are excluded from the recruitment such as elderly, pregnant women, children, patients with comorbidities; Heterogeneity: Patients within one treatment group differ in baseline characteristics such as severity of disease; Long term: Follow up more than 12 months after the intervention; Participation: Eligible individuals who did not participate in trials; Pathophysiol: Pathophysiological issues such as bacterial cause or various genetic constitution; Preferences: Patients and physicians may have preferences about what treatment is best; Rare disease: Rare diseases may not be represented in clinical trials and rare adverse events may not be detected by small studies; Specialisation: The level of education and experience of a physician may influence the outcome: Survival: Proportion of patients that sustain a specific wanted status after a certain time period; Validity: To measure what should be measured; minimizing uncertainty and systematic error, dealing with selection bias; other abbreviations. Ref: reference. 
The non-systematic reviews covered 15 of 16 categories with 12 reporting on various topics, 4 reporting on surgery, no report on acupuncture, and 1 to 2 reporting on each of the rest of clinical entities.

Of the 15 methodological topics, which are relevant for the integration of various study designs in systematic reviews, 5 topics were frequently reported by more than 10 articles (Table 3). The rest were addressed by 1 article or up to 6 articles. Validity was reported by 30 reviews (systematic 3, non-systematic 27), applicability by 21 reviews (systematic 6 , non-systematic 15), confounding by 21 reviews (systematic 2, nonsystematic 19), adverse events by 18 reviews (systematic 4, non-systematic 14), and long-term follow up by 15 reviews (systematic 4, non-systematic 11). Systematic reviews reported 13 categories leaving pathogenesis and rare diseases out. Non-systematic reviews reported 12 categories and did not refer to case load, specialisation, and survival.

\section{Key messages}

We qualitatively summarized the key messages of the 42 included methods studies based on the extraction of major statements (Table S2). We identified a clear tendency in the message that nonrandomized studies should be conducted and integrated in systematic reviews to complement available RCTs or replace lacking RCTs in 85\% (36 of 42 ) of all reviews. We judged the difference between systematic reviews $75 \%$ (6 of 8 ) and non-systematic reviews $88 \%$ (30 of 34 ) as not considerable. Thus the majority of identified reviews supported the view that nonrandomized studies are important and should be an integral part of assessing health care interventions. Only a minority of reviews regarded RCTs as the sole means of finding reliable answers to clinical research questions. Most papers acknowledged the advantages and the disadvantages of RCTs and nonrandomized studies with regard to specific methodologic topics or specific clinical outcomes. Some papers addressed the problem that RCTs are not possible for assessing certain questions and that case reports may have a considerable impact on safety issues.

\section{Comparison of randomized vs. nonrandomized controlled design}

We identified 49 studies, 18 trials and 31systematic reviews that compared the effect measures found in randomized controlled trials with those in nonrandomized controlled trials (Table 4). Of these 49 studies, 39 reported about the same or similar intervention in both study designs and 10 studies that included different interventions in the analyses. In $35 \%$ (17 of 49 ) studies, there was a different direction or a statistically significant difference of the magnitude of effect between randomized and nonrandomized controlled trials. In 53\% (26 of 49) studies, the effect did not differ considerably between those two designs. In $12 \%$ (6 of 49) studies, both results, a difference as well as no difference were reported. 
Table 4. Reviews and studies comparing randomized vs. nonrandomized controlled results

\begin{tabular}{|c|c|c|c|c|c|c|}
\hline \multirow[t]{2}{*}{ First author } & \multirow[t]{2}{*}{ Year } & \multirow[t]{2}{*}{ Ref } & \multirow[t]{2}{*}{ Intervention } & \multicolumn{3}{|c|}{ Difference R vs. N } \\
\hline & & & & Yes & Various & No \\
\hline Abraham & 2010 & [62] & same & & & no \\
\hline Algra & 2012 & [63] & same & & & no \\
\hline Antman & 1985 & [64] & same & yes & & \\
\hline Aslani & 2010 & {$[65]$} & same & & & no \\
\hline Benis & 2002 & {$[66]$} & same & yes & & \\
\hline Benson & 2000 & [67] & same & & & no \\
\hline Bhandari & 2004 & [68] & same & yes & & \\
\hline Britton & 1998 & [17] & same & & & no \\
\hline Carroll & 1996 & [69] & same & yes & & \\
\hline CASS & 1984 & [70] & same & & & no \\
\hline Cheng & 2012 & [71] & same & & & no \\
\hline Choi & 2012 & [72] & same & & & no \\
\hline Clagett & 1984 & [73] & same & & & no \\
\hline Colditz & 1989 & [74] & various & yes & & \\
\hline Conaty & 2004 & [75] & same & & & no \\
\hline Concato & 2000 & [76] & same & & & no \\
\hline Deeks & 2003 & [77] & various & & various & \\
\hline Edwards & 2012 & [78] & various & & & no \\
\hline Flossman & 2007 & [79] & same & & & no \\
\hline Franklin & 2000 & {$[80]$} & same & & & no \\
\hline Furlan (Exam) & 2008 & [81] & same & & various & \\
\hline Furlan (Meth) & 2008 & [82] & same & yes & & \\
\hline Golder & 2011 & [83] & various & & & no \\
\hline Gross & 2005 & [84] & same & & & no \\
\hline Guyatt & 2000 & [85] & same & yes & & \\
\hline Hannan & 2008 & [86] & various & & various & \\
\hline Hlatky & 1988 & [87] & same & & & no \\
\hline loannidis & 2001 & [58] & various & yes & & \\
\hline Kunz & 2007 & [54] & same & yes & & \\
\hline Kunz & 1998 & [53] & same & yes & & \\
\hline Kuss & 2011 & [88] & same & & & no \\
\hline Lawlor & 2004 & [89] & same & yes & & \\
\hline Linde & 2002 & [34] & same & & & no \\
\hline MacLehose & 2000 & [11] & various & & & no \\
\hline Mueller & 2010 & [90] & same & yes & & \\
\hline Naudet & 2011 & [91] & same & yes & & \\
\hline Odgaard-Jensen & 2011 & [55] & various & & various & \\
\hline Papanikolaou & 2006 & [92] & various & & various & \\
\hline Phillips & 1999 & [93] & same & & & no \\
\hline
\end{tabular}




\begin{tabular}{|c|c|c|c|c|c|c|}
\hline \multirow[t]{2}{*}{ First author } & \multirow[t]{2}{*}{ Year } & \multirow[t]{2}{*}{ Ref } & \multirow[t]{2}{*}{ Intervention } & \multicolumn{3}{|c|}{ Difference R vs. N } \\
\hline & & & & Yes & Various & No \\
\hline$\overline{\mathrm{RMIT}}$ & 1994 & {$[94]$} & same & & & no \\
\hline Rovers & 2001 & [95] & same & & & no \\
\hline Schmoor & 2008 & [96] & same & & & no \\
\hline Shea & 2010 & [97] & same & yes & & \\
\hline Shikata & 2006 & [98] & various & & various & \\
\hline Tzoulaki & 2011 & [99] & same & yes & & \\
\hline Vis & 2008 & [100] & same & yes & & \\
\hline Vist & 2008 & [101] & same & & & no \\
\hline Wilkes & 2010 & [102] & same & & & no \\
\hline Wolfe & 2004 & [103] & same & yes & & \\
\hline Frequency & & & & 17 & 6 & 26 \\
\hline
\end{tabular}

Legend: Abbreviations. CASS: Coronary artery surgery study; Difference R vs N: difference between randomized vs. nonrandomized results; Ref: reference; RMIT: Recurrent Miscarriage Immunotherapy Trialists

\section{Discussion}

We identified and summarized qualitative evidence sufficient enough to guide finding and integrating the right research design for answering various clinical questions within the conduct of systematic reviews of health care interventions.

It is obvious that intended effects of interventions such as the physician-reported outcomes of prevention of death and healing or improving of disease in ideal settings with financially affordable follow up and with ample number of available participants are best investigated in well planned RCTs. There is no equal or better alternative study design. The results may or may not be applicable to the general population. Many people with particular characteristics such as younger or older age, gender, pregnancy, or comorbidity may have been excluded and may have experienced opposing effects or an unfavorable and unwanted balance of benefit and harm. Pediatricians may seek information on drugs from observational studies if data on the treatment of children from RCTs are not available. Unintended, severe adverse events require longterm observation including postmarketing analysis, administrative databases, and case reports to identify harmful drugs that have to be withdrawn from the market. The types of different study design that need to be included in a systematic review depend on the nature of the clinical questions that the review addresses.

Oxman and collaborators assessed the effects of randomisation and concealment of allocation on the results of healthcare studies and reported their results in three papers within the time period from 1998 to 2011 [53-55]. The authors concluded that "the results of randomised and non-randomised studies - sometimes - differed". In many cases the results did not differ. The authors argued "that it is not generally pos- 
sible to predict the magnitude, or even the direction, of possible selection biases and consequent distortions of treatment effects from studies with non-random allocation or controlled trials with inadequate or unclear allocation concealment". We believe that trials with random allocation and adequate allocation concealment may show contradictory results. We also believe that it is not possible to foresee the magnitude or the direction of bias in those adequately randomized trials with absolute certainty [56]. Nevertheless, the authors stated that "randomized controlled trials are a safeguard against biased estimates of treatment effects". Various design prerequisites and adjustment procedures in nonrandomized controlled trials can minimize bias and confounding, however, it is not kown for certain in a particular trial whether the results reflect the reality or whether they are distorted. The same principle holds true for trials with adequate randomization and concealment of allocation. Even if the risk of a false estimate determined in a series of trials would be lower than in trials with inadequate randomization and concealment of allocation the fact is that the result of the primary outcome measure in a single specific trial cannot be regarded as an absolute and certain proof regardless of the p-values or confidence intervals. Ioannidis 2005 concluded that, quote: "Controversies are most common with highly cited nonrandomized studies, but even the most highly cited randomized trials may be challenged and refuted over time, especially small ones" [57]. The authors found that 5 of 6 highly cited nonrandomized studies had been contradicted or had found stronger effects versus 9 of 39 randomized controlled trials $(P=0.008)$. Our assessment adds to the existing work done by Oxman group and the loannidis group that the effect did not differ considerably between the randomized and the nonrandomized designs in more than half of the studies. The general postulate or dogma of the RCT as a safeguard against biased estimates of treatment effects may create deceptive promises and may give researchers a false sense of security. We infer from our findings just the same as Shrier 2007 has expressed before, quote: "(...)that excluding observational studies in systematic reviews a priori is inappropriate and internally inconsistent with an evidence-based approach" [45].

According to the Cochrane handbook, the Cochrane Collaboration focuses particularly on systematic reviews of RCTs and considers inclusion of nonrandomized studies mainly if RCTs are lacking. We see a vast number of clinical research questions that are not investigated by RCTs. There may be many reasons, for example, patients' and physicians' preferences that prevent the accumulation of true randomized study data. Our results suggest that the Cochrane Collaboration might be advised to consider more reasons for including nonrandomized studies on the condition of a rigorous risk of bias assessment and confinement to specific interventions and outcomes.

In general, a high risk of bias is inherent in all nonrandomized studies. Certain study characteristics such as prospective design, concurrent control group, adjustment of results with respect to different baseline values, and confounder control can limit additional bias. For example, loannidis 2001 [58] reported that discrepancies between 
RCT and nonrandomized studies were less common when only nonrandomized studies with a prospective design were considered. The Cochrane Collaboration offers a guide for inclusion of nonrandomized studies [59] and it has developed a tool for assessing the risk of bias in both RCT and controlled nonrandomized studies [60].

\section{Conclusions}

Different study designs addressing the same question yielded varying results, with differences in about half of all examples. The risk of presenting uncertain results without knowing for sure the direction and magnitude of the effect holds true for both nonrandomized and randomized controlled trials, though, the risk of bias and confounding is probably higher in the nonrandomized ones. The integration of multiple study designs in systematic reviews is required if patients should be informed on the many facets of patient relevant issues of health care interventions. 


\section{References}

1. Haynes B. Can it work? Does it work? Is it worth it? The testing of health care interventions is evolving. BMJ. 1999;319(7211):652-3.

2. Djulbegovic B, Paul A. From efficacy to effectiveness in the face of uncertainty: indication creep and prevention creep. Journal of the American Medical Association. 2011;305(19):2005-6.

3. Victora CG, Habicht JP, Bryce J. Evidence-based public health: moving beyond randomized trials. American Journal of Public Health. 2004;94(3):400-5.

4. Djulbegovic M, Djulbegovic B. Implications of the principle of question propagation for comparativeeffectiveness and "data mining" research. Journal of the American Medical Association. 2011;305(3): 298-9.

5. Vandenbroucke JP. Observational research, randomised trials, and two views of medical science. PLoS Medicine. 2008;5(3):e67.

6. Centre of Evidence-Based Medicine. Levels of evidence. Oxford: Centre of Evidence-Based Medicine; 2009.

7. Concato J, Peduzzi P, Huang GD, O'Leary TJ, Kupersmith J. Comparative effectiveness research: what kind of studies do we need? Journal of Investigative Medicine. 2010;58(6): 764-9.

8. Hoppe DJ, Schemitsch EH, Morshed S, Tornetta P 3rd, Bhandari M. Hierarchy of evidence: where observational studies fit in and why we need them. The Journal of Bone and Joint Surgery: American Volume. 2009;91 Suppl 3:2-9.

9. National Center for Biotechnology Information. MeSH: Randomized Controlled Trials as Topic. Bethesda: National Center for Biotechnology Information, U.S. National Library of Medicine; 2011.

10. National Center for Biotechnology Information. MeSH: Epidemiologic Study Characteristics as Topic. Bethesda: National Center for Biotechnology Information, U.S. National Library of Medicine; 2011.

11. MacLehose RR, Reeves BC, Harvey IM, Sheldon TA, Russell IT, Black AM. A systematic review of comparisons of effect sizes derived from randomised and non-randomised studies. Health Technology Assessment. 2000;4(34):1-154.

12. Pibouleau L, Boutron I, Reeves BC, Nizard R, Ravaud P. Applicability and generalisability of published results of randomised controlled trials and non-randomised studies evaluating four orthopaedic procedures: methodological systematic review. BMJ. 2009;339:b4538.

13. Fraser C, Murray A, Burr J. Identifying observational studies of surgical interventions in MEDLINE and EMBASE. BMC Medical Research Methodology. 2006;6:41.

14. Archampong D, Borowski D, Wille-Jorgensen P, Iversen LH. Workload and surgeon's specialty for outcome after colorectal cancer surgery. Cochrane Database of Systematic Reviews. 2012;3:CD005391.

15. Atkins D. Creating and synthesizing evidence with decision makers in mind: integrating evidence from clinical trials and other study designs. Medial Care. 2007;45(10 Suppl 2):S16-22.

16. Black $\mathrm{N}$. Why we need observational studies to evaluate the effectiveness of health care. BMJ. 1996;312(7040):1215-8.

17. Britton A, McKee M, Black N, McPherson K, Sanderson C, Bain C. Choosing between randomised and non-randomised studies: a systematic review. Health Technology Assessment. 1998;2(13):i-iv, 1-124.

18. Chambers $D$, Rodgers $M$, Woolacott $N$. Not only randomized controlled trials, but also case series should be considered in systematic reviews of rapidly developing technologies. Journal of Clinical Epidemiology. 2009;62(12):1253-1260.e1254.

19. Chambers D, Fayter D, Paton F, Woolacott N. Use of non-randomised evidence alongside randomised trials in a systematic review of endovascular aneurysm repair: strengths and limitations. European Journal of Vascular and Endovascular Surgery. 2010;39(1):26-34.

20. Chou R, Aronson N, Atkins D, Ismaila AS, Santaguida P, Smith DH, et al. AHRQ series paper 4: assessing harms when comparing medical interventions: AHRQ and the effective health-care program. Journal of Clinical Epidemiology. 2010;63(5):502-12. 
21. Chumbler NR, Kobb R, Brennan DM, Rabinowitz T. Recommendations for research design of telehealth studies. Telemedicine Journal and E-Health. 2008;14(9):986-9.

22. Concato J, Lawler EV, Lew RA, Gaziano JM, Aslan M, Huang GD. Observational methods in comparative effectiveness research. American Journal of Medicine. 2010; 123(12 Suppl 1):e16-23.

23. Essock SM, Drake RE, Frank RG, McGuire TG. Randomized controlled trials in evidence-based mental health care: getting the right answer to the right question. Schizophrenia Bulletin. 2003;29(1):115-23.

24. Fletcher RH. Evaluation of interventions. Journal of Clinical Epidemiology. 2002;55(12):1183-90.

25. Fletcher AE. Controversy over "contradiction": Should randomized trials always trump observational studies? American Journal of Ophthalmology. 2009;147(3):384-6.

26. Gale RP, Eapen M, Logan B, Zhang MJ, Lazarus HM. Are there roles for observational database studies and structured quantification of expert opinion to answer therapy controversies in transplants? Bone Marrow Transplantation. 2009;43(6):435-46.

27. Grzeskowiak LE, Gilbert AL, Morrison JL. Investigating outcomes associated with medication use during pregnancy: a review of methodological challenges and observational study designs. Reproductive Toxicology. 2012;33(3):280-9.

28. Hadley J, Yabroff KR, Barrett MJ, Penson DF, Saigal CS, Potosky AL. Comparative effectiveness of prostate cancer treatments: evaluating statistical adjustments for confounding in observational data. Journal of the National Cancer Institute. 2010;102(23):1780-93.

29. Hartling L, McAlister FA, Rowe BH, Ezekowitz J, Friesen C, Klassen TP. Challenges in systematic reviews of therapeutic devices and procedures. Annals of Internal Medicine. 2005;142(12 Pt 2):1100-11.

30. Hodgson R, Bushe C, Hunter R. Measurement of long-term outcomes in observational and randomised controlled trials. British Journal of Psychiatry: Supplement. 2007;50:s78-84.

31. Horn SD, Gassaway J, Pentz L, James R. Practice-based evidence for clinical practice improvement: an alternative study design for evidence-based medicine. Studies in Health Technology and Informatics. 2010;151:446-60.

32. Kovesdy CP, Kalantar-Zadeh K. Observational studies versus randomized controlled trials: avenues to causal inference in nephrology. Advances in Chronic Kidney Disease. 2012;19(1):11-8.

33. Lewsey JD, Leyland AH, Murray GD, Boddy FA. Using routine data to complement and enhance the results of randomised controlled trials. Health Technology Assessment. 2000;4(22):1-55.

34. Linde K, Scholz M, Melchart D, Willich SN. Should systematic reviews include non-randomized and uncontrolled studies? The case of acupuncture for chronic headache. Journal of Clinical Epidemiology. 2002;55(1):77-85.

35. McCarthy CM, Collins ED, Pusic AL. Where do we find the best evidence? Plastic and Reconstructive Surgery. 2008;122(6):1942-47.

36. Mercer SL, DeVinney BJ, Fine $L$, Green LW, Dougherty D. Study designs for effectiveness and translation research: identifying trade-offs. American Journal of Preventive Medicine. 2007;33(2):139-54.

37. Mitchell AA, Lesko SM. When a randomised controlled trial is needed to assess drug safety. The case of paediatric ibuprofen. Drug Safety. 1995;13(1):15-24.

38. Norris SL, Atkins D. Challenges in using nonrandomized studies in systematic reviews of treatment interventions. Annals of Internal Medicine. 2005;142(12 Pt 2):1112-9.

39. Norris SL, Atkins D, Bruening W, Fox S, Johnson E, Kane R. Observational studies in systemic reviews of comparative effectiveness: AHRQ and the Effective Health Care Program. Journal of Clinical Epidemiology. 2011;64(11):1178-86.

40. Ogilvie D, Egan M, Hamilton V, Petticrew M. (Systematic reviews of health effects of social interventions: 2. Best available evidence: how low should you go? Journal of Epidemiology and Community Health. 2005;59(10):886-92.

41. Olivier P, Montastruc JL. The nature of the scientific evidence leading to drug withdrawals for pharmacovigilance reasons in France. Pharmacoepidemiology and Drug Safety. 2006;15(11):808-12.

42. Reeves BC, van Binsbergen J, van Weel C. Systematic reviews incorporating evidence from nonrandomized study designs: reasons for caution when estimating health effects. European Journal of Clinical Nutrition. 2005;59 Suppl 1:S155-61. 
43. Rosendaal FR. Bridging case-control studies and randomized trials. Current Control Trials in Cardiovascular Medicine. 2001;2(3):109-10.

44. Sharma V, Minhas R. Explanatory models are needed to integrate RCT and observational data with the patient's unique biology. Journal of the Royal Society of Medicine. 2012;105(1):11-24.

45. Shrier I, Boivin JF, Steele RJ, Platt RW, Furlan A, Kakuma R, et al. Should meta-analyses of interventions include observational studies in addition to randomized controlled trials? A critical examination of underlying principles. American Journal of Epidemiology. 2007;166(10):1203-09.

46. Silverman SL. From randomized controlled trials to observational studies. American Journal of Medicine. 2009;122(2):114-20.

47. Vandenbroucke JP. Observational research and evidence-based medicine: What should we teach young physicians? Journal of Clinical Epidemiology. 1998;51(6):467-72.

48. Vandenbroucke JP. When are observational studies as credible as randomised trials? The Lancet. 2004;363(9422):1728-31.

49. Vandenbroucke JP. The HRT controversy: observational studies and RCTs fall in line. The Lancet. 2009;373(9671):1233-5.

50. Vandenbroucke JP. Why do the results of randomised and observational studies differ? BMJ. 2011;343:d7020.

51. Wilcken B. Rare diseases and the assessment of intervention: what sorts of clinical trials can we use? Journal of Inherited Metabolic Disease. 2001;24(2):291-8.

52. Zlowodzki M, Jonsson A, Bhandari M. Common pitfalls in the conduct of clinical research. Medical Principles and Practice. 2006;15(1):1-8.

53. Kunz R, Oxman AD. The unpredictability paradox: review of empirical comparisons of randomised and non-randomised clinical trials. BMJ. 1998;317(7167):1185-90.

54. Kunz R, Vist G, Oxman AD. Randomisation to protect against selection bias in healthcare trials. Cochrane Database of Systematic Reviews. 2007;(2):MR000012.

55. Odgaard-Jensen J, Vist GE, Timmer A, Kunz R, Akl EA, Schunemann $H$, et al. Randomisation to protect against selection bias in healthcare trials. Cochrane Database of Systematic Reviews. 2011;(4):MR: 000012.

56. Savovic J, Jones HE, Altman DG, Harris RJ, Juni P, Pildal J, et al. Influence of reported study design characteristics on intervention effect estimates from randomized, controlled trials. Annals of Internal Medicine. 2012;157(6):429-38.

57. loannidis JP. Contradicted and initially stronger effects in highly cited clinical research. Journal of the American Medical Association. 2005;294(2):218-28.

58. Ioannidis JP, Haidich AB, Pappa M, Pantazis N, Kokori SI, Tektonidou MG, et al. Comparison of evidence of treatment effects in randomized and nonrandomized studies. Journal of the American Medical Association. 2001;286(7):821-30.

59. Reeves BC, Deeks JJ, Higgins JPT, Wells GA. Chapter 13. Including non-randomized studies. In: Higgins JPT, Green S (editors). Cochrane Handbook for Systematic Reviews of Interventions Version 5.1.0 [updated March 2011]. The Cochrane Collaboration; 2011.

60. Higgins JPT, Altman DG, Sterne JAC. Chapter 8: Assessing risk of bias in included studies. In: Higgins JPT, Green S (editors). Cochrane Handbook for Systematic Reviews of Interventions Version 5.1.0 [updated March 2011]. The Cochrane Collaboration; 2011.

61. Hadley G, Derry S, Moore RA, Wee B. Can observational studies provide a realistic alternative to randomized controlled trials in palliative care? Journal of Pain and Palliative Care Pharmacotherapy. 2009;23(2):106-13.

62. Abraham NS, Byrne CJ, Young JM, Solomon MJ. Meta-analysis of well-designed nonrandomized comparative studies of surgical procedures is as good as randomized controlled trials. Journal of Clinical Epidemiology. 2010;63(3):238-45.

63. Algra AM, Rothwell PM. Effects of regular aspirin on long-term cancer incidence and metastasis: a systematic comparison of evidence from observational studies versus randomised trials. The Lancet Oncology. 2012;13(5):518-27. 
64. Antman K, Amato D, Wood W, Carson J, Suit H, Proppe K, et al. Selection bias in clinical trials. Journal of Clinical Oncology. 1985;3(8):1142-7.

65. Aslani N, Brown CJ. Does mesh offer an advantage over tissue in the open repair of umbilical hernias? A systematic review and meta-analysis. Hernia 2010;14(5):455-62.

66. Benis MM. Are pacifiers associated with early weaning from breastfeeding? Advances in Neonatal Care. 2002;2(5):259-66.

67. Benson K, Hartz AJ. A comparison of observational studies and randomized, controlled trials. New England Journal of Medicine. 2000;342(25):1878-86.

68. Bhandari M, Tornetta P 3rd, Ellis T, Audige L, Sprague S, Kuo JC, et al. Hierarchy of evidence: differences in results between non-randomized studies and randomized trials in patients with femoral neck fractures. Archives of Orthopaedic and Trauma Surgery. 2004;124(1):10-6.

69. Carroll D, Tramer M, McQuay H, Nye B, Moore A. Randomization is important in studies with pain outcomes: systematic review of transcutaneous electrical nerve stimulation in acute postoperative pain. British Journal of Anaesthesia. 1996;77(6):798-803.

70. [No authors listed]. Coronary artery surgery study (CASS): a randomized trial of coronary artery bypass surgery. Comparability of entry characteristics and survival in randomized patients and nonrandomized patients meeting randomization criteria. Journal of the American College of Cardiology. 1984;3(1):11428.

71. Cheng Y, Xiong XZ, Wu SJ, Lin YX, Cheng NS. Laparoscopic vs. open cholecystectomy for cirrhotic patients: a systematic review and meta-analysis. Hepatogastroenterology. 59(118):1727-34.

72. Choi HJ, Hahn S, Lee J, Park BJ, Lee SM, Kim HS, et al. Surfactant lavage therapy for meconium aspiration syndrome: a systematic review and meta-analysis. Neonatology. 2012;101(3):183-91.

73. Clagett GP, Youkey JR, Brigham RA, Orecchia PM, Salander JM, Collins GJ Jr, et al. Asymptomatic cervical bruit and abnormal ocular pneumoplethysmography: a prospective study comparing two approaches to management. Surgery. 1984;96(5):823-30.

74. Colditz GA, Miller JN, Mosteller F. How study design affects outcomes in comparisons of therapy. I: Medical. Statistics in Medicine. 1989;8(4):441-54.

75. Conaty S, Watson L, Dinnes J, Waugh N. The effectiveness of pneumococcal polysaccharide vaccines in adults: a systematic review of observational studies and comparison with results from randomised controlled trials. Vaccine. 2004;22(23-24):3214-24.

76. Concato J, Shah N, Horwitz RI. Randomized, controlled trials, observational studies, and the hierarchy of research designs. New England Journal of Medicine. 2000;342(25):1887-92.

77. Deeks JJ, Dinnes J, D'Amico R, Sowden AJ, Sakarovitch C, Song F, et al. Evaluating non-randomised intervention studies. Health Technology Assessment. 2003;7(27):iii-x, 1-173.

78. Edwards JP, Kelly EJ, Lin Y, Lenders T, Ghali WA, Graham AJ. Meta-analytic comparison of randomized and nonrandomized studies of breast cancer surgery. Canadian Journal of Surgery. 2012;55(3):155-62.

79. Flossmann E, Rothwell PM; British Doctors Aspirin Trial and the UK-TIA Aspirin Trial. Effect of aspirin on long-term risk of colorectal cancer: consistent evidence from randomised and observational studies. The Lancet. 2007;369(9573):1603-13.

80. Franklin ME, Abramowitz JS, Kozak MJ, Levitt JT, Foa EB. Effectiveness of exposure and ritual prevention for obsessive-compulsive disorder: randomized compared with nonrandomized samples. Journal of Consulting and Clinical Psychology. 2000;68(4):594-602.

81. Furlan AD, Tomlinson G, Jadad AA, Bombardier C. Examining heterogeneity in meta-analysis: comparing results of randomized trials and nonrandomized studies of interventions for low back pain. Spine. 2008;33(3):339-48.

82. Furlan AD, Tomlinson G, Jadad AA, Bombardier C. Methodological quality and homogeneity influenced agreement between randomized trials and nonrandomized studies of the same intervention for back pain. Journal of Clinical Epidemiology. 2008;61(3):209-31.

83. Golder S, Loke YK, Bland M. Meta-analyses of adverse effects data derived from randomised controlled trials as compared to observational studies: methodological overview. PLoS Medicine. 2011;8(5): e1001026. 
84. Gross CP, Garg PP, Krumholz HM. The generalizability of observational data to elderly patients was dependent on the research question in a systematic review. Journal of Clinical Epidemiology. 2005;58(2):130-7.

85. Guyatt GH, DiCenso A, Farewell V, Willan A, Griffith L. Randomized trials versus observational studies in adolescent pregnancy prevention. Journal of Clinical Epidemiology. 2000;53(2):167-74.

86. Hannan EL (2008) Randomized clinical trials and observational studies: guidelines for assessing respective strengths and limitations. Journal of the American College of Cardiology Cardiovascular Interventions. 2008;1(3):211-7.

87. Hlatky MA, Califf RM, Harrell FE Jr., Lee KL, Mark DB, Pryor DB. Comparison of predictions based on observational data with the results of randomized controlled clinical trials of coronary artery bypass surgery. Journal of the American College of Cardiology. 1988;11(2):237-45.

88. Kuss $\mathrm{O}$, Legler T, Borgermann J. Treatments effects from randomized trials and propensity score analyses were similar in similar populations in an example from cardiac surgery. Journal of Clinical Epidemiology. 2011;64(10):1076-84.

89. Lawlor DA, Davey Smith G, Kundu D, Bruckdorfer KR, Ebrahim S. Those confounded vitamins: what can we learn from the differences between observational versus randomised trial evidence? The Lancet. 2004;363(9422):1724-7.

90. Muller D, Sauerland S, Neugebauer EA, Immenroth M. Reported effects in randomized controlled trials were compared with those of nonrandomized trials in cholecystectomy. Journal of Clinical Epidemiology. 2010;63(10):1082-90.

91. Naudet F, Maria AS, Falissard B. Antidepressant response in major depressive disorder: a metaregression comparison of randomized controlled trials and observational studies. PLoS One. 2011;6(6): e20811.

92. Papanikolaou PN, Christidi GD, loannidis JP. Comparison of evidence on harms of medical interventions in randomized and nonrandomized studies. Canadian Medical Association Journal. 2006;174(5):635-41.

93. Phillips AN, Grabar S, Tassie JM, Costagliola D, Lundgren JD, Egger M. Use of observational databases to evaluate the effectiveness of antiretroviral therapy for HIV infection: comparison of cohort studies with randomized trials. EuroSIDA, the French Hospital Database on HIV and the Swiss HIV Cohort Study Groups. Acquired Immune Deficiency Syndrome. 1999;13(15):2075-82.

94. [No authors listed]. Worldwide collaborative observational study and meta-analysis on allogenic leukocyte immunotherapy for recurrent spontaneous abortion. Recurrent Miscarriage Immunotherapy Trialists Group. American Journal of Reproductive Immunology. 1994;32(2):55-72.

95. Rovers MM, Straatman H, Ingels K, van der Wilt GJ, van den Broek P, Zielhuis GA. Generalizability of trial results based on randomized versus nonrandomized allocation of OME infants to ventilation tubes or watchful waiting. Journal of Clinical Epidemiology. 2001;54(8):789-94.

96. Schmoor C, Caputo A, Schumacher M. Evidence from nonrandomized studies: a case study on the estimation of causal effects. American Journal of Epidemiology. 2008;167(9):1120-9.

97. Shea MK, Houston DK, Nicklas BJ, Messier SP, Davis CC, Miller ME. The effect of randomization to weight loss on total mortality in older overweight and obese adults: the ADAPT Study. The Journals of Gerontology: Series A, Biological Sciences and Medical Sciences. 2010;65(5):519-25.

98. Shikata S, Nakayama T, Noguchi Y, Taji Y, Yamagishi H. Comparison of effects in randomized controlled trials with observational studies in digestive surgery. Annals of Surgery. 2006;244(5):668-76.

99. Tzoulaki I, Siontis KC, loannidis JP. Prognostic effect size of cardiovascular biomarkers in datasets from observational studies versus randomised trials: meta-epidemiology study. BMJ. 2011;343:d6829.

100.Vis AN, Roemeling S, Reedijk AM, Otto SJ, Schroder FH (2008) Overall survival in the intervention arm of a randomized controlled screening trial for prostate cancer compared with a clinically diagnosed cohort. European Urology. 2008;53(1):91-8.

101.Vist GE, Bryant D, Somerville L, Birminghem T, Oxman AD. Outcomes of patients who participate in randomized controlled trials compared to similar patients receiving similar interventions who do not participate. Cochrane Database of Systematic Reviews. 2008;(3):MR000009. 
102.Wilkes MM, Navickis RJ, Chan WW, Lewiecki EM. Bisphosphonates and osteoporotic fractures: a crossdesign synthesis of results among compliant/persistent postmenopausal women in clinical practice versus randomized controlled trials. Osteoporosis International. 2010;21(4):679-88.

103. Wolfe F, Michaud K, Dewitt EM. Why results of clinical trials and observational studies of antitumour necrosis factor (anti-TNF) therapy differ: methodological and interpretive issues. Annals of the Rheumatic Diseases. 2004; 63 Suppl 2:ii13-ii17.

Supplementary tables associated with this article can be found, in the online version, at doi: 10.1371/journal.pone.0085035. 


\section{CHAPTER 3}

Autologous hematopoietic stem cell transplantation following high dose chemotherapy for non-rhabdomyosarcoma soft tissue sarcomas

Peinemann F, Smith LA, Bartel C. Autologous hematopoietic stem cell transplantation following high dose chemotherapy for non-rhabdomyosarcoma soft tissue sarcomas. Cochrane Database of Systematic Reviews. 2013;8:CD008216. 


\section{Abstract}

Background Soft tissue sarcomas (STS) are a highly heterogeneous group of rare malignant solid tumors. Non-rhabdomyosarcoma soft tissue sarcomas (NRSTS) comprise all STS except rhabdomyosarcoma. In patients with advanced local or metastatic disease, autologous hematopoietic stem cell transplantation (HSCT) applied after highdose chemotherapy (HDCT) is a planned rescue therapy for HDCT-related severe hematologic toxicity. The rationale for this update is to determine whether any randomized controlled trials (RCTs) have been conducted and to clarify whether HDCT followed by autologous HSCT has a survival advantage.

Objectives To assess the effectiveness and safety of HDCT followed by autologous HSCT for all stages of non-rhabdomyosarcoma soft tissue sarcomas (NRSTS) in children and adults.

Search methds For this update we modified the search strategy to improve the precision and reduce the number of irrelevant hits. All studies included in the original review were considered for re-evaluation in the update. We searched the electronic databases CENTRAL (2012, Issue 11) in The Cochrane Library, MEDLINE, and EMBASE (05 December 2012) from their inception using the newly developed search strategy. Online trials registers and reference lists of systematic reviews were searched.

Selection criteria Terms representing STS and autologous HSCT were required in the title or abstract. In studies with aggregated data, participants with NRSTS and autologous HSCT had to constitute at least $80 \%$ of the data. Single-arm studies were included in addition to studies with a control arm because the number of comparative studies was expected to be very low.

Data collection and analysis Two review authors independently extracted study data. Some studies identified in the original review were re-examined and found not to meet the inclusion criteria and were excluded in this update. For studies with no comparator group, we synthesized the results for studies reporting aggregate data and conducted a pooled analysis of individual participant data using the Kaplan-Meyer method. The primary outcomes were overall survival (OS) and treatment-related mortality (TRM).

Main results The selection process was carried out from the start of the search dates for the update. We included 57 studies, from 260 full text articles screened, reporting on 275 participants that were allocated to HDCT followed by autologous HSCT. All studies were not comparable due to various subtypes. We identified a single comparative study, an RCT comparing HDCT followed by autologous HSCT versus standard chemotherapy (SDCT). The overall survival (OS) at three years was $32.7 \%$ versus $49.4 \%$ with a hazard ratio (HR) of 1.26 (95\% confidence interval $(\mathrm{Cl}) 0.70$ to $2.29, \mathrm{P}$ value 0.44 ) and thus not significantly different between the treatment groups. In a subgroup of patients that had a complete response before treatment, OS was higher in both treatment groups and OS at three years was $42.8 \%$ versus $83.9 \%$ with a 
$\mathrm{HR}$ of 2.92 (95\% $\mathrm{Cl} 1.1$ to $7.6, \mathrm{P}$ value 0.028 ) and thus was statistically significantly better in the SDCT group. We did not identify any other comparative studies. We included six single-arm studies reporting aggregate data of cases; three reported the OS at two years as $20 \%, 48 \%$, and $51.4 \%$. One other study reported the OS at three years as $40 \%$ and one further study reported a median os of 13 months (range 3 to 19 months). In two of the single-arm studies with aggregate data, subgroup analysis showed a better OS in patients with versus without a complete response before treatment. In a survival analysis of pooled individual data of 80 participants, OS at two years was estimated as $50.6 \%(95 \% \mathrm{Cl} 38.7$ to 62.5$)$ and at three years as $36.7 \%$ (95\% $\mathrm{Cl} 24.4$ to 49.0). Data on TRM, secondary neoplasia and severe toxicity grade 3 to 4 after transplantation were sparse. The one included RCT had a low risk of bias and the remaining 56 studies had a high risk of bias.

Authors' conclusions A single RCT with a low risk of bias shows that OS after HDCT followed by autologous HSCT is not statistically significantly different from standarddose chemotherapy. Therefore, HDCT followed by autologous HSCT for patients with NRSTS may not improve the survival of patients and should only be used within controlled trials if ever considered. 


\section{Plain Language Summary}

High-dose chemotherapy followed by autologous hematopoietic stem cell transplantation for non-rhabdomyosarcoma soft tissue sarcomas

Review question

We reviewed the evidence about the effect of high-dose chemotherapy followed by autologous hematopoietic stem cell transplantation compared to standard-dose chemotherapy on overall survival in people with non-rhabdomyosarcoma soft tissue sarcomas. We found one randomized controlled trial (RCT) comparing both treatments and 48 studies with results from transplantation only.

\section{Background}

Non-rhabdomyosarcoma soft tissue sarcomas are a group of rare cancers. People with inoperable or metastatic disease have a poor prognosis. It was believed that higher doses of chemotherapy might improve patients' survival. However, high doses of chemotherapy stop the production of blood cells in the bone marrow and are not compatible with life. Stem cells collected from people before highdose chemotherapy can be transplanted back to the patient if the blood cell count gets too low. Due to a lack of research studies, it has not been proven that patients treated with this procedure live any longer than patients treated with standard chemotherapy. We wanted to determine whether using high-dose chemotherapy followed by autologous hematopoietic stem cell transplantation was better or worse than standard-dose chemotherapy.

\section{Study characteristics}

The evidence is current to 5 December 2012. The single RCT that was identified compared 38 patients in the transplantation group versus 45 patients in the chemotherapy only group and was judged to have a low risk of bias (high methodological quality). The participants were 18 to 65 years old, had various types of non-rhabdomyosarcoma soft tissue sarcomas and were observed for a median follow-up time of 55 months. The rest of the studies reported results for a series of or individual transplanted patients only, with various ages, tumor types and follow up times; they all had a high risk of bias. The treatment period among studies ranged from 1994 to 2008 . The single RCT and some of the other studies were funded by non-profit organizations. Three studies reported financial support by biopharmaceutical companies. Most studies did not give details of funding. 


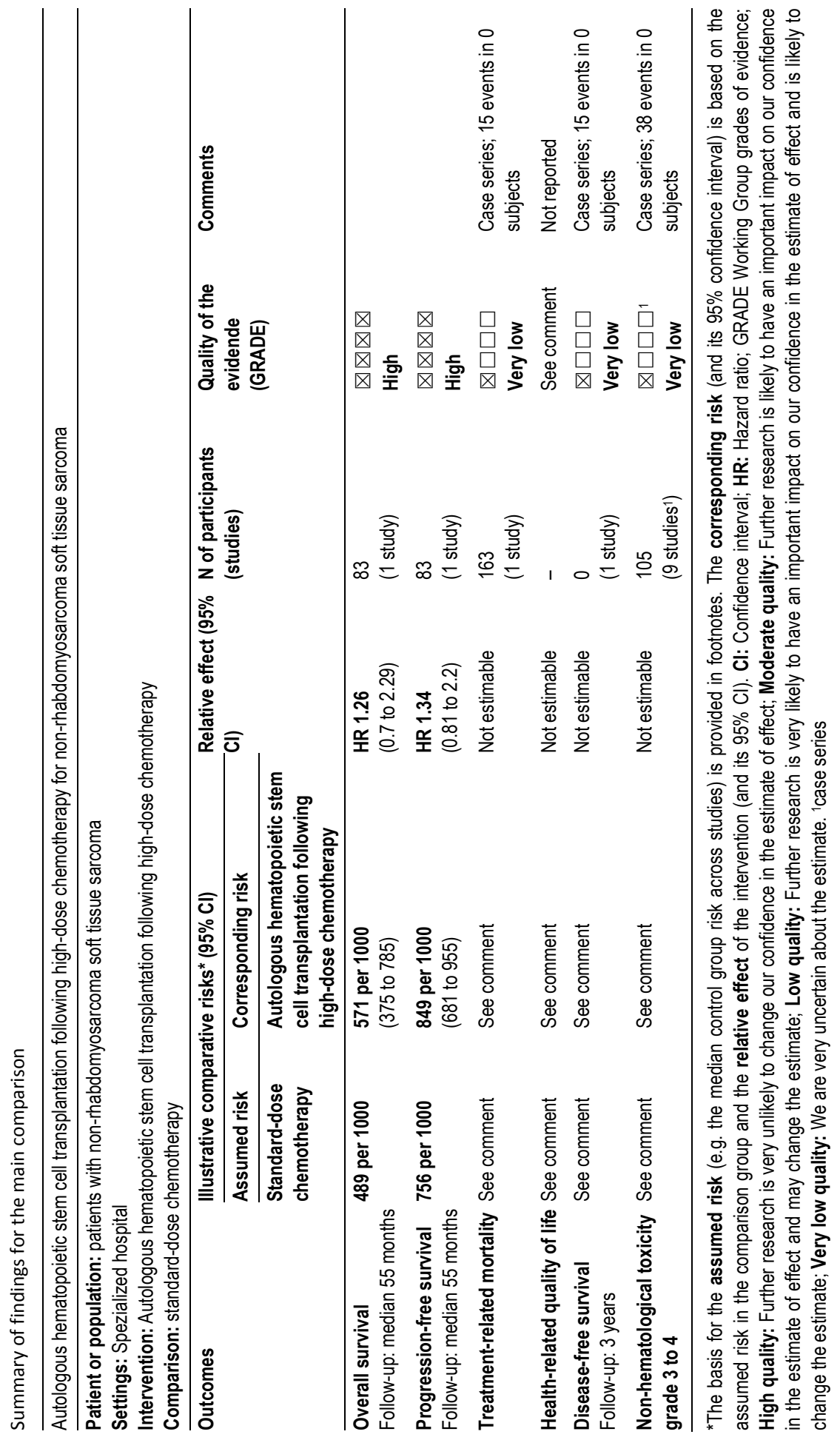




\section{Key results}

In the single RCT, the overall survival (OS) at three years was $32.7 \%$ in the transplantation group versus $49.4 \%$ in the chemotherapy only group, and this was not found to be significant. There was one case of treatment-related mortality in the transplantation group and none in the chemotherapy only group.

\section{Quality of evidence}

The overall quality of the data was based on a single RCT, which had a low risk of bias. The rest of the studies had a high risk of bias due to single-arm and retrospective study design and were not useful for comparing two treatments. Currently the research evidence indicates that patients with non-rhabdomyosarcoma soft tissue sarcomas should not be treated with high-dose chemotherapy followed by autologous hematopoietic stem cell transplantation. If this treatment is offered it should be done only within clinical controlled trials and after careful consideration.

\section{Background}

\section{Description of the condition}

Soft tissue sarcomas (STS) are a highly heterogeneous group of rare malignant solid tumors of non-epithelial extraskeletal body tissue and are classified on a histogenetic basis [Enzinger 2001]. STS have a significant risk of distant metastasis in addition to the potential for locally destructive growth and recurrence. Non-rhabdomyosarcoma soft tissue sarcomas (NRSTS) comprise all STS except rhabdomyosarcoma, which primarily affects children and young adults. In this review we investigated NRSTS which are categorized as malignant according to the World Health Organization (WHO) 2002 classification [Fletcher 2002] as adopted by the European Society for Medical Oncology (ESMO) Guidelines Working Group [ESMO 2012]. This latter classification excludes the Ewing family of tumors (EFT).

NRSTS usually originate de novo and rarely from benign tumors. In most cases the pathogenesis is unknown; however, some factors have been found to be associated with the development of NRSTS [Enzinger 2001]. These include exposure to ionizing radiation, environmental carcinogenic substances, oncogenic viruses and immunologic factors. Genetic factors can also play a role since some inherited diseases such as neurofibromatosis type 1 are associated with a higher risk of NRSTS [Tsao 2000].

In Western countries about four new cases of NRSTS are estimated per 100,000 population every year [ESMO 2012], with rhabdomyosarcoma and the Ewing family of tumors excluded from this statistic. STS constitute about $1 \%$ of malignancies in adults and $7 \%$ in children [ $\mathrm{NCl} 2009$ a]. Rhabdomyosarcoma represents about $50 \%$ of STS in 
children [Gurney 1997; Miller 1995]. NRSTS are rare in both children and adults and the distribution of NRSTS differs significantly between children and adults (Table 1) according to [Spunt 2006].

Table 1. Frequency of subtypes of included NRSTS in patients of young versus advanced age

\begin{tabular}{llll}
\hline Young age (<20 years) & & Advanced age (>= 20 years \\
\hline Synovial sarcoma & $7.7 \%$ & Leiomyosarcoma & $13.7 \%$ \\
Malignant fibrous histiocytoma & $4.9 \%$ & Malignant fibrous histiocytoma & $10.1 \%$ \\
Fibrosarcoma & $4.5 \%$ & Liposarcoma & $8.0 \%$ \\
Liposarcoma & $2.8 \%$ & Hemangiosarcoma & $2.5 \%$ \\
Epitheloid sarcoma & $2.0 \%$ & Spindle cell sarcoma & $2.3 \%$ \\
\hline
\end{tabular}

Estimates in the table according to [Spunt 2006]

Abbreviations. NRSTS: non-rhabdomyosarcoma soft tissue sarcomas

Based on the Surveillance, Epidemiology and End Results (SEER) cancer statistics review (1975 to 2007) of the National Cancer Institute (NCI), in the US 10,520 new cases and 3920 deaths from STS were estimated for the year 2010 [NCl 2010a]. Separate data were not available for rhabdomyosarcoma and NRSTS. The distribution of STS increased with age according to SEER data from 2001 to 2005. Of all STS cases, $10.3 \%$ were in children and young adults less than 20 years of age $[\mathrm{NCl} 2008 \mathrm{a}]$. The median age at diagnosis of STS, including tumors of the heart, was 57 years [ $\mathrm{NCl} 2008 \mathrm{~b}]$.

\section{Staging}

Disease progression may be dichotomized into the two categories of limited and extensive disease. Limited disease is typically a localized, small-sized, low-grade and operable and accessible tumor that has no regional lymph node involvement and no distant metastases. Extensive disease can also be denoted as advanced disease, defined as localized, large-sized and high-grade tumor that may not be completely removed by surgery, may be invasive and may have regional lymph node involvement or distant metastases. Both categories differ significantly in terms of prognosis and treatment. Where many patients with limited disease may be cured by surgery, extensive disease is associated with a poor outcome and many patients receive chemotherapy as palliative therapy.

The American Joint Committee on Cancer (AJCC) tumor-nodemetastasis (TNM) staging system combines grade, depth and size of the tumor as well as regional lymph node involvement and distant metastases and describes the extent of a cancer's spread from stage 0 to IV [AJCC 2002]. A review reported the five-year overall survival (OS) estimates for stage I (low-grade, superficial and deep), II (high-grade, superficial and deep), III (high-grade, large and deep) and IV (any metastasis to lymph nodes or 
distant sites) as approximately $90 \%, 70 \%, 50 \%$ and $10 \%$ to $20 \%$, respectively; information on treatment was not given [Clark 2005]. A multicenter study a total of 2185 participants with advanced STS revealed a median survival of 12 months [Van Glabbeke 1999]. In the same study, of the 1922 (26\%) eligible participants who responded to chemotherapy the five-year OS was 10\%; in univariate analyses the response to chemotherapy was not predicted by the same factors as was OS.

\section{Symptoms}

The location of the primary tumor can involve any area of the body. The distribution is $40 \%$ lower limb and girdle, 20\% upper limb and girdle, 20\% abdominal sites, 10\% trunk and $10 \%$ head and neck [Clark 2005]. NRSTS can involve any type of tissue and typically affect muscles, tendons, adipose tissue, blood vessels and joints [Sondak 2001] and commonly present as a painless mass. The symptoms depend on the anatomical site of origin, the size of the mass and other aspects. Retroperitoneal sarcomas are most often asymptomatic, until the mass grows large enough to be clinically obvious or presses on vital organs and causes pain [Dileo 2005].

Patients who relapse or suffer progressive disease after therapy or metastasis are commonly called high-risk patients because these signs are associated with shorter survival time. Spontaneous recovery from NRSTS is unknown.

\section{Description of the intervention}

\section{Standard therapy}

Surgery is the standard treatment for localized NRSTS [ESMO 2012] and can be curative if distant dissemination is not present [Kotilingam 2006]. Chemotherapy is a standard treatment for patients with distant metastasis [ESMO 2012] and is regarded mainly as a palliative treatment for high-risk patients who are characterized by inoperable, locally advanced and metastatic disease. Doxorubicin, ifosfamide, gemcitabine, dacarbacine, docetaxel and trabectedin are used in monotherapy or in combinations [ESMO 2012]. [Riedel 2012] provides an overview of current systemic therapies and discusses possible novel therapeutic agents and treatment strategies.

High-dose chemotherapy [HDCT] followed by autologous hematopoietic stem cell transplantation [HSCT]

Autologous hematopoietic stem cell transplantation (HSCT) is defined as the transplantation of stem cells that have been collected previously from bone marrow or peripheral blood of the same person. High-dose chemotherapy (HDCT) uses higher doses of chemotherapeutic agents than are usually applied in standarddose chemotherapy. HDCT may be tolerated by the patient or it may ablate the patient's bone marrow reserves and create an absolute requirement for stem cell rescue. Instead of HDCT, 
highdose radiation therapy may be used to treat NRSTS patients. Autologous HSCT applied after HDCT or high-dose radiation is a planned rescue therapy for HDCT-related severe hematologic toxicity [Banna 2007]. Ideally, a mega-therapy regimen should be used consisting of several non-cross resistant agents that have a steep dose-response curve and little extramedullary toxicity [Ladenstein 1997].

HDCT and autologous HSCT are not standard treatment options; they are an experimental approach mainly used to treat high-risk people with an unfavorable prognosis [stage IV with distant metastases]. HDCT and autologous HSCT may be used in special cases after careful consideration, usually for patients who respond well to standard chemotherapy according to Response Evalauation Criteria in Solid Tumors (RECIST) [Therasse 2000] criteria [Kasper 2005; Kasper 2007b]. Carboplatin, cisplatin, cyclophosphamide, etoposide, ifosfamide, melphalan, mitoxantrone and thiotepa, for example, have been used in HDCT regimens. Independent of the disease status, HDCT and autologous HSCT are hazardous interventions that carry the risk of life-threatening organ failure.

\section{Adverse events}

Non-hematological adverse events, such as short-term and longterm organ toxicities, must be considered when using HDCT [Ladenstein 1997]. Hematological adverse events as a result of autologous HSCT are usually manageable but life-threatening consequences of pancytopenia. They generally affect all patients and include, for example, graft failure, severe infections and bleeding.

\section{Frequency}

Of a total of 20,017 autologous HSCTs that were registered in Europe in the year 2010, by the European Group for Blood and Marrow Transplantation (EBMT), 45 were indicated for STS [Passweg 2012].

\section{How the intervention might work}

HDCT followed by autologous HSCT was adopted to treat highrisk patients because it was believed that escalating doses in chemotherapy might increase survival by capturing putatively remnant malignant cells and might overcome resistance to standarddose chemotherapy [Banna 2007]. High-dose chemotherapy may cause severe hematologic and non-hematologic toxicity and autologous HSCT is a planned rescue therapy for the HDCT-related demise of hematopoietic stem cells. 


\section{Why it is important to do this review}

In the last two decades, from 1986 to 2007, the lack of evidence and need to conduct randomized controlled trials (RCTs) was stated by authors seeking to clarify the relevance of HDCT followed by autologous HSCT in high-risk patients with STS [Blay 2000; Carvajal 2005; Dumontet 1992; Ek 2006; Elias 1998; Kasper 2007a; Ladenstein 1997; Pinkerton 1986; Reichardt 2002; Rosti 2002; Schlemmer 2006; Seeger 1991; Woods 1999]. Some authors have warned against the use of HDCT followed by autologous HSCT, indicating the possibility of repositioning of malignant cells [Woods 1999]. Others have questioned the use of HDCT with reference to the potential existence of refractory cancer stem cells [Banna 2007; Bonnet 1997; Sanchez-Garcia 2007]. The rationale for this review update is to review the latest available evidence and to clarify whether RCTs have been conducted and whether results of any study show evidence of a survival advantage.

\section{Objectives}

To assess the effectiveness and safety of high-dose chemotherapy (HDCT) followed by autologous hematopoietic stem cell transplantation (HDCT) for all stages of nonrhabdomyosarcoma soft tissue sarcomas (NRSTS) in children and adults.

\section{Methods}

\section{Criteria for considering studies for this review}

Types of studies

Inclusion criteria

Randomized controlled trials (RCTs). Since we expected to find few if any RCTs, nonRCTs were also included as follows. Prospective non-randomized controlled trials [denoted quasi-RCTs in the first version], other non-RCTs such as prospective and retrospective cohort studies, case-control studies, phase I and II prospective studies, case series and case reports.

Results from RCTs and controlled clinical trials (CCTs) may provide data for estimation of effects on overall survival (OS) and answer the question: does the intervention provide a significantly better survival than the control and does the quality of the studies fit with the assumption that the intervention is better than the control? Data from non-comparative studies (phase I and II prospective studies, case series and case reports) were collected to estimate treatment-related mortality (TRM) within a cohort of 
participants. Due to the lack of a control group these studies do not provide data for estimation of treatment effect.

\section{Exclusion criteria}

None

\section{Rationale for including non-RCTs}

Authors of studies on HDCT with autologous HSCT have stated that RCTs are both necessary and feasible. However, NRSTS is a rare disease and, according to the results of a previous literature search, currently there are no published RCTs available. In addition, CCTs or studies with any comparative data may be unlikely or rare. If they do exist they may be of low methodological quality. Based on the assumption that it is unlikely that the intervention has been or will be studied in RCTs in the near future, this systematic report of the findings and the limitations of all available published studies will be useful, for example for informing the design of appropriate RCTs and providing a summary of all of the evidence on the topic to date.

\section{Types of participants}

\section{Inclusion criteria}

We have adopted the World Health Organization (WHO) classification of soft tissue tumors to define the population of patients with NRSTS [Fletcher 2002]. We present the designation of tumors that were regarded as (malignant) soft tissue sarcomas in the present review in Table 2. The clear delineation of soft tissue sarcomas to be included in the present report and the grounds for exclusion of some tumor types was hindered by the presence of more than 30 heterogenous tumor entities, the distinction between categories of malignant tumors and categories of intermediate malignancies as described in the WHO classification (Fletcher 2002), and a complicated histology and terminology.

Studies were included as long as at least $80 \%$ of patients had NRSTS. Children as well as adults were investigated and age limits did not apply. Participants were included regardless of the severity of the disease and the clinical staging information, as long as they received autologous (from either a peripheral or bone marrow source, or both) HSCT.

\section{Exclusion criteria}

We present the terms for tumors that were not considered in the present review in Table 3. Whilst the WHO classification of NRSTS includes the Ewing family of tumors, that is extraosseous tumor types, we excluded these types because they are primarily bone sarcomas. Because extraosseous types are rarely diagnosed and share common features, they were regarded as one entity with osseous types and were excluded. 
Table 2. Included non-rhabdomyosarcoma soft tissue sarcomas (NRSTS)

Category* Associated subtypes

Adipocytic tumors

Anaplastic soft tissue sarcoma

Angiosarcoma

Angiosarcoma of soft tissue; hemangiosarcoma; hemangiopericytoma; lymphangiosarcoma

Clear cell myomelanocytic tumor

Clear cell sarcoma of soft tissue tumor

Desmoplastic small round cell tumor

Epitheloid sarcoma

Fibrosarcoma

Adult fibrosarcoma; myxofibrosarcoma; low grade fibromyxoid sarcoma, hyalinizing spindle cell tumor; sclerosing epitheloid fibrosarcoma

Fibromyxoid sarcoma

Epitheloid hemangioendothelioma

Intimal sarcoma

Leiomyosarcoma

Liposarcoma

Dedifferentiated liposarcoma; myxoid liposarcoma; round cell liposarcoma; pleomorphic liposarcoma; mixed-type liposarcoma; liposarcoma, not otherwise specified; chondroid liposarcoma (added by authors)

Malignant fibrous histiocytoma

Pleomorphic malignant fibrous histiocytoma, undifferentiated pleomorphic sarcoma; giant cell malignant fibrous histiocytoma, undifferentiated pleomorphic sarcoma with giant cells; inflammatory malignant fibrous histiocytoma, undifferentiated pleomorphic sarcoma with prominent inflammation; undifferentiated pleomorphic sarcoma; spindle cell sarcoma

Malignant glomus tumor

Malignant hemangiopericytoma

Malignant mesenchymoma

Mesenchymomal sarcoma

Neoplasms with perivascular epithelioid cell differentiation (PEComa)

Rhabdoid sarcoma

Extrarenal rhabdoid tumor; extracerebral rhabdoid tumor

Synovial sarcoma

*category of malignant tumors according to the World Health Organization Classification of Tumours: Pathology and Genetics of Tumours of Soft Tissue and Bone [Fletcher 2002] 
Table 3. Excluded tumor types

\begin{tabular}{|c|c|}
\hline Category & Associated subtypes \\
\hline \multicolumn{2}{|l|}{ Atypical teratoid/rhabdoid tumors } \\
\hline Chondrosarcoma & $\begin{array}{l}\text { Mesenchymal chondrosarcoma; extraskeletal myxoid chondrosarcoma } \\
\text { ('chondroid type') }\end{array}$ \\
\hline \multicolumn{2}{|l|}{ Clear cell sarcoma of the kidney } \\
\hline \multicolumn{2}{|l|}{ Dermatofibrosaroma protuberans } \\
\hline \multicolumn{2}{|l|}{ Endometrial stroma sarcoma } \\
\hline Ewing family of tumors & $\begin{array}{l}\text { Ewing sarcoma; skeletal Ewing sarcoma; extraskeletal Ewing } \\
\text { sarcoma; peripheral primitive neuroectodermal tumor (pPNET); Askin } \\
\text { tumor }\end{array}$ \\
\hline \multicolumn{2}{|l|}{ Extragonadal germ cell sarcoma } \\
\hline \multicolumn{2}{|l|}{ Follicular dendritic cell sarcoma } \\
\hline \multicolumn{2}{|l|}{ Ganglioneuroblastoma } \\
\hline \multicolumn{2}{|l|}{ Gastrointestinal stromal tumor } \\
\hline \multicolumn{2}{|l|}{ Giant cell fibroblastoma } \\
\hline \multicolumn{2}{|l|}{ Giant cell tumor of bone } \\
\hline \multicolumn{2}{|l|}{ Histiocytic sarcoma } \\
\hline \multicolumn{2}{|l|}{ Interdigitating dendritic cell sarcoma } \\
\hline \multicolumn{2}{|l|}{ Interdigitating reticulum cell sarcoma } \\
\hline \multicolumn{2}{|l|}{ Kaposi sarcoma } \\
\hline \multicolumn{2}{|l|}{ Lymphoblastic lymphosarcoma } \\
\hline \multicolumn{2}{|l|}{ Malignant ectomesenchymoma } \\
\hline \multicolumn{2}{|l|}{ Medulloblastoma } \\
\hline \multicolumn{2}{|l|}{ Myeloid sarcoma } \\
\hline \multicolumn{2}{|l|}{ Myxosarcoma (cardiac tumor) } \\
\hline \multicolumn{2}{|l|}{ Nephroblastoma } \\
\hline \multicolumn{2}{|l|}{ Neuroblastoma (Wilms tumor) } \\
\hline Osteosarcoma & Extraskeletal osteosarcoma \\
\hline \multicolumn{2}{|l|}{ Paraganglioma } \\
\hline \multicolumn{2}{|l|}{$\begin{array}{l}\text { Peripheral nerve sheath tumor, malignant } \\
\text { (neurofibrosarcoma) }\end{array}$} \\
\hline \multicolumn{2}{|l|}{ Rhabdoid tumor, renal } \\
\hline \multicolumn{2}{|l|}{ Rhabdoid tumor, cerebral } \\
\hline \multicolumn{2}{|l|}{ Rhabdomyosarcoma } \\
\hline \multicolumn{2}{|c|}{ Schwannoma, malignant (Schwannosarcoma) } \\
\hline \multicolumn{2}{|l|}{ Stromal cell sarcoma } \\
\hline \multicolumn{2}{|l|}{ Unclassified sarcoma } \\
\hline \multicolumn{2}{|l|}{ Undifferentiated sarcoma } \\
\hline Uterine endometrial stromal sarcoma & \\
\hline
\end{tabular}




\section{Types of interventions}

Intervention: autologous hematopoietic stem cell transplantation (HSCT), stem cells from a peripheral source or the bone marrow, serving as a rescue therapy usually applied after high-dose chemotherapy (HDCT).

Comparison: standard-dose chemotherapy, which is defined as chemotherapy at a lower dose than HDCT without the need for stem cell rescue.

Types of outcome measures

\section{Primary outcomes}

- Overall survival (OS): the event was death by any cause, from diagnosis or start of HDCT and autologous HSCT.

- Treatment-related mortality (TRM): incidence of deaths that were classified as treatment related or the participants died of treatment complications.

\section{Secondary outcomes}

- Disease-free survival (DFS): time free of disease after diagnosis or start of HDCT and autologous HSCT. We provided the definitions reported in the studies.

- Progression-free survival (PFS): time staying free of disease progression after diagnosis or start of HDCT and autologous HSCT. We provided the definitions reported in the studies.

- Event-free survival (EFS): time staying free of any of a particular group of defined events after diagnosis or start of HDCT and autologous HSCT. We provided the definitions reported in the studies.

- Non-hematological toxicity grade 3 to 4: adverse events classified according to the common toxicity criteria [ $\mathrm{NCl} 2009 \mathrm{~b}$ ] within 90 days of start of HDCT and autologous HSCT; grades 3 and 4 of toxicity were extracted for non-hematological (nausea, mucositis, kidney, liver, nervous system, heart, other) toxicities.

- Secondary neoplasia: as classified by the study authors.

- Health-related quality of life measured by validated questionnaires.

\section{Search methods for identification of studies}

\section{Electronic searches}

We conducted an electronic database search of MEDLINE (Ovid), including articles published between 1946 and 5 December 2012, by using the search strategy shown in Appendix 1. We searched EMBASE (Ovid), including articles published between 1980 and 5 December 2012, by using the search strategy shown in Appendix 2. We searched The Cochrane Library, including articles published from inception to 5 December 2012, by using the search strategy shown in Appendix 3. The original strategies which were 
run on 5 February 2010 and are shown in Appendix 4 for MEDLINE (Ovid), in Appendix 5 for EMBASE (Ovid), and in Appendix 6 for The Cochrane Library. For this update we considered all studies that were included in the original review and re-evaluated them. We searched for ongoing trials by scanning the online registries ClinicalTrials.gov [ClinicalTrials.gov 2012] and the World Health Organization International Clinical Trials Registry Platform [ICTRP 2012] on 5 December 2012 for additional completed or ongoing studies using the search strategy "sarcoma AND chemotherapy AND transplantation". For the update of the present review we searched abstracts of annual meetings of the following societies via EMBASE (Ovid): American Society of Clinical Oncology (ASCO), American Society of Hematology (ASH), Bone Marrow Transplantation (BMT) Tandem Meeting of the American Society for Blood and Marrow Transplantation (ASBMT) and the Center for International Blood and Marrow Transplant Research (CIBMTR), and European Group for Blood and Marrow Transplantation (EBMT).

The search strategies used have been developed and executed by the author team.

\section{Searching other resources}

We located information about trials not registered in electronic databases by searching the reference lists of relevant articles and review articles such as [Banna 2007, Ek 2006, Pedrazzoli 2006, and Verma 2008a]. For the update, we did not identify more recent reviews. We contacted authors to replenish missing information.

\section{Data collection and analysis}

\section{Selection of studies}

We endorsed the PRISMA statement, adhered to its principles and conformed to its checklist [Moher 2009]. We re-ran the whole selection process including all records retrieved from the inception of each database. We retrieved all titles and abstracts by electronic searching and downloaded them to the reference management database EndNote Version X3 [Thomson Reuters Corp 2012]. We removed duplicates and two review authors examined the remaining references independently. We excluded those studies that clearly did not meet the inclusion criteria and we obtained copies of the full texts of potentially relevant references. Two authors assessed the eligibility of retrieved papers independently. We resolved disagreement by discussion and it was not necessary to consult a third review author. We considered studies written in languages other than English and asked peers familiar with the particular language and with the principles of study evaluation to translate major methodological issues. We also used the [Google Translate 2012] program. We documented reasons for the exclusion of studies. 


\section{Data extraction and management}

We re-extracted the data from all selected studies identified from the inception of each database. Two review authors independently abstracted data on study characteristics, patients and interventions, duration of follow up, outcomes, and deviations from the protocol. In addition, two review authors independently assessed the risk of bias. We resolved differences between review authors by discussion or by appeal to a third review author. All included studies were full-text publications.

We extracted the following data.

- General information on author, title, source, publication date.

- Study characteristics: trial design, setting, inclusion and exclusion criteria, comparability of patients' characteristics between groups, treatment allocation, blinding, subgroup analysis, length of follow-up.

- Participant characteristics: age; gender; number of participants recruited, /allocated, affected, analyzed; additional diagnoses; participants lost to follow-up.

- Interventions: type of high-dose chemotherapy, source of stem cells, and type of standard-dose chemotherapy.

- Outcomes: overall survival, treatment-related mortality, disease-free survival, progression-free survival, event-free survival including type of event, toxicity, secondary neoplasia, healthrelated quality of life.

\section{Assessment of risk of bias in included studies}

Two review authors independently assessed the risk of bias in the included studies using six criteria. We have used four criteria of The Cochrane Collaboration's tool for assessing risk of bias [Higgins 2011a]:

1. random sequence generation (selection bias);

2. allocation concealment (selection bias);

3. blinding of outcome assessment (detection bias);

4. selective reporting such as not reporting pre-specified outcomes (reporting bias).

We extended the tool for assessing risk of bias with five additional criteria that are specific for the inclusion criteria for the present review and that are critical for confidence in the results:

1. prospective design;

2. comparable baseline characteristics;

3. assignment of patients to treatment groups;

4. concurrent control;

5. loss to follow-up.

We applied The Cochrane Collaboration's criteria for judging risk of bias [Higgins 2011b]. In general, a 'low risk' of bias is judged if the bias is unlikely to seriously alter 
the results, for example, participants and investigators enrolling participants could not foresee assignment. A 'high risk' of bias is judged if the bias seriously weakens confidence in the results, for example, participants or investigators enrolling participants could possibly foresee assignments. 'Unclear risk' of bias is judged if the bias raises some doubt about the results, for example, the method of concealment is not described or not described in sufficient detail to allow a definite judgement.

We judged studies as prospective if an explicit statement was reported or there were clues suggesting a prospective design (for example prior approval of treatment, informed consent). We judged studies as retrospective if an explicit statement was reported or was implied by a description that data were reviewed from an existing source. We regarded each of the following items as an indication of a retrospective design: registry reports and reviewing of medical records.

\section{Measures of treatment effect}

The primary effect measure was the hazard ratio (HR) for timeto-event data. If the HR was not directly given in the publication, we planned to estimate HRs according to methods proposed by [Parmar 1998] and [Tierney 2007].

We planned to calculate odds ratios (ORs) with 95\% confidence intervals (Cls) for dichotomous outcomes. In the case of rare events, we planned to use Peto odds ratio instead. We planned to analyze continuous data and to present them as mean differences, if all results were measured on the same scale (for example length of hospital stay). If this was not the case (for example pain or quality of life), we planned to use standardized mean differences. Studies reporting aggregate data that combined the results of several participants (including results from separately reported subpopulations that fulfilled the inclusion criteria) were distinguished from studies with individual data of single participants. Data from these studies were described as narrative summaries. In some studies diagnoses of NRSTS were mixed with non-NRSTS solid tumors and rhabdomyosarcomas to such an extent that the proportion of NRSTS participants was less than $80 \%$ of the study population. In this case, if data on single participants were identified that fulfilled the inclusion criteria of the present review we included the study and data for the individual participant in our data analysis.

Estimates of OS were considered for the evaluation if the use of the Kaplan-Meier method was reported in the study. We described survival estimates from studies reporting aggregate data independent of the start of the follow-up period on the condition that these estimates were not pooled with those of other studies.

A survival analysis was conducted of individual participant level data based on the Kaplan-Meier method. Pooling required binary information on OS [0 = alive; $1=$ dead] and on follow-up. In the majority of cases, the starting point of follow-up was the beginning of treatment. However, we accepted other starting points such as the time 
when the diagnosis or indication for treatment was established. Statistical analyses of time to event data were performed using SAS Version 9.2 [SAS Institute Corp 2012].

Unit of analysis issues

None

Dealing with missing data

We conformed to The Cochrane Collaboration's principal options for dealing with missing data and analysed only the available data [Higgins 2011c]. If data were missing or only imputed data were reported we contacted trial authors to request data on the outcomes among participants who were assessed. We contacted the authors of the studies by [Bui-Nguyen 2012, Ivanova 2010, Jordan 2010, Philippe-Chomette 2012, Schlemmer 2006] to ask for missing data about the histologic types that were combined as 'others'. The authors responded well and as a consequence we could base the inclusion or exclusion of patient data on the additional data.

\section{Assessment of heterogeneity}

We planned to assess heterogeneity between studies by visual inspection of forest plots; by estimation of the percentage heterogeneity between trials which cannot be ascribed to sampling variation ( ${ }^{2}$ statistic) [Higgins 2003]; by a formal statistical test of the significance of the heterogeneity (Cochran's Q) [Deeks 2011]; and, if possible, by subgroup analyses [see 'Subgroup analysis and investigation of heterogeneity']. We planned to investigate and report possible reasons if there was evidence of substantial heterogeneity. We planned to use the random-effects model with inverse variance weighting for statistical pooling [DerSimonian 1986]. We did not pool estimates.

\section{Assessment of reporting biases}

We conformed to The Cochrane Collaboration's criteria and planned to evaluate reporting biases such as publication bias, time lag bias, multiple (duplicate) publication bias, location bias, citation bias, language bias and outcome reporting bias [Sterne 2011]. We did not assess reporting bias because of the low number of identified studies.

\section{Data synthesis}

One review author entered the data into [Review Manager 2011]. Another review author checked the entered data. Methods of synthesizing the studies depended on the quality, design and heterogeneity of the studies identified.

We planned to synthesize data on mortality (HDCT and autologous HSCT versus SDCT) by using the hazard ratio (HR) as effect measure in a random-effects model. 
However, data were too scarce to be reasonably pooled. Aggregate data were synthesized as narrative. In contrast, individual data were pooled and available time-to-event data were analyzed in a Kaplan-Meier survival analysis.

We used the software GRADEpro 3.2 [GRADEpro 2008] to create the 'Summary of findings' table as suggested in the Cochrane Handbook for Systematic Reviews of Interventions [Schunemann 2011].

\section{Subgroup analysis and investigation of heterogeneity}

We had planned subgroup analyses based on age, stage, and time period of treatment. However, we found no appropriate data to conduct these analyses.

\section{Sensitivity analysis}

We had planned sensitivity analyses to compare the results of studies with low versus high risk of bias. As all included studies had a high risk of bias, no sensitivity analyses were carried out.

\section{Results}

\section{Description of studies}

Clinical heterogeneity was substantial because tumor subdiagnosis varied considerable between patients. Furthermore, tumor stage was not reported for all participants. Study design was tenuously reported due to the identification of either aggregate data or individual patient data in one-arm studies. Overall, the likelihood of bias was very high except in the single randomized controlled trial (RCT). All studies were not comparable due to various subtypes.

Results of the search

For this update we modified the search strategy to improve the precision and reduce the number of irrelevant hits. In the original review, we applied a search strategy that was designed to include all solid tumors including the Ewing family of tumors and rhabdomyosarcoma. This strategy resulted in the retrieval of a large number of documents (4782) including a very high fraction of not relevant retrieved documents. We revised the search strategy and this retrieved a considerably reduced number of retrieved documents (1035) from the inception of each electronic databases. The new strategy did not identify some single-arm studies with individual data that were included in the original review. Some individual cases are hidden in articles that do not mention soft tissue sarcomas and transplantation in the title or abstract. Some of those are missed by the new strategy. It is impossible to identify all published cases of 
transplanted patients with NRSTS. Therefore, the number of identified relevant cases will vary with different strategies. The retrieval information confirmed that the number of studies with comparative data and aggregate data did not vary and the number of these types of identified studies was robust. The new search strategy was more economical in terms of spending resources for study selection for the present review, and also for future updates. We did not ignore the results of the original review and reevaluated all studies that were identified by the old strategy and were included in the original review.

We retrieved 1035 records applying the new search strategy. We also retrieved six ongoing studies. We imported 15 studies that were included in the original review but were not identified with the new search strategy. We screened 773 different articles after removal of duplicates (Figure 1). The titles and abstracts of 513 articles did not fulfil the inclusion criteria or they reported about ongoing studies. A total of 260 of the retrieved articles were evaluated in detail using the full text. Of these, a total of 62 records reporting about 57 studies were included in the present review and the other 198 references were excluded. We identified one randomized controlled trial (RCT), six single-arm studies with aggregate data, and 50 single-arm studies with individual data.

Eight studies were published after the original retrieval and were added to the included studies [Bisogno 2010; Buerk 2010; BuiNguyen 2012; Cook 2012; EtienneMastroianni 2002; Houet 2010; Jordan 2010; Philippe-Chomette 2012]. Nine further studies were included in the original review but were not identified by the new search strategy [Fang 2008; Graham 1997; Hawkins 2002; Kretschmar 1996; Krskova 2007; Matsuzaki 2002; Peters 1986; Peters 1989; Slease 1988] (Table 4; online at doi: 10.1002/14651858.CD008216.pub4). These 15 studies were included in the update in addition to the results of the new search strategy. Three studies were included in the original review and identified in the update but were excluded after re-evaluation [Ivanova 2010; Kaminski 2000; Kuehne 2000]. Three studies were excluded in the original review and identified in the update but were included after re-evaluation [Blay 2000; Fetscher 1996; Mingo 2005]. Six further studies were included in the original review and not identified in the update but were excluded after re-evaluation. Four studies reported about undifferentiated sarcoma, which is not included [Endo 1996; Frapier 1998; Mesia 1994; Nakamura 2008]. One study reported about rhabdoid tumor but without information about the localisation, which is required for identification of the extrarenal and the extracerebral rhabdoid tumors [Ronghe 2004]. One study reported on undifferentiated sarcoma and rhabdoid tumor without information about the localisation [Shaw 1996]. We retrieved a total of 49 studies in ClinicalTrials.gov 2012 and found 14 potentially relevant studies. We identified six ongoing studies, whereof two studies are currently recruiting [NCT00638898; NСT01288573] and four studies are not recruiting participants [NCT00002601; NCT00002854; NCT00141765; NCT00623077]. We identified three completed studies, one terminated study that was withdrawn due to slow accrual, and four studies with unknown status and information 
that has not been verified recently. The investigators did not provide results via the registry and we did not found a publication in PubMed 2012 matching the data shown in the registry. Of the rest of the 35 studies, 15 studies did not include the diagnosis of interest, 15 studies did not include the intervention of interest, and five did not include the outcome of interest. We did not identify other relevant studies searching in the two trials registries [ICTRP 2012] and [ISRCTN 2012]. We did not identify any additional studies from screening the reference lists of included studies and reviews.

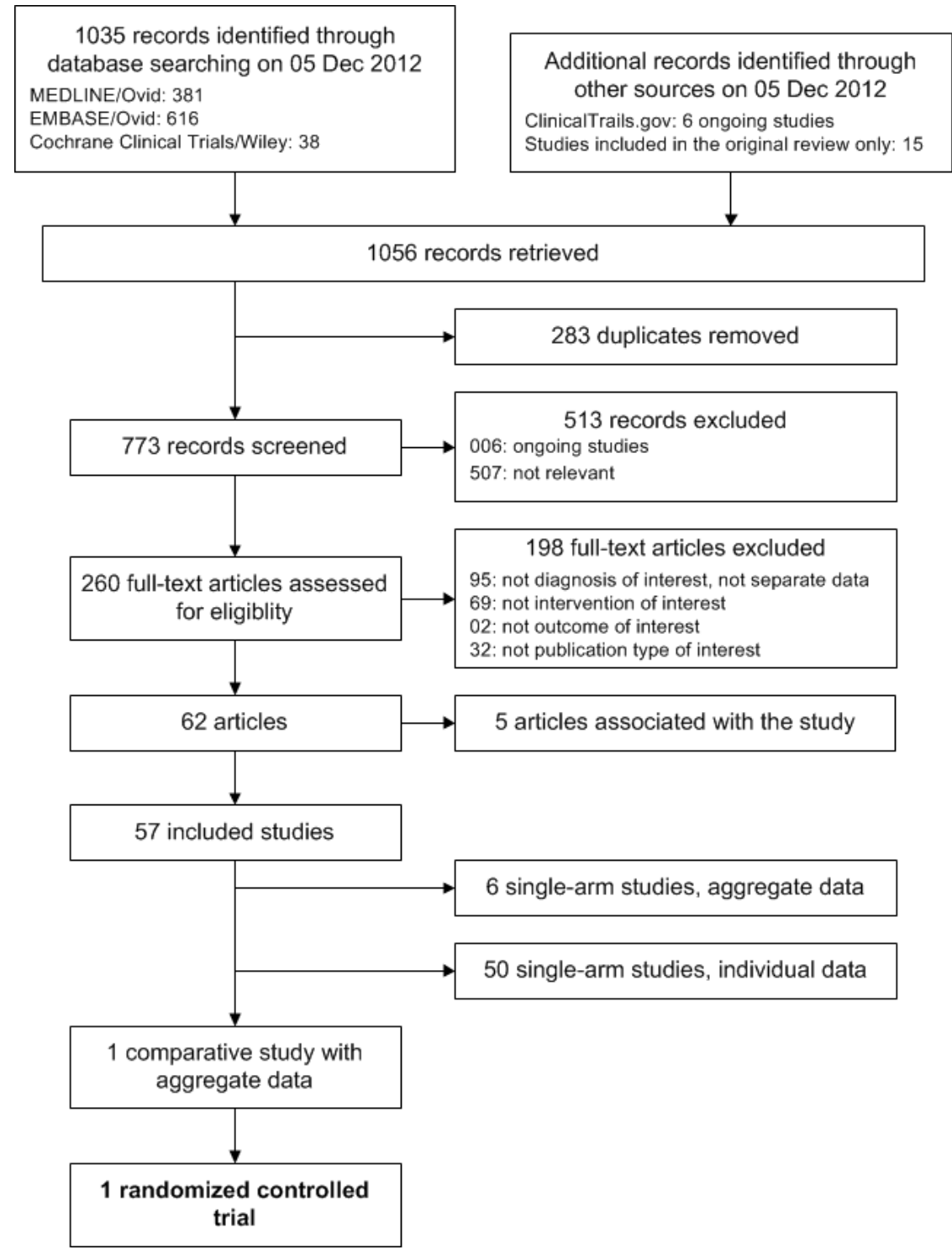

Figure 1. Literature search and study flow. 


\section{Included studies}

We identified 57 studies including a total of 275 participants that received HDCT and autologous HSCT. The characteristics of the individual 57 included studies are described in the section Characteristics of included studies (online at doi: 10.1002/14651858.CD008216.pub4). We have provided a tabulated overview of the seminal characteristics of the included studies in Table 5.

Table 5. Overview of included studies

\begin{tabular}{|c|c|c|c|c|c|c|c|}
\hline \multirow[t]{2}{*}{ Study } & \multirow{2}{*}{$\begin{array}{c}\text { Total, } \\
\text { N }\end{array}$} & \multicolumn{2}{|c|}{ Diagnosis } & \multirow[b]{2}{*}{$\begin{array}{l}\text { Affected patients, } \\
\mathrm{N} \text { type of included diagnosis }\end{array}$} & \multirow{2}{*}{$\begin{array}{l}\text { Start of } \\
\text { follow-up }\end{array}$} & \multirow{2}{*}{$\begin{array}{l}\text { Pros- } \\
\text { pective }\end{array}$} & \multirow{2}{*}{$\begin{array}{l}\text { HDCT vs } \\
\text { SDCT, } \\
\text { N analyzed }\end{array}$} \\
\hline & & $\begin{array}{l}\text { Not rel, } \\
\mathrm{N}(\%)\end{array}$ & $\begin{array}{c}\text { Rel, } \\
N\end{array}$ & & & & \\
\hline \multicolumn{8}{|c|}{ Aggregate comparative data (HDCT \& autologous HSCT vs SDCT) } \\
\hline [Bui-Nguyen 2012] & 87 & $18(20)$ & 69 & $\begin{array}{l}\text { 16x LMS, 16x MFH, 10x LPS, } \\
\text { 9x SYN, 6x ANG, 2x UDS, } \\
\text { 2x MME, 2x DSRCT, 2x FIB, } \\
\text { 1x LMS, 1x UCS, 1x CCS }\end{array}$ & Randomization & YES & $\begin{array}{l}38 \text { vs. } 45 \\
\text { in } \mathrm{ITT}^{*}\end{array}$ \\
\hline Subtotal comparativ & data in & 1 study & & & & & 38 vs. 45 \\
\hline \multicolumn{8}{|c|}{ Aggregate case series data (HDCT \& autologous HSCT only) } \\
\hline [Bertuzzi 2003] & 10 & $0(0)$ & 10 & 10x DSRCT & Therapy & YES & 10 \\
\hline [Bisogno 2010] & 14 & $0(0)$ & 14 & 14x DSRCT & Diagnosis & YES & 14 \\
\hline [Blay 2000] & 24 & $2(10)$ & 22 & $24 x$ NRSTS & Therapy & YES & 24 \\
\hline [Bokemeyer 1997] & 18 & $2(11)$ & 16 & $\begin{array}{l}5 x \text { MFH, } 2 x \text { HAP, } 3 x \text { SYN, } \\
2 x \text { LMS, } 2 x \text { MES }\end{array}$ & Therapy & No & 36 \\
\hline [Cook 2012] & 36 & $0(0)$ & 36 & 36x DSRCT & Therapy & No & 36 \\
\hline $\begin{array}{l}\text { [Philippe-Chomette } \\
\text { 2012] }\end{array}$ & 14 & $0(0)$ & 14 & $14 x$ DSRCT & Diagnosis & No & 14 \\
\hline \multicolumn{5}{|c|}{ Subtotal case series in 6 studies } & & & 114 \\
\hline \multicolumn{8}{|c|}{ Individual cases data (HDCT \& autologous HSCT only) } \\
\hline \multicolumn{5}{|c|}{ Subtotal case series in 50 studies } & & & 123 \\
\hline \multicolumn{8}{|c|}{ Summary of patient count } \\
\hline \multicolumn{5}{|c|}{ Subtotal HDCT \& autologous HSCT in 57 studies } & & & 275 \\
\hline \multicolumn{5}{|c|}{ Subtotal SDCT in 1 study } & & & 45 \\
\hline \multicolumn{5}{|l|}{ Total in 57 studies } & & & 320 \\
\hline
\end{tabular}

*modified ITT: histologically ineligible patients excluded from primary group of analysis; HDCT group: 3 of 41 randomized data excluded; SDCT group: 1 of 46 randomized data excluded

Abbreviations: Diag: diagnosis; HDCT: high-dose chemotherapy (\& autologous hematopoietic stem cell transplantation); HR: hazard ratio; HSCT: hematopoietic stem cell transplantation; ITT: intention to treat; N: number of participants; Rel: relevant; SDCT: standard-dose chemotherapy; vs.: versus

Diagnoses: ANA: anaplastic soft tissue sarcoma; ANG: angiosarcoma; CCS: clear cell sarcoma; DSRCT: desmoplastic small round- cell tumor; EPI: epitheloid sarcoma; FIB: fibrosarcoma; FMS: fibromyxoid sarcoma; HAP: hemangiopericytoma; LIP: liposarcoma; LMS: leiomyosarcoma; MES: mesenchymal sarcoma; MFH: malignant fibrous histiocytoma; MHP: malignant hemangioperiocytoma; MME: malignant myoepithelioma; NRSTS: various types of nonrhabdomyosarcoma soft tissues sarcomas; RHA: rhabdoid tumor; SCS: spindle cell sarcoma; SYN: synovial sarcoma; UCS: unclassified sarcoma; UDS: undifferentiated sarcoma 


\section{Design}

We included one RCT with two parallel treatment groups, HDCT and autologous HSCT versus SDCT [Bui-Nguyen 2012]. It was an open, multicenter, randomized phase III study. All patients received the same baseline treatment. Patients were eligible for randomization if they had responded to chemotherapy or, for stable disease, if a complete surgical resection of all disease sites could be carried out. Randomization was carried out centrally. The intention-to-treat (ITT) modified population included all randomly assigned patients excluding patients found to be ineligible at central histology review.

We included six single-arm studies that reported aggregate data of participants that received HDCT and autologous HSCT and that consisted of at least $80 \%$ with relevant NRSTS [Bertuzzi 2003; Bisogno 2010; Blay 2000; Bokemeyer 1997; Cook 2012; Philippe-Chomette 2012]. Three of the studies collected the data prospectively [Bertuzzi 2003; Bisogno 2010; Blay 2000] and three retrospectively [Bokemeyer 1997; Cook 2012; Philippe-Chomette 2012]. The remaining 50 studies comprised single-arm studies without appropriate aggregate data. Relevant participants were considered in the survival analysis of pooled individual data.

\section{Sample sizes}

The authors of the RCT [Bui-Nguyen 2012] conducted an ITT analysis of 38 participants in the HDCT arm versus 41 participants in the SDCT arm. Six single-arm studies reported aggregate data of 10 [Bertuzzi 2003], 14 [Bisogno 2010], 24 [Blay 2000], 16 [Bokemeyer 1997], 36 [Cook 2012], and 14 [Philippe-Chomette 2012] participants with NRSTS who received HDCT and autologous HSCT. Fifty studies reported on 123 individual relevant participants. Overall survival and follow-up data were reported for 80 participants in 41 studies and subsequently those data could be considered in survival analysis of the pooled individual data.

\section{Setting}

The 57 studies were set in 12 different countries, eight countries in Europe (Czech Republic, France, Germany, Greece, Italy, Netherlands, Spain, United Kingdom), two in North America (Canada, United States), and two in Asia (Korea, Japan). Most of the transplanted patients were studied in the USA (79 of 260) and France (79 of 260). In four countries (France, Germany, Italy, USA) 10 or more patients were studied. The only RCT [Bui-Nguyen 2012] was set in France.

\section{Participants}

We included 275 patients with 15 different relevant histological diagnoses in 57 studies. Most patients $(N=109)$ had desmoplastic small round-cell tumor; 10 or more patients were reported for angiosarcoma, desmoplastic small round-cell tumor, leiomyosarcoma, liposarcoma, malignant fibrous histiocytoma, and synovial sarcoma. 
[Bui-Nguyen 2012] reported the age in the HDCT arm in a range of 18.5 to 65.0 years (median 45.8 years) and a comparable age in the SDCT arm with a range of 18.7 to 65.0 years (median 43.3 years). Males were $58.5 \%$ of participants (24 of 41 ) in the HDCT arm and $50 \%$ (23 of 46 ) in the CDCT arm.

[Bertuzzi 2003] reported a range of 15 to 60 years of age (median 29 years) for the 10 male patients that were included. [Bisogno 2010] included 13 males and one female, the age range was 2 to 17.8 years (median 10.3 years). [Blay 2000] reported on 30 patients of which 17 were males and 13 females. The age ranged from 17 to 57 years (median 34 years). [Bokemeyer 1997] reported the age range between 25 and 57 years with a median of 45 years. Gender was not specified. [Cook 2012] reported the age range between 8 and 46 years with a median of 19 years; 29 were males and 7 were females. [Philippe-Chomette 2012] reported an age range of 4 to 22.6 years for 14 transplanted patients in the HDCT arm; 12 of those patients were males and 2 females.

Age was provided for 113 of 123 individual patients ranging from 1 to 65 years with a median of 27 years. Gender was provided for 83 individual patients, of which 55 were male and 28 were female. Follow-up was provided for 80 individual patients, ranging from 0 to 120 months with a median of 17 months.

\section{Interventions}

Components and the dosage of various chemotherapeutic regimens are described in the Characteristics of included studies (shown in the unabridged article).

In the study by [Bui-Nguyen 2012], 87 patients received courses one to five of standard-dose chemotherapy. Forty-one patients were randomized to receive HDCT and transplantation of autologous peripheral stem cells as course six in the HDCT arm. Of these, 38 patients were analyzed in a modified ITT analysis. Forty-six patients were randomized to again receive standard-dose chemotherapy as course six. Of these, 45 patients were analyzed in a modified ITT analysis.

In the study by [Bertuzzi 2003], after a four-course induction phase 10 patients in complete or partial response received HDCT and autologous HSCT using peripheral blood as the stem cell source. In the study by [Bisogno 2010], after an induction phase of nine weeks 14 patients at various clinical stages received three consecutive intensified-dose combinations and autologous HSCT using peripheral blood as the stem cell source. In the study by [Blay 2000], after induction chemotherapy for most of the patients 24 patients with an advanced clinical stage including $87 \%$ with metastasis received HDCT and autologous HSCT. The stem cell source was mainly bone marrow $(\mathrm{N}=25)$ and a few patients received stem cells from peripheral blood $(N=5)$. In the study by [Bokemeyer 1997], 16 patients received HDCT and autologous HSCT from peripheral blood. In the study by [Cook 2012], 36 patients received HDCT and autologous HSCT mainly from peripheral blood ( $N=33$ ) and a few from bone marrow $(N=2)$, with information missing in one patient. In the study by [Philippe-Chomette 2012], 14 patients received various regimens of HDCT and autologous HSCT. The source of stem cells was not reported. 


\section{Primary outcome}

All seven included studies with aggregate data [Bertuzzi 2003; Bisogno 2010; Blay 2000; Bokemeyer 1997; Bui-Nguyen 2012; Cook 2012; Philippe-Chomette 2012] reported overall survival (OS). Among the 50 studies with individual data from 123 patients, OS and follow-up were reported for 80 patients. Ten studies reported treatment-related mortality (TRM), five of seven studies with aggregate data and five of 50 studies with individual data. There were 13 events in nine and zero events in one study.

\section{Secondary outcomes}

One study reported disease-free survival, five studies reported progression-free survival, nine reported non-hematological toxicity grade 3 to 4 , and one study reported secondary neoplasia. Five studies reported on five severe adverse events.

\section{Excluded studies}

A total of 198 references of the potentially relevant articles were excluded (Figure 1) based on:

- not diagnosis of interest, NRSTS according to Table 2 or relevant data not reported separately $(n=95)$;

- not intervention of interest, not HDCT and autologous HSCT ( $n=69$ );

- not outcome of interest or not reported separately $(n=2)$;

- not publication type of interest, a review, editorial, letter, duplicate data, or congress abstract $(n=32)$.

Excluded studies are described in the 'Characteristics of excluded studies table' (shown in the unabridged article).

\section{Risk of bias in included studies}

We have identified one comparative study with a randomized design [Bui-Nguyen 2012]. We think that this trial stands out and has substantially less risk of bias than the rest of the studies. Fiftysix of 57 studies were single-arm studies that subsequently had a very high risk of bias, see Characteristics of included studies. An overviews of the risk of bias is shown in Figure 2 (online at doi: 10.1002/14651858.CD008216.pub4) and the risk of bias for each study is shown in Figure 3 (online at doi: 10.1002/14651858. CD008216.pub4).

\section{Allocation}

We have identified true randomization including highly probable adequate random sequence generation for [Bui-Nguyen 2012] and judged a low risk of bias for this study. We judged a high risk of bias for the rest of the studies. 


\section{Assignment of patients to treatment groups}

In the study by [Bui-Nguyen 2012], patients were assigned to two different treatment arms in a randomized fashion. Thus we judged a low risk of bias for this study. The rest of the studies were singlearm studies with an observational design and we judged a high risk of bias for these studies.

\section{Blinding}

Blinding of outcome assessment was not addressed in all included studies. Thus, we judged a high risk of bias for all studies.

\section{Incomplete outcome data}

[Bui-Nguyen 2012] conducted a modified ITT analysis. The exclusion of histologically ineligible patients after randomization affected three of 41 patients in the HDCT arm and one of 46 patients in the SDCT arm. All other studies analyzed the patients as treated. Thus we judged a low risk of bias for [Bui-Nguyen 2012] and a high risk of bias for the rest.

\section{Selective reporting}

In the study by [Bui-Nguyen 2012], allocation was carried out centrally, though masking of allocation was not described in full detail. Thus we judged an unclear risk of bias for this study. We judged a high risk of bias for the rest of the studies.

\section{Other potential sources of bias}

\section{Prospective design}

The one RCT was prospective [Bui-Nguyen 2012], three of the six single-arm studies with aggregate data [Bertuzzi 2003; Bisogno 2010; Blay 2000] and 12 of the 50 singlearm studies with individual data [Fraser 2006; Graham 1997; Hawkins 2002; Jordan 2010; Kasper 2010; Kushner 1996; Kushner 2001; Lafay-Cousin 2000; Lashkari 2009; Patel 2004; Peters 1986; Peters 1989] had prospective parts. The prospective design may be advantageous for studies that present aggregate data from a series of patients treated in a certain time period. The prospective design is not relevant for individual data. Thus, we judged a low risk of bias for [Bui-Nguyen 2012, Bertuzzi 2003, Bisogno 2010, and Blay 2000] and we judged a high risk of bias for the rest.

\section{Comparable baseline characteristics}

[Bui-Nguyen 2012] had a randomized controlled design and the baseline characteristics of both treatment groups were comparable. Thus, we judged a low risk of bias for [BuiNguyen 2012] and a high risk of bias for the rest. 


\section{Concurrent control}

We identified a concurrent control group in [Bui-Nguyen 2012] and judged a low risk of bias. The rest of the studies did not report a control group and we judged a high risk of bias. Note: [Philippe-Chomette 2012] reported the results of some cases with conventional chemotherapy. The data for those cases were probably observed and not part of an experimental design, collected retrospectively in different time periods.

\section{Loss to follow-up}

Bui-Nguyen 2012 conducted a modified ITT analysis. The exclusion of histologically ineligible patients after randomization affected three of 41 patients in the HDCT arm and one of 46 patients in the SDCT arm. All other studies analyzed the participants as treated. Thus we judged a low risk of bias for [Bui-Nguyen 2012] and a high risk of bias for the rest.

\section{Effects of interventions}

See: Summary of findings for the main comparison Autologous hematopoietic stem cell transplantation following high-dose chemotherapy for non-rhabdomyosarcoma soft tissue sarcoma

\section{Primary outcome}

\section{Overall survival}

Overall survival (OS) was not statistically significantly different between HDCT and autologous HSCT versus SDCT at three years in the RCT by [Bui-Nguyen 2012]: $32.7 \%$ versus $49.4 \%$ with a HR of $1.26(95 \% \mathrm{Cl} 0.70$ to $2.29, \mathrm{P}=0.44)$ (Table 6). The authors separately analyzed patients that had achieved a complete response to induction therapy before HDCT. OS was higher in the complete response patients compared to all patients and OS was statistically significantly different between the treatment arms. The OS among the patients that have achieved a complete response at three years before HDCT was $42.8 \%$ versus $83.9 \%$ with a HR of 2.92 ( 1.1 to $7.6, \mathrm{P}=0.028$ ) (Table 6).

The single-arm studies with aggregate data reported an OS at two years ranging from $20 \%$ to $51.4 \%$ and at three years ranging from $38.9 \%$ to $40 \%$ (Table 6). [Blay 2000] and [Cook 2012] compared patients that had achieved versus not achieved a complete response before HDCT. [Blay 2000] reported an OS at two years of $63 \%$ versus $27 \%$, and [Cook 2012] reported an OS at three years of $57 \%$ versus $28 \%$ (Table 6). Again, the achievement of a complete response before HDCT was favorable with respect to OS. We conducted a survival analysis using individual data on the condition that survival status and time to event were reported. This was true for 65\% (80 of 123) of the patient data; for 43 patients, follow-up data were not available. We estimated an OS at two years of $50.6 \%(95 \% \mathrm{Cl} 38.7$ to 62.5$)$ and at three years of $36.7 \%(95 \% \mathrm{Cl} 24.4$ to 
49.0) (Table 6). Both estimates were within the range of the other studies. We provided the OS for each individual case in Table 7 (online at doi: 10.1002/14651858. CD008216.pub4). The graphical presentation of the Kaplan-Meier graph of all 80 included patients at risk is shown in Figure 4. We also analyzed the subgroup of patients with the diagnosis of desmoplastic small round-cell tumor because this diagnosis constituted the largest proportion, 34\% (27 out of 80 ), of individual patients considered for the survival analysis (Figure 5; online at doi: 10.1002/14651858.CD008216.pub4). Of the individual data from patients with desmoplastic small round-cell tumor, $77 \%$ (27 of 35) had follow-up information. Both survival curves do not appear to be considerably different, though the median survival was 2.8 years within the subgroup of 27 patients with desmoplastic small round-cell tumor versus 2.2 years within the total population of 80 patients.

Table 6. Overall survival (OS)

\begin{tabular}{|c|c|c|c|}
\hline \multirow[t]{2}{*}{ Study } & \multicolumn{3}{|c|}{ Overall survival, $\%(95 \% \mathrm{Cl})$} \\
\hline & All patients assessed & $\begin{array}{l}\text { Complete response } \\
\text { before the time of HSCT }\end{array}$ & $\begin{array}{l}\text { Not complete response } \\
\text { before the time of HSCT }\end{array}$ \\
\hline \multicolumn{4}{|c|}{ Aggregate comparative data (HDCT \& autologous HSCT vs SDCT) } \\
\hline [Bui-Nguyen 2012] & $\begin{array}{l}3 \text { years: } 32.7 \% \text { vs. } 49.4 \% \\
\text { HR } 1.26(0.70 \text { to } 2.29, p=0.44)\end{array}$ & $\begin{array}{l}3 \text { years: } 42.8 \% \text { vs. } 83.9 \% \\
\text { HR } 2.92(1.1 \text { to } 7.6, p=0.028)\end{array}$ & $n / r$ \\
\hline \multicolumn{4}{|c|}{ Aggregate case series data (HDCT \& autologous HSCT only) } \\
\hline [Bertuzzi 2003] & 2 years: $20 \%$ & $\mathrm{n} / \mathrm{r}$ & $n / r$ \\
\hline [Bisogno 2010] & $\begin{array}{l}2 \text { years: } 48 \% \\
3 \text { years: } 38.9 \%\end{array}$ & $\mathrm{n} / \mathrm{r}$ & $\mathrm{n} / \mathrm{r}$ \\
\hline [Blay 2000] & $\mathrm{n} / \mathrm{r}$ & 2 years: $63 \%$ & 2 years: $27 \%$ \\
\hline [Bokemeyer 1997] & Median: 13 mo; range: 3 to 19 & $\mathrm{n} / \mathrm{r}$ & $\mathrm{n} / \mathrm{r}$ \\
\hline [Cook 2012] & 3 years: $40 \%$ (24 to 58$)$ & 3 years: $57 \%$ (29 to 83$)$ & 3 years: $28 \%$ ( 9 to 51$)$ \\
\hline $\begin{array}{l}\text { [Philippe-Chomette } \\
\text { 2012] }\end{array}$ & 2 years: $51.4 \%$ (23.2 to 79.6$)$ & $\mathrm{n} / \mathrm{r}$ & $n / r$ \\
\hline \multicolumn{4}{|c|}{ Individual cases data (HDCT \& autologous HSCT only) } \\
\hline 50 studies & $\begin{array}{l}2 \text { years: } 50.6 \%(38.7 \text { to } 62.5) \\
3 \text { years: } 36.7 \%(24.4 \text { to } 49.0) \\
5 \text { years: } 29.9 \%(16.7 \text { to } 43.1)\end{array}$ & $\mathrm{n} / \mathrm{r}$ & $\mathrm{n} / \mathrm{r}$ \\
\hline
\end{tabular}

Some estimates were deduced from Kaplan-Meier plots. Bisogno 2010: 1 of 14 patients was reported to have achieved complete response before HDCT. Blay 2000: all patients in subgroup $\mathrm{N}=24$, patients that achieved complete remission before HDCT $N=8$, patients that did not achieve complete remission before HDCT N =16. Bui-Nguyen 2012: all patients $\mathrm{N}=38$ vs. $\mathrm{N}=45$, patients that achieved complete remission before HDCT $N=20$ vs. $N=19$. Cook 2012: all patients $N=$ 36 , patients that achieved complete remission before HDCT $N=13$, patients that did not achieve complete remission before HDCT $\mathrm{N}=18$.

Abbreviation: $\mathrm{Cl}$ : confidence interval; HDCT: high-dose chemotherapy; HR: hazard ratio; HSCT: hematopoietic stem cell transplantation; n/a: not applicable; $n / r$ : not reported; OS: overall survival; $p=p$ value; SDCT: standard-dose chemotherapy. 


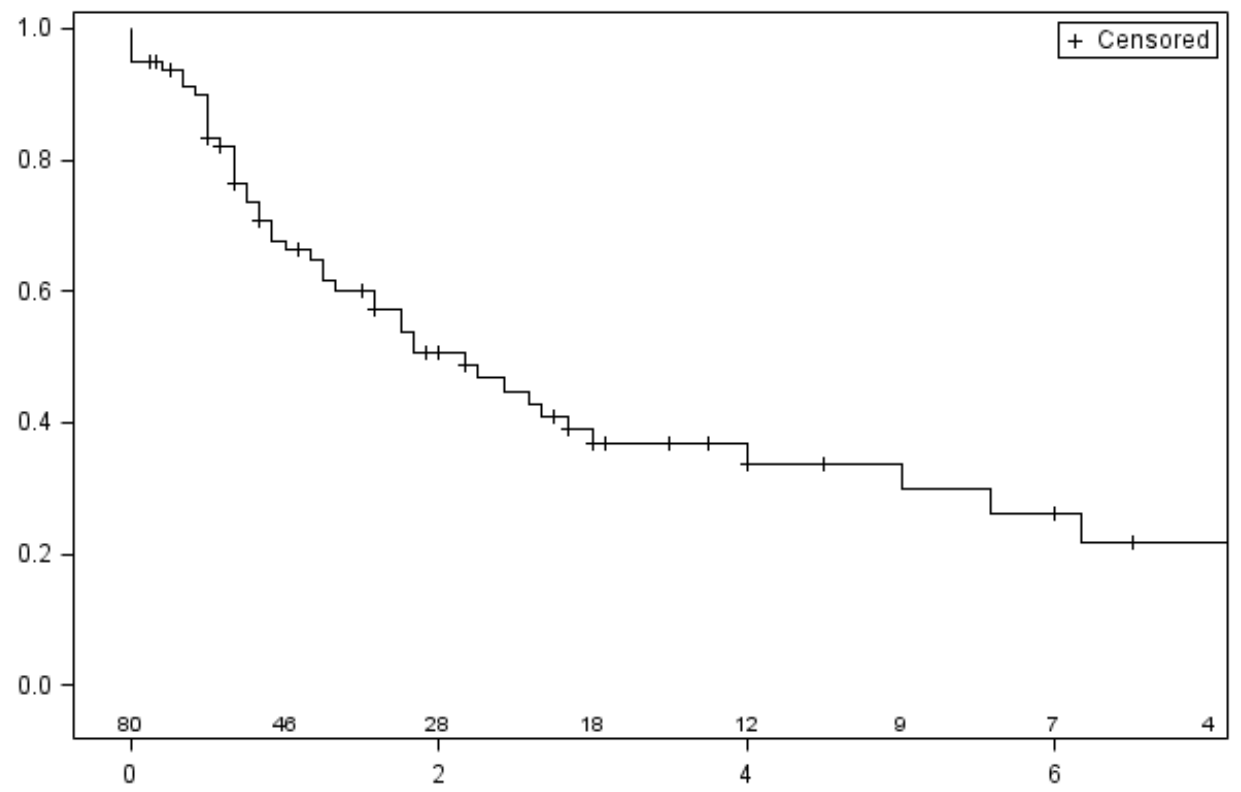

Figure 4. Kaplan-Meyer analysis of overall survival of individual cases data from patient with various NRSTS

$X$-axis below line: years

$X$-axis above line: number of patients at risk

Y-axis: probability of overall survival

Number of subjects at risk after each additional year of follow up.

The Kaplan-Meyer analysis of overall survival was conducted using individual data of patients with NRSTS with available follow-up information (total 80, failed 46, censored 34) from 41 case series and case reports. Information about outcome (dead or alive) and follow-up (time of survival after diagnosis or begin of treatment) was required for each individual.

Abbreviations: NRSTS: non-rhabdomyosarcoma soft tissue sarcoma

Treatment-related mortality

Treatment-related mortality (TRM) was addressed in 12 studies (163 transplanted participants). Ten of 12 studies reported a procedure-related death for 15 participants and two of 12 studies reported zero treatment-related deaths (Table 8). A conservative estimate of TRM was 5.5\% (15 procedure-related deaths of a total of 275 transplanted patients).

\section{Secondary outcomes}

\section{Disease-free survival}

Cook 2012 reported an OS at three years of $23 \%$ regarding all patients and $40 \%$ versus $9 \%$ regarding patients with and without a complete response before HDCT respectively (Table 9). 
Table 8. Treatment-related mortality (TRM)

\begin{tabular}{lcl}
\hline Study & Events (N) & Cause of death \\
\hline Aggregate comparative data (HDCT \& autologous & HSCT vs SDCT) \\
[Bui-Nguyen 2012] & 1 & Treatment-related leukemia death 2 years after HSCT \\
Aggregate case series data (HDCT \& autologous & HSCT only) \\
[Bertuzzi 2003] & 0 & n/a \\
[Bisogno 2010] & 0 & n/a \\
[Blay 2000] & 1 & Sudden toxic death of unknown cause at day 29 \\
[Bokemeyer 1997] & $n / r$ & n/a \\
[Cook 2012] & 2 & $n / r$ \\
[Philippe-Chomette 2012] & 1 & Died of treatment toxicity 12 months after HSCT \\
Individual cases data (HDCT \& autologous & HSCT only) \\
[Doros 2008] & 1 & n/r \\
[Engelhardt 2007] & 3 & Sepsis; sepsis; pulmonary metastases \\
[Kasper 2007] & 1 & Cardiac arrest of unknown origin \\
[Navid 2006] & 1 & Hepatic and renal failure \\
[Saab 2007] & 2 & Acute myocardial infarction; veno-occlusive disease \\
[Slease 1988] & 2 & Staphylococcus sepsis; progressive encephalopathy \\
Sum in 12 studies & 15 & \\
\hline
\end{tabular}

Blay 2000: The authors did not specify, whether the patient was among the 24 patients with adult-type sarcomas or among the 6 patients with rhabdomyosarcoma and Ewing's sarcoma both of which are not included in the present review. Cook 2012: 1 death within 100 days.

Abbreviation: HDCT: high-dose chemotherapy; HSCT: hematopoietic stem cell transplantation; n/a: not applicable; n/r: not reported; $p=p$ value; SDCT: standard-dose chemotherapy; TRM: treatment-related mortality.

Table 9. Disease-free survival (DFS)

\begin{tabular}{|c|c|c|c|}
\hline \multirow[t]{2}{*}{ Study } & \multicolumn{3}{|c|}{ Disease-free survival, \% $(95 \% \mathrm{Cl})$} \\
\hline & All patients assessed & $\begin{array}{l}\text { Complete response before } \\
\text { the time of HSCT }\end{array}$ & $\begin{array}{l}\text { Not complete response } \\
\text { before the time of HSCT }\end{array}$ \\
\hline \multicolumn{4}{|c|}{ Aggregate case series data (HDCT \& autologous HSCT only) } \\
\hline [Cook 2012] & 3 years: $23 \%$ (10 to 39$)$ & 3 years: $40 \%$ (15 to 69$)$ & 3 years: $9 \%(0$ to 29$)$ \\
\hline
\end{tabular}

Cook 2012: all patients $N=36$, patients that achieved complete remission before HDCT $N=13$, patients that did not achieve complete remission before HDCT $\mathrm{N}=18$.

Abbreviation: Cl: confidence interval; HDCT: high-dose chemotherapy; HSCT: hematopoietic stem cell transplantation; n/a: not applicable; n/r: not reported; DFS: disease-free survival.

\section{Progression-free survival}

Progression-free survival (PFS) was not statistically significantly different between HDCT and autologous HSCT versus SDCT in the RCT by [Bui-Nguyen 2012] at three years (9.3\% versus $21.6 \%$ with a $\mathrm{HR}$ of 1.34 ( $95 \% \mathrm{Cl} 0.81$ to $2.20, \mathrm{P}=0.25)$ ) (Table 10$)$. The authors separately analyzed patients that had achieved a complete response to induction therapy before HDCT. PFS was higher in the complete response patients 
compared to all patients and OS was statistically significantly different between the treatment arms: PFS among the patients that have achieved complete response at three years before HDCT was $20.0 \%$ versus $62.3 \%$ with a $\mathrm{HR}$ of 2.87 (95\% $\mathrm{Cl} 1.3$ to $6.3, \mathrm{P}=$ 0.009) (Table 10). [Blay 2000] reported a considerable difference between the PFS of patients with complete response before HDCT at two and five years (62\% versus $5 \%$ ).

Non-hematological toxicity grade 3 to 4

Non-hematological toxicity grade 3 to 4 was addressed in nine studies and 38 serious adverse event were described for 105 participants in nine studies (Table 11). A conservative estimate was $13.8 \%$ (38 events of non-hematological toxicity grade 3 to 4 in a total of 275 transplanted patients).

\section{Secondary neoplasia}

Secondary neoplasia was addressed in one case report (Table 12).

\section{Health-related quality of life}

Health-related quality of life scales were not addressed in the included studies.

Table 10. Progression-free survival (PFS)

\begin{tabular}{|c|c|c|c|}
\hline \multirow[t]{2}{*}{ Study } & \multicolumn{3}{|c|}{ Progression-free survival, $\%(95 \% \mathrm{Cl})$} \\
\hline & All patients assessed & $\begin{array}{l}\text { Complete response before the } \\
\text { time of HSCT }\end{array}$ & $\begin{array}{l}\text { Not complete response } \\
\text { before the time of HSCT }\end{array}$ \\
\hline \multicolumn{4}{|c|}{ Aggregate comparative data (HDCT \& autologous HSCT vs SDCT) } \\
\hline [Bui-Nguyen 2012] & $\begin{array}{l}3 \text { years: } 9.3 \% \text { vs. } 21.6 \% \\
\text { HR } 1.34(0.81 \text { to } 2.20, p=0.25)\end{array}$ & $\begin{array}{l}3 \text { years: } 20.0 \% \text { vs. } 62.3 \% \\
\text { HR } 2.87(1.3 \text { to } 6.3, p=0.009)\end{array}$ & $\mathrm{n} / \mathrm{r}$ \\
\hline \multicolumn{4}{|c|}{ Aggregate case series data (HDCT \& autologous HSCT only) } \\
\hline [Bertuzzi 2003] & 2 years: $0 \%$ & $\mathrm{n} / \mathrm{r}$ & $\mathrm{n} / \mathrm{r}$ \\
\hline [Bisogno 2010] & $\begin{array}{l}2 \text { years: } 23 \% \\
3 \text { years: } 15.5 \%\end{array}$ & $\mathrm{n} / \mathrm{r}$ & $n / r$ \\
\hline [Blay 2000] & $n / r$ & $\begin{array}{l}2 \text { years: } 62 \% \\
5 \text { years: } 62 \%\end{array}$ & $\begin{array}{l}2 \text { years: } 5 \% \\
5 \text { years: } 5 \%\end{array}$ \\
\hline [Bokemeyer 1997] & Median: 8 mo; range: 2 to 19 & $\mathrm{n} / \mathrm{r}$ & $\mathrm{n} / \mathrm{r}$ \\
\hline \multicolumn{4}{|c|}{ Individual cases data (HDCT \& autologous HSCT only) } \\
\hline 50 studies & $\begin{array}{l}2 \text { years: } 50.6 \% \text { (38.7 to } 62.5) \\
3 \text { years: } 36.7 \%(24.4 \text { to } 49.0) \\
5 \text { years: } 29.9 \%(16.7 \text { to } 43.1)\end{array}$ & $\mathrm{n} / \mathrm{r}$ & $n / r$ \\
\hline
\end{tabular}

Some estimates were deduced from Kaplan-Meier plots. Disease-free survival (DFS), event-free survival (EFS), failurefree survival (FFS), or health-related quality of life (HRQL) not reported. Bisogno 2010: Definition of endpoint: "For eventfree survival (EFS), the interval between diagnosis and the date of latest follow- up, relapse or death was considered." In figure 1 of the article, the endpoint was designated as progression-free survival, which also is meaningful regarding the definition. Blay 2000: including 5 patients with rhabdomyosarcoma and 1 patient with primitive neuroectodermal tumor. Abbreviation: $\mathrm{Cl}$ : confidence interval; HDCT: high-dose chemotherapy; HR: hazard ratio; HSCT: hematopoietic stem cell transplantation; PFS: progression-free survival; SDCT: standard-dose chemotherapy 
Table 11. Non-hematological toxicity grade 3 to 4

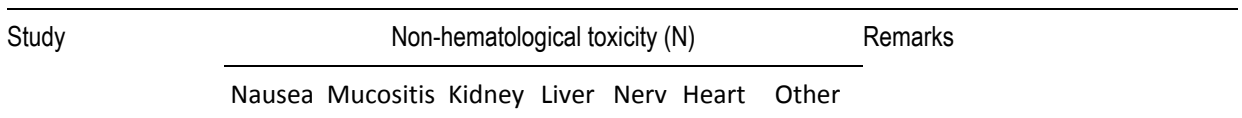

Aggregate comparative data (HDCT \& autologous HSCT only)

[Bui-Nguyen 2012] $\quad 3 \quad 4 \quad 4 \quad n / r \quad n / r \quad n / r \quad n / r \quad 3 \quad$ Other: infection (2); pain (1)

Aggregate case series data (HDCT \& autologous HSCT only)

[Bisogno 2010] $1 \quad n / r \quad n / r \quad n / r \quad n / r \quad n / r \quad n / r \quad$ No grade 4 organ dysfunction

$\begin{array}{llllllllll}\text { [Blay 2000] } & 8 & \mathrm{n} / \mathrm{r} & 5 & \mathrm{n} / \mathrm{r} & 1 & 0 & \mathrm{n} / \mathrm{r} & \mathrm{n} / \mathrm{r}\end{array}$

$\begin{array}{llllllllll}\text { [Bokemeyer 1997] } & n / r & 2 & 2 & n / r & 1 & n / r & 1 & \text { Nerv: central neurotoxicity; }\end{array}$

Other: septic episode

Individual cases data (HDCT \& autologous HSCT only)

\begin{tabular}{lccccccll} 
[Garrido 1998] & $\mathrm{n} / \mathrm{r}$ & $\mathrm{n} / \mathrm{r}$ & $\mathrm{n} / \mathrm{r}$ & $\mathrm{n} / \mathrm{r}$ & 1 & $\mathrm{n} / \mathrm{r}$ & $\mathrm{n} / \mathrm{r}$ & Neuroleptic malignant syndrome \\
[Kozuka 2002] & 1 & $\mathrm{n} / \mathrm{r}$ & $\mathrm{n} / \mathrm{r}$ & $\mathrm{n} / \mathrm{r}$ & $\mathrm{n} / \mathrm{r}$ & $\mathrm{n} / \mathrm{r}$ & $\mathrm{n} / \mathrm{r}$ & $\mathrm{n} / \mathrm{r}$ \\
[Kushner 2001] & $\mathrm{n} / \mathrm{r}$ & $\mathrm{n} / \mathrm{r}$ & $\mathrm{n} / \mathrm{r}$ & $\mathrm{n} / \mathrm{r}$ & 1 & $\mathrm{n} / \mathrm{r}$ & $\mathrm{n} / \mathrm{r}$ & $\mathrm{n} / \mathrm{r}$ \\
[Patel 2004] & $\mathrm{n} / \mathrm{r}$ & $\mathrm{n} / \mathrm{r}$ & 1 & 1 & $\mathrm{n} / \mathrm{r}$ & $\mathrm{n} / \mathrm{r}$ & 1 & Other: respiratory distress \\
[Yonemoto 1999] & $\mathrm{n} / \mathrm{r}$ & $\mathrm{n} / \mathrm{r}$ & $\mathrm{n} / \mathrm{r}$ & 1 & $\mathrm{n} / \mathrm{r}$ & $\mathrm{n} / \mathrm{r}$ & $\mathrm{n} / \mathrm{r}$ & $\mathrm{n} / \mathrm{r}$ \\
\hline Sum & 12 & 7 & 8 & 2 & 4 & 0 & 5 & $\begin{array}{l}38 \text { events in } 105 \text { patients of } \\
9 \text { studies }\end{array}$ \\
\hline
\end{tabular}

Single-arm studies, only transplanted patients. Toxicity defined by National Cancer Institute (NCl) common terminology criteria for adverse events (CTCAE), [NCl 2009b].

Abbreviation. HSCT: autologous haematopoietic stem cell transplantation following high-dose chemotherapy; n/a: not applicable; n/r: not reported; N: number.

Table 12. Sedondary neoplasia

\begin{tabular}{lcl}
\hline Study & Events (N) & Diagnosis \\
\hline Individual cases data (HDCT \& autologous HSCT only) \\
[Yamamura 2003] & 1 & Chronic myelogenous leukemia \\
\hline
\end{tabular}

Single-arm studies, only transplanted patients.

Abbreviation: HDCT: high-dose chemotherapy; HSCT: hematopoietic stem cell transplantation. 


\section{Discussion}

\section{Summary of main results}

Unlike in the first Cochrane systematic review published in 2011, we identified a randomized controlled trial (RCT) comparing HDCT followed by autologous HSCT to standard chemotherapy (SDCT) [Bui-Nguyen 2012]. The authors reported a difference in overall survival (OS) after the treatment in favor of SDCT (32.7\% versus $49.4 \%$ ) but the difference was not statistically significant (HR $1.26,95 \% \mathrm{Cl} 0.70$ to $2.29, \mathrm{P}=0.44$ ). Progression-free survival was also in favor of SDCT (9.3\% versus $21.6 \%)$ but again the difference was not significant ( $\mathrm{HR} 1.34,95 \% \mathrm{Cl} 0.81$ to $2.20, \mathrm{P}=0.25$ ). Therefore, there is evidence that patients may not have a better survival after HDCT followed by autologous HSCT. If at all, this intervention should only be offered after careful consideration and only within controlled clinical trials. Of the participants, $20 \%$ have diagnoses not relevant to the present review and the $80 \%$ of participants with relevant diagnoses have 12 different types of NRSTS. The heterogeneity of types of NRSTS may be important because the OS may differ between the tumor types and the results of frequent types may overlay those of infrequent types.

We identified six case series reporting aggregate data that represented at least $80 \%$ of patients with NRSTS. These results described observed survival after a single experimental treatment. The results do not allow conclusions about an effect or benefit of this treatment that is not established. Of the six studies, four case series reported on transplanted patients with desmoplastic small round-cell tumors. OS at two years ranged between $20 \%$ and $51.4 \%$. Two case series had a variety of NRSTS. Unfortunately they did not report Kaplan-Meier survival estimates. Our estimated OS of $50.6 \%$ at two years for the remaining studies with participant level data falls slightly below the upper limit of the range of $20 \%$ to $51.4 \%$ reported for six studies with aggregate data. Follow-up information was available for $65 \%$ (80 out of 123 ) of participants that could be included in the survival analysis. For treatment-related mortality (TRM), even the more conservative estimate of 5.5\% (15 out of 275 transplanted patients) is considerably higher than the 2.0\% TRM within the first days following HSCT reported by the European Group for Blood and Marrow Transplantation (EBMT) Registry [EBMT 2009] for the year 1998 [Rosti 2002]. Secondary neoplasia was reported for just one participant, which was probably an extreme underestimation of the true frequency because of the relatively short follow-up in the included studies and the fact that the included studies were not designed to specifically detect secondary neoplasia. The detection of secondary neoplasia depends on a long follow-up, which might be provided by cancer registers. This reported incidence compares with a frequency of $4.0 \%$ for secondary neoplasia based on register data [Neglia 2001] and 6.9\% [Baker 2003] after a long observation period of 20 years. Non-hematological severe organ toxicity grade 3 to 4 was reported for $36 \%$ (38 of 105) transplanted patients with relevant NRSTS in nine 
studies. Lower grade and hematological toxicity were not included and should be accounted for to get a full picture of adverse events.

\section{Overall completeness and applicability of evidence}

Many of the studies we identified had to be excluded because they included participants with different heterogenous tumors without separate reporting, or the proportion of participants with NRSTS was fewer than $80 \%$. Furthermore, some treatments were performed 10 to 20 years ago. Thus, the results may not be applicable to patients who are treated today. It is also a possibility that the results reflect the course of the disease and a consequence of the prior therapy rather than a consequence of the test intervention.

\section{Quality of the evidence}

The one RCT has a low risk of bias, whereas the remaining 48 studies were judged as having a high risk of bias. The characteristics of these single-arm studies showed that there are many different tumor types of NRSTS treated by transplantation, though each individual NRSTS entity was scarce. We found that a pooled survival analysis of individual participant data was considerably hampered. Specifically, the required follow-up information was incomplete or missing for 34\% (37 out of 108) of participants and, therefore, corresponding data could not be included in the survival analysis. Each tumor type may carry an individual risk profile and, therefore, ideally should be evaluated separately. The body of evidence does not allow robust conclusions to be made in relation to the objectives of the review.

\section{Potential biases in the review process}

\section{Strengths}

The search strategy was broad and it is very likely that all relevant studies were identified. The WHO classification of NRSTS was adopted and modified to define a clear terminology for the study selection process. Studies were excluded if the proportion of noneligible participants were greater or equal to $20 \%$ of the total population. Authors were contacted to ask for additional data.

\section{Limitations}

The results of studies may be difficult to compare because followup started at different time points, that is at diagnosis or at start oftreatment. The delay between diagnosis and starting high-dose chemotherapy can be considerable. The median delay between diagnosis and intensification was four to 39 months in a study on 22 partici- 
pants with STS including 11 NRSTS and 11 rhabdomyosarcoma patients [Dumontet 1992]. We did a sensitivity analysis restricting the pooled analysis to individual cases that were followed from the start of the treatment and we excluded cases that were followed from diagnosis. However, we found only a very marginal difference in survival estimates.

We identified one RCT with a low risk of bias. This means that the results of this RCT may be used as evidence for the evaluation of the efficacy of autologous HSCT following HDCT for NRSTS. All other identified studies were single-arm studies with an inherent very high risk of bias. This means that the results of the singlearm studies are not helpful to decide whether autologous HSCT following HDCT for NRSTS is a meaningful treatment option. Many studies were excluded because participants with NRSTS were mixed with participants with other malignant diseases. The heterogeneity of NRSTS and the possible different terminology used in publications may have led us to overlook studies with eligible participants. This may be more an issue for case series but it is highly unlikely for controlled trials. The pooled survival analysis of individual data was based on less than half of all the individual data available and the exclusion of these data, whilst intending to reduce bias, may also have introduced bias.

\section{Agreements and disagreements with other studies or reviews}

We agree with [Pedrazzoli 2006] that the potential benefit of this treatment option has not been investigated sufficiently in comparative studies. A systematic review [Verma 2008a] was performed to determine whether first-line dose-intensive chemotherapy supported by growth factor or autologous bone marrow or stem cell transplantation improves outcomes compared with standard-dose chemotherapy in patients with inoperable, locally advanced or metastatic soft tissue sarcoma. [Verma 2008a] included only one case series [Schlemmer 2006] with HDCT followed by autologous HSCT, which was excluded from the present review because $40 \%$ of patients were not diagnosed with the disease of interest. [Kasper 2005 concluded that the use of HDCT for locally advanced or metastatic adult (soft tissue and bone) sarcomas still remains highly investigational and should not be performed outside clinical trials.

\section{Authors' Conclusions}

\section{Implications for practice}

The evidence base does not support the use of HDCT followed by autologous HSCT in high-risk patients with NRSTS. If this treatment is offered it should only be after careful consideration and integrated within a prospective concurrent, preferably randomized, controlled trial. 


\section{Implications for research}

It is doubtful whether further studies are necessary to clarify the relevance of HDCT followed by autologous HSCT in patients with NRSTS. If non-randomized controlled studies are conducted, a low risk of bias should be achieved. Single-arm studies are not helpful. Criteria for the included tumor types should adhere to the WHO classification.

\section{Differences between protocol and review}

\section{Differences between the recent version and the updated version of the review}

It is not clear that the unclassified and the undifferentiated tumor types are nonrhabdomyosarcoma soft tissue sarcomas. Therefore, we did not consider these tumor types for the present review and relocated both types from the list of included to the list of excluded tumor types. As a result, the following seven studies were included in the original review but excluded in the update: [Endo 1996; Frapier 1998; Mesia 1994; Nakamura 2008; Ronghe 2004; Shaw 1996; Watanabe 2006].

In contrast to the recent version, we excluded the article by [Ivanova 2007]. According to e-mail correspondence with the author AB Shvarova of a related article [Ivanova 2010] and co-worker at the same research institution, the proportion of patients with NRSTS was less than $50 \%$. Most of the retrospectively observed patients were children diagnosed with rhabdomyosarcoma. In contrast to the recent version, we included the study by [Blay 2000] because we accepted the results of a subgroup analysis comprising $91 \%$ (22 out of 24 ) relevant patients. In agreement with the recent version, the exclusion of the study by [Schlemmer 2006] based on a proportion of NRSTS patients below $80 \%$ was confirmed according to a recent author contact.

We complemented PFS estimates. We conducted an updated search and included five further studies [Bisogno 2010; Buerk 2010; Hara 2010; Houet 2010; Jordan 2010] that were identified in the update and therefore not reported in the recent version. One study reported aggregate data of 14 participants [Bisogno 2010] and three studies reported individual data of nine participants which were suitable for inclusion in the meta-analysis [Buerk 2010; Hara 2010; Jordan 2010].

Concerning the two articles by [Kasper 2007a] and [Kasper 2010], we stated in the recent version that some participants were reported in both articles. In the present updated version, we evaluated these duplicate data and identified six participants by coincidental information on age, histology, and metastatic sites. We included eight instead of 14 participants reported by [Kasper 2007a] and seven participants reported by [Kasper 2010]. Consequently, we removed the duplicate data of six participants from the pooled analysis. We did not find additional reviews in the updated search. 
We changed the search strategy to increase the fraction of the identified relevant documents of all identified relevant and not relevant documents (precision). The new search strategy is more economical in terms of spending resources for study selection for the present review and also for future updates. The new search strategy was not only used for the time period to be updated but was used from inception of all electronic databases searched. The screening process was redone regarding the complete retrieved records. All identified studies were evaluated in detail regardless of being part of the original review. We considered and re-evaluated all studies that were included in the original review. Therefore, the search strategy is composed of two parts. The new more narrow strategy is spanning the time from inception to 5 December 2012. The old more broad strategy is spanning from inception to 5 February 2010. 


\section{References}

\section{References to studies included in this review}

Al Balushi Z, Bulduc S, Mulleur C, Lallier M. Desmoplastic small round cell tumor in children: a new therapeutic approach. Journal of Pediatric Surgery. 2009;44(5):949-52.

Andres R, Mayordomo JI, Isla D, Ramon-y-Cajal S, Tejero E, Navarro A, et al. Desmoplastic small round cell tumor of the abdomen. Oncologia. 2006;29(2):73-5.

Bernbeck B, Bahci S, Meisel R, Troeger A, Schonberger S, Laws H-J, et al. Serial intense chemotherapy combining topotecan, etoposide, carboplatin and cyclophosphamide (TECC) followed by autologous hematopoietic stem cell support in patients with high risk soft tissue sarcoma (STS). Klinische Padiatrie. 2007;219(6):318-22.

Bertuzzi 2003: next 2 references

Bertuzzi A, Castagna L, Quagliuolo V, Ginanni V, Compasso S, Magagnoli M, et al. Prospective study of highdose chemotherapy and autologous peripheral stem cell transplantation in adult patients with advanced desmoplastic small round-cell tumour. British Journal of Cancer. 2003;89(7):1159-61.

Bertuzzi A, Castagna L, Nozza A, Quagliuolo V, Siracusano L, Balzarotti M, et al. High-dose chemotherapy in poorprognosis adult small round-cell tumors: clinical and molecular results from a prospective study. Journal of Clinical Oncology. 2002;20(8):2181-8.

Bisogno G, Ferrari A, Rosolen A, Alaggio R, Scarzello G, Garaventa A, et al. Sequential intensified chemotherapy with stem cell rescue for children and adolescents with desmoplastic small round-cell tumor. Bone Marrow Transplantation. 2010;45(5):907-11.

Blay 2000: next 2 references

Blay JY, Bouhour D, Ray-Coquard I, Dumontet C, Philip T, Biron P. High-dose chemotherapy with autologous hematopoietic stem-cell transplantation for advanced soft tissue sarcoma in adults. Journal of Clinical Oncology. 2000; 18(21):3643-50.

Blay JY, Bouhour D, Brunat-Mentigny M, Rivoire M, Philip I, Philip T, et al. High-dose chemotherapy (VIC) and bone marrow support in advanced sarcomas. Bone Marrow Transplantation. 1994;14 Suppl 1:55.

Bley TA, Zeiser R, Juttner E, Windfuhr-Blum M, Ghanem N, Kotter E, et al. Thrombectomy discloses intravascular growth of chondroid liposarcoma mimicking a long distance vena cava thrombosis. In Vivo. 2004;18(4):463-4.

Bolke E, Ruf L, Budach W, Reinecke P, Rohrborn A, Pape H, et al. Tandem high-dose chemotherapy supported by autologous peripheral blood stem-cell transplantation and radiotherapy for recurrent malignant fibrous histiocytoma. Wiener Klinische Wochenschrift. 2005;117(23-24):833-6.

Bokemeyer C, Franzke A, Hartmann JT, Schober C, Arseniev L, Metzner B, et al. A phase I/II study of sequential, dose-escalated, high dose ifosfamide plus doxorubicin with peripheral blood stem cell support for the treatment of patients with advanced soft tissue sarcomas. Cancer. 1997; 80(7):1221-7.

Burk J, Gerlach U, Baumann T, Langer M, Winterer JT. Epithelioid angiosarcoma of the scapula. In Vivo. 2010;24 (5):783-6.

Bui-Nguyen 2012: next 2 references

Bui-Nguyen B, Ray-Coquard I, Chevreau C, Penel N, Bay JO, Coindre JM, et al. High-dose chemotherapy consolidation for chemosensitive advanced soft tissue sarcoma patients: an open-label, randomized controlled trial. Annals of Oncology. 2012;23(3):777-84.

Binh NN, Chevreau C, Penel N, Bay J, Coindre J, Mathoulin-Pelissier S, et al. Consolidation with high-dose chemotherapy for responding patients to standard chemotherapy in advanced, metastatic soft tissue sarcoma (STS): A randomized trial from FNCLCC-French Sarcoma Group. Journal of Clinical Oncology. 2009;27(15 Suppl):10505.

Cole P, Ladanyi M, Gerald WL, Cheung NK, Kramer K, LaQuaglia MP, et al. Synovial sarcoma mimicking desmoplastic small round-cell tumor: critical role for molecular diagnosis. Medical and Pediatric Oncology. 1999;32(2):97-101. 
Cook 2012: next 2 references

Cook RJ, Wang Z, Arora M, Lazarus HM, Kasow KA, Champagne MA, et al. Clinical outcomes of patients with desmoplastic small round cell tumor of the peritoneum undergoing autologous HCT: a CIBMTR retrospective analysis. Bone Marrow Transplantation. 2012;47(11):1455-8.

Cook RJ, Wang Z, Arora M, Lazarus HM, Kasow KA, Champagne MA, et al. Is there a role for ASCT in patients with desmoplastic small round cell tumor of the peritoneum?. Blood. 2011;118(21):3092.

Doros L, Kaste SC, Rodriguez-Galindo C. Sister Mary Joseph's nodule as presenting sign of a desmoplastic small round cell tumor. Pediatric Blood and Cancer. 2008;50(2):388-90.

Engelhardt M, Zeiser R, Ihorst G, Finke J, Müller Cl. High-dose chemotherapy and autologous peripheral blood stem cell transplantation in adult patients with high-risk or advanced Ewing and soft tissue sarcoma. Journal of Cancer Research and Clinical Oncology. 2007;133(1):1-11.

Etienne-Mastroianni BE, Falchero L, Chalabreysse L, Loire R, Ranchere D, Souquet PJ, et al. Primary sarcomas of the lung: A clinicopathologic study of 12 cases. Lung Cancer. 2002;38(3):283-9.

Fang 2008 \{published data only\}

Fang X, Rodabaugh K, Penetrante R, Wong M, Wagner T, Sait S, et al. Desmoplastic small round cell tumor (DSRCT) with ovarian involvement in 2 young women. Applied Immunohistochemistry and Molecular Morphology. 2008;16(1):94-9.

Farruggia P, D'Angelo P, Lo Cascio M, Solazzo L, Montemaggi P, Novara V, et al. Synovial sarcoma of the neck in a child: a multidisciplinary approach. Pediatric Hematology and Oncology. 2008;25(5):431-7.

Fetscher S, Kiani A, Kanz L, Brugger W, Lange W, Mertelsmann R. Neo-adjuvant high-dose chemotherapy with autologous peripheral blood stem cell transplantation for inoperable relapse of nuchal liposarcoma resistant to standard-dose chemotherapy. Annals of Oncology. 1996;7(8):871.

Fetscher S, Brugger W, Bertz H, Krieger G, Kanz L, Mertelsmann R, et al. High-dose chemotherapy with autologous peripheral blood stem cell transplantation for metastatic gastric leiomyosarcoma. Bone Marrow Transplantation. 1997;20(9):787-8.

Fraser CJ, Weigel BJ, Perentesis JP, Dusenbery KE, DeFor TE, Baker KS, et al. Autologous stem cell transplantation for high-risk Ewing's sarcoma and other pediatric solid tumors. Bone Marrow Transplantation. 2006;37(2):175-81.

Garrido SM, Chauncey TR. Neuroleptic malignant syndrome following autologous peripheral blood stem cell transplantation. Bone Marrow Transplantation. 1998;21(4): 427-8.

Graham ML, Herndon JE 2nd, Casey JR, Chaffee S, Ciocci GH, Krischer JP, et al. High-dose chemotherapy with autologous stem-cell rescue in patients with recurrent and high-risk pediatric brain tumors. Journal of Clinical Oncology. 1997;15(5):1814-23.

Hara T, Tsurumi H, Kasahara S, Ogawa K, Takada J, Imai K, et al. Long-term survival of a patient with splenic angiosarcoma after resection, high-dose chemotherapy, and autologous peripheral blood stem cell transplantation. Internal Medicine. 2010;49(20):2253-7.

Hawkins DS, Felgenhauer J, Park J, Kreissman S, Thomson B, Douglas J, et al. Peripheral blood stem cell support reduces the toxicity of intensive chemotherapy for children and adolescents with metastatic sarcomas. Cancer. 2002;95 (6):1354-65.

Hoogerbrugge PM, Egeler RM. Autologous transplantation of G-CSF mobilized bone marrow cells in a child with disseminated fibrosarcoma. Bone Marrow Transplantation. 1997;20(7):613-4.

Houet L, Moller I, Engelhardt M, Kohler G, Schmidt H, Herchenbach D, et al. Long-term remission after CD34+selected PBSCT in a patient with advanced intra-abdominal desmoplastic small round-cell tumor. Bone Marrow Transplantation. 2010;45(4):793-5.

Jordan K, Wolf HH, Voigt W, Kegel T, Mueller LP, Behlendorf T, et al. Bevacizumab in combination with sequential high-dose chemotherapy in solid cancer, a feasibility study. Bone Marrow Transplantation. 2010;45 (12):1704-9.

Kasper 2007a: next 2 references

Kasper B, Dietrich S, Mechtersheimer G, Ho AD, Egerer G. Large institutional experience with dose-intensive chemotherapy and stem cell support in the management of sarcoma patients. Oncology. 2007;73(12):58-64. 
Kasper B, Lehnert T, Bernd L, Mechtersheimer G, Goldschmidt H, Ho AD, et al. High-dose chemotherapy with autologous peripheral blood stem cell transplantation for bone and soft-tissue sarcomas. Bone Marrow Transplantation. 2004;34(1):37-41.

Kasper B, Scharrenbroich I, Schmitt T, Wuchter P, Dietrich S, Ho AD, et al. Consolidation with high-dose chemotherapy and stem cell support for responding patients with metastatic soft tissue sarcomas: prospective, singleinstitutional phase II study. Bone Marrow Transplantation. 2010;45(7):1234-8.

Kozuka T, Kiura K, Katayama H, Fujii N, Ishimaru F, Ikeda K, et al. Tandem high-dose chemotherapy supported by autologous peripheral blood stem cell transplantation for recurrent soft tissue sarcoma. Anticancer Research. 2002;22 (5):2939-44.

Kretschmar CS, Colbach C, Bhan I, Crombleholme TM. Desmoplastic small cell tumor: a report of three cases and a review of the literature. Journal of Pediatric Hematology and Oncology. 1996;18(3):293-8.

Krskova L, Sumerauer D, Stejskalova E, Kodet R. A novel variant of SYT-SSX1 fusion gene in a case of spindle cell synovial sarcoma. Diagnostic Molecular Pathology. 2007;16 (3):179-83.

Kurre P, Felgenhauer JL, Miser JS, Patterson K, Hawkins DS. Successful dose-intensive treatment of desmoplastic small round cell tumor in three children. Journal of Pediatric Hematology and Oncology. 2000;22(5):446-50.

Kushner BH, LaQuaglia MP, Wollner N, Meyers PA, Lindsley KL, Ghavimi F, et al. Desmoplastic small roundcell tumor: prolonged progression-free survival with aggressive multimodality therapy. Journal of Clinical Oncology. 1996;14(5):1526-31.

Kushner BH, Cheung NK, Kramer K, Dunkel IJ, Calleja E, Boulad F. Topotecan combined with myeloablative doses of thiotepa and carboplatin for neuroblastoma, brain tumors, and other poor-risk solid tumors in children and young adults. Bone Marrow Transplantation. 2001;28(6):551-6.

Kushner BH, LaQuaglia MP, Gerald WL, Kramer K, Modak S, Cheung NKV. Solitary relapse of desmoplastic small round cell tumor detected by positron emission tomography/computed tomography. Journal of Clinical Oncology. 2008;26(30):4995-6.

Lafay-Cousin L, Hartmann, Plouvier P, Mechinaud F, Boutard P, Oberlin O. High-dose thiotepa and hematopoietic stem cell transplantation in pediatric malignant mesenchymal tumors: a phase II study. Bone Marrow Transplantation. 2000;26(6):627-32.

Lashkari A, Chow WA, Valdes F, Leong L, Phan V, Twardowski P, et al. Tandem high-dose chemotherapy followed by autologous transplantation in patients with locally advanced or metastatic sarcoma. Anticancer Research. 2009;29(8):3281-8.

Lippe P, Berardi R, Cappelletti C, Massacesi C, Mattioli R, Latini L, et al. Desmoplastic small round cell tumour: a description of two cases and review of the literature. Oncology. 2003;64(1):14-7.

Livaditi E, Mavridis G, Soutis M, Papandreou E, Moschovi M, Papadakis V, et al. Diffuse intraabdominal desmoplastic small round cell tumor: a ten-year experience. European Journal of Pediatric Surgery. 2006;16(6):423-7.

Madigan CE, Armenian SH, Malogolowkin MH, Mascarenhas L. Extracranial malignant rhabdoid tumors in childhood: The Childrens Hospital Los Angeles experience. Cancer. 2007;110(9):2061-6.

Matsuzaki A, Suminoe A, Hattori H, Hoshina T, Hara T. Immunotherapy with autologous dendritic cells and tumorspecific synthetic peptides for synovial sarcoma. Journal of Pediatric Hematology and Oncology. 2002;24(3):220-3.

Mazuryk M, Paterson AH, Temple W, Arthur K, Crabtree T, Stewart DA. Benefit of aggressive multimodality therapy with autologous stem cell support for intra-abdominal desmoplastic small round cell tumor. Bone Marrow Transplantation. 1998;21(9):961-3.

Mingo L, Seguel F, Rollan V. Intraabdominal desmoplastic small round cell tumour. Pediatric Surgery International. 2005;21(4):279-81.

Mitchell PL, Shepherd VB, Proctor HM, Dainton M, Cabral SD, Pinkerton CR. Peripheral blood stem cells used to augment autologous bone marrow transplantation. Archives of Disease in Childhood. 1994;70(3):237-40. 
Navid F, Santana VM, Billups CA, Merchant TE, Furman WL, Spunt SL, et al. Concomitant administration of vincristine, doxorubicin, cyclophosphamide, ifosfamide, and etoposide for high-risk sarcomas. Cancer. 2006;106(8): 1846-56.

Patel SR, Papadopolous N, Raymond AK, Donato M, Seong CM, Yasko AW, et al. A phase II study of cisplatin, doxorubicin, and ifosfamide with peripheral blood stem cell support in patients with skeletal osteosarcoma and variant bone tumors with a poor prognosis. Cancer. 2004;101(1):156-63.

Peters WP, Eder JP, Henner WD, Schryber S, Wilmore D, Finberg R, et al. High-dose combination alkylating agents with autologous bone marrow support: a Phase 1 trial. Journal of Clinical Oncology. 1986;4(5):646-54.

Peters WP, Stuart A, Klotman M, Gilbert C, Jones RB, Shpall EJ, et al. High-dose combination cyclophosphamide, cisplatin, and melphalan with autologous bone marrow support. Cancer Chemotherapy and Pharmacology. 1989;23 (6):377-83.

Philippe-Chomette P, Kabbara N, Andre N, Pierron G, Coulomb A, Laurence V, et al. Desmoplastic small round cell tumors with EWS-WT1 fusion transcript in children and young adults. Pediatric Blood and Cancer. 2012;58(6):891-7.

Recchia F, Saggio G, Amiconi G, Di Blasio A, Cesta A, Candeloro G, et al. Cardiac metastases in malignant fibrous histiocytoma. Tumori. 2006;92(1):76-8.

Saab R, Khoury JD, Krasin M, Davidoff AM, Navid F. Desmoplastic small round cell tumor in childhood: The St. Jude Children's Research Hospital experience. Pediatric Blood and Cancer. 2007;49(3):274-9.

Slease RB, Benear JB, Selby GB, Reitz CL, Hughes WL, Watkins CL, et al. High-dose combination alkylating agent therapy with autologous bone marrow rescue for refractory solid tumors. Journal of Clinical Oncology. 1988;6(8):1314-20.

Sung KW, Yoo KH, Chung EH, Jung HL, Koo HH, Shin HJ, et al. Successive double high-dose chemotherapy with peripheral blood stem cell rescue collected during a single leukapheresis round in patients with high-risk pediatric solid tumors: a pilot study in a single center. Bone Marrow Transplantation. 2003;31(6):447-52.

Yamamura R, Yamane T, Aoyama Y, Nakamae H, Makita K, Shima E, et al. Development of chronic myelocytic leukemia after chemotherapy for malignant fibrous histiocytoma. Acta Haematologica. 2003;109(3):141-4.

Yonemoto T, Tatezaki S, Ishii T, Satoh T. High-dose chemotherapy with autologous peripheral blood stem cell transplantation (PBSCT) for refractory bone and soft tissue sarcomas (Article in Japanese). Gan To Kagaku Ryoho. 1999; 26(10):1431-5.

\section{References to studies excluded from this review}

References listed online at doi: 10.1002/14651858.CD008216.pub4.

\section{References to ongoing studies}

NCT00002601. Somlo G. Combination chemotherapy and peripheral stem cell transplantation in treating patients with sarcoma. ClinicalTrials.gov 2012.

NCT00002854. Somlo G. High-dose combination chemotherapy plus peripheral stem cell transplantation in treating patients with advanced cancer. ClinicalTrials.gov 2012.

NCT00141765. Levine JE. Study of high-dose chemotherapy with bone marrow or stem cell transplant for rare poorprognosis cancers. ClinicalTrials.gov 2012.

NCT00623077. Verneris MR. Total marrow irradiation added to an alkylatorintense conditioning regimen for patients with high risk or relapsed solid tumors. ClinicalTrials.gov 2012.

NCT00638898. Pawlowska A. Busulfan, melphalan, topotecan hydrochloride, and a stem cell transplant in treating patients with newly diagnosed or relapsed solid tumor. ClinicalTrials.gov 2012. 
NCT01288573. Medical Monitor Genzyme. A combined study in pediatric cancer patients for dose ranging and efficacy/safety of plerixafor plus standard regimens for mobilization versus standard regimens alone. ClinicalTrials.gov 2012.

\section{Additional references}

AJCC 2002. American Joint Committee on Cancer. AJCC cancer staging handbook. 6. Berlin: Springer; 2002.

Baker KS, DeFor TE, Burns LJ, Ramsay NK, Neglia JP, Robison LL. New malignancies after blood or marrow stem-cell transplantation in children and adults: incidence and risk factors. Journal of Clinical Oncology. 2003;21(7):1352-8.

Bonnet D, Dick JE. Human acute myeloid leukemia is organized as a hierarchy that originates from a primitive hematopoietic cell. Nature Medicine. 1997;3(7):730-7.

Carvajal R, Meyers P. Ewing's sarcoma and primitive neuroectodermal family of tumors. Hematology/Oncology Clinics of North America. 2005;19(3):501-25.

Clark MA, Fisher C, Judson I, Thomas JM. Soft-tissue sarcomas in adults. New England Journal of Medicine. 2005;353(7):701-11.

ClinicalTrials.gov 2012. ClinicalTrials.gov. Bethesda: National Institutes of Health; 2012.

Deeks JJ, Higgins JPT, Altman DG. Chapter 9: Analysing data and undertaking meta-analyses. In: Higgins JPT, Green S (editors). Cochrane Handbook for Systematic Reviews of Interventions Version 5.1.0 (updated March 2011). The Cochrane Collaboration; 2011.

DerSimonian R, Laird N. Meta-analysis in clinical trials. Controlled Clinical Trials. 1986;7(3):177-88.

Dileo P, Demetri GD. Update on new diagnostic and therapeutic approaches for sarcomas. Clinical Advances in Hematology \& Oncology. 2005;3(10):781-91.

EBMT 2009. European Group for Blood and Marrow Transplantation (EBMT). London: EBMT Central Registry Office; 2009.

Enzinger 2001. Weiss SW, Goldblum JR. General considerations. In: Weiss SW, Goldblum JR (editors). Enzinger and Weiss's soft tissue tumors. St Louis: Mosby; 2001:1-19.

ESMO / European Sarcoma Network Working Group. Soft tissue and visceral sarcomas: ESMO Clinical Practice Guidelines for diagnosis, treatment and follow-up. Annals of Oncology. 2012;23 Suppl 7:vii92-9.

Fletcher CDM, Rydholm A, Singer S, Sundaram M, Coindre JM. Soft tissue tumours: WHO classification, epidemiology, clinical features, histopathological typing and grading. In: Fletcher CDM, Unni KK, Mertens F (editors). World Health Organization classification of tumours. Pathology and genetics of tumours of soft tissue and bone. Lyon: International Agency for Research on Cancer; 2002:12-8.

Fletcher CDM, Bridge JA, Hogendoorn PCW, Mertens F (editors). WHO Classification of Tumours of Soft Tissue and Bone. Fourth edition. Lyon: International Agency for Research on Cancer (IARC), 2013.

Google Translate 2012. Google, Inc. Google Translate. Mountain View: Google, Inc; 2012.

GRADEpro 2008. Brozek J, Oxman A, Schunemann H. GRADEpro (GRADE profiler). Version 3.2 for Windows. Copenhagen: Information Management System (IMS), Nordic Cochrane Centre, The Cochrane Collaboration; 2008.

Gurney JG, Young JL, Roffers SD, Smith MA, Bunin GR. Soft tissue sarcomas. In: Ries LAG, Smith MA, Gurney JG, Linet M, Tamra T, Young JL, Bunin GR (editors). Cancer incidence and survival among children and adolescents: United States SEER program 1975-1995 (SEER Pediatric Monograph) NIH Pub. No. 99-4649. Bethesda: National Cancer Institute; 1997:111-24.

Higgins JP, Thompson SG, Deeks JJ, Altman DG. Measuring inconsistency in meta-analyses. BMJ. 2003;327:557-60.

Higgins 2011a. Higgins JPT, Altman DG, Sterne JAC. Chapter 8: Assessing risk of bias in included studies: Table 8.5.a. In: Higgins JPT, Green S (editors). Cochrane Handbook for Systematic Reviews of Interventions Version 5.1.0 (updated March 2011). The Cochrane Collaboration; 2011. 
Higgins 2011b. Higgins JPT, Altman DG, Sterne JAC. Table 8.5.d: Criteria for judging risk of bias in the 'Risk of bias' assessment tool. Chapter 8: Assessing risk of bias in included studies. In: Higgins JPT, Green S editor(s). Cochrane Handbook for Systematic Reviews of Interventions Version 5.1.0 (updated March 2011). The Cochrane Collaboration; 2011.

Higgins 2011c. Higgins JPT, Deeks JJ, Altman DG. Section 16.1 Missing data. Chapter 16: Special topics in statistics. In: Higgins JPT, Green S (editors). Cochrane Handbook for Systematic Reviews of Interventions Version 5.1.0 (updated March 2011). The Cochrane Collaboration; 2011.

ICTRP 2012. International Clinical Trials Registry Platform. World Health Organization; 2012.

ISRCTN 2012. International Standard Randomised Controlled Trial Number Register. Current Controlled Trials Ltd; 2012.

Ivanova NM, Aliev MD, Shvarova AV, Dzampaev AZ, Mentkevich GL. Innovation approaches to treatment of children with malignant tumors of the musculoskeletal system (Article in Russian). Vestnik Rossiiskoi Akademii Meditsinskikh Nauk. 2007;10:26-32.

Kasper 2007b. Kasper B. Standards and novel therapeutic options in the treatment of patients with soft tissue sarcoma. Reviews on Recent Clinical Trials. 2007;2(3):206-11.

Kotilingam D, Lev DC, Lazar AJ, Pollock RE. Staging soft tissue sarcoma: evolution and change. CA: A Cancer Journal for Clinicians. 2006;56(5):282-91.

Miller RW, Young JL Jr, Novakovic B. Childhood cancer. Cancer. 1995;75(1 Suppl):395-405.

Moher D, Liberati A, Tetzlaff J, Altman DG. Preferred reporting items for systematic reviews and metaanalyses: the PRISMA statement. PLoS Medicine. 2009;6:e1000097.

$\mathrm{NCI}$ 2008a. SEER Cancer Statistics Review, 1975-2005. Table I-10. Age distribution (\%) of incidence cases by site, 2001-2005. Bethesda: National Cancer Institute; 2008.

$\mathrm{NCI}$ 2008b. SEER Cancer Statistics Review, 1975-2005. Table I11. Median age of cancer patients at diagnosis, 20012005, N. Bethesda: National Cancer Institute; 2008.

$\mathrm{NCl}$ 2009a. A Snapshot of Sarcoma. Bethesda: National Cancer Institute; 2009.

$\mathrm{NCl}$ 2009b. Common Terminology Criteria for Adverse Events (CTCAE) and Common Toxicity Criteria (CTC). Bethesda: National Cancer Institute; 2009.

NCI 2010a. SEER Cancer Statistics Review, 1975-2007. Table I-1. Estimated new cancer cases and deaths for 2010. Bethesda: National Cancer Institute; 2010.

Neglia JP, Friedman DL, Yasui Y, Mertens AC, Hammond S, Stovall M, et al. Second malignant neoplasms in five-year survivors of childhood cancer: Childhood Cancer Survivor Study. Journal of the National Cancer Institute. 2001;93(8):618-29.

Parmar MK, Torri V, Stewart L. Extracting summary statistics to perform meta-analyses of the published literature for survival endpoints. Statistics in Medicine. 1998;17(24):2815-34.

Pedrazzoli P, Ledermann JA, Lotz JP, Leyvraz S, Aglietta M, Rosti G, et al. High dose chemotherapy with autologous hematopoietic stem cell support for solid tumors other than breast cancer in adults. Annals of Oncology. 2006;17(10):1479-88.

Pinkerton R, Philip T, Bouffet E, Lashford L, Kemshead J. Autologous bone marrow transplantation in paediatric solid tumours. Clinics in Haematology. 1986;15(1):187-203.

Reichardt P. High-dose chemotherapy in adult soft tissue sarcoma. Critical Reviews in Oncology/Hematology. 2002;41(2):157-67.

Review Manager 2011. Cochrane Review Manager (RevMan 5.1). Copenhagen: The Nordic Cochrane Centre, The Cochrane Collaboration; 2011.

Riedel RF. Systemic therapy for advanced soft tissue sarcomas: highlighting novel therapies and treatment approaches. Cancer. 2012;118(6):1474-85.

Rosti G, Ferrante P, Ledermann J, Leyvraz S, Ladenstein R, Koscielniak E, et al. High-dose chemotherapy for solid tumors: results of the EBMT. Critical Reviews in Oncology/ Hematology. 2002;41(2):129-40.

Sanchez-Garcia I, Vicente-Duenas C, Cobaleda C. The theoretical basis of cancer-stem-cell-based therapeutics of cancer: Can it be put into practice?. BioEssays. 2007;29(12):1269-80.

SAS Institute Inc. SAS computer program. Cary: SAS Institute Inc.; 2012. 
Schunemann HJ, Oxman AD, Vist GE, Higgins JPT, Deeks JJ, Glasziou P, et al. Chapter 12: Interpreting results and drawing conclusions. In: Higgins JPT, Green S (editors). Cochrane Handbook for Systematic Reviews of Interventions Version 5.1.0 (updated March 2011). The Cochrane Collaboration 2011.;

Seeger RC, Reynolds CP. Treatment of high-risk solid tumors of childhood with intensive therapy and autologous bone marrow transplantation. Pediatric Clinics of North America. 1991;38(2):393-424.

Sondak VK, Chang AE. Clinical evaluation and treatment of soft tissue tumors. In: Weiss SW, Goldblum JR (editors). Enzinger and Weiss's soft tissue tumors. St Louis: Mosby; 2001:21-44.

Spunt SL, Pappo AS. Childhood nonrhabdomyosarcoma soft tissue sarcomas are not adult-type tumors. Journal of Clinical Oncology. 2006;24(12):1958-9.

Sterne JAC, Egger M, Moher D. Chapter 10: Addressing reporting biases. In: Higgins JPT, Green S (editors). Cochrane Handbook for Systematic Reviews of Interventions Version 5.1.0 (updated March 2011). The Cochrane Collaboration; 2011.

Therasse P, Arbuck SG, Eisenhauer EA, Wanders J, Kaplan RS, Rubinstein L, et al. New guidelines to evaluate the response to treatment in solid tumors. Journal of the National Cancer Institute. 2000;92(3):205-16.

Thomson Reuters. EndNote X4.0.2. New York, Thomson Reuters; 2012.

Tierney JF, Stewart LA, Ghersi D, Burdett S, Sydes MR. Practical methods for incorporating summary time-toevent data into meta-analysis. Trials. 2007;8:16.

Tsao H. Update on familial cancer syndromes and the skin. Journal of the American Academy of Dermatology. 2000;42(6):939-69.

Van Glabbeke M, van Oosterom AT, Oosterhuis JW, Mouridsen H, Crowther D, Somers R, et al. Prognostic factors for the outcome of chemotherapy in advanced soft tissue sarcoma: an analysis of 2,185 patients treated with anthracycline-containing first-line regimens--a European Organization for Research and Treatment of Cancer Soft Tissue and Bone Sarcoma Group Study. Journal of Clinical Oncology. 1999;17(1):150-7.

\section{References to other published versions of this review}

Peinemann F, Smith LA, Kromp M, Bartel C, Kroger N, Kulig M. Autologous hematopoietic stem cell transplantation following high-dose chemotherapy for nonrhabdomyosarcoma soft tissue sarcomas. Cochrane Database of Systematic Reviews. 2011;(2):CD008216. DOI: 10.1002/14651858.CD008216.pub3 


\section{CHAPTER 4}

First-line matched related donor hematopoietic stem cell transplantation compared to immunosuppressive therapy in acquired severe aplastic anemia

Peinemann F, Grouven U, Kroger N, Bartel C, Pittler MH, Lange S. First-line matched related donor hematopoietic stem cell transplantation compared to immunosuppressive therapy in acquired severe aplastic anemia. PLoS One. 2011;6(4):e18572. 


\begin{abstract}
Introduction Acquired severe aplastic anemia (SAA) is a rare and progressive disease characterized by an immune-mediated functional impairment of hematopoietic stem cells. Transplantation of these cells is a first-line treatment option if HLA-matched related donors are available. First-line immunosuppressive therapy may be offered as alternative. The aim was to compare the outcome of these patients in controlled trials.

Methods A systematic search was performed in the bibliographic databases MEDLINE, EMBASE, and The Cochrane Library. To show an overview of various outcomes by treatment group we conducted a meta-analysis on overall survival. We evaluated whether studies reported statistically significant factors for improved survival.

Results 26 non-randomized controlled trials (7,955 patients enrolled from 1970 to 2001) were identified. We did not identify any RCTs. Risk of bias was high except in 4 studies. Young age and recent year of treatment were identified as factors for improved survival in the HSCT group. Advanced age, SAA without very severe aplastic anemia, and combination of anti-lymphocyte globulin with cyclosporine $A$ were factors for improved survival in the IST group. In 19 studies (4,855 patients), summary statistics were sufficient to be included in meta-analysis. Considerable heterogeneity did not justify a pooled estimate. Adverse events were inconsistently reported and varied significantly across studies.
\end{abstract}

Conclusions Young age and recent year of treatment were identified as factors for improved survival in the transplant group. Advanced age, SAA without very severe aplastic anemia, and combination of anti-lymphocyte globulin with cyclosporine $A$ were factors for improved survival in the immunosuppressive group. Considerable heterogeneity of non-randomized controlled studies did not justify a pooled estimate. Adverse events were inconsistently reported and varied significantly across studies. 


\section{Introduction}

Acquired severe aplastic anemia (SAA) is a rare [1] and potentially fatal disease which is characterized by hypocellular bone marrow and pancytopenia, and mainly affects young adults. The incidence rate was estimated at less than 4 per million people per year [2]. The major signs and symptoms are severe infections, bleeding, and exhaustion. The underlying pathophysiology is thought to be an aberrant immune response involving the T-cell mediated destruction of hematopoietic stem cells. In most cases, the cause is unknown, although various triggers such as drugs, toxins, and viruses have been reported $[3,4]$.

The treatment of SAA mainly includes immunosuppressive therapy (IST) with antithymocyte globulin (ATG)/antilymphocyte globulin (ALG) and cyclosporine A (CSA), or allogeneic hematopoietic stem cell transplantation (HSCT) [3,4,5]. Allogeneic HSCT is seen as the treatment of choice for selected patients with an HLA-matched related donor [6,7]. Allogeneic HSCT is associated with graft failure, graft-versus-host disease (GVHD), and organ toxicities. On the other hand, patients may not respond to IST and long-term IST is associated with the development of clonal diseases [8]. Clinical treatment algorithms have been suggested to find a decision that meets individual conditions, personal preferences, and prognostic factors [9].

The present systematic review and meta-analysis compares the outcome after firstline HLA-matched related donor HSCT vs. IST in SAA patients in published controlled trials.

\section{Methods}

While preparing this systematic review and meta-analysis, we endorsed the PRISMA statement, adhered to its principles and conformed to its checklist $[10,11]$.

\section{Study inclusion criteria}

We included patients with acquired severe aplastic anemia who received, as first-line treatment, allogeneic HSCT from HLA-matched related donors (MRD) as the test intervention and IST as the control intervention. Study design was limited to randomized controlled trials (RCTs) and non-randomized intervention studies [12]. We did not set a minimum sample size to be considered. Fulltext publications in English language were considered. We set no limits on year of publication or year of treatment. A protocol is not available. 


\section{Search strategy}

MEDLINE (1950 to 2010), EMBASE (1980 to 2010) and The Cochrane Library (to 2010) were searched without restrictions on study design and publication year (final search 10 January 2010). The first database search was conducted 24 January 2006. The final search 10 January 2010 included a modified strategy to consider MeSH changes and to render the exclusion of animal studies more precisely. The MeSH term BONE MARROW TRANSPLANTATION was deleted from one category [13]. For MeSH 2008 there was a major revision of Publication Types (PT) and the phrase "as Topic" was added [14]. We introduced (ANIMALS not (ANIMALS and HUMANS)).sh. and replaced (ANIMALS not HUMANS).sh. To account for these changes, both searches were not restricted to any publication year. The terms and the syntax used for the search in MEDLINE via Ovid as shown in Table 1 were tailored to the requirements of the other 2 databases. Reference lists of all included original articles and 5 recent reviews (2007 to 2009) $[8,9,15,16,17]$ were handsearched. Abstracts of the American Society of Hematology Annual Meeting 2004 to 2009 [18] and information on studies registered at ClinicalTrials.gov [19] were searched online (April 2010).

\section{Study selection}

First, articles were excluded if the title and/or the abstract clearly referred to other diagnoses than severe aplastic anemia and in addition clearly referred to other interventions than allogeneic hematopoietic stem cell transplantation. Second, articles not excluded in the first step were evaluated whether patients were analyzed in a test group after first-line allogeneic HSCT from a MRD and were compared with patients after first-line IST in a control group. Reporting of extractable information about overall survival was required for all included studies. For each excluded study, an appropriate reason was documented. All steps of the literature screening process were performed by two independent reviewers. Any disagreements were resolved by discussion. Criteria for classification of severity of aplastic anemia and quality of response after immunosuppressive treatment were applied according to the EBMT [20].

\section{Risk of bias}

Risk of bias within studies was evaluated by assessing study design, such as retroor prospective planning, concurrent control group, criteria for assignment of patients to treatment arms, control for confounding factors, and other criteria, such as unclear selection of patients and analysis of the same patients in both treatment groups, that may increase the risk of bias especially in non-randomized trials [21]. A low risk of bias required a 'yes' for all three of the following topics: concurrent control group, control for confounding factors, and no other risk of bias factors. 
Table 1. Search strategy used in MEDLINE via Ovid

Database: Ovid MEDLINE(R) In-Process \& Other Non-Indexed Citations, Ovid MEDLINE(R) Daily and Ovid MEDLINE(R) $<1950$ to Present>

Search Strategy: row number, search term (number of retrieved records)

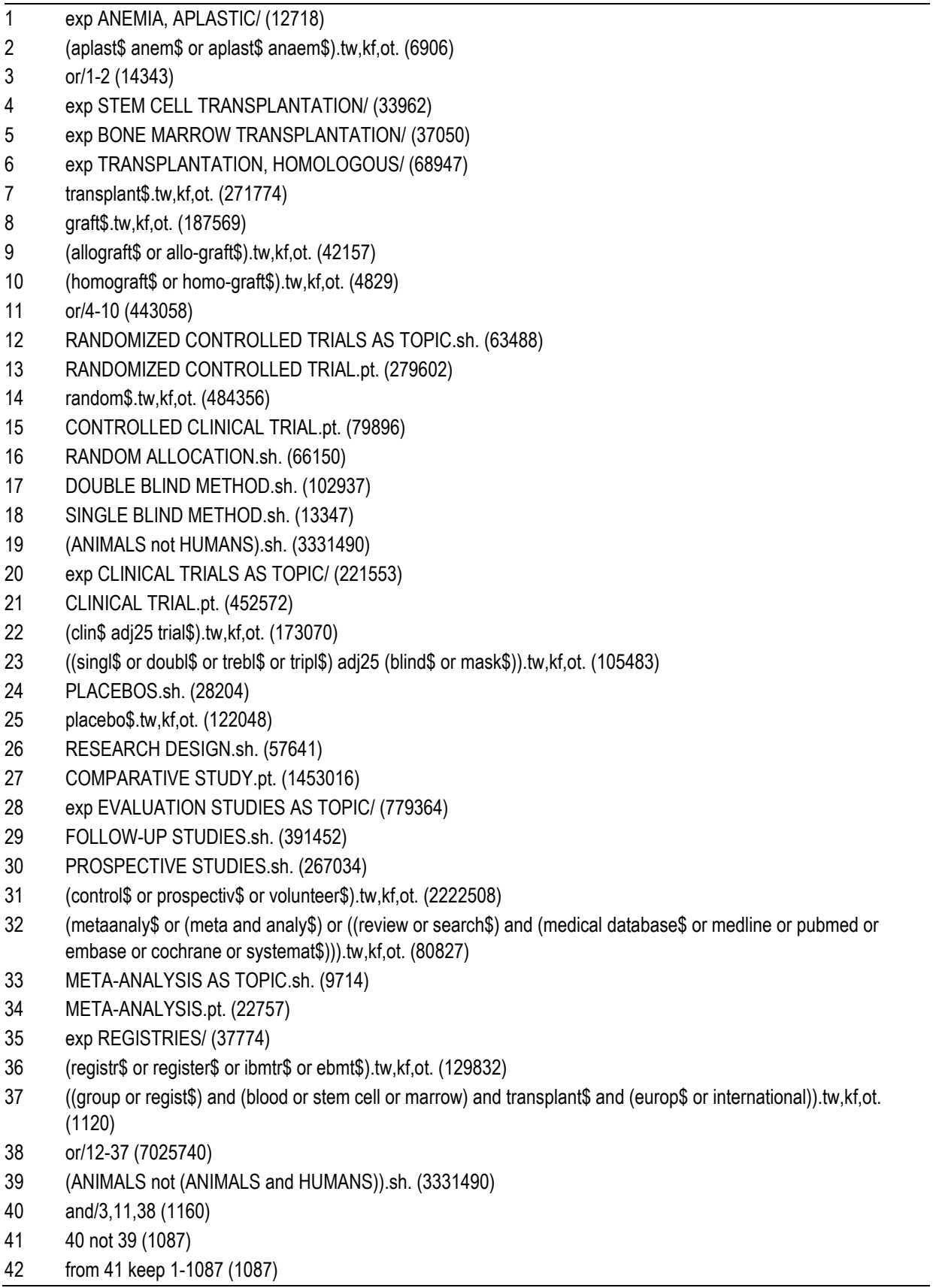




\section{Primary outcome: overall survival}

The primary effect measure for meta-analyses was the hazard ratio. If the hazard ratio was not directly given in the publication, we extracted summary statistics from Kaplan Meier survival functions and estimated hazard ratios according to methods proposed by Parmar 1998 [22]. For estimation, we applied a tool which uses $p$ values of the appropriate log-rank test comparing the two survival functions of interest, number of patients analyzed, and number of events on each arm [23]. If this information was not available, hazard ratios were deduced from the graphical display of the survival curves, if possible. Meta-analyses were conducted using the generic variance approach $[24,25]$ and the random effects model [26]. Calculations were conducted using SAS version 9.2 (SAS Institute Inc., Cary, North Carolina, USA). The results of the meta-analyses were graphically displayed by means of a forest plot. Heterogeneity of the results was visually assessed and quantified using the 12 value [27]. A funnel plot was prepared by using The Cochrane Collaboration's Review Manager 5 (http://www.cc-ims.net/ revman). In the case of considerable heterogeneity $(12 \geq 50 \%)$, a pooled estimate is not reasonable and, therefore, was not calculated [28].

\section{Subgroup analysis}

Sensitivity analysis: We tried to explain heterogeneity identified in the meta-analysis of overall survival by evaluating dichotomized subpopulations of study and patients characteristics in several sensitivity analyses [29]. Subgroups in individual studies: We extracted overall survival data of subgroups to reproduce survival functions from some individual studies if reported for both treatments. Data on subgroup analyses were extracted if available. The difference between the estimates of 2 subgroups was evaluated by conducting a test of interaction based on meta-regression models [30]. Calculations were conducted using SAS version 9.2 (SAS Institute Inc., Cary, North Carolina, USA).

\section{Factors for improved survival}

We extracted statistically significant results from multivariate analyses on factors for improved survival, such as age, disease severity, treatment period, and type of IST, if reported in the included studies.

\section{Data collection and analysis}

All steps of the data collection process were performed by two independent reviewers. Any disagreements were resolved by discussion. We collected study characteristics such as the number and region of participating centers, the treatment period, the 
number of analyzed patients per treatment arm, the proportion of patients with diseases other then SAA, a regimen other than firstline treatment, and median follow-up. Median age, gender, and time interval from diagnosis to treatment were extracted as patients' characteristics. For the HSCT arm we extracted the number of patients who were treated with conditioning irradiation and conditioning ATG or ALG. For the IST arm we extracted the number of patients treated with ATG or ALG alone or in combination with CSA.

The primary outcome was overall survival from the beginning of HSCT or IST. Kaplan Meier estimates were extracted directly from the text or deduced from survival curves given in the publication. The principal summary measure was the hazard ratio as specified in the meta-analysis section. We extracted the $p$ value of the log-rank test of the overall survival functions and the 5-year estimate of both treatment arms. Results from subgroup analyses were also extracted.

The secondary outcomes were overall mortality, graft failure, GVHD, no response to IST, and health-related quality of life.

Graft failure included both primary and secondary types; acute GVHD was considered if grade II-IV was reported and chronic GVHD was considered if an extensive course was reported.

\section{Results}

\section{Search results}

Of 3,085 retrieved publications, 358 full-text papers were obtained for further assessment, and 26 non-randomized controlled clinical trials were identified that met the inclusion criteria and were included in the present study [31,32,33,34,35,36,37,38, $39,40,41,42,43,44,45,46,47,48,49,50,51,52,53,54,55,56]$ (Figure 1). We did not identify any RCTs.

An overview of the study characteristics is presented in Table 2. Patients were recruited between 1970 and 2002 in 24 studies, whereas in 2 studies, year of treatment was not reported. In 13 studies [31,34,35,39,41,42,43,44,45,46,47,49,54], disease severity (SAA or VSAA) or first-line treatment was clearly classified for all patients. The proportion of patients with moderate aplastic anemia, unknown disease severity, or second-line treatment was less than $20 \%$ in 6 studies [32,36,38,40,50,52] and was $20 \%$ or more in 7 studies $[33,37,48,51,53,55,56] .25$ included trials used information about the availability of MRD to allocate patients to comparison groups, called Mendelian (genetic) randomization [57,58]. In 3 studies [41,52,53], relevant data were not reported for the total study population but were reported separately for subgroups. 


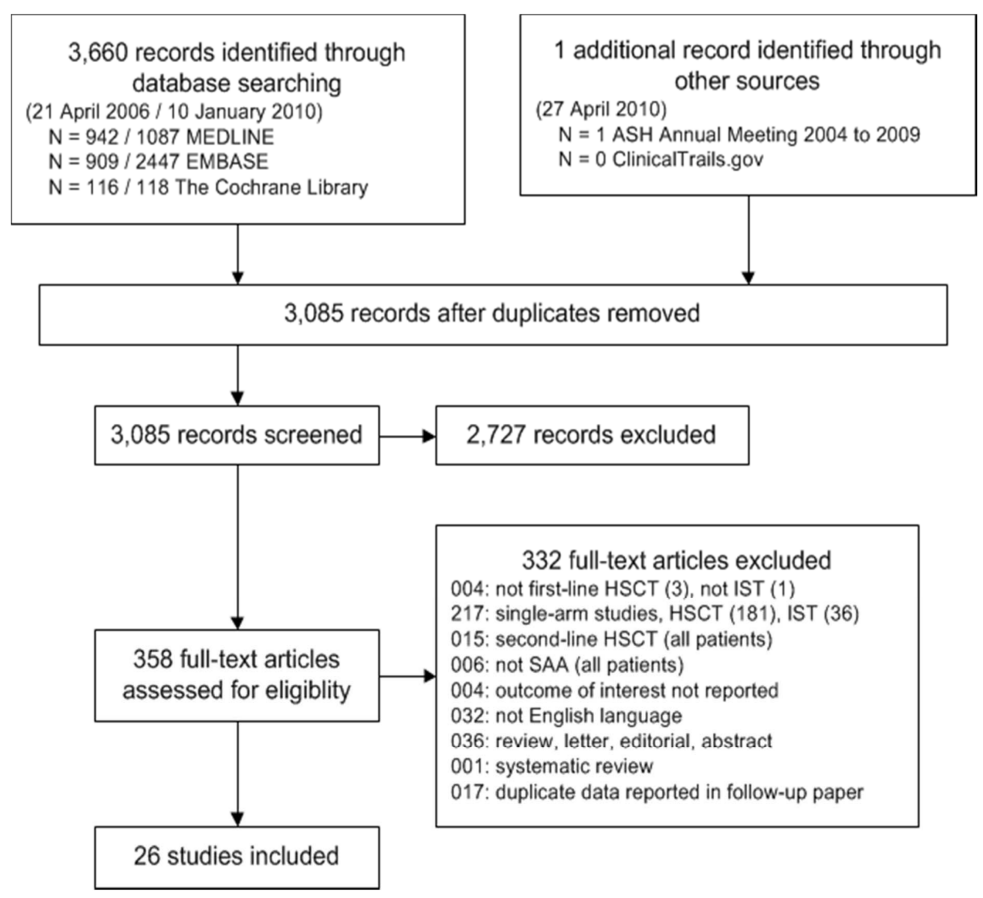

Figure 1. Literature search and study flow.

Abbreviations: HSCT: hematopoietic stem cell transplantation; IST: immunosuppressive therapy; SAA: severe aplastic anemia.

\section{Baseline data}

An overview of characteristics of 7,955 analyzed patients in 26 studies is presented in Table 3. Median age (HSCT vs. IST: 9-24 vs. 5-55 years) was reported in 15 of 26 studies and the difference between groups was not statistically different (sign test: $p=$ 0.119). Gender (HSCT vs. IST: 44-76 vs. 43-78 percent males) was reported in 19 of 26 studies and median of the time from diagnosis to treatment (HSCT vs. IST: $27-300$ vs. $12-150$ days) was reported in 15 of 26 studies.

An overview of the treatment characteristics is presented in Table 4. Conditioning irradiation was reported in 22 of 26 studies (0\%-100\%) and ATG or ALG was used in 9 studies $(2 \%-100 \%)$ in the HSCT arms. In the IST arms, ATG or ALG (8\%-100\%) and CSA $(0 \%-100 \%)$ was reported in 25 of 26 studies. IST was composed of ATG or ALG in 25 studies and was combined with CSA in 13 studies. 


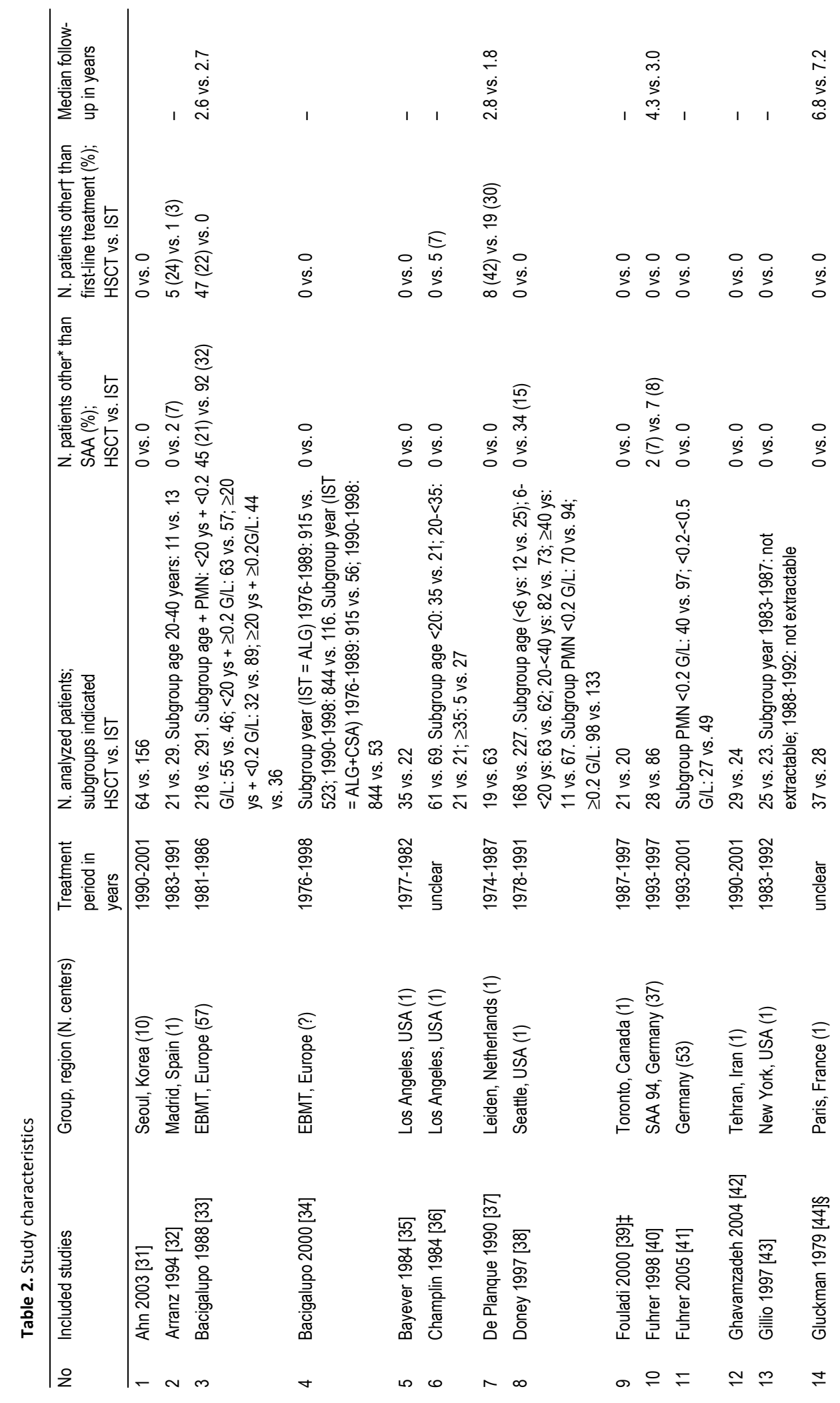




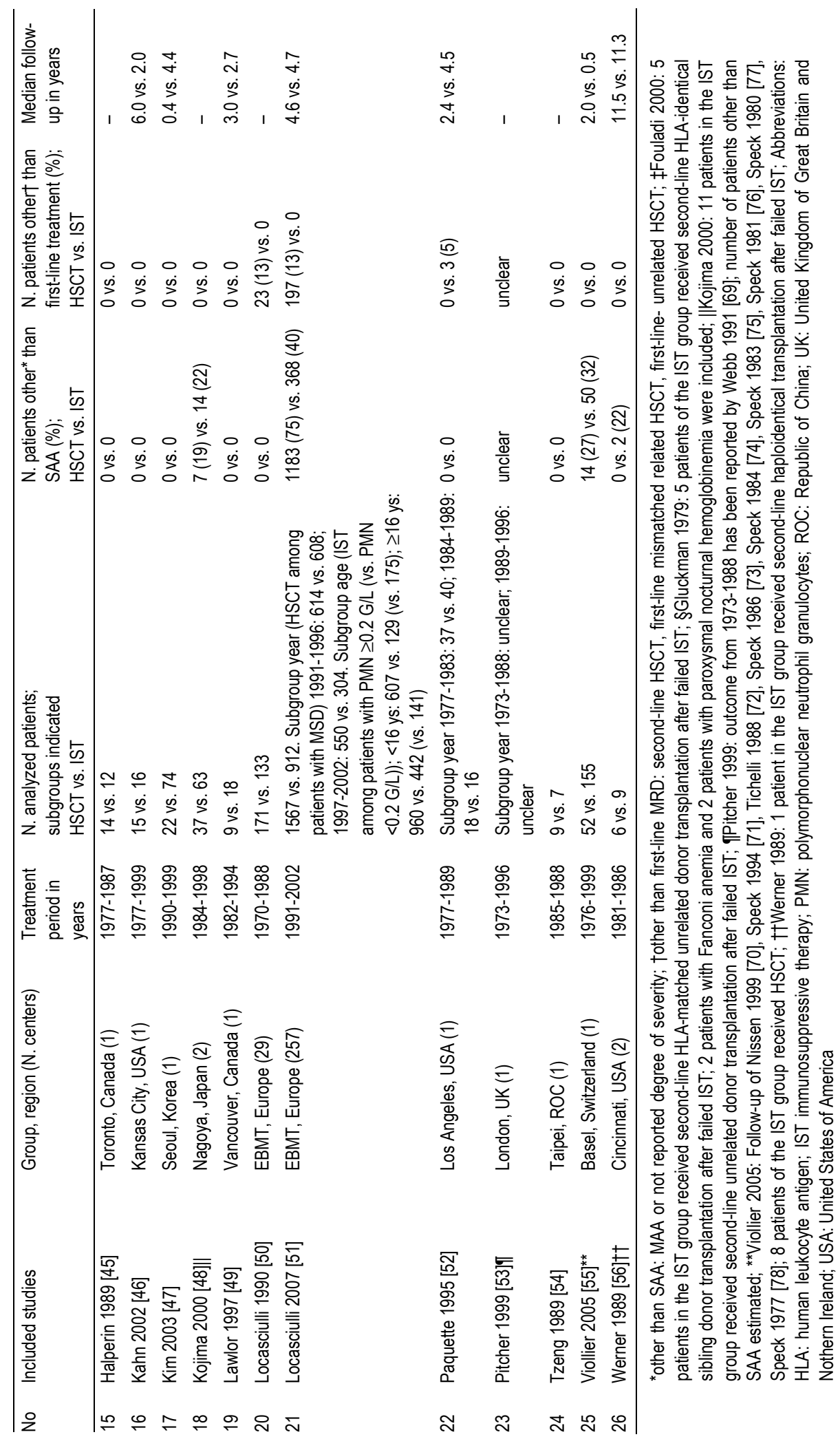




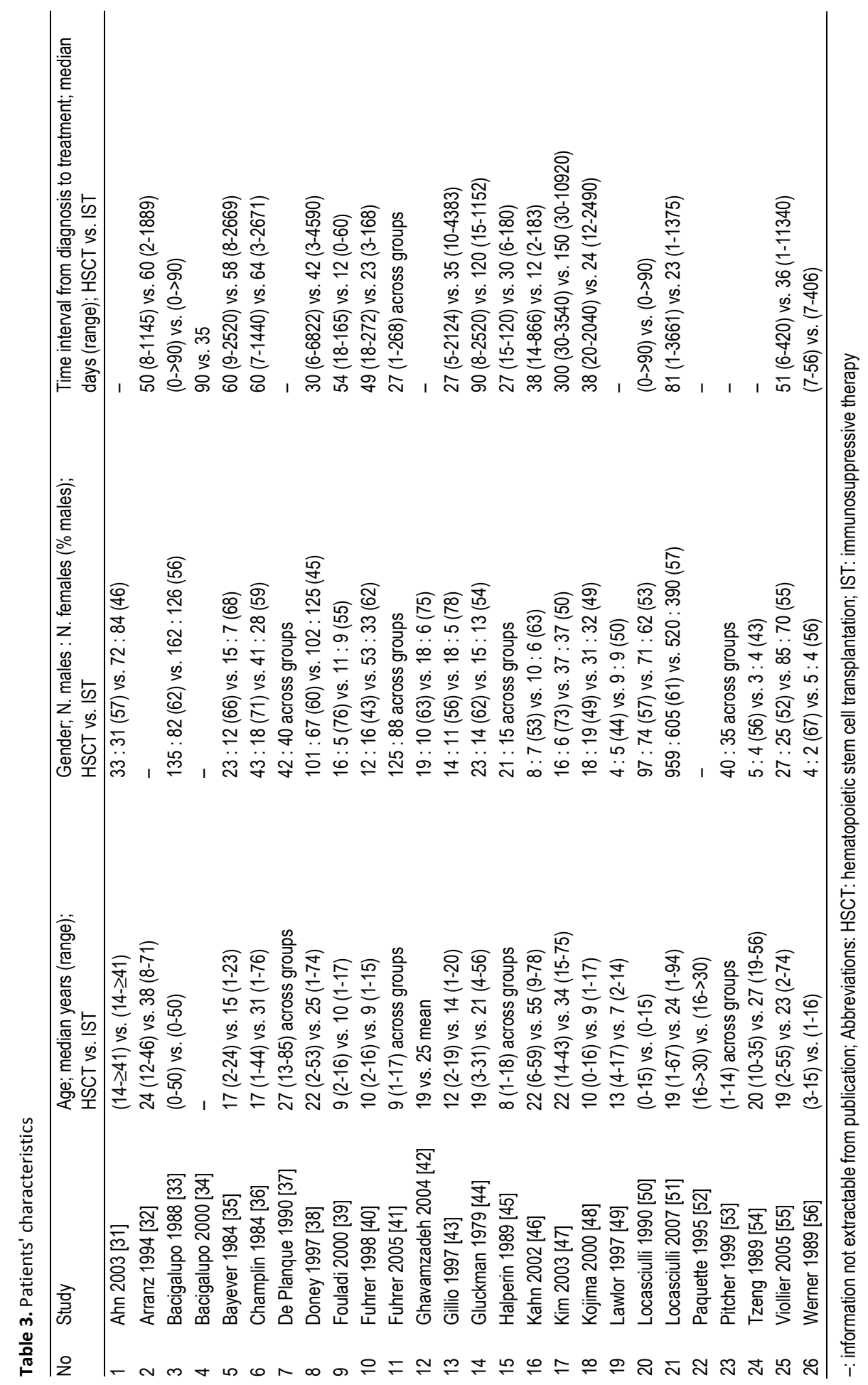


Table 4. Treatment characteristics

\begin{tabular}{|c|c|c|c|c|c|}
\hline \multirow[t]{2}{*}{ No } & \multirow[t]{2}{*}{ Study } & \multicolumn{2}{|c|}{ HSCT; N. treated / N. total (\%) } & \multicolumn{2}{|l|}{ IST; N. treated / N. total (\%) } \\
\hline & & Irradiation* & ATG or ALG & $\overline{\text { ATG or ALG }}$ & $\mathrm{CSA}$ \\
\hline 1 & Ahn 2003 [31] & $6 / 64(9)$ & $53 / 64(83)$ & $148 / 156(95)$ & $67 / 156(43)$ \\
\hline 2 & Arranz 1994 [32] & $20 / 21(95)$ & - & $29 / 29(100)$ & 0 \\
\hline 3 & Bacigalupo 1988 [33] & $110 / 218(50)$ & - & $291 / 291(100)$ & 0 \\
\hline 4 & Bacigalupo 2000 [34] & $433 / 1759(25)$ & $28 / 1759(2)$ & - & - \\
\hline 5 & Bayever 1984 [35] & $35 / 35(100)$ & 0 & $22 / 22(100)$ & 0 \\
\hline 6 & Champlin 1984 [36] & $59 / 61(97)$ & 0 & $69 / 69(100)$ & 0 \\
\hline 7 & De Planque 1990 [37] & $15 / 19(79)$ & $1 / 19(5)$ & $83 / 83(100)$ & 0 \\
\hline 8 & Doney 1997 [38] & 0 & $21 / 168(24)$ & 225 / 227 (99) & $1 / 227$ (1) \\
\hline 9 & Fouladi 2000 [39] & $12 / 21(57)$ & $5 / 21(24)$ & $20 / 20(100)$ & $19 / 20(95)$ \\
\hline 10 & Fuhrer 1998 [40] & - & $28 / 28(100)$ & $86 / 86(100)$ & $86 / 86(100)$ \\
\hline \multirow[t]{2}{*}{11} & Fuhrer 2005 [41] & 0 & 0 & VSAA: 97 / 97 (100) & VSAA: 97 / 97 (100) \\
\hline & & & & SAA: 49 / 49 (100) & SAA: 49 / 49 (100) \\
\hline 12 & Ghavamzadeh 2004 [42] & 0 & $29 / 29(100)$ & $2 / 24(8)$ & 24 / 24 (100) \\
\hline 13 & Gillio 1997 [43] & $17 / 25(68)$ & $3 / 25$ (12) & $23 / 23(100)$ & 0 \\
\hline 14 & Gluckman 1979 [44] & $10 / 37(27)$ & $9 / 37$ (24) & $28 / 28(100)$ & 0 \\
\hline 15 & Halperin 1989 [45] & $14 / 14(100)$ & $14 / 14(100)$ & $12 / 12(100)$ & 0 \\
\hline 16 & Kahn 2002 [46] & $8 / 15(53)$ & 0 & $16 / 16(100)$ & $16 / 16(100)$ \\
\hline 17 & Kim 2003 [47] & $17 / 22(77)$ & $2 / 22(9)$ & $74 / 74(100)$ & $17 / 74(23)$ \\
\hline 18 & Kojima 2000 [48] & $26 / 37(70)$ & $9 / 37(24)$ & 27 / 63 (43) & $2 / 63(3)$ \\
\hline 19 & Lawlor 1997 [49] & $2 / 9(22)$ & $1 / 9(11)$ & $18 / 18(100)$ & $15 / 18(83)$ \\
\hline 20 & Locasciulli 1990 [50] & $59 / 171(35)$ & $34 / 171(20)$ & $133 / 133(100)$ & 0 \\
\hline 21 & Locasciulli 2007 [51] & 282 / 1567 (18) & $319 / 1567(20)$ & $495 / 912(54)$ & 846 / 912 (93) \\
\hline \multirow[t]{2}{*}{22} & Paquette 1995 [52] & - & - & 1977-1983: 40 / $40(100)$ & 0 \\
\hline & & & & 1984-1989: 16 / 16 (100) & \\
\hline \multirow[t]{2}{*}{23} & Pitcher 1999 [53] & - & - & 1973-1988: 18 / $18(100)$ & 1973-1988: 0 \\
\hline & & & & 1989-1996: 25 / 25 (100) & 1989-1996: 14 / 25 (56) \\
\hline 24 & Tzeng 1989 [54] & $9 / 9(100)$ & 0 & $7 / 7$ (100) & 0 \\
\hline 25 & Viollier 2005 [55] & - & - & $155 / 155(100)$ & 0 \\
\hline 26 & Werner 1989 [56] & $2 / 6(33)$ & - & $8 / 9(89)$ & $2 / 9(22)$ \\
\hline
\end{tabular}

*Irradiation: conditioning irradiation: thoraco-abdominal irradiation, total body irradiation, or total lymphoid irradiation. Abbreviations: ALG: anti-lymphocyte globulin; ATG: anti-thymocyte globulin; CSA: cyclosporine A; HSCT: hematopoietic stem cell transplantation; IST: immunosuppressive therapy 


\section{Primary outcome: overall survival}

An overview of the overall survival is presented in Table 5. 5-year overall survival was reported in 17 studies (HSCT vs. IST: $32 \%-98 \%$ vs. 37\%-92\%). 5 studies reported a statistically significant difference of survival functions in favor of HSCT $[38,47,48,50,51]$ and 1 study in favor of IST [46]. 9 studies [31,33,35,40,42,43,49,54,55] did not find a statistically significant difference of survival functions and 11 studies did not report a significance test.

We included 19 studies (4,855 patients) [31,32,33,35,37,38,39,40,42,43,45,46,47, $48,49,50,51,54,55]$ in a meta-analysis on overall survival, which provided summary statistics required for estimating the hazard ratio. The pooled hazard ratio was statistically not significant and was characterized by a considerable heterogeneity indicated by an 12 value of $75 \%$ (Figure 2). A pooled estimate was not justified.

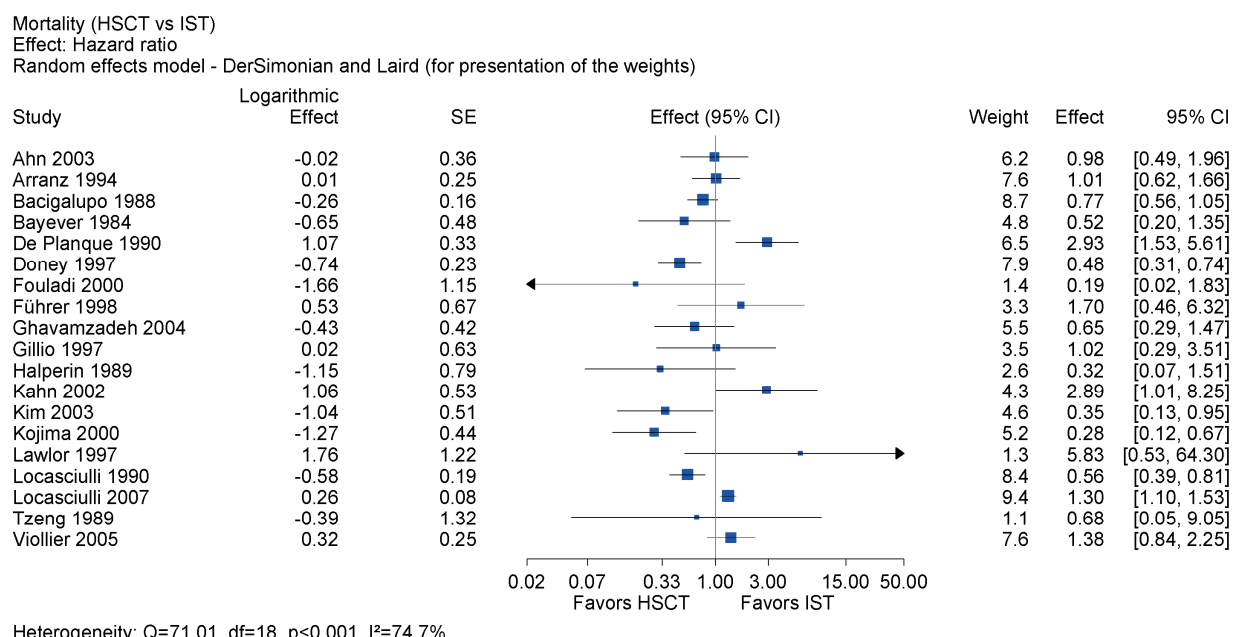

Heterogeneity: $Q=71.01, d f=18, p<0.001,\left.\right|^{2}=74.7 \%$

Figure 2. Meta-analysis of all studies with available data.

Meta-analysis of overall survival using hazard-ratio as effect measure after first-line HSCT vs. first-line IST. Pooled estimate not justified because of considerable heterogeneity and of not sufficient external validity. Abbreviations: HSCT: hematopoietic stem cell transplantation; IST: immunosuppressive therapy; SAA: severe aplastic anemia; SE: standard error. 


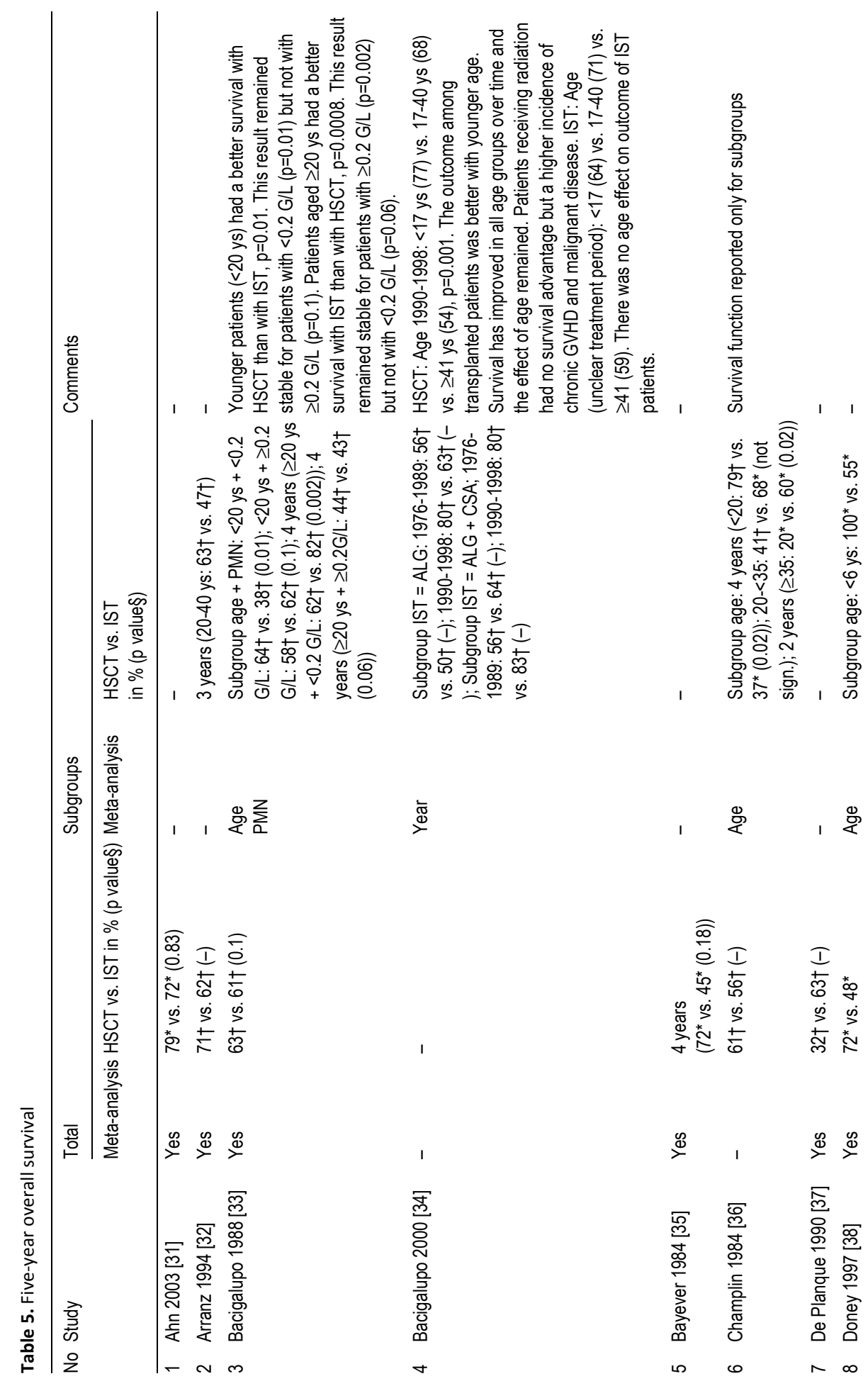




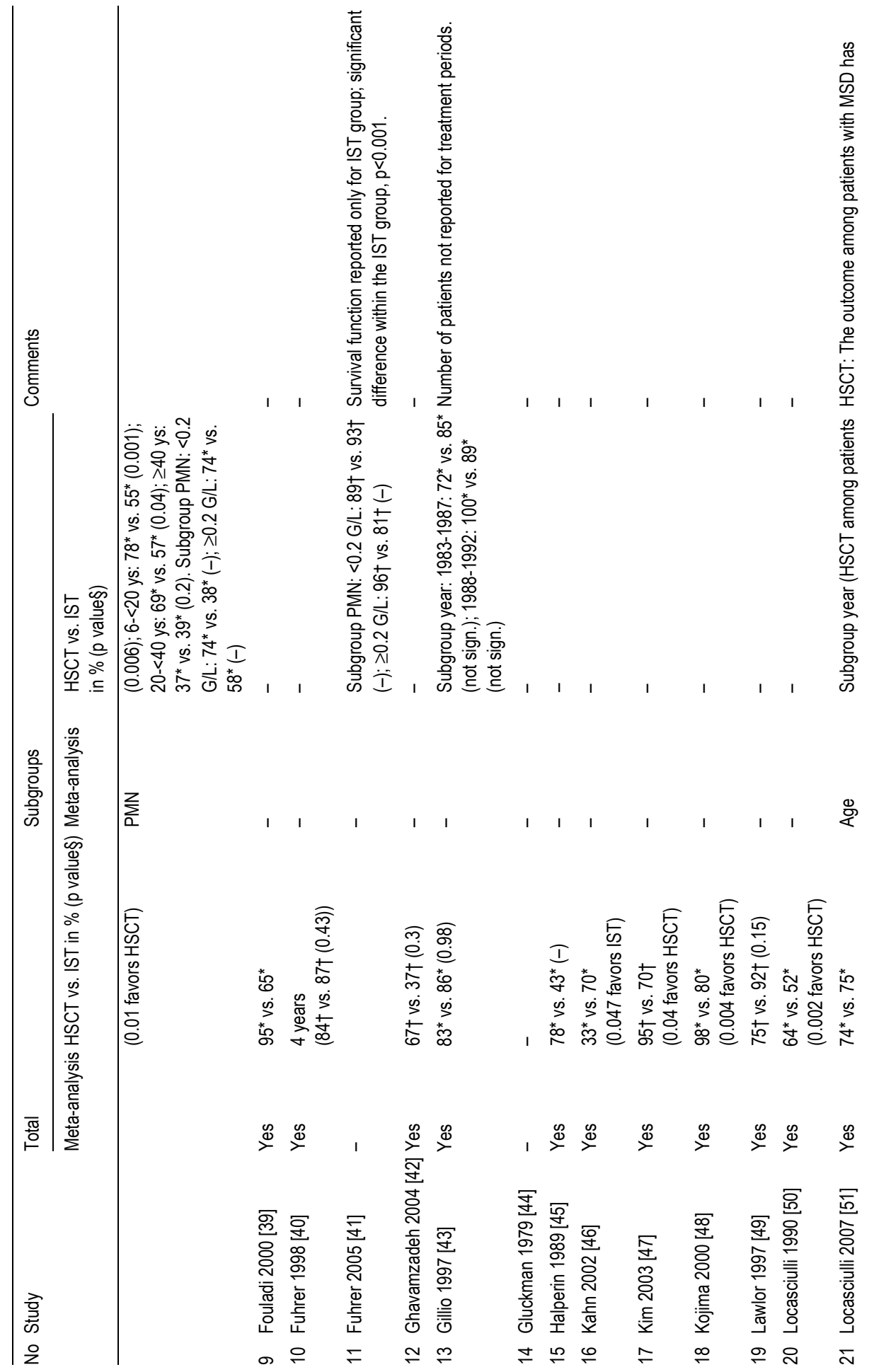




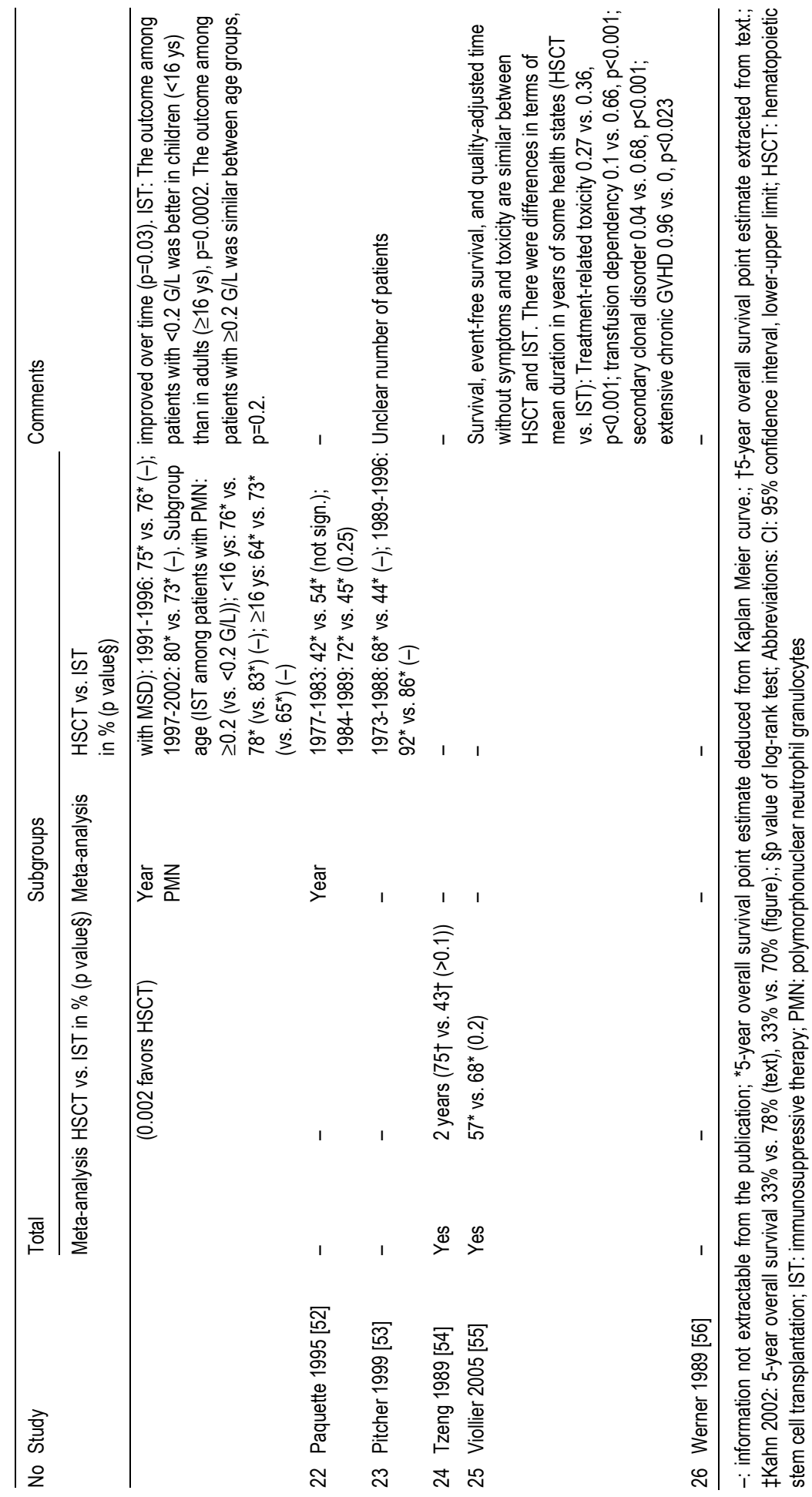




\section{Risk of bias}

Risk of bias within studies was high for 21 of 26 included studies mainly due to flaws of study design, assignment of patients to treatment groups, and missing control for confounding (Table 6). In 7 studies, an upper age limit was applied as additional assignment criteria.

Table 6. Risk of bias

\begin{tabular}{|c|c|c|c|c|c|c|}
\hline No Included studies & $\begin{array}{l}\text { Pros- } \\
\text { pective } \\
\text { design }\end{array}$ & $\begin{array}{l}\text { Concurrent } \\
\text { control }\end{array}$ & $\begin{array}{l}\text { No other assignment } \\
\text { criteria than MRD }\end{array}$ & $\begin{array}{l}\text { Control for } \\
\text { confounding } \\
\text { factors }^{\star}\end{array}$ & $\begin{array}{l}\text { No other risk of bias } \\
\text { factors } \dagger\end{array}$ & $\begin{array}{l}\text { Risk of } \\
\text { biasł }\end{array}$ \\
\hline 1 Ahn 2003 [31] & no & YES & YES & YES & YES & LOW \\
\hline 2 Arranz 1994 [32] & no & YES & no (age 40$) \S$ & no & YES & high \\
\hline 3 Bacigalupo 1988 [33] & no & YES & YES & YES & YES & LOW \\
\hline 4 Bacigalupo 2000 [34] & no & YES & YES & YES & YES & LOW \\
\hline 5 Bayever 1984 [35] & no & YES & YES & no & YES & high \\
\hline 6 Champlin 1984 [36] & no & YES & no (age 45$) \S$ & no & no (selection unclear) & ) high \\
\hline 7 De Planque 1990 [37] & no & YES & no (second-line) & no & YES & high \\
\hline 8 Doney 1997 [38] & no & YES & no (age 55)§ & no & YES & high \\
\hline 9 Fouladi 2000 [39] & no & YES & YES & no & YES & high \\
\hline 10 Fuhrer 1998 [40] & no & YES & YES & no & YES & high \\
\hline 11 Fuhrer 2005 [41] & YES & YES & YES & no & YES & high \\
\hline 12 Ghavamzadeh 2004 [42] & no & YES & no (age 45)§ & no & YES & high \\
\hline 13 Gillio 1997 [43] & no & YES & YES & no & YES & high \\
\hline 14 Gluckman 1979 [44] & no & YES & YES & no & no (5 in both groups) & high \\
\hline 15 Halperin 1989 [45] & no & YES & YES & no & YES & high \\
\hline 16 Kahn 2002 [46] & no & no & no (age 40)§ & no & YES & high \\
\hline 17 Kim 2003 [47] & no & YES & no (age 50$) \S$ & no & YES & high \\
\hline 18 Kojima 2000 [48] & no & YES & YES & no & YES & high \\
\hline 19 Lawlor 1997 [49] & no & YES & YES & no & YES & high \\
\hline 20 Locasciulli 1990 [50] & no & YES & YES & YES & YES & LOW \\
\hline 21 Locasciulli 2007 [51] & no & YES & no (alternate donor) & no & YES & high \\
\hline 22 Paquette 1995 [52] & no & YES & YES & no & no (selection unclear) & ) high \\
\hline 23 Pitcher 1999 [53] & no & YES & YES & no & YES & high \\
\hline 24 Tzeng 1989 [54] & no & YES & YES & no & YES & high \\
\hline 25 Viollier 2005 [55] & YES & YES & no (age 40)§ & no & YES & high \\
\hline 26 Werner 1989 [56] & no & YES & YES & no & YES & high \\
\hline
\end{tabular}

${ }^{*}$ Control for confounding factors; no: no adjusted analysis.

†No other risk of bias factors; no: selection of patients unclear; except Gluckman 1979: no: 5 patients with failed first-line IST followed by second-line HSCT were analyzed in both treatment groups.

$\ddagger$ Risk of bias: LOW required concurrent control group (YES), control for confounding factors (YES), and no other risk of bias factors (YES).

§Upper age limit in years.

Abbreviations: HSCT: hematopoietic stem cell transplantation; IST immunosuppressive therapy; MRD: HLA-matched related donor; PMN: polymorphonuclear neutrophil granulocytes 
The funnel plot of 19 studies included in meta-analysis shows no asymmetry (Figure 3), which may be consistent with absent publication bias. In 7 of 26 included studies, data of the primary outcome were not sufficiently reported to be included in the main meta-analysis.

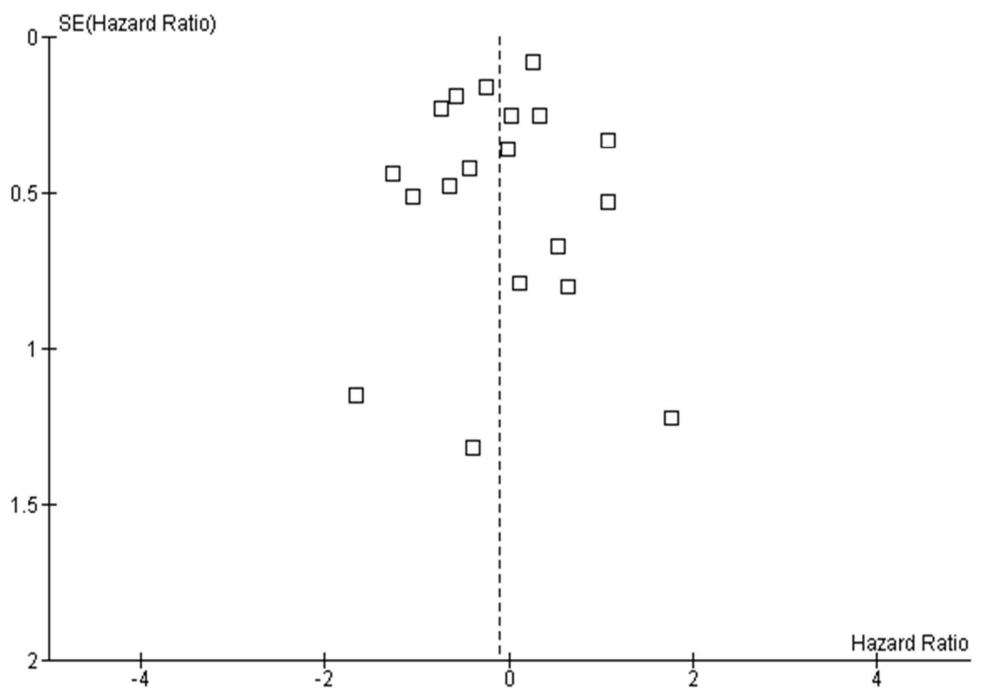

Figure 3. Funnel plot using data from Figure 2.

Distribution of estimates can be regarded as funnel-shaped and compatible with a moderate publication bias. Abbreviations: SE: standard error.

\section{Subgroup and sensitivity analysis}

The difference between the estimates was not statistically significant in both approaches and for all evaluated items, except for age, which was statistically significant in the evaluation of subgroups from individual studies and not statistically significant in the sensitivity analysis (Table 7).

\section{Factors for improved overall survival}

We evaluated patient characteristics that were evaluated in multivariate regression analyses (Table 8). 11 studies reported statistically significant factors for improved survival and 15 studies did not. Frequency of reporting the main factors, that is, age, year of transplant and type of IST is presented in Table 9.

Young age was identified as a statistically significant factor for improved overall survival for patients in the HSCT group in 5 studies. The results for patients in the IST group were less clear because advanced age was a favorable factor in 3 studies and 
young age a favorable factor in 2 studies. The actual age limit, which was used to dichotomize participants into young vs. advanced age varied across studies. Level of polymorphonuclear neutrophilic granulocytes (PMN) between $0.2 \mathrm{G} / \mathrm{L}$ and $0.5 \mathrm{G} / \mathrm{L}$

was found to be an important factor for improved survival after IST in 5 studies. Only 1 study found an advantage with less than $0.2 \mathrm{G} / \mathrm{L}$ in patients who were younger than 17 years. Recent year of treatment was an important factor for improved survival after HSCT in 4 studies and after IST in 1 study. Improvement of outcome over time was accompanied with treatment refinement, such as combination of methotrexate with CSA for GVHD prophylaxis and reduction of conditioning irradiation. Another example of improvement of outcome with treatment refinement is the combination of ALG and CSA instead of monotherapy of ALG. This combination was identified as factor for improved survival in 2 studies.

Table 7. Sensitivity analysis

\begin{tabular}{|c|c|c|c|c|}
\hline Characteristic & $\begin{array}{l}\text { Type of } \\
\text { analysis }\end{array}$ & Subgroups & Included studies & Statistics* \\
\hline Age & $\begin{array}{l}\text { Sensitivity } \\
\text { analysis }\end{array}$ & $\begin{array}{l}\text { Median age in HSCT or IST group } \\
\geq 18 \text { years vs. }<18 \text { years }\end{array}$ & $\begin{array}{l}{[32,38,46,47,51,54,55] \text { vs. }} \\
{[35,39,40,43,48,49]}\end{array}$ & $p=0.449$ \\
\hline Age & $\begin{array}{l}\text { Subgroups } \\
\text { in individual } \\
\text { studies }\end{array}$ & $\begin{array}{l}\text { Advanced vs. young age (various } \\
\text { definitions) }\end{array}$ & {$[33,36,38,51]$} & $p=0.040$ \\
\hline $\begin{array}{l}\text { Year of } \\
\text { treatment }\end{array}$ & $\begin{array}{l}\text { Sensitivity } \\
\text { analysis }\end{array}$ & $\begin{array}{l}\text { Center year of observation period } \\
\text { (HSCT or IST) } \geq 1995 \text { vs. }<1995\end{array}$ & $\begin{array}{l}{[31,42,50,31] \text { vs. }} \\
{[32,33,35,37,38,39,40,43,45,46,47,48,4} \\
9,54,55]\end{array}$ & $p=0.945$ \\
\hline $\begin{array}{l}\text { Year of } \\
\text { treatment }\end{array}$ & $\begin{array}{l}\text { Subgroups } \\
\text { in individual } \\
\text { studies }\end{array}$ & $\begin{array}{l}\text { Recent vs. early year of treatment } \\
\text { (various definitions) }\end{array}$ & {$[33,51,52]$} & $p=0.884$ \\
\hline $\begin{array}{l}\text { Severity of } \\
\text { disease }\end{array}$ & $\begin{array}{l}\text { Subgroups } \\
\text { in individual } \\
\text { studies }\end{array}$ & $\begin{array}{l}\text { high PMN (SAA without VSAA) vs. } \\
\text { low PMN (VSAA) }\end{array}$ & {$[33,38,51]$} & $p=0.086$ \\
\hline $\begin{array}{l}\text { Study } \\
\text { population }\end{array}$ & $\begin{array}{l}\text { Sensitivity } \\
\text { analysis }\end{array}$ & $\begin{array}{l}\text { Number of patients per study } \geq 100 \\
\text { vs. }<100\end{array}$ & $\begin{array}{l}{[31,33,38,40,48,50,51,55] \text { vs. }} \\
{[32,35,37,39,42,43,45,46,47,49,54]}\end{array}$ & $p=0.604$ \\
\hline $\begin{array}{l}\text { Time interval } \\
\text { HSCT }\end{array}$ & $\begin{array}{l}\text { Sensitivity } \\
\text { analysis }\end{array}$ & $\begin{array}{l}\text { Median interval from diagnosis to } \\
\text { HSCT } \geq 50 \text { days vs. }<50 \text { days }\end{array}$ & $\begin{array}{l}{[32,35,39,47,51,55] \text { vs. }} \\
{[38,40,43,45,46,48]}\end{array}$ & $p=0.809$ \\
\hline $\begin{array}{l}\text { Time interval } \\
\text { IST }\end{array}$ & $\begin{array}{l}\text { Sensitivity } \\
\text { analysis }\end{array}$ & $\begin{array}{l}\text { Median interval from diagnosis to } \\
\text { IST } \geq 50 \text { days vs. }<50 \text { days }\end{array}$ & $\begin{array}{l}{[32,35,47] \text { vs. }} \\
{[38,39,40,43,45,46,48,50,55]}\end{array}$ & $p=0.530$ \\
\hline Location & $\begin{array}{l}\text { Sensitivity } \\
\text { analysis }\end{array}$ & Multicenter study vs. single center & $\begin{array}{l}{[31,33,40,48,50,51] \text { vs. }} \\
{[32,35,37,38,39,42,43,45,46,47,49,54,5} \\
5]\end{array}$ & $p=0.474$ \\
\hline
\end{tabular}

*Statistics: test of interaction 
Table 8. Factors influencing overall survival with statistical significance

\begin{tabular}{|c|c|c|c|c|}
\hline No & Included studies & Characteristic & Favors HSCT & Favors IST \\
\hline 1 & Ahn 2003 [31] & $n / r$ & $\mathrm{n} / \mathrm{a}$ & $\mathrm{n} / \mathrm{a}$ \\
\hline 2 & Arranz 1994 [32] & $\mathrm{n} / \mathrm{r}$ & $\mathrm{n} / \mathrm{a}$ & $\mathrm{n} / \mathrm{a}$ \\
\hline \multirow[t]{2}{*}{3} & Bacigalupo 1988 [33] & Age (years) & $<20$ & $\geq 20$ \\
\hline & & PMN (G/L) & $<0.2$ & $0.2-<0.5$ \\
\hline \multirow[t]{3}{*}{4} & Bacigalupo 2000 [34] & Age (years) & $<17 ;<41$ & No effect \\
\hline & & Year of transplant & $\geq 1990$ & $n / r$ \\
\hline & & Type of IST & $n / a$ & $\begin{array}{l}A L G+C S A \text { (vs. ALG or CSA } \\
\text { alone) }\end{array}$ \\
\hline 5 & Bayever 1984 [35] & $n / r$ & $\mathrm{n} / \mathrm{a}$ & $\mathrm{n} / \mathrm{a}$ \\
\hline 6 & Champlin 1984 [36] & Age (years) & $<20$ & $\geq 20$ \\
\hline \multirow[t]{2}{*}{7} & De Planque 1990 [37] & Age (years) & No effect & $<45$ \\
\hline & & PMN (G/L) & No effect & $\geq 0.2$ \\
\hline \multirow[t]{2}{*}{8} & Doney 1997 [38] & Age (years) & $<40$ & - \\
\hline & & PMN (G/L) & No effect & $\geq 0.2$ \\
\hline 9 & Fouladi 2000 [39] & PMN (G/L) & No effect & $\geq 0.2$ \\
\hline 10 & Fuhrer 1998 [40] & $n / r$ & $\mathrm{n} / \mathrm{a}$ & $\mathrm{n} / \mathrm{a}$ \\
\hline 11 & Fuhrer 2005 [41] & PMN (G/L) & - & $\begin{array}{l}<0.2 \text { (among patients aged } 0 \\
\text { to } 17 \text { years) }\end{array}$ \\
\hline 12 & Ghavamzadeh 2004 [42] & $n / r$ & $\mathrm{n} / \mathrm{a}$ & $\mathrm{n} / \mathrm{a}$ \\
\hline 13 & Gillio 1997 [43] & $\mathrm{n} / \mathrm{r}$ & $\mathrm{n} / \mathrm{a}$ & $\mathrm{n} / \mathrm{a}$ \\
\hline 14 & Gluckman 1979 [44] & $n / r$ & $\mathrm{n} / \mathrm{a}$ & $\mathrm{n} / \mathrm{a}$ \\
\hline 15 & Halperin 1989 [45] & $\mathrm{n} / \mathrm{r}$ & $\mathrm{n} / \mathrm{a}$ & $\mathrm{n} / \mathrm{a}$ \\
\hline 16 & Kahn 2002 [46] & $n / r$ & $\mathrm{n} / \mathrm{a}$ & n/a \\
\hline 17 & Kim 2003 [47] & $n / r$ & $\mathrm{n} / \mathrm{a}$ & n/a \\
\hline 18 & Kojima 2000 [48] & $n / r$ & $\mathrm{n} / \mathrm{a}$ & $\mathrm{n} / \mathrm{a}$ \\
\hline 19 & Lawlor 1997 [49] & $n / r$ & $\mathrm{n} / \mathrm{a}$ & $\mathrm{n} / \mathrm{a}$ \\
\hline \multirow[t]{3}{*}{20} & Locasciulli 1990 [50] & Year of transplant & $\geq 1981$ & No effect \\
\hline & & Age (years) & No effect & $\begin{array}{l}\geq 6 \text { (among patients with PMN } \\
<0.2 \mathrm{G} / \mathrm{L} \text { ) }\end{array}$ \\
\hline & & PMN (G/L) & No effect & $\geq 0.2$ \\
\hline \multirow[t]{4}{*}{21} & Locasciulli 2007 [51] & Age (years) & $<16$ & $\begin{array}{l}<16 \text { (among patients with } \\
\mathrm{PMN}<0.2 \mathrm{G} / \mathrm{L} \text { ) }\end{array}$ \\
\hline & & Year of treatment & $\geq 1997$ & No effect \\
\hline & & Type of IST & $\mathrm{n} / \mathrm{a}$ & $A L G+C S A$ \\
\hline & & PMN (G/L) & $\mathrm{n} / \mathrm{r}$ & No effect \\
\hline 22 & Paquette 1995 [52] & $\mathrm{n} / \mathrm{r}$ & $\mathrm{n} / \mathrm{a}$ & $\mathrm{n} / \mathrm{a}$ \\
\hline 23 & Pitcher 1999 [53] & Year of transplant & $\geq 1989$ & $\geq 1989$ \\
\hline 24 & Tzeng 1989 [54] & $n / r$ & $\mathrm{n} / \mathrm{a}$ & n/a \\
\hline 25 & Viollier 2005 [55] & $\begin{array}{l}\text { Quality-adjusted time } \\
\text { without symptoms and } \\
\text { toxicity }\end{array}$ & $\begin{array}{l}\text { Treatment-related toxicity; } \\
\text { transfusion dependency; } \\
\text { secondary clonal disorder }\end{array}$ & Extensive chronic GVHD \\
\hline 26 & Werner 1989 [56] & $n / r$ & $\mathrm{n} / \mathrm{a}$ & n/a \\
\hline
\end{tabular}


-: information not extractable from the publication.

*5-year overall survival point estimate deduced from Kaplan Meier curve

$\lceil 5$-year overall survival point estimate extracted from text

¥Kahn 2002: 5 -year overall survival $33 \%$ vs. $78 \%$ (text), $33 \%$ vs. $70 \%$ (figure)

$\S p$ value of log-rank test

Abbreviations: ALG: anti-lymphocyte globulin; CSA: cyclosporine A; GVHD: graft-versus-host disease; HSCT: hematopoietic stem cell transplantation; IST: immunosuppressive therapy; n/a: not applicable; n/r: not reported; PMN: polymorphonuclear neutrophil granulocytes

Table 9. Frequency of reporting statistically significant factors of improved survival

\begin{tabular}{lll}
\hline Characteristic & HSCT & IST \\
\hline Age (years): young vs. advanced & $5[34,35,37,39,52]$ & $2[38,52]$ \\
Age (years): advanced vs. young & 0 & $3[34,37,51]$ \\
PMN (G/L): $<0.2$ vs. 0.2 to $<0.5$ & $1[34]$ & $1[42]$ \\
PMN (G/L): 0.2 to $<0.5$ vs. $<0.2$ & 0 & $5[34,38-40,51]$ \\
Year of treatment: recent vs. earlier period & $4[35,51,52,54]$ & $1[54]$ \\
Type of IST: ALG+CSA vs. ALG & n/a & $2[35,52]$ \\
\hline
\end{tabular}

Abbreviations: ALG: anti-lymphocyte globulin; CSA: cyclosporine A; HSCT: hematopoietic stem cell transplantation; IST: immunosuppressive therapy; n/a: not applicable; PMN: polymorphonuclear neutrophil granulocytes

\section{Secondary outcomes}

An overview of graft failure, GVHD, no response, and overall mortality is presented in Table 10. Graft failure (reported in 15 studies) ranged from $1 \%$ to $43 \%$, acute GVHD grade II to IV (reported in 16 studies) ranged from $0 \%$ to $88 \%$, and extensive chronic GVHD (reported in 10 studies) ranged from 3 to $27 \%$. No response to IST (extractable from 14 studies) ranged from $6 \%$ to $71 \%$. Overall mortality was reported in 23 studies (HSCT vs. IST: $3 \%-67 \%$ vs. $9 \%-58 \%$ ). 
Table 10. Adverse events: graft failure, GVHD, no response, overall mortality

\begin{tabular}{|c|c|c|c|c|c|c|}
\hline \multirow[t]{2}{*}{ No } & \multirow[t]{2}{*}{ Study } & \multicolumn{3}{|c|}{ HSCT; N. affected / N. evaluable (\%) } & \multirow{2}{*}{$\begin{array}{l}\text { IST; } \\
\text { N. affected / } \\
\text { N. evaluable (\%) } \\
\text { No response }\end{array}$} & \multirow{2}{*}{$\begin{array}{l}\text { HSCT vs. IST; } \\
\text { N. affected / } \\
\text { N. evaluable (\%) } \\
\text { Overall mortality }\end{array}$} \\
\hline & & $\begin{array}{l}\text { Any graft } \\
\text { failure }\end{array}$ & $\begin{array}{l}\text { Acute GVHD } \\
\text { grade II-IV }\end{array}$ & $\begin{array}{l}\text { Extensive chronic } \\
\text { GVHD }\end{array}$ & & \\
\hline$\overline{1}$ & Ahn 2003 [31] & $11 / 61(18)$ & $20 / 50(40)$ & $12 / 50(24)$ & - & 13 / 64 (20) vs. 37 / 156 (24) \\
\hline 2 & Arranz 1994 [32] & - & - & - & - & $9 / 71$ (13) vs. $8 / 62(13)$ \\
\hline 3 & Bacigalupo 1988 [33] & - & - & - & - & 87 / 218 (40) vs. 75 / 291 (26) \\
\hline 4 & Bacigalupo 2000 [34] & \multicolumn{2}{|c|}{$211 / 1759$ (12)228 / 1759 (13) } & $176 / 1759(10)$ & & $\begin{array}{l}611 / 1759 \text { (35) vs. } 540 / 1592 \\
(34)\end{array}$ \\
\hline 5 & Bayever 1984 [35] & $1 / 35(3)$ & 10 / $34(29)$ & $7 / 34(21)$ & 14 / $22(64)$ & $9 / 35$ (26) vs. 9 / 22 (41) \\
\hline 6 & Champlin 1984 [36] & $3 / 61(9)$ & $25 / 58(43)$ & $9 / 58$ (16) any type & 33 / $69(48)$ & 23 / 61 (38) vs. 26 / 69 (38) \\
\hline 7 & De Planque 1990 [37] & $3 / 19(16)$ & 14 / $16(88)$ & $3 / 11(27)$ & $16 / 82(20)$ & 8 / 19 (42) vs. 25 / 63 (40) \\
\hline 8 & Doney 1997 [38] & $18 / 168(11)$ & $46 / 150(31)$ & $26 / 150(17)$ & 122 / $227(54)$ & 50 / 168 (30) vs. 130 / 227 (57) \\
\hline 9 & Fouladi 2000 [39] & $1 / 21(5)$ & $3 / 20(15)$ & $1 / 20(5)$ & - & $1 / 21$ (5) vs. 6 / $20(30)$ \\
\hline 10 & Fuhrer 1998 [40] & - & - & - & - & 4 / 28 (14) vs. 8 / 86 (9) \\
\hline 11 & Fuhrer 2005 [41] & - & - & - & - & - \\
\hline 12 & \multicolumn{2}{|l|}{ Ghavamzadeh 2004 [42]- } & 14 / 29 (48) & - & 14 / $24(58)$ & 9 / 29 (31) vs. 14 / 24 (58) \\
\hline 13 & Gillio 1997 [43] & $1 / 25(4)$ & 2 / 25 (8) III-IV & $2 / 25(8)$ & 13 / $23(57)$ & 5 / 25 (20) vs. 5 / 23 (22) \\
\hline 14 & Gluckman 1979 [44] & 16 / $37(43)$ & $8 / 37(22)$ & - & 20 / $28(71)$ & 20 / 37 (54) vs. 14 / 29 (48) \\
\hline 15 & Halperin 1989 [45] & - & - & - & $1 / 12(8)$ & $3 / 14$ (21) vs. $7 / 12$ (58) \\
\hline 16 & Kahn $2002[46]$ & $3 / 15(20)$ & \multicolumn{2}{|c|}{$7 / 15$ (47) any type $1 / 15$ (7) any type } & $1 / 16(6)$ & 10 / 15 (67) vs. 5 / 16 (31) \\
\hline 17 & Kim 2003 [47] & $1 / 22(5)$ & $2 / 21(10)$ & $3 / 21(14)$ & $41 / 74(55)$ & 2 / 22 (9) vs. 20 / 74 (27) \\
\hline 18 & Kojima 2000 [48] & $1 / 37(3)$ & $2 / 36(6)$ & $1 / 36(3)$ & $31 / 63(49)$ & $1 / 37$ (3) vs. 21 / 63 (33) \\
\hline 19 & Lawlor 1997 [49] & $1 / 9(11)$ & $5 / 9(56)$ & $3 / 9$ (33) any type & $5 / 18(28)$ & $2 / 9$ (22) vs. 2 / $18(11)$ \\
\hline 20 & Locasciulli $1990[50]$ & - & - & - & - & 58 / 171 (34) vs. 57 / 133 (44) \\
\hline 21 & Locasciulli 2007 [51] & - & 42 / 1567 (3) any & - & - & $371 / 1567$ (24) vs. 228 / 912 (25) \\
\hline 22 & Paquette 1995 [52] & - & - & - & - & - \\
\hline 23 & Pitcher 1999 [53] & - & - & - & - & - \\
\hline 24 & Tzeng 1989 [54] & $2 / 9(22)$ & $0 / 9(0)$ & $2 / 9$ (22) any type & $4 / 7(57)$ & 2 / 9 (22) vs. 4 / 7 (57) \\
\hline 25 & Viollier 2005 [55] & $5 / 52(1)$ & - & 12 / $52(23)$ & $41 / 155(27)$ & 24 / 52 (46) vs. 61 / 155 (39) \\
\hline 26 & Werner 1989 [56] & - & - & - & - & $0 / 6(0)$ vs. $1 / 9(11)$ \\
\hline
\end{tabular}

-: information extractable from publication.

*Bayever 1984: acute GVHD including interstitial pneumonia; chronic GVHD including moderate or severe types. Abbreviations: GVHD: graft-versus-host disease; HSCT: hematopoietic stem cell transplantation; IST: immunosuppressive therapy

†Bacigalupo 2000: less acute GVHD with methotrexate plus cyclosporine A vs. methotrexate or cyclosporine A alone; incidence of acute GVHD III to IV has been reduced from $20 \%$ to $6 \%$ with time $(p<0.00001)$, however, survial for patients with acute GVHD >I has not improved with time; incidence of extensive chronic GVHD has been reduced from $15 \%$ to $5 \%$ with time $(p<0.00001)$, however, survival for patients with extensive chronic GVHD beyond day 100 after HSCT has not been improved with time.

Abbreviations: GVHD: graft-versus-host disease; HSCT: hematopoietic stem cell transplantation; IST: immunosuppressive therapy 


\section{Discussion}

\section{Primary outcome}

We found high risk of bias among 26 identified non-randomized controlled studies. Considerable heterogeneity of 19 studies included in a meta-analysis of overall survival did not justify a pooled estimate. The aim to compare the primary outcome between treatment groups in an overall synthesis of available data was not achieved. We were able to identify statistically significant factors for improved overall survival reported in the studies. Young age (rather than advanced age) and recent (rather than earlier) year of treatment were associated with a better overall survival in the HSCT group. Advanced age (rather than young age), SAA without VSAA (rather than VSAA), and combination of ALG and CSA (rather than ALG alone) were associated with a better overall survival in the IST group. While pooling data on overall survival of all participating patients did not appear sensible, we conducted sensitivity meta-analysis of subgroups to explain heterogeneity and of subgroups reported in individual studies. Unfortunately, these evaluations were hampered by the fact that individual patient data were not available and instead of that we relied on published aggregate data if reported. It should be mentioned that ALG is no longer available.

Although young age was recognized as a major influence factor on overall survival, the appropriate definition for young age varies considerably across studies. For example, the cut-off for young vs. advanced age was 16 years in the study of Bacigalupo 2008 [16], 30 years in the study of Ljungman 2009 [59], and 40 years in the study of Marsh 2009 [9].

Bacigalupo 2008 [16] reported that the outcome has improved since 1996 for HSCT but not for IST. This result was supported by 4 studies whereas 1 study did find an improvement for the IST group as well. Several factors may have contributed to recent improvements for HSCT, such as detailed HLA-matching, less irradiation-based conditioning, less acute GVHD with a prophylaxis combination of methotrexate plus CSA instead of methotrexate alone [34], refinement of the type and dosage of conditioning drugs, and general advancement of medical and nursing clinical science.

We found that a combination therapy of ALG plus CSA favored overall survival in the IST group, underscoring that refinement of therapy obviously has also improved the outcome with IST. Gafter-Gvili 2008 [60] concluded in a systematic review and metaanalysis that combination of ALG plus CSA should be considered the gold standard for IST for patients with SAA.

6 studies $[33,37,38,39,41,50]$ evaluated whether the disease severity of VSAA (PMN $<0.2 \mathrm{G} / \mathrm{L}$ ) vs. SAA (without VSAA; PMN 0.2 to $<0.5 \mathrm{G} / \mathrm{L}$ ) had an impact on overall survival. 5 studies $[33,37,38,39,50]$ consistently found that SAA without VSAA favored the outcome in IST group when compared to VSAA. 2 studies $[39,50]$ included only children and 3 studies $[33,37,38]$ included also adults. These results may suggest that 
HSCT may be the preferred treatment option for patients with VSAA and that IST may be the preferred option for patients with SAA without VSAA. However, Fuhrer 2005 [41] reported contradictory results that VSAA favored the outcome in IST group. The results may be relevant for children only because all analyzed patients were younger than 17 years of age. We did not find another study confirming the results, especially not in 2 studies mentioned above.

We believe that this is the first comprehensive systematic review and meta-analysis about studies comparing first-line HSCT versus first-line IST in patients with SAA.

\section{Secondary outcomes}

Studies inconsistently reported adverse events and their frequencies varied significantly across studies. Graft failure was highest in early studies but could affect up to $18 \%$ of patients in recent studies. Rates for acute GVHD grade III to IV reached up to $40 \%$ and for extensive chronic GVHD reached up to $24 \%$ in recent studies. A considerable number of patients not responding to IST may indicate the importance of unrelated donor transplantation.

\section{Duplicate publication bias}

Identical data may have been included twice in the present systematic review. We searched for follow-up papers of a single study to include the update version and exclude former presentations. Register analyses can provide results based on a large number of patients but registers may use data that may have been published previously by the contributing study centers. We identified 5 studies published on behalf of the EBMT [33,34,50,51] which are probably based on overlapping data. Locasciulli 2007 [51] presented an update of the EBMT data and, therefore, investigated considerably more patients (2,479 patients) than Locasciulli 1990 [50] (304 patients). The courses of the survival functions are clearly different between the 2 studies. In Locasciulli 1990 [50] (Figure 1 of the article), in the majority of the follow-up period the course of the Kaplan-Meier curve after HSCT is above that after IST (congruent in the first 12 months), indicating an advantage from HSCT. In Locasciulli 2007 [51] (Figure 1 of the article), in the majority of the follow-up period the course of the Kaplan-Meier curve after HSCT is below that after IST (in the first 60 months). Only at the very end of the follow-up period (from 100 to 120 months) is the HSCT curve above the IST curve. The difference between the 2 survival functions was assessed by a log-rank test. The authors stated that 10-year survival was significantly superior in patients treated with BMT than in those in whom immunosuppression was used $(73 \%$ versus $68 \%$, $p=0.002$ ). On the contrary, we are convinced that the survival functions clearly show that IST was statistically significantly better than HSCT. Our interpretation of the results is supported by Linden 2007 [61], who addressed the specific problem of inter- 
preting the crossing of the survival functions using Locasciulli 2007 [51] as an example. Locasciulli 1990 [50] clearly reported that only data from SAA patient were included. In contrast, Locasciulli 2007 [51] included a considerable proportion of patients with moderate aplastic anemia or with unknown severity of disease. A study population with different patients' characteristics with respect to disease severity might have contributed to the different results. Medical advancement after a time difference of 17 years between publication dates of both studies might have had a greater impact on improved survival after HSCT than on survival after IST.

\section{Outcome reporting bias}

Outcome reporting bias [62] is defined as the selection of a subset of the originally recorded outcome variables for publication. Systematic reviews need to address the issue of missing outcome data because outcome reporting bias can affect their conclusions [63]. We identified considerable outcome reporting bias. A major flaw of all studies was the lack of statistical summary data such as standard error or confidence interval for point estimates and $p$ values of logrank test. To pool as many studies as possible, we estimated the hazard ratio. The number of patients at risk was scarcely reported.

\section{Study publication bias}

Study publication bias is defined as publication of research results depending on their results [64]. Funnel plots of both reported meta-analyses show moderate asymmetry and do not indicate considerable publication bias. The strengths of the present systematic review are the broadness of the search strategy and the comprehensiveness of the published data included. Nevertheless, there may be a slight possibility that an unknown number of studies were not registered and not published.

\section{Language bias}

Results in English language articles could be different from those of articles written in other languages [65]. Non-English language articles require expensive translations to prevent selective outcome extraction and misinterpretation of results. Funding for translation was not provided and we excluded all non-English language articles, including German articles. Restricting the inclusion of studies to English articles may have little effect on summary treatment effect estimates [66,67] and German language articles may not play a preeminent role in the dissemination of medical research [68]. 


\section{Internal validity}

We identified a high risk of bias within all non-randomized controlled studies except for 4 studies. Assignment of patients to treatment groups was reported to be based on availability of MRD in all 26 studies, although, in 7 studies an upper age limit was applied as additional assignment criteria. This type of allocation has specific requirements, such as allelic vs. serologic typing, number of analyzed loci, time spent searching for donors, documentation of all individuals analyzed including families of IST patients, number of analyzed individuals per family, intent-totreat analysis. However, these requirements were not reported in the included studies.

\section{Heterogeneity}

We included as many controlled studies as possible in order to not miss any valuable outcome information. Consequently, we accepted studies that considered a considerable number of patients with moderate aplastic anemia or unknown disease severity. Pooling of data from patients with varying characteristics may have compromised the generalizability of results. Furthermore, important subgroups such as young and advanced age were confused in the meta-analysis.

In an attempt to reduce heterogeneity we strictly confined the meta-analysis to studies that clearly included at least $80 \%$ of patients with SAA and first-line treatment (data not shown). We found a moderate heterogeneity and a statistically significant pooled estimate that favored HSCT. Many studies including large and recently published ones were excluded. The result suggested a global preference for one treatment disregarding conditions other than the treatment that might have a determined impact on the outcome. We believe that this procedure would have introduced a study selection bias and a misleading conclusion and was therefore not pursued.

\section{Strengths and limitations of the present review}

The strengths of this review are the broadness of the search strategy and the comprehensiveness of the published data included. Significant factors that may influence the survival of the patients were considered in the present systematic review. We estimated hazard ratios from published aggregate survival functions and did not use individual patient data. Subgroup analysis was not helpful to explain considerable heterogeneity found in meta-analysis. While the results of the meta-analysis may not be conclusive, they can provide useful summaries of the state of knowledge. 


\section{Conclusions}

Young age and recent year of treatment were identified as factors for improved survival in the transplant group. Advanced age, SAA without very severe aplastic anemia, and combination of anti-lymphocyte globulin with cyclosporine $A$ were factors for improved survival in the immunosuppressive group. Considerable heterogeneity of non-randomized controlled studies did not justify a pooled estimate. Adverse events were inconsistently reported and varied significantly across studies. 


\section{References}

1. Office of Rare Diseases Terms: Aplastic anemia. Bethesda: National Institutes of Health; 2010.

2. Kaufman DW, Kelly JP, Issaragrisil S, Laporte JR, Anderson T, Levy M, et al. Relative incidence of agranulocytosis and aplastic anemia. American Journal of Hematology. 2006;81(1):65-7.

3. Brodsky RA, Jones RJ. Aplastic anaemia. The Lancet. 2005;365(9471):1647-56.

4. Young NS, Calado RT, Scheinberg P. Current concepts in the pathophysiology and treatment of aplastic anemia. Blood. 2006;108(8): 2509-19.

5. EBMT-AAWP. Guidelines for treating of aplastic anemia. London: European Group for Blood and Marrow Transplantation (EBMT) Aplastic Anaemia Working Party (AAWP); 2000.

6. Ljungman P, Urbano-Ispizua A, Cavazzana-Calvo M, Demirer T, Dini G, Einsele $H$, et al. Allogeneic and autologous transplantation for haematological diseases, solid tumours and immune disorders: Definitions and current practice in Europe. Bone Marrow Transplantation. 2006;37(5):439-49.

7. Marsh J (2006) Making therapeutic decisions in adults with aplastic anemia. American Society of Hematology Education Program. 2006:78-85.

8. Guinan EC (2009) Acquired aplastic anemia in childhood. Hematology/Oncology Clinics of North America. 2009;23(2):171-91.

9. Marsh JCW, Ball SE, Cavenagh J, Darbyshire P, Dokal I, Gordon-Smith EC, et al. Guidelines for the diagnosis and management of aplastic anaemia. British Journal of Haematology. 2009;147(1): 43-70.

10. Moher D, Liberati A, Tetzlaff J, Altman DG (2009) Preferred reporting items for systematic reviews and meta-analyses: the PRISMA statement. PLoS Medicine. 2009;6(7):e1000097.

11. Liberati A, Altman DG, Tetzlaff J, Mulrow C, Gotzsche PC, loannidids JP, et al. The PRISMA statement for reporting systematic reviews and meta-analyses of studies that evaluate health care interventions: explanation and elaboration. PLoS Medicine. 2009;6(7):e1000100.

12. The Cochrane Collaboration. Glossary of Terms (Version 4.2.5). The Cochrane Collaboration; 2005.

13. National Library of Medicine. MeSH Tree Number Changes - 2007 MeSH. September 14, 2006. Bone Marrorw Transplantation, deleted MN: E4.936.225.687.155. Bethesda: National Library of Medicine; 2006.

14. Tybaert S. MeSH Data Changes - 2008. National Library of Medicine Technical Bulletin. 2007;(359):e6.

15. Armand $\mathrm{P}$, Antin JH. Allogeneic stem cell transplantation for aplastic anemia. Biology of Blood and Marrow Transplantation. 2007;13(5):505-16.

16. Bacigalupo A. Treatment strategies for patients with severe aplastic anemia. Bone Marrow Transplantation. 2008;42 Suppl 1:S42-S44.

17. Davies JK, Guinan EC. An update on the management of severe idiopathic aplastic anaemia in children. British Journal of Haematology. 136(4):549-64.

18. Bloodjournal of the American Society of Hematology, ASH Annual Meeting Abstracts: search terms = aplastic + anemia + transplantation. Washington: American Society of Hematology; 2010.

19. ClinicalTrials.gov: search terms $=$ aplastic + anemia + transplantation. Bethesda: National Institutes of Health; 2010.

20. Schrezenmeier H, Bacigalupo A, Aglietta M, Frickhofen N, Fuhrer M, Gluckman E, et al. Guidelines for Treatment of Aplastic Anemia. Consensus Document of a group of interntional experts. In: Schrezenmeier H, Bacigalupo A, editors. Aplastic Anemia Pathophysiology and Treatment. Cambridge: Cambridge University Press; 2000. pp. 308-315.

21. Reeves BC, Deeks JJ, Higgins JPT, Wells GA. Section 13.5: Assessing risk of bias in non-randomized studies. Chapter 13: Including non-randomized studies. In: Higgins JPT, Green S (editors), Cochrane Handbook for Systematic Reviews of Interventions Version 5.0.1 (updated September 2008). The Cochrane Collaboration; 2008.

22. Parmar MK, Torri V, Stewart L. Extracting summary statistics to perform meta-analyses of the published literature for survival endpoints. Statistics in Medicine. 1998;17(24):2815-34. 
23. Tierney JF, Stewart LA, Ghersi D, Burdett S, Sydes MR. Practical methods for incorporating summary time-to-event data into meta-analysis. Trials. 2007;8:16.

24. Deeks JJ, Higgins JPT, Altman DG. Section 9.4.3: A generic inverse-variance approach to meta- analysis. Chapter 9: Analysing data and undertaking meta-analyses. In: Higgins JPT, Green S (editors). Cochrane Handbook for Systematic Reviews of Interventions Version 5.0.1 (updated September 2008). The Cochrane Collaboration; 2008.

25. Higgins JPT, Deeks JJ (editors). Section 7.7.7: Data extraction for estimates of effects. Chapter 7: Selecting studies and collecting data. In: Higgins JPT, Green S (editors), Cochrane Handbook for Systematic Reviews of Interventions Version 5.0.1 (updated September 2008). The Cochrane Collaboration; 2008.

26. DerSimonian R, Laird N. Meta-analysis in clinical trials. Controlled Clinical Trials. 1986;7(3):177-88.

27. Higgins JPT, Thompson SG, Deeks JJ, Altman DG. Measuring inconsistency in meta-analyses. BMJ. 2003;327(7414):557-60.

28. Reeves BC, Deeks JJ, Higgins JPT, Wells GA. Section 13.6.2.4: When pooling is judged not to be appropriate. Chapter 13: Including non-randomized studies. In: Higgins JPT, Green S (editors), Cochrane Handbook for Systematic Reviews of Interventions Version 5.0.1 (updated September 2008). The Cochrane Collaboration; 2008.

29. Deeks JJ, Higgins JPT, Altman DG. Section 9.5.2: Identifying and measuring heterogeneity. Chapter 9: Analysing data and undertaking meta-analyses. In: Higgins JPT, Green S (editors). Cochrane Handbook for Systematic Reviews of Interventions Version 5.0.1 (updated September 2008). The Cochrane Collaboration; 2008.

30. Thompson SG, Higgins JP. How should meta-regression analyses be undertaken and interpreted? Statistis in Medicine. 21(11):1559-73.

31. Ahn MJ, Choi JH, Lee YY, Choi IY, Kim IS, Yoon SS, et al. Outcome of adult severe or very severe aplastic anemia treated with immunosuppressive therapy compared with bone marrow transplantation: multicenter trial. International Journal of Hematology. 2003;78(2):133-8.

32. Arranz R, Otero MJ, Ramos R, Steegmann JL, Lamana ML, Tomas JF, et al. Clinical results in 50 multiply transfused patients with severe aplastic anemia treated with bone marrow transplantation or immunosuppressive therapy. Bone Marrow Transplantation. 1994;13(4):383-7.

33. Bacigalupo A, Hows J, Gluckman E, Nissen C, Marsh J, Van Lint MT, et al. Bone marrow transplantation (BMT) versus immunosuppression for the treatment of severe aplastic anaemia (SAA): a report of the EBMT SAA working party. British Journal of Haematology. 1988;70(2):177-82.

34. Bacigalupo A, Brand R, Oneto R, Bruno B, Socie G, Passweg J, et al. Treatment of acquired severe aplastic anemia: bone marrow transplantation compared with immunosuppressive therapy--The European Group for Blood and Marrow Transplantation experience. Seminars in Hematology. 2000;37(1):69-80.

35. Bayever E, Champlin R, Ho W, Lenarsky C, Storch S, Ladisch S, et al. Comparison between bone marrow transplantation and antithymocyte globulin in treatment of young patients with severe aplastic anemia. Journal of Pediatrics. 1984;105(6):920-5.

36. Champlin R, Ho W, Bayever E, Winston DJ, Lenarsky C, Feig SA, et al. Treatment of aplastic anemia: results with bone marrow transplantation, antithymocyte globulin, and a monoclonal anti-T cell antibody. Progress in Clinical and Biological Research. 1984;148:227-38.

37. De Planque MM, Richel DJ, Fibbe WE, den Ottolander GJ, Guiot HF, Zwaan FE. Acquired severe aplastic anaemia in adults--a single centre study with 13 years follow-up. The Netherlands Journal of Medicine. 1990;37(3-4):103-10.

38. Doney K, Leisenring W, Storb R, Appelbaum FR. Primary treatment of acquired aplastic anemia: outcomes with bone marrow transplantation and immunosuppressive therapy. Seattle Bone Marrow Transplant Team. Annals of Internal Medicine. 1997;126(2):107-15.

39. Fouladi M, Herman R, Rolland-Grinton M, Jones-Wallace D, Blanchette V, Calderwood S, et al. Improved survival in severe acquired aplastic anemia of childhood. Bone Marrow Transplantation. 2000;26(11):1149-56. 
40. Fuhrer M, Burdach S, Ebell W, Gadner H, Haas R, Harbott J, et al. Relapse and clonal disease in children with aplastic anemia (AA) after immunosuppressive therapy (IST): the SAA 94 experience. German/Austrian Pediatric Aplastic Anemia Working Group. Klinische Padiatrie. 1998;210(4):173-9.

41. Fuhrer M, Rampf U, Baumann I, Faldum A, Niemeyer C, Janka-Schaub G, et al. Immunosuppressive therapy for aplastic anemia in children: a more severe disease predicts better survival. Blood. 2005;106(6):2102-4.

42. Ghavamzadeh A, Iravani M, Vafaiezadeh F, Jahani M, Mousavi A. Bone marrow transplantation versus immunosuppressive therapy in severe aplastic anemia, 1990 - 2001. Archives of Iranian Medicine. 2004;7(4):272-8.

43. Gillio AP, Boulad F, Small TN, Kernan NA, Reyes B, Childs BH, et al. Comparison of long-term outcome of children with severe aplastic anemia treated with immunosuppression versus bone marrow transplantation. Biology of Blood and Marrow Transplantation. 1997;3(1):18-24.

44. Gluckman E, Devergie A, Faille A, Bussel A, Benbunan M, Bernard J. Antilymphocyte globulin treatment in severe aplastic anemia--comparison with bone marrow transplantation. Report of 60 cases. Haematology and Blood Transfusion. 1979;24:171-9.

45. Halperin DS, Grisaru D, Freedman MH, Saunders EF. Severe acquired aplastic anemia in children: 11-year experience with bone marrow transplantation and immunosuppressive therapy. The American Journal of Pediatric Hematology/Oncology. 1989;11(3):304-9.

46. Ellis RJ, Kahn Q, Skikne BS, Mayo MS, Allgood JW, Bodensteiner DM, et al. A retrospective analysis of long-term survival in severe aplastic anemia patients treated with allogeneic bone marrow transplantation or immunosuppressive therapy with antithymocyte globulin and cyclosporin $A$ at a single institution. Military Medicine: 2002;167(7):541-5.

47. Kim I, Yoon SS, Park S, Kim BK, Kim NK. The treatment of severe aplastic anemia: outcomes of bone marrow transplantation and immunosuppressive therapy in a single institution of Korea. Journal of Korean Medical Science. 2003;18(3):365-71.

48. Kojima S, Horibe K, Inaba J, Yoshimi A, Takahashi Y, Kudo K, et al. Long-term outcome of acquired aplastic anaemia in children: comparison between immunosuppressive therapy and bone marrow transplantation. British Journal of Haematology. 2000;111(1):321-8.

49. Lawlor ER, Anderson RA, Davis JH, Fryer CJ, Pritchard SL, Rogers PC, et al. Immunosuppressive therapy: a potential alternative to bone marrow transplantation as initial therapy for acquired severe aplastic anemia in childhood? Journal of Pediatric Hematology/Oncology. 1997;19(2):115-23.

50. Locasciulli A, van't Veer L, Bacigalupo A, Hows J, Van Lint MT, Gluckman E, et al. Treatment with marrow transplantation or immunosuppression of childhood acquired severe aplastic anemia: a report from the EBMT SAA Working Party. Bone Marrow Transplantation. 1990;6(3):211-7.

51. Locasciulli A, Oneto R, Bacigalupo A, Socie G, Korthof E, Bekassy A, et al. Outcome of patients with acquired aplastic anemia given first line bone marrow transplantation or immunosuppressive treatment in the last decade: a report from the European Group for Blood and Marrow Transplantation (EBMT). Haematologica. 2007;92(1):11-8.

52. Paquette RL, Tebyani N, Frane M, Ireland P, Ho WG, Champlin E, et al. Long-term outcome of aplastic anemia in adults treated with antithymocyte globulin: comparison with bone marrow transplantation. Blood. 1995;85(1):283-90.

53. Pitcher LA, Hann IM, Evans JP, Veys P, Chessells JM, Webb DK. Improved prognosis for acquired aplastic anaemia. Archives of Disease in Childhood. 1999;80(2):158-62.

54. Tzeng CH, Chen PM, Chuang MW, Liu JH, Hsieh RK, Liu CJ, et al. Treatment of severe aplastic anemia: comparison of bone marrow transplantation to immunotherapy. Zhonghua yi xue za zhi = Chinese Medical Journal. 1989;43(1):21-8.

55. Viollier R, Passweg J, Gregor M, Favre G, Kuhne T, Nissen C, et al. Quality-adjusted survival analysis shows differences in outcome after immunosuppression or bone marrow transplantation in aplastic anemia. Annals of Hematology. 2005;84(1):47-55.

56. Werner EJ, Stout RD, Valdez LP, Harris RE. Immunosuppressive therapy versus bone marrow transplantation for children with aplastic anemia. Pediatrics. 1989;83(1):61-5. 
57. Gray R, Wheatley K. How to avoid bias when comparing bone marrow transplantation with chemotherapy. Bone Marrow Transplantation. 1991;7 Suppl 3:9-12.

58. Wheatley K, Gray R. Commentary: Mendelian randomization--an update on its use to evaluate allogeneic stem cell transplantation in leukaemia. International Journal of Epidemiology. 2004;33(1):15-7.

59. Ljungman P, Bregni M, Brune M, Cornelissen J, de Witte T, Dini G, et al. Allogeneic and autologous transplantation for haematological diseases, solid tumours and immune disorders: current practice in Europe 2009. Bone Marrow Transplantation. 2010;45(2):219-34.

60. Gafter-Gvili A, Ram R, Gurion R, Paul M, Yeshurun M, Raanani P, et al. ATG plus cyclosporine reduces allcause mortality in patients with severe aplastic anemia--systematic review and meta-analysis. Acta Haematologica. 2008;120(4):237-43.

61. Linden T, Gerss J, Jurgens H. The crux of the log rank test. Haematologica. 2007;92(12):e122.

62. Chan AW, Hrobjartsson A, Haahr MT, Gotzsche PC, Altman DG. Empirical evidence for selective reporting of outcomes in randomized trials: comparison of protocols to published articles. Journa of the American Medical Association. 2004;291(20):2457-65.

63. Kirkham JJ, Dwan KM, Altman DG, Gamble C, Dodd S, Smyth R, et al. The impact of outcome reporting bias in randomised controlled trials on a cohort of systematic reviews. BMJ. 2010;340:c365.

64. Song F, Eastwood AJ, Gilbody S, Duley L, Sutton AJ. Publication and related biases. Health Technol Assessment. 2000;4(10):1-115.

65. Egger $M$, Zellweger-Zahner $\mathrm{T}$, Schneider $\mathrm{M}$, Junker $\mathrm{C}$, Lengeler $\mathrm{C}$, Antes $\mathrm{G}$. Language bias in randomised controlled trials published in English and German. The Lancet. 1997;350(9074):326-9.

66. Juni P, Holenstein F, Sterne J, Bartlett C, Egger M. Direction and impact of language bias in metaanalyses of controlled trials: empirical study. International Journal of Epidemiology. 2002;31(1):115-23.

67. Moher D, Pham B, Lawson ML, Klassen TP. The inclusion of reports of randomised trials published in languages other than English in systematic reviews. Health Technol Assessment. 2003;7(41):1-90.

68. Galandi D, Schwarzer G, Antes G. The demise of the randomised controlled trial: bibliometric study of the German-language health care literature, 1948 to 2004. BMC Medical Research Methodology. 2006;6:30.

69. Webb DK, Hann IM, Chessells JM. Acquired aplastic anaemia: still a serious disease. Archives of Disease in Childhood. 1991;66(7):858-61.

70. Nissen C, Tichelli A, Gratwohl A, Warthmann C, Moser Y, dalle Carbonare V, et al. High incidence of transiently appearing complement-sensitive bone marrow precursor cells in patients with severe aplastic anemia--A possible role of high endogenous IL-2 in their suppression. Acta Haematologica. 1999;101(4):165-72.

71. Speck R, Tichelli A, Gratwohl A, Nissen C. Treatment of severe aplastic anemia: A longterm followup of 175 patients on antilymphocyte globulin or bone marrow transplantation. Chinese Medical Journal. 1994;107(10):739.

72. Tichelli A, Gratwohl A, Wursch A, Nissen C, Speck B. Late haematological complications in severe aplastic anaemia. British Journal of Haematology. 1988;69: 413-8.

73. Speck B, Gratwohl A, Nissen C, Osterwalder B, Wursch A, Tichelli. Treatment of severe aplastic anemia. Experimental Hematology. 1986;14:126-32.

74. Speck B, Gratwohl A, Nissen C, Osterwalder B, Signer E, Jeannet M. Treatment of severe aplastic anemia: a prospective study of antilymphocyte globulin versus bone marrow transplantation. Progress in Clinical and Biological Research. 1984;148:249-58.

75. Speck B, Gratwohl A, Nissen C, Osterwalder B, Signer E, Jeannet M. Bone marrow graft versus ALG in patients with aplastic anaemia. Biomedicine and Pharmacotherapy. 1983;37:139-43.

76. Speck B, Gratwohl A, Nissen C, Leibundgut U, Ruggero D, Osterwalder B, et al. Treatment of severe aplastic anaemia with antilymphocyte globulin or bone-marrow transplantation. British Medical Journal. 1981;282:860-3. 
77. Speck B, Gratwohl A, Nissen C, Ruggero D, Cornu P, Burri HP. Severe aplastic anemia: a prospective study on the value of different therapeutic approaches in 37 successive patients. Proceedings of the Annual Meeting of the European Foundation for Bone Marrow Transplantation, Sils Maria (Engadine), Switzerland, 13-16 April 1980. Blut. 1980;41:160-3.

78. Speck B, Gluckman E, Haak HL, van Rood JJ. Treatment of aplastic anaemia by antilymphocyte globulin with and without allogeneic bone-marrow infusions. The Lancet. 1977;2(8049):1145-8. 


\section{CHAPTER 5}

Permanent interstitial low-dose-rate brachytherapy for patients with localised prostate cancer: a systematic review of randomised and nonrandomised controlled clinical trials

Peinemann F, Grouven U, Bartel C, Sauerland S, Borchers H, Pinkawa M, Heidenreich A, Lange S. Permanent interstitial low-dose-rate brachytherapy for patients with localised prostate cancer: a systematic review of randomised and nonrandomised controlled clinical trials. European Urology. 2011;60(5):881-93. 


\section{Abstract}

Context Prostate cancer (PCa) is the most common cancer in men. Permanent interstitial low-dose-rate brachytherapy (LDR-BT) is a short-distance radiation therapy in which low-energy radioactive sources are implanted permanently into the prostate.

Objective To assess the effectiveness and safety of LDR-BT compared to treatment alternatives in men with localised PCa.

Evidence acquisition Bibliographic databases (Medline, Embase, and the Cochrane Library) were searched from inception until June $\mathbf{2 0 1 0}$ for randomised and nonrandomised controlled trials comparing LDR-BT with radical prostatectomy (RP), externalbeam radiation therapy (EBRT), or no primary therapy (NPT). Primary outcome was overall survival (OS). Secondary outcomes were disease-free survival (DFS), biochemical recurrence-free survival (bRFS), physician-reported severe adverse events (SAE), and patient-reported outcomes (PRO).

Evidence synthesis A total of 31 studies, including 1 randomised controlled trial (RCT), were identified. Risk of bias was high for all 31 studies. OS was reported in one nonrandomised controlled study; however, these data were not interpretable because of strong residual confounding. DFS was not reported. Comparison of bRFS between treatment groups is not validated; thus, results were not interpretable. Physicianreported urogenital late toxicity grade 2 to 3 was more common in the LDR-BT group when compared to the EBRT group. With respect to PRO, better scores for sexual and urinary function as well as urinary incontinence were reported for LDR-BT compared to RP. Better scores for bowel function were reported for LDR-BT compared to EBRT.

Conclusions We found a low amount of evidence in studies that exclusively compared LDR-BT with other treatment modalities. LDR-BT may have some different physician-reported SAE and patient-reported outcomes. The current evidence is insufficient to allow a definitive conclusion about OS. Randomised trials focusing on long-term survival are needed to clarify the relevance of LDR-BT in patients with localised PCa. 


\section{Introduction}

Localised prostate cancer (PCa) is defined by the categories T1 to T2 of the TNM staging system [1] if combined with an absence of both regional lymph node metastasis (NO) and distant metastasis (MO). The European Association of Urology suggested four different treatment concepts for localised PCa [2].

Brachytherapy [2] is short-distance radiation therapy (RT) that places radiation sources with different durations and rates of dose delivery in or near tumours [3]. Permanent interstitial low-dose rate brachytherapy (LDR-BT) refers to implanting lowenergy radioactive sources that emit radiation at a rate $<2 \mathrm{~Gy} / \mathrm{h}$ [4]. The radioisotopes iodine 125 or palladium-103 are contained in titanium pellets of the size of rice grains, which are called seeds. Sixty to 100 seeds are typically inserted into the prostate through a transperineal route guided by transrectal ultrasound. LDRBT is a minimally invasive procedure that can be carried out as an outpatient treatment and is completed in 45-90 min under spinal or general anaesthesia. However, a large prostate volume $(\geq 60 \mathrm{ml}$ ) can be technically challenging and basically represents a relative contraindication to LDRBT. LDR-BT has to be distinguished from high-dose brachytherapy (HDR-BT), which uses the radioisotope iridium 192 as a high-energy-emitting radiation source with a rate of $\geq 12 \mathrm{~Gy} / \mathrm{h}$ [4]. The source is placed temporarily in the prostate using needles as applicators.

The term primary (rather than definitive) therapy was suggested to convey a clear message concerning both the intent and the nature of RT and surgical operation, including LDR-BT, radical prostatectomy (RP), and external-beam RT (EBRT) [5]. The term no primary therapy (NPT) is used in the present systematic review to accommodate all types of observation, including active surveillance, watchful waiting, and observing without distinctive management.

LDR-BT, as compared to RP and EBRT, may have similar survival outcomes but may reduce the incidence of local adverse events and may provide better health-related quality of life (HRQL) [6,7]. However, randomised controlled trials (RCT) are lacking $[8,9]$. The aim of this systematic review was to assess the benefit and harm of LDR-BT relative to RP, EBRT, or NPT in men with localised PCa.

\section{Evidence Acquisiton}

While preparing this systematic review, we endorsed the Preferred Reporting Items for Systematic Reviews and MetaAnalyses statement, adhered to its principles, and conformed to its checklist [10]. Data are based on works conducted by the Institute for Quality and Efficiency in Health Care and commissioned by the Federal Joint Committee of the selfgoverning statutory health insurance system in Germany [11,12]. 


\subsection{Study inclusion criteria}

We included RCTs and nonrandomised controlled trials evaluating LDR-BT as monotherapy in patients with localised PCa. The proportion of relevant patients had to be at least $80 \%$ of the study population, and the response rate of questionnaires was expected to be at least $70 \%$. For nonrandomised studies to be included, comparable baseline characteristics between treatment groups or adjustment for imbalances of these data were required. Limits on year of publication or language were not applied.

\subsection{Search strategy}

Medline, Embase, and the Cochrane Library were searched without restrictions on study design, publication year, or language. The last database searches were conducted in June 2010. Terms and syntax used for the search in Medline via Ovid (Table S1; online at doi: 10.1016/j.eururo.2011.06.044) were tailored to the requirements of the other two databases. Reference lists of all included primary articles and two recent reviews $[8,9]$ were handsearched for further information. Information on studies registered at ClinicalTrials.gov [13], World Health Organisation International Clinical Trials Registry Platform [14], International Standard Randomised Controlled Trial Number Register [15], National Institute for Health Research UK Clinical Research Network's Portfolio Database [16], and National Cancer Institute Physician Data Query Clinical Trial [17] were searched online (June 2010) for RCTs.

\subsection{Study selection}

The study population included patients (no age limit) with localised PCa as classified by the TNM classification system [1]. Test intervention was LDR-BT; HDR-BT was not included. The control intervention was RP, EBRT, or NPT.

In the first step of study selection, bibliographic records were excluded if the title or the abstract clearly referred to other diagnoses than localised PCa or if a single-arm study was reported. In the second step, articles not excluded in the first step were evaluated to determine whether the test intervention were compared to at least one of the defined control interventions using an included study design. For each excluded study of the second step, an appropriate reason was documented (Fig. 1). All steps of the literature screening process were performed by two independent reviewers; any disagreements were resolved by discussion. 
3785 records after duplicates removed identified through database searching (PubMed, MEDLINE, EMBASE, The Cochrane Library)

08 December 2005 primary search $n=2262$

18 June 2006 update search $n=271$

14 June 2010 last update search $n=1252$
0 additional records identified through other sources

14 June 2010 register search:

ClinicalTrails.gov; WHO ICTRP; ISRCTN

register; NIHR UKCRN; Clinical Trials NCl

PDQ; ( $n=0$ controlled studies)

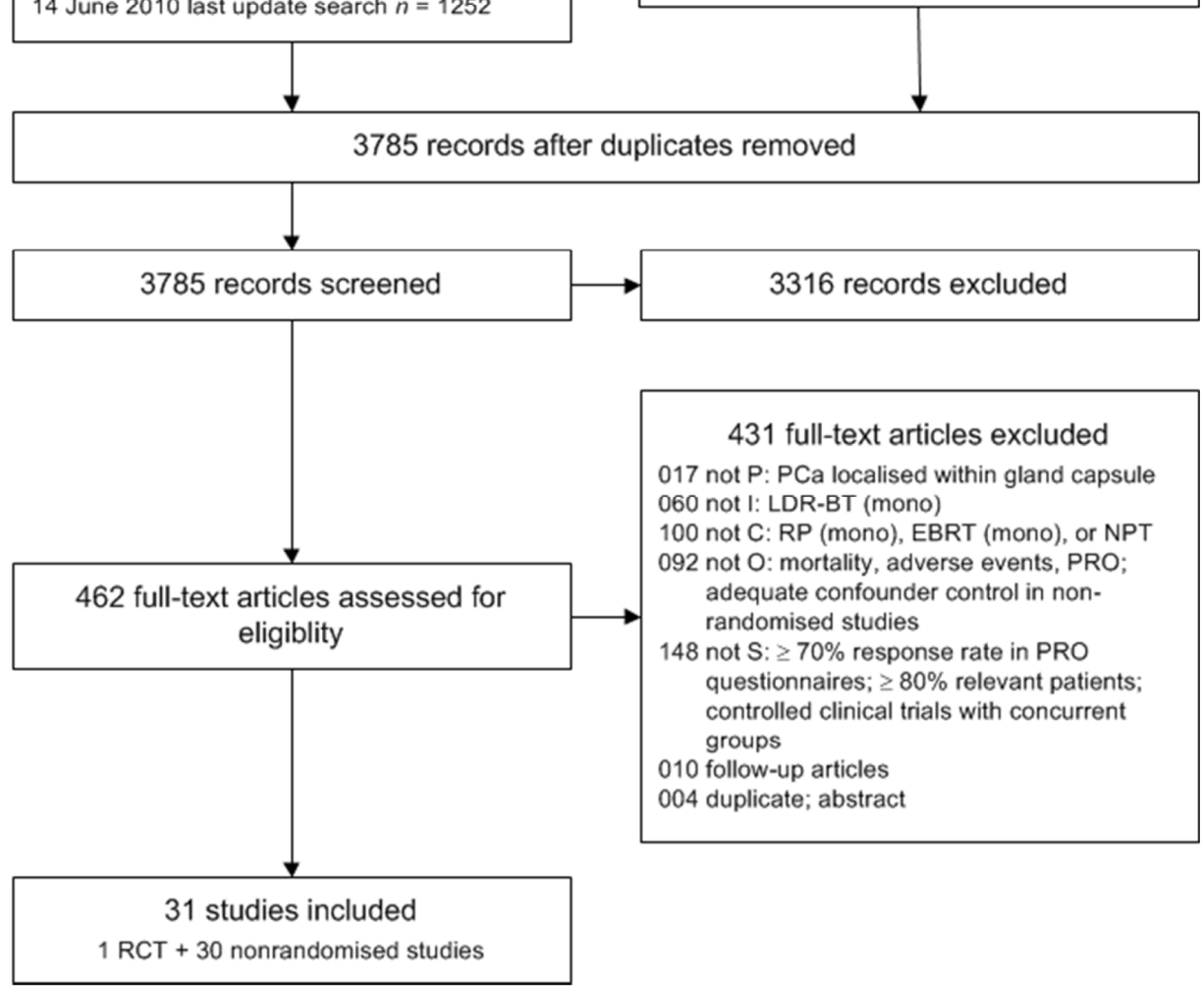

Figure 1. Literature retrieval and study selection.

Abbreviations: EBRT: external-beam radiation therapy; ISRCTN: International Standard Randomised Controlled Trial Number Register; LDR-BT: low-dose rate brachytherapy; NCI PDQ: National Cancer Institute Physician Data Query Clinical Trials; NIHR UKCRN: National Institute for Health Research UK Clinical Research Network's Portfolio Database; NPT: no primary therapy; PRO: patient-reported outcome; RCT: randomised controlled trial; RP: radical prostatectomy; WHO ICTRP: World Health Organization International Clinical Trials Registry Platform.

\subsection{Data collection and analysis}

For included studies, data on study characteristics, patients and interventions, risk of bias, duration of follow-up, and outcomes were abstracted independently by two review authors. Differences between reviewers were resolved by discussion or by appeal 
to a third review author. Primary outcome was overall survival (OS). Secondary outcomes were clinically defined disease-free survival (DFS), biochemical recurrence-free survival (bRFS), physicianreported severe adverse events (SAE), and patient-reported outcomes (PRO) such as function and bother scores as well as generic HRQL.

BRFS, also called prostate-specific antigen (PSA)-based recurrence-free survival, is a widely used laboratory-reported outcome. We believe that it should not be regarded as a validated surrogate for comparing different treatment groups in patients with a localised $\mathrm{PCa}-\mathrm{a}$ problem further addressed in the discussion section. SAE included sexual problems, urinary problems such as lower urinary tract symptoms and urinary incontinence, bowel problems such as rectal incontinence, toxicity-for example, urogenital or gastrointestinal acute or late toxicity according to modified Radiation Therapy Oncology Group radiation scale [18] - and other SAE such as secondary neoplasia. The questionnaires included in this systematic review to assess function, bother, and generic $H R Q L$ are listed in Table 1.

The primary effect measure for survival outcomes was the hazard ratio (HR). For nonrandomised studies, either comparability of baseline characteristics or an appropriate adjustment from a multiple regression analysis was required. We identified bRFS data qualified for quantitative pooling in a meta-analysis. However, we regard bRFS as an unvalidated surrogate for a pooled estimate may draw conclusions that are too far from reality. We did not identify OS and DFS data appropriate for pooling. Therefore, details of planned extraction of summary statistics and estimation of pooled data are not reported.

Results were accepted as adjusted if at least one of six predefined confounding factors was considered in a multiple regression model or in a stratified or matched analysis: age, T stage of the TNM classification, PSA, Gleason score, prostate size, and comorbidity. Unadjusted results were used from RCTs and from nonrandomised studies if no adjusted analysis were available and baseline characteristics were comparable. Other accepted effect measures were risk difference, risk ratio, odds ratio (OR), and mean difference. The reporting of a statistically significant effect in at least two studies and at the same time no reporting of contradicting results after a follow-up of at least 6 mo were required to determine whether the data were in favour of LDR-BT or the compared treatment.

\subsection{Assessment of risk of bias and quality of reporting}

Two reviewers independently assessed the quality of RCTs. A low risk of bias required a "yes" for all five of the following criteria: (1) adequate generation of the randomisation sequence; (2) adequate allocation concealment; (3) blinding of outcome assessors; (4) completeness of outcome data, including reporting of dropouts before and losses to follow-up after the beginning of treatment; and (5) an analysis based on intention to treat (ITT) of patients at the time of randomisation. In studies reporting PROs, the presence of baseline scores was evaluated in addition to the other six confounders. 


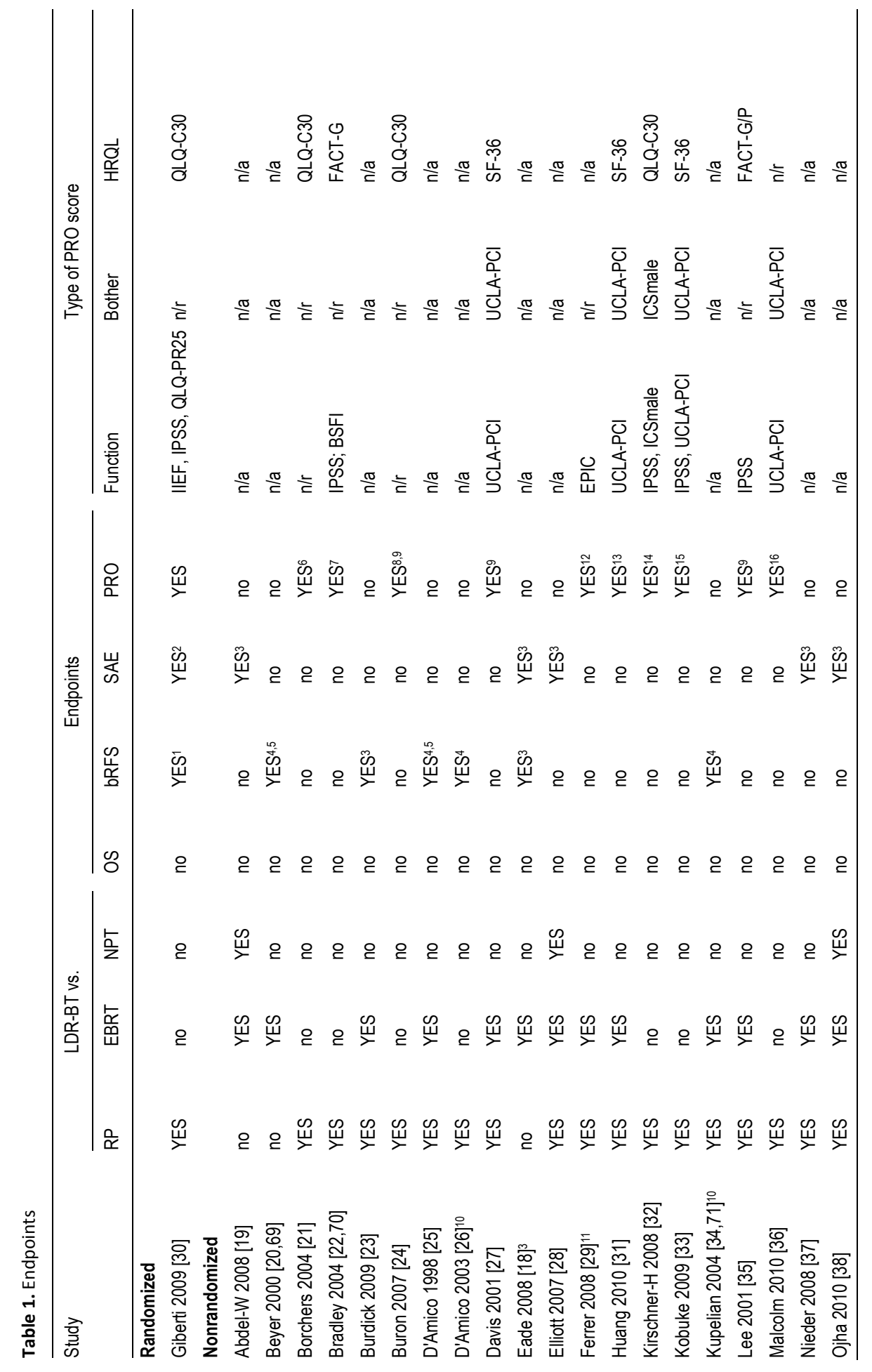




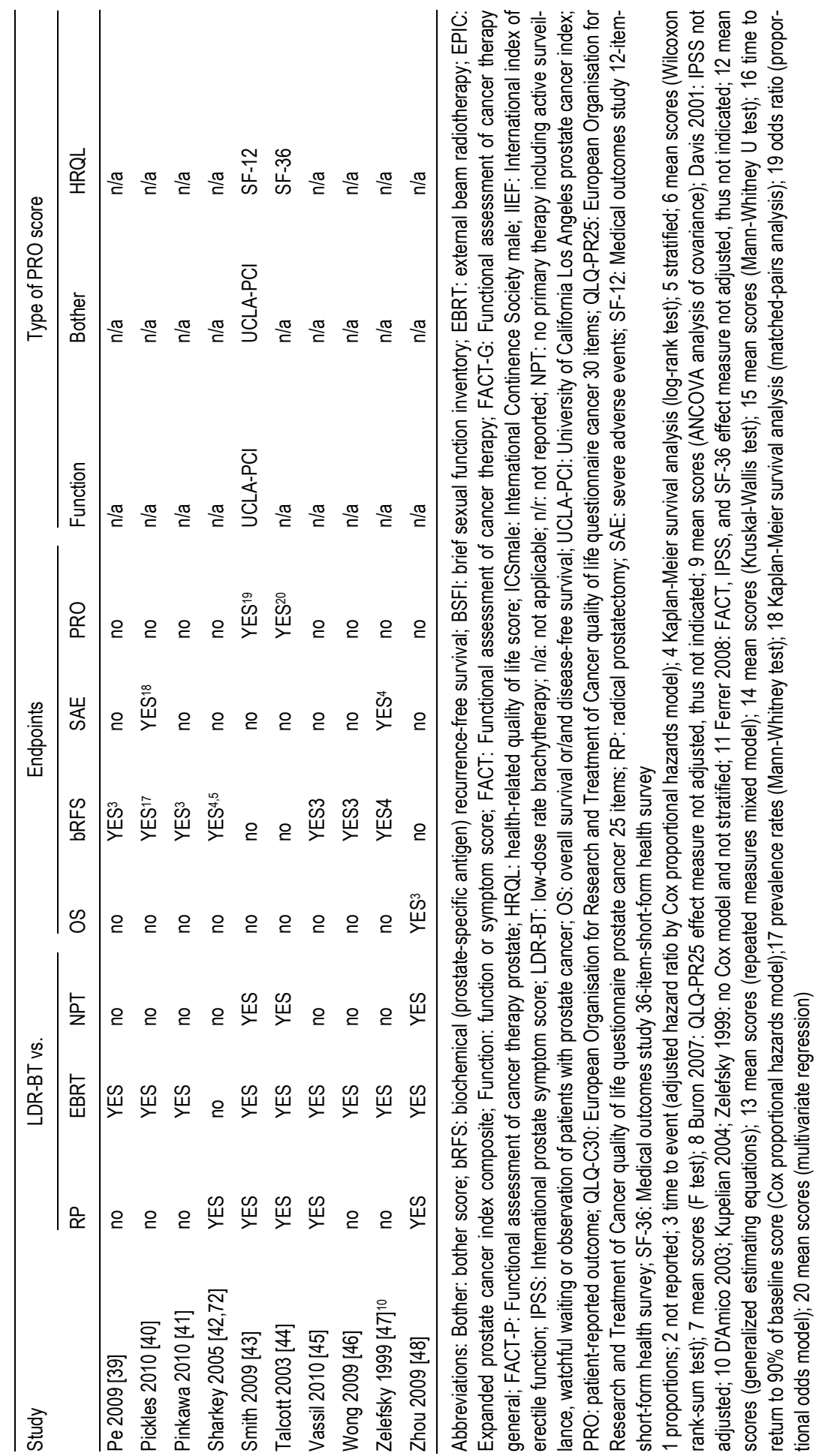


All nonrandomised studies were assigned per se a high risk of bias because of their nonrandomised design. To further differentiate risk of bias in these nonrandomised studies, additional flaws were categorised as small or large. The category small additional flaws required a "yes" for all four of the following criteria: (1) concurrent control group; (2) consecutive recruitment; (3) control for at least three out of the six predefined confounding factors age, T stage, PSA, Gleason score, prostate size, and comorbidity; and (4) reporting of patient flow or missing data. When there was evidence of multiple publications of the same study population, results were only included if they came from a different subpopulation.

\section{Evidence synthesis}

\subsection{Search results}

After exclusion of duplicates, 3785 bibliographic records were screened for potential eligibility, and 462 full-text papers were obtained for further assessment (Fig. 1). A total of 31 studies [18-48] met the inclusion criteria. The present systematic review included 1 RCT [30] and 30 nonrandomised studies.

\subsection{Baseline data}

An overview of the study characteristics, such as data obtained from registries, study location, treatment period, follow-up, EBRT dose, and number of included patients, is presented in Table 2. Median age in the EBRT group was up to $7 \mathrm{yr}$ higher than in the LDRBT group and in the LDR-BT group up to $9 \mathrm{yr}$ higher than in the RP group in the majority of studies. Most studies included only the T1 and T2 categories of TNM classification, with a few studies reporting on patients with T3 or T4 categories (42\% per group). Although the majority of patients in the primary studies had a Gleason score $<7$ and a PSA level $<10$ $\mathrm{ng} / \mathrm{ml}$, most studies also included a considerable proportion (about 20-30\%) of patients with a PSA level $\geq 10 \mathrm{ng} / \mathrm{ml}$. Prostate size and comorbidity were reported only in a few studies. LDR-BT was mostly performed using iodine-125 as the isotope, but in a few studies, palladium-103 was used instead. EBRT was conducted with different radiation doses between and among studies. Median total dose ranged from $68 \mathrm{~Gy}$ to $78 \mathrm{~Gy}$. Neoadjuvant or adjuvant androgen-deprivation therapy differed among patients. RP was carried out with or without a nerve-sparing technique using either a retropubic or perineal route.

Of 30 nonrandomised studies, 7 reported results from registries [19,28,31,37, $38,43,48$ ]. Table S2 (online at doi: 10.1016/j.eururo.2011.06.04) shows categorisation of six different patients' characteristics (age, TNM stage, PSA, Gleason score, size of prostate, comorbidity) as comparable between treatment groups, adjusted for as a confounder, or not considered in data analysis. 


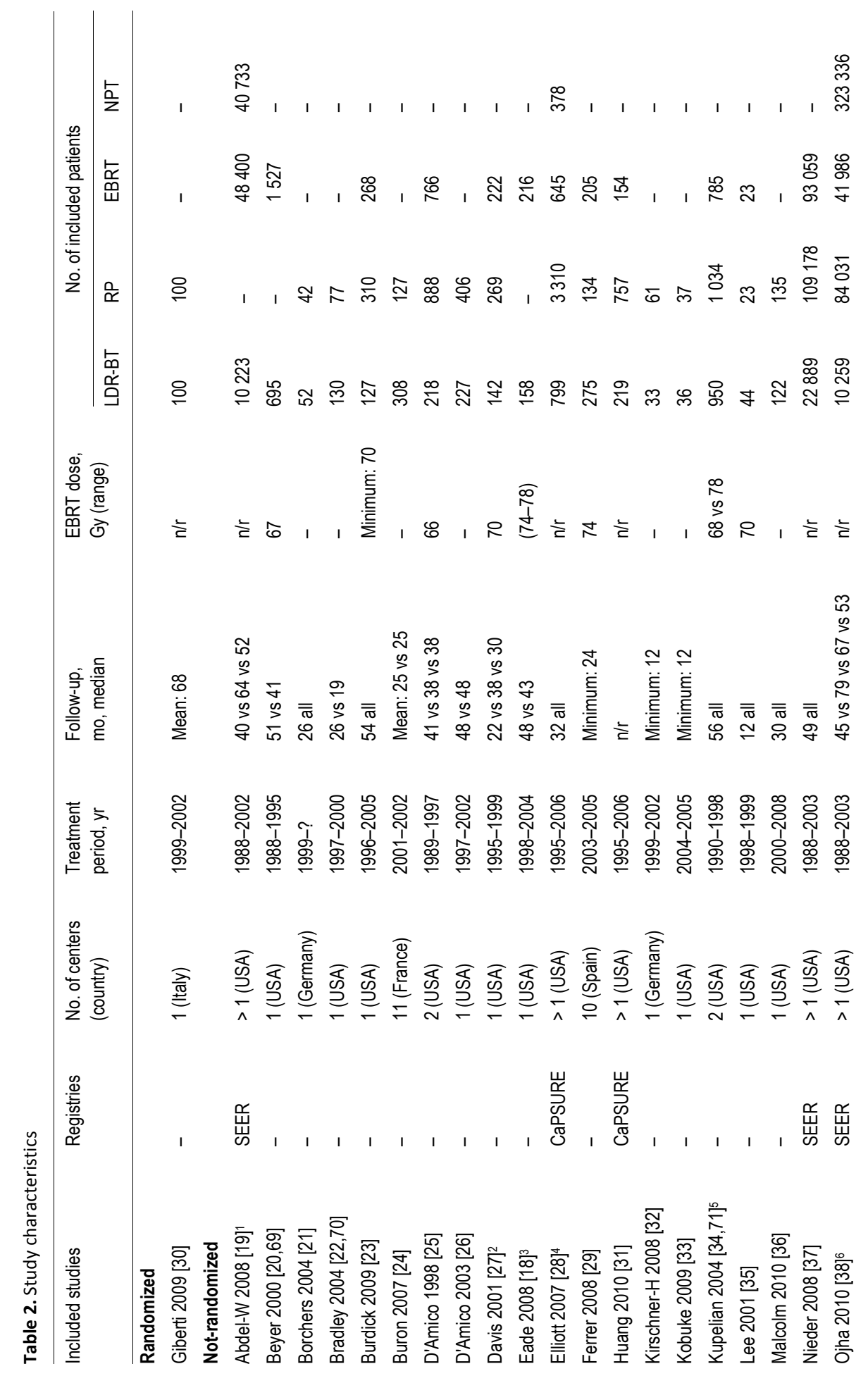




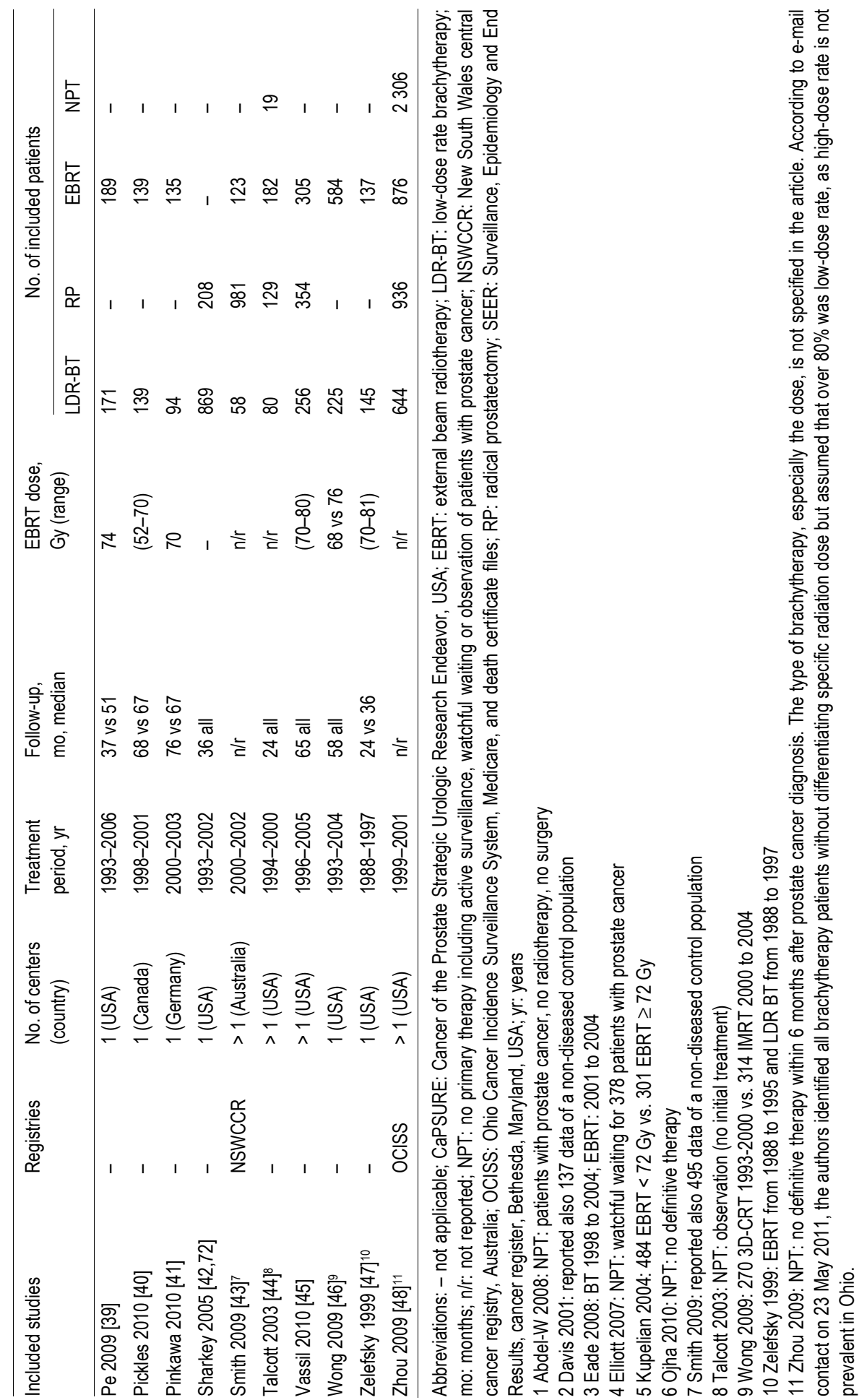




\subsection{Risk of bias and quality of studies}

Risk of bias of the RCT by Giberti 2009 [30] was evaluated as high. Patients were randomised, using a computerised blocked random number list, into 2 groups of 100 patients each. Randomisation was performed by a urologist not participating in the surgical operations; however, concealment of allocation was not reported. Outcome assessment was performed by another urologist blinded to patient treatment. Furthermore, a considerable number of patients were lost to follow-up (15\% in the brachytherapy group and $11 \%$ in the RP group), management of the missing data was not addressed, and no ITT analysis was performed. There was no information on prior sample size calculation and no statement about funding and competing interests.

Risk of bias was high for all 30 nonrandomised studies because of the nonrandomised design (Table 3). Additional large flaws were identified in $63 \%$ of studies (19 of 30) [18-21, 24-28,32,37-39,41,42,44,45,47,48], and additional small flaws were identified in the other $37 \%$ (11 of 30 ).

\subsection{Primary outcome: overall survival}

An overview of conclusions based on the available data is presented in Table 4. Only one nonrandomised study reported improvement in overall mortality (HR: 0.40; $95 \%$ confidence interval $[\mathrm{Cl}], 0.32-0.52$ ) for monotherapy of localised disease in the LDR-BT group compared to the NPT group [48] at 7-yr follow-up, as listed in the overview of reported end points in Table 1. Improvement of disease-specific mortality (HR: $0.45 ; 95 \% \mathrm{Cl}, 0.23-$ 0.87 ) was also reported in this study, but not in any other identified study. As detailed later, results were deemed not interpretable in the present systematic review.

\subsection{Secondary outcomes}

An overview of conclusions based on the available data is presented in Table 4. Table 1 shows the end points that were reported by the accordant studies. DFS was not identified in the included studies; bRFS was reported in 14 studies (Table 5). Time-to-event data were in favour of LDR-BT compared to RP in three of seven studies and were not significantly different in four of seven studies. Concerning EBRT, time-toevent data were in favour of LDR-BT compared to EBRT in 3 of 10 studies and were not significantly different in 7 of 10 studies. In an additional study, Kupelian 2004 [34] reported results after EBRT for two subgroups stratified by dose level. The outcome was in favour of LDR-BT compared to low-dose EBRT and was not significantly different after highdose EBRT. In all four studies [34,40,41,46] applying low-dose EBRT, outcome was in favour of LDR-BT, although Wong et al. evaluated two different types of EBRT with different dose levels (Table 2). 


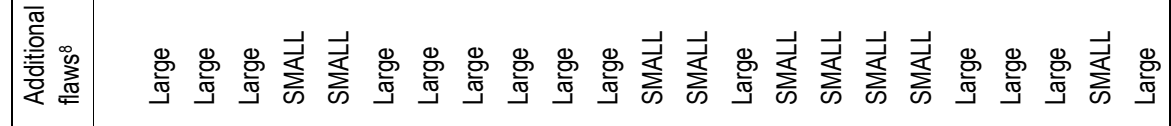

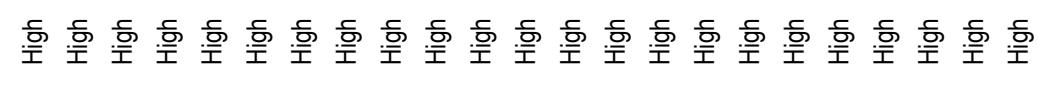

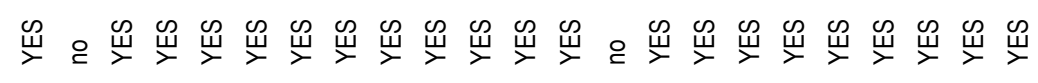

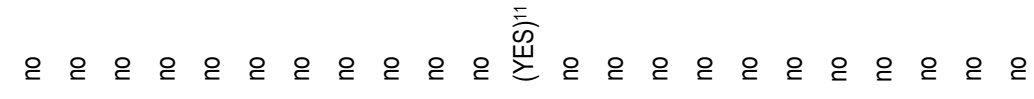

욜 离出

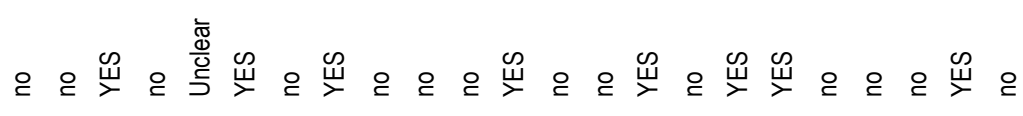

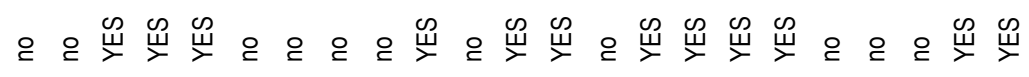

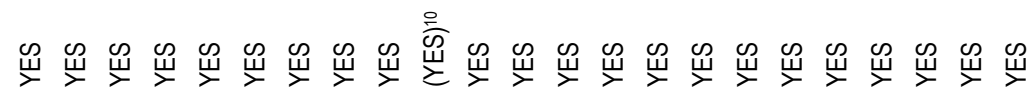

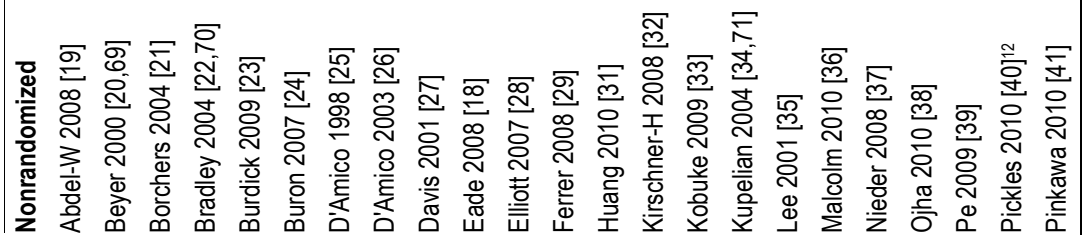




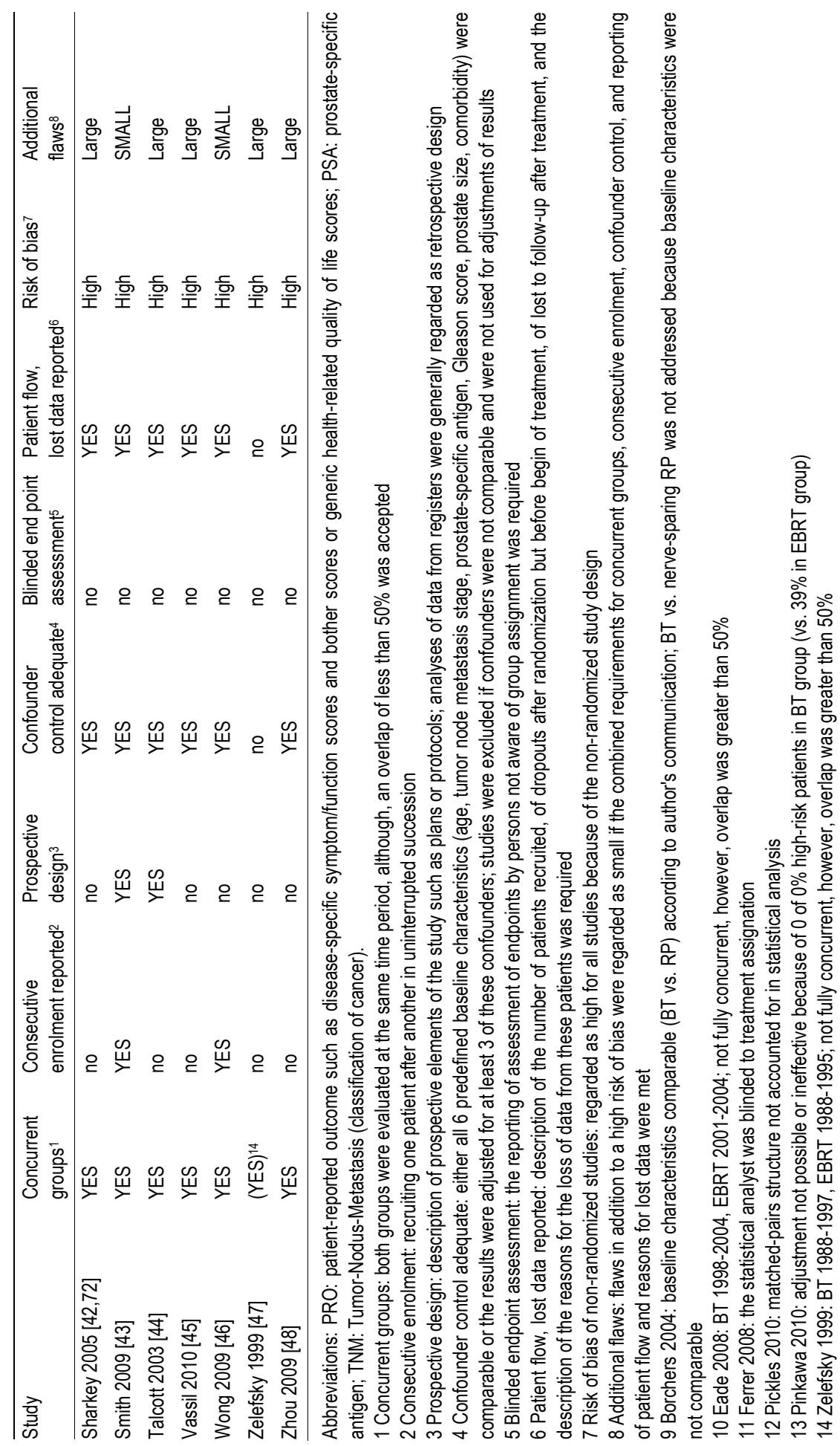


Table 4. Overview of conclusions

\begin{tabular}{llcc}
\hline Endpoint & \multicolumn{3}{c}{ LDR-BT vs } \\
\cline { 2 - 4 } & NPT & EBRT & RP
\end{tabular}

\section{Primary end points}

Overall survival

$\begin{array}{ccc}n / i & n / i & n / i \\ n / i & n / i & n / i \\ n / r & n / r & n / r \\ n / r & n / i & n / i\end{array}$

Cause-specific survival

Secondary end points

Disease-free survival

Biochemical recurrence-free survival

$n / r$

$\mathrm{n} / \mathrm{i}$

$n / i$

Physician-reported severe adverse events

\section{Toxicity}

Gastrointestinal (acute or late), urogenital (acute), grade 2-3

Urogenital (late toxicity, grade 2-3)

$\begin{array}{lll}\mathrm{n} / \mathrm{r} & \leftrightarrow & \mathrm{n} / \mathrm{r} \\ \mathrm{n} / \mathrm{r} & \boldsymbol{n} & \mathrm{n} / \mathrm{r} \\ & & \\ \leftrightarrow & \leftrightarrow & \leftrightarrow \\ \mathrm{n} / \mathrm{r} & \mathrm{n} / \mathrm{r} & \leftrightarrow \\ \leftrightarrow & \leftrightarrow & \leftrightarrow\end{array}$

\section{Urinary tract}

Urethral stricture

Urinary incontinence

$\leftrightarrow$

$\leftrightarrow$

$\leftrightarrow$

\section{Patient-reported outcomes}

Sexual

Function

Bother function

Erectile dysfunction

\section{Urinary}

Function

Bother function

Irritation

(Stress) incontinence

Bother (stress) incontinence

\section{Bowel}

Function

Bother function

\section{Generic HRQL}

Physical component score Mental component score

$\begin{array}{lll}\leftrightarrow & \leftrightarrow & \uparrow \\ \mathrm{n} / \mathrm{r} & \leftrightarrow & \leftrightarrow \\ & \mathrm{n} / \mathrm{r} & \leftrightarrow \\ \leftrightarrow & \leftrightarrow & \uparrow \\ \leftrightarrow & \leftrightarrow & \leftrightarrow \\ \mathrm{n} / \mathrm{r} & \leftrightarrow & \leftrightarrow \\ \mathrm{n} / \mathrm{r} & \leftrightarrow & \leftrightarrow \\ \mathrm{n} / \mathrm{r} & \mathrm{n} / \mathrm{r} & \leftrightarrow \\ & & \leftrightarrow \\ \leftrightarrow & \leftrightarrow & \leftrightarrow \\ \leftrightarrow & \leftrightarrow & \leftrightarrow \\ \leftrightarrow & \leftrightarrow & \leftrightarrow \\ \leftrightarrow & \leftrightarrow & \leftrightarrow\end{array}$

Abbreviations: EBRT: external beam radiotherapy; HRQL: health-related quality of life; LDR-BT=low-dose-rate brachytherapy; n/i: not interpretable; n/r: not reported; NPT=no primary therapy including active surveillance, watchful waiting, or observation of patients with prostate cancer; RP: radical prostatectomy.

$\boldsymbol{\uparrow}$ : At least 2 studies reporting statistically significant effect in favor of LDR-BT in the accordant category and no contradicting effects in other studies

$\boldsymbol{\downarrow}$ : At least 2 studies reporting statistically significant effect in favor of control treatment in the accordant category and no contradicting effects in other studies

$\leftrightarrow$ : Fewer than 2 studies reporting statistically significant effects or contradicting effects or difference between groups not statistically significant 
Table 5. Biochemical recurrence-free survival at 5 years

\begin{tabular}{|c|c|c|c|c|c|}
\hline \multirow[t]{2}{*}{ Study } & \multicolumn{3}{|c|}{ LDR-BT vs EBRT } & \multicolumn{2}{|r|}{ LDR-BT vs RP } \\
\hline & $\begin{array}{l}\text { LDR-BT, } \\
\text { 5-yr survival, } \\
\%\end{array}$ & $\begin{array}{l}\text { EBRT, } \\
\text { 5-yr survival, } \\
\%\end{array}$ & $\begin{array}{l}\mathrm{HR}(95 \% \mathrm{Cl}) \\
p \text { value }\end{array}$ & \multicolumn{2}{|c|}{$\begin{array}{l}\mathrm{RP}, 5-\mathrm{yr} \quad \mathrm{HR}(95 \% \mathrm{Cl}) \\
\text { survival, } \% p \text { value }\end{array}$} \\
\hline \multicolumn{6}{|l|}{ Randomized } \\
\hline Giberti $2009[30]^{2}$ & $\mathrm{n} / \mathrm{r}$ & - & - & $\mathrm{n} / \mathrm{r}$ & $0.96(0.35-2.42) ; 0.875^{3}$ \\
\hline \multicolumn{6}{|l|}{ Not-randomized } \\
\hline Beyer $2000[20,69]^{4}$ & 71 & 69 & $\mathrm{n} / \mathrm{r} ; 0.94$ & - & - \\
\hline Burdick 2009 [23] & $\mathrm{n} / \mathrm{r}$ & $\mathrm{n} / \mathrm{r}$ & $1.04(0.56-1.94) ; 0.9$ & $\mathrm{n} / \mathrm{r}$ & $0.44(0.25-0.77) ; 0.004$ \\
\hline D'Amico $1998[25]^{5}$ & 88 & 89 & $\mathrm{n} / \mathrm{r} ;>0.250$ & 85 & $\mathrm{n} / \mathrm{r} ;>0.250$ \\
\hline D'Amico $2003[26]^{6}$ & 95 & - & - & 93 & $\mathrm{n} / \mathrm{r} ; 0.160$ \\
\hline Eade $2008[18]^{7}$ & 94 & 100 & $4.00(0.80-20.03) ; 0.09$ & - & - \\
\hline Kupelian $2004[34,71]$ & 83 & - & - & 81 & $0.96(0.76-1.21) ; 0.72$ \\
\hline \multicolumn{2}{|c|}{ Kupelian $2004[34,71]<72$ Gy 83} & 51 & $0.43(0.28-0.66) ; n / r$ & - & - \\
\hline \multicolumn{2}{|c|}{ Kupelian $2004[34,71] \geq 72$ Gy 83} & 81 & $0.89(0.51-1.55) ; \mathrm{n} / \mathrm{r}$ & - & - \\
\hline Pe 2009 [39] & 96 & 95 & $0.850(\mathrm{n} / \mathrm{r}) ; 0.780$ & - & - \\
\hline Pickles $2010[40]^{8}$ & 95 & 85 & $0.32(0.16-0.63) ; 0.001$ & - & - \\
\hline Pinkawa $2010[41]^{9}$ & $\mathrm{n} / \mathrm{r}$ & $\mathrm{n} / \mathrm{r}$ & $0.50(0.30-0.80) ;<0.010$ & - & - \\
\hline Sharkey 2005 [42,72] & 93 & - & n.a. & 85 & $0.44(0.27-0.73) ;<0.002$ \\
\hline Vassil 2010 [45] & 90 & 86 & $0.99(0.62-1.58) ; 0.969$ & 80 & $0.52(0.33-0.78) ; 0.003$ \\
\hline Wong 2009 [46] & 94 & $87 ; 7410$ & $\mathrm{n} / \mathrm{r} ;<0.00111$ & - & - \\
\hline Zelefsky $1999[47]^{12}$ & 82 & 88 & $\mathrm{n} / \mathrm{r} ; 0.090$ & - & - \\
\hline
\end{tabular}

Abbreviations: -: not applicable; bRFS: Biochemical recurrence-free survival; Cl: confidence interval; EBRT: external beam radiotherapy; HR: hazard ratio; LDR-BT: low-dose rate brachytherapy; n/r: not reported; RP: radical prostatectomy; TNM: Tumor-Nodus-Metastasis (classification of cancer); yr: year

$1 \mathrm{p}$ value: Table 5 specifies statistical test

2 Giberti 2009: presented frequency rates without censoring, thus relative risk was based on these rates

$3 p$ value calculated using unconditioned test for comparing two independent proportions by Andres 1994 [73]

4 Beyer 2000: baseline data were not comparable, although data were not statistically different between treatment groups after stratification according to PSA, Gleason score, T category of TNM, and age.

5 D'Amico 1998: baseline data were not comparable, although data were not statistically different between treatment groups after stratification according to PSA, Gleason score, and T category of TNM.

6 D'Amico 2003: baseline data were not comparable and neither adjusted nor stratified for

7 Eade 2008: 4-year Brfs

8 Pickles 2010: HR was estimated from summary time-to-event data using the tool provided by Tierney 2007 [74]; median dose was less than $72 \mathrm{~Gy}$

9 Pinkawa 2010: median dose was less than $72 \mathrm{~Gy}$

10 Wong 2009: intensity-modulated radiotherapy (IMRT); 3-dimensional conformal radiotherapy (3D-CRT)

11 Wong 2009: $p$ value relates to a statistical test of a group of 4 values: LDR-BT, EBRT-IMRT, EBRT-3D-CRT, and a fourth not relevant item characterized by a low number of participants

12 Zelefsky 1999: baseline data were not comparable and neither adjusted nor stratified for 
Physician-reported SAE were reported in one RCT [30] and seven nonrandomised studies $[18,19,28,37,38,40,47]$ (Table 1). Results comprising type of control intervention, proportion of events, HR and $p$ value, and interpretation of effect are listed in Table 6. An effect was defined as a statistically significant difference between intervention groups. A better score was defined as at least two effects in one direction without contrasting effect after a minimum 6-mo follow-up. Urogenital late toxicity grade 2 to 3 was significantly more common in three studies in the LDR-BT group compared to the EBRT group. The difference between groups of other SAE was not significant. An effect was reported in a single study only, or the results were contradictory among several studies.

PROs such as function or bother scores as well as generic HRQL were reported in 13 studies (Table 1) $[21,22,24,27,29-33,35,36,43,44]$, including the single RCT. Concerning sexual function or bother, better scores were reported for the LDR-BT group compared with RP (Table S3; online at doi: 10.1016/j.eururo.2011.06.04). Concerning urinary tract problems, urinary function scores and urinary incontinence scores were better for the LDR-BT group than the RP group (Table S4; online at doi: 10.1016/j.eururo.2011.06.04). Concerning bowel scores, better scores were reported for the LDR-BT group than the EBRT group (Table S5; online at doi: 10.1016/j.eururo.2011.06.04). Concerning generic HRQL, we found only two contrasting effects (Table S6; online at doi: 10.1016/j.eururo.2011.06.04). Differences between groups that were not statistically different and failure to report results of statistical tests were major reasons. 
Table 6. Results: Severe adverse events

\begin{tabular}{|c|c|c|c|c|c|}
\hline End point & $\begin{array}{l}\text { LDR-BT } \\
\text { versus... }\end{array}$ & Study & Events, \% & $\mathrm{HR}(95 \% \mathrm{Cl}) ; p$ value & Effect ${ }^{1}$ \\
\hline \multicolumn{6}{|l|}{ Toxicity } \\
\hline Gastrointestinal early² & EBRT & Pickles 2010 [40] & 4 vs 5 & $\mathrm{n} / \mathrm{r} ; 0.852^{3}$ & $\mathrm{n} / \mathrm{s}$ \\
\hline \multirow[t]{2}{*}{ Gastrointestinal late ${ }^{4}$} & EBRT & Eade 2008 [18] & $n / r$ & $3.18(1.00-10.05) ; 0.050$ & Pro EBRT (1) \\
\hline & EBRT & Pickles 2010 [40] & 1.0 vs 3.8 & $\mathrm{n} / \mathrm{r} ; 0.018^{5}$ & Contra EBRT (1) \\
\hline Urogenital early² & EBRT & Pickles 2010 [40] & 2.9 vs 0.7 & $\mathrm{n} / \mathrm{r} ; 0.211^{3}$ & $\mathrm{n} / \mathrm{s}$ \\
\hline \multirow[t]{3}{*}{ Urogenital late ${ }^{4}$} & EBRT & Eade 2008 [18] & 19.2 vs 3.5 & $9.90(3.70-26.47) ;<0.001$ & Pro EBRT (1) \\
\hline & EBRT & Pickles 2010 [40] & 6.5 vs 0.0 & $\mathrm{n} / \mathrm{r} ;<0.001^{5}$ & Pro EBRT (2) \\
\hline & EBRT & Zelefsky 1999 [47] & $\mathrm{n} / \mathrm{r}$ & $7.19(3.68-13.96) ;<0.001$ & Pro EBRT (3) \\
\hline \multicolumn{6}{|l|}{ Urinary tract } \\
\hline \multirow[t]{5}{*}{ Urethral stricture } & $\mathrm{RP}$ & Elliott 2007 [28] & 1.8 vs 8.4 & $0.16(0.01-1.87) ;$ n.r. & $\mathrm{n} / \mathrm{s}$ \\
\hline & $\mathrm{RP}$ & Giberti 2009 [30] & 2.0 vs 6.5 & $\mathrm{n} / \mathrm{r} ; 0.221^{3}$ & $\mathrm{n} / \mathrm{s}$ \\
\hline & EBRT & Elliott 2007 [28] & 1.8 vs 1.7 & 0.95 (0.07-12.78); n.r. & $\mathrm{n} / \mathrm{s}$ \\
\hline & EBRT & Eade 2008 [18] & 7.0 vs 0.0 & $\mathrm{n} / \mathrm{r} ;<0.001^{3}$ & Pro EBRT (1) \\
\hline & NPT & Elliott 2007 [28] & 1.8 vs 1.1 & $1.68(0.46-6.14) ; 0.430$ & $n / s$ \\
\hline \multicolumn{2}{|c|}{ Urinary bladder catheterisation EBRT } & Pickles 2010 [40] & 15.0 vs 0.0 & $\mathrm{n} / \mathrm{r},<0.001$ & Pro EBRT (1) \\
\hline Urinary incontinence & $\mathrm{RP}$ & Giberti 2009 [30] & 0.0 vs 18.4 & $\mathrm{n} / \mathrm{r} ;<0.001^{3}$ & Contra RP (1) \\
\hline Urinary irritation & $\mathrm{RP}$ & Giberti 2009 [30] & 20.0 vs 5.0 & $\mathrm{n} / \mathrm{r} ;<0.001^{3}$ & Pro RP (1) \\
\hline \multicolumn{6}{|l|}{ Secondary neoplasia } \\
\hline \multirow[t]{2}{*}{ Second primary tumor } & EBRT & Abdel-W 2008 [19] & 4.7 vs 10.3 & $0.84(0.73-0.97) ; n / r$ & Contra EBRT (1) \\
\hline & NPT & Abdel-W 2008 [19] & 4.7 vs 7.9 & $0.96(0.87-1.06) ; 0.397$ & $\mathrm{n} / \mathrm{s}$ \\
\hline \multirow[t]{2}{*}{ Urinary bladder carcinoma } & $\mathrm{RP}$ & Nieder 2008 [37] & 0.5 vs 0.7 & $1.52(1.24-1.87) ; n / r$ & Pro RP (1) \\
\hline & EBRT & Nieder 2008 [37] & 0.5 vs 1.3 & $0.81(0.60-1.10) ; n / r$ & $n / s$ \\
\hline \multirow[t]{2}{*}{ Rectal carcinoma } & $\mathrm{RP}$ & Nieder 2008 [37] & 0.2 vs 0.3 & $1.08(0.77-1.54) ; n / r$ & $\mathrm{n} / \mathrm{s}$ \\
\hline & EBRT & Nieder 2008 [37] & 0.2 vs 0.4 & $0.86(0.52-1.43) ; n / r$ & $\mathrm{n} / \mathrm{s}$ \\
\hline \multirow[t]{3}{*}{ Acute myeloid leukaemia } & $\mathrm{RP}$ & Ojha 2010 [38] & 0.1 vs 0.1 & $0.98(0.23-4.18) ; n / r$ & $\mathrm{n} / \mathrm{s}$ \\
\hline & EBRT & Ojha 2010 [38] & 0.1 vs 0.2 & $0.60(0.14-2.50) ; n / r$ & $\mathrm{n} / \mathrm{s}$ \\
\hline & NPT & Ojha 2010 [38] & 0.1 vs 0.1 & $1.22(0.46-3.22) ; n / r$ & $\mathrm{n} / \mathrm{s}$ \\
\hline
\end{tabular}

Abbreviations: $\mathrm{Cl}$ : confidence interval; EBRT: external beam radiotherapy; HR: hazard ratio; LDR-BT: low-dose rate brachytherapy; n/r: not reported or insufficient data; $\mathrm{n} / \mathrm{s}$ : difference between treatment groups not statistically significant; NPT: no primary therapy including active surveillance, watchful waiting or observation of patients with prostate cancer; RP: radical prostatectomy

1 Count of statistically significant effects per category

2 Gastrointestinal toxicity (early, grade 2-3); urogenital toxicity (early, grade 2-3)

$3 p$ value calculated using unconditioned test for comparing two independent proportions by Andres 1994 [73]

4 Gastrointestinal toxicity (late, grade 2-3); urogenital toxicity (late, grade 2-3)

$5 \mathrm{p}$ value calculated using chi-square test 


\subsection{Discussion}

\subsubsection{Outcomes}

We found a high risk of bias among all 31 identified studies, including 1 RCT. Recent systematic reviews $[8,9,49,50]$ also addressed the lack of RCTs investigating brachytherapy. Wilt 2008 [49] pointed out that long-term, adequately powered randomised trials to provide reliable estimates about the relative effectiveness of treatments are needed.

Only one nonrandomised study reported equivalent improvement of overall and disease-specific mortality for localised disease $7 \mathrm{yr}$ after LDR-BT compared to NPT [48]. The mortality-incidence ratio of PCa can be estimated at $15 \%$, and the overall $5-\mathrm{yr}$ relative survival of patients in comparison to the general population was reported at 99.1\% [51]. Both statistics are compatible with a long life expectancy compared to other cancers. Thus, even significant improvement of disease-specific mortality is not expected to have an important impact on overall mortality. Yet, a large difference in OS is reported, which strongly indicates structural differences in the patient populations between the treatment groups, possibly resulting in biased effect estimates because of considerable residual confounding.

Concerning physician-reported SAE, a statistically significant effect in favour of LDRBT in at least two studies and no contradicting effects in other studies were found for urogenital late toxicity grade 2 to 3 when compared to EBRT. Concerning PROs, a statistically significant effect in favour of LDR-BT in at least two studies and no contradicting effects in other studies compared with RP was identified for sexual function, urinary function, and urinary incontinence. Some of the results are not unexpected considering the treatment-specific impact on physical integrity. An advantage for LDR-BT in urinary and sexual domains was similarly observed at 5-yr follow-up in the Surgical Prostatectomy Versus Interstitial Radiation Intervention Trial [52]. An analogous effect in favour of LDR-BT was identified for bowel function when compared to EBRT. Some of the results are also not unexpected, because the bowel may be affected by EBRT.

The current evidence does not allow a determination of whether LDR-BT has an additional benefit or harm compared to other treatment alternatives in patients with localised PCa. Informed decision-making requires detailed and unbiased description of possible benefits and harms for each intervention with respect to the individual needs and health preferences of the patients. Unfortunately, conflicts of interest may hamper unbiased counselling [53], and experts such as urologists or radiotherapists prefer the modality they deliver $[54,55]$. Thus, individual preferences by patients and physicians play a central role in the decision whether to treat or to pursue active surveillance [56]. Ethical issues such as patient and physician preferences as well as transparent counselling should be considered in study designs. RCTs on surgical treatment of cancer are especially threatened by low rates of accrual, and physicians offered the 
following main explanations in questionnaire: concern that the doctor-patient relationship would be affected by an RCT, difficulty with informed consent, and dislike of open discussions involving uncertainty [57].

\subsubsection{Biochemical recurrence-free survival}

We found inconsistent results for bRFS. Some studies found significant differences between LDR-BT versus RP and LDRBT versus EBRT, whereas others reported insignificant differences. All studies in favour of LDR-BT over EBRT reported application of lowdose EBRT. These results are in agreement with the results of a meta-analysis by Viani 2009, who concluded that high doses are superior to low-dose RT in preventing biochemical failure [58].

BRFS is the most commonly used end point in the included studies and may be the best tool available for detecting recurrence of PCa in individuals. However, for the purpose of statistical comparison of different treatments, bRFS is not an appropriate end point. BRFS represents a surrogate end point and is not validated for comparing LDRBT to RP, EBRT, or NPT. Different definitions of this surrogate and serious reservations for interpreting comparative results are in effect. Therefore, this outcome is presented as supporting data only to allow a description of available information.

PSA-based recurrence was traditionally considered an attractive surrogate end point for survival [59], but this was mainly based on data after RP. It has not been validated for any treatment of localised PCa. Different definitions exist for bDFS after EBRT (Phoenix definition) [60] and after RP [61]. The term is not defined for follow-up after LDR-BT and is not helpful for comparing two treatment alternatives, especially not for comparing LDR-BT to RP [62]. Sensitivity and specificity of the Phoenix criteria to detect late clinical recurrence range between $60 \%$ and $80 \%$ for patients after EBRT [60]. More than half of the patients who have a biochemical recurrence-free survival (bRFS) according to the Phoenix definition subsequently die from other causes than PCa [63]. The predictive value of a BCR after LDR-BT using the Phoenix definition depends on the duration of follow-up [64]. Short-term studies focussing on PSA-based RFS, therefore, tend to overestimate the efficacy of LDR-BT compared to RP, because PSA recurrence-by its very definition-is unlikely to occur within the first months after LDR-BT. The proportion of false-positive values in PSA bounce can be considerable for accurate estimates of treatment efficacy after brachytherapy if the follow-up is $<3 \mathrm{yr}[64,65]$. All these points raise serious questions about the validity of BCR-free survival as an outcome measure.

\subsubsection{Strengths and limitations of the present review}

The strengths of this review are the broadness of the search strategy and the comprehensiveness of the published data included. However, the lack of RCT data and the poor methodologic quality of the included studies imply that the validity and the over- 
all robustness of results are limited. In addition, the included studies were heterogeneous with regard to patient characteristics, isotopes used in LDR-BT, surgical approaches in RP, and radiation dose in EBRT. As in any systematic review, the limitations in drawing conclusions are directly dependent on the quality and homogeneity of the primary studies.

We identified a high risk of bias within all studies. As the different treatment options in localised PCa (LDR-BT, RP, EBRT, and NPT) differ substantially with regard to techniques, possible benefits, and possible harms, clinical guidelines recommend these treatments to specific patient subgroups, causing selection bias and covariate imbalance in observational studies. Because statistical adjustment is unable to fully control for such strong confounding factors, this problem may be overcome only by RCTs.

\subsubsection{Future prospects}

We have identified three ongoing RCTs that may provide sufficient evidence in upcoming years to allow conclusions about the comparative effectiveness of LDR-BT. With support from the German statutory health care system, a preference-based multicentre RCT comparing LDR-BT, RP, EBRT, and active surveillance is planned to start recruitment in 2011 [66]. Standard Treatment Against Restricted Treatment (START) is an international (Canada, United States, United Kingdom) two-arm multicentre RCT to investigate the outcome of active surveillance in patients with low-risk PCa compared to LDR-BT, EBRT, or RP [67]. Surgery Against Brachytherapy (SABRE 1), a randomised evaluation, is an international (United Kingdom, Canada) multicentre RCT to compare LDR-BT against RP [68].

\section{Conclusions}

We found a low amount of evidence in studies that exclusively compared LDR-BT with other treatment modalities. LDR-BT may have some different physician-reported SAE and PROs. The current evidence is insufficient to allow a definitive conclusion about OS. Randomised trials focussing on long-term survival are needed to clarify the relevance of LDR-BT in patients with localised PCa. 


\section{References}

1. Ebele JN, Sauter G, Epstein JI, Sesterhenn IA. Pathology and genetics of tumours of the urinary system and male genital organs. Lyon: International Agency for Research on Cancer; 2004. Web site: http://www.iarc.fr/

2. Heidenreich A, Bolla M, Joniau S, Mason M, Matveev V, Mottet N, et al. Guidelines on prostate cancer. Arnhem: European Association of Urology; 2010. Web site: http://www. uroweb.org/

3. Prostate cancer. Guideline for the management of clinically localized prostate cancer: 2007 update. American Urological Association. Web site: http://www.auanet.org/

4. Nath R. Overview of brachytherapy physics. In: Thomadsen BR, Rivard MR, Butler W (editors). Brachytherapy physics. ed. 2. Madison: Medical Physics Publishing; 2005.

5. Soloway MS, Gorin MA, Katkoori D. "Definitive therapy" for cancer: is our message clear? European Urology. 2010;58(2):256-7.

6. Rosenthal SA, Bittner NH, Beyer DC, et al. American Society for Radiation Oncology (ASTRO) and American College of Radiology (ACR) practice guideline for the transperineal permanent brachytherapy of prostate cancer. International Journal of Radiation Oncology, Biology, Physics. 2011;79(2):335-41.

7. Crook JM, Gomez-Iturriaga A, Wallace K, Ma C, Alibhai SM, Jewett MA, et al. Comparison of healthrelated quality of life 5 years after SPIRIT (Surgical Prostatectomy [RP] versus Interstitial Radiation [BT] Intervention trial ACOSOG Z0070). International Journal of Radiation Oncology, Biology, Physics. 2010;78(Suppl 1):S76.

8. Wilt TJ, MacDonald R, Rutks I, Shamliyan TA, Taylor BC, Kane RL. Systematic review: comparative effectiveness and harms of treatments for clinically localized prostate cancer. Annals of Internal Medicine. 2008;148(6):435-48.

9. Koukourakis G, Kelekis N, Armonis V, Kouloulias V. Brachytherapy for prostate cancer: a systematic review. Advances in Urology. 2009:327945.

10. Moher D, Liberati A, Tetzlaff J, Altman DG. Preferred reporting items for systematic reviews and metaanalyses: the PRISMA statement. PLoS Medicine. 2009;6(7):e1000097.

11. Institut fur Qualitat und Wirtschaftlichkeit im Gesundheitswesen. Interstitielle Brachytherapy beim lokal begrenzten Prostatakarzinom. Abschlussbericht N04-02 [in German; executive summary in English]. Koln: Institut fur Qualitat und Wirtschaftlichkeit im Gesundheitswesen; 2007. Web site: https://www.iqwig.de/

12. Institut fur Qualitat und Wirtschaftlichkeit im Gesundheitswesen. Interstitielle Brachytherapy beim lokal begrenzten Prostatakarzinom. Rapid Report N10-01 [in German; executive summary in English]. Koln: Institut fur Qualitat und Wirtschaftlichkeit im Gesundheitswesen; 2011. Web site: https://www.iqwig.de/

13. ClinicalTrials.gov. Bethesda: National Institutes of Health; 2011. Web site: http://clinicaltrials.gov.

14. International Clinical Trials Registry Platform. Geneva: World Health Organization; 2011. Web site: http://apps.who.int/trialsearch

15. International Standard Randomised Controlled Trial Number Registry. London: ISRCTN Registry; 2010. Web site: http://www.isrctn.com/

16. UK Clinical Research Network Study Portfolio; 2010. Web site: http://public.ukcrn.org.uk/search.

17. National Cancer Institute Clinical Trials (PDQ). Bethesda: National Cancer Institute; 2010. Web site: http://www.cancer.gov/clinicaltrials/search

18. Eade TN, Horwitz EM, Ruth K, Buyyounouski MK, D'Ambrosio DJ, Feigenberg SJ, et al. A comparison of acute and chronic toxicity for men with low-risk prostate cancer treated with intensity-modulated radiation therapy or 125 I permanent implant. International Journal of Radiation Oncology, Biology, Physics. 2008;71(2):338-45.

19. Abdel-Wahab M, Reis IM, Hamilton K. Second primary cancer after radiotherapy for prostate cancer: a seer analysis of brachytherapy versus external beam radiotherapy. International Journal of Radiation Oncology, Biology, Physics. 2008;72(1):58-68. 
20. Beyer DC, Brachman DG. Failure free survival following brachytherapy alone for prostate cancer: comparison with external beam radiotherapy. Radiotherapy and Oncology. 2000;57(3):263-7.

21. Borchers H, Kirschner-Hermanns R, Brehmer B, Tietze L, Reineke T, Pinkawa M, et al. Permanent 125Iseed brachytherapy or radical prostatectomy: a prospective comparison considering oncological and quality of life results. BJU International. 2004;94(6):805-11.

22. Bradley EB, Bissonette EA, Theodorescu D. Determinants of longterm quality of life and voiding function of patients treated with radical prostatectomy or permanent brachytherapy for prostate cancer. BJU International. 2004;94(7):1003-9.

23. Burdick MJ, Reddy CA, Ulchaker J, et al. Comparison of biochemical relapse-free survival between primary Gleason score 3 and primary Gleason score 4 for biopsy Gleason score 7 prostate cancer. International Journal of Radiation Oncology, Biology, Physics. 2009;73(5):1439-45.

24. Buron C, Le Vu B, Cosset JM, Angermeier K, Altman A, Chehade N, Pommier P, Peiffert D, Delannes M, et al. Brachytherapy versus prostatectomy in localized prostate cancer: results of a French multicenter prospective medico-economic study. International Journal of Radiation Oncology, Biology, Physics. 2007;67(3):812-22.

25. D'Amico AV, Whittington R, Malkowicz SB, Schultz D, Blank K, Broderick GA, et al. Biochemical outcome after radical prostatectomy, external beam radiation therapy, or interstitial radiation therapy for clinically localized prostate cancer. Journal of the American Medical Association. 1998;280(11):969-74.

26. D'Amico AV, Tempany CM, Schultz D, Cormack RA, Hurwitz M, Beard C, et al. Comparing PSA outcome after radical prostatectomy or magnetic resonance imaging-guided partial prostatic irradiation in select patients with clinically localized adenocarcinoma of the prostate. Urology. 2003;62(6):1063-7.

27. Davis JW, Kuban DA, Lynch DF, Schellhammer PF. Quality of life after treatment for localized prostate cancer: differences based on treatment modality. Journal of Urology. 2001;166(3):947-52.

28. Elliott SP, Meng MV, Elkin EP, McAninch JW, Duchane J, Carroll PR, et al. Incidence of urethral stricture after primary treatment for prostate cancer: data from CaPSURE. Journal of Urology. 2007;178(2):529-34.

29. Ferrer M, Suarez JF, Guedea F, Fernandez P, Macias V, Marino A, et al. Health-related quality of life 2 years after treatment with radical prostatectomy, prostate brachytherapy, or external beam radiotherapy in patients with clinically localized prostate cancer. International Journal of Radiation Oncology, Biology, Physics. 2008;72(2):421-32.

30. Giberti C, Chiono L, Gallo F, Schenone M, Gastaldi E. Radical retropubic prostatectomy versus brachytherapy for low-risk prostatic cancer: a prospective study. World Journal of Urology. 2009;27(5):607-12.

31. Huang GJ, Sadetsky N, Penson DF. Health related quality of life for men treated for localized prostate cancer with long-term followup. Journal of Urology. 2010;183(6):2206-12.

32. Kirschner-Hermanns R, Brehmer B, Borchers H, Kahle C, Eble MJ, Reineke T, et al. Do patients with urodynamically proven infravesical obstruction and detrusor overactivity have a higher risk for longterm bothersome symptoms after brachytherapy in comparison to patients treated with radical prostatectomy for localized prostate cancer? Current Urology. 2008;2(3):135-41.

33. Kobuke M, Saika T, Nakanishi Y, Ebara S, Manabe D, Uesugi T, et al. Prospective longitudinal comparative study of health-related quality of life in patients treated with radical prostatectomy or permanent brachytherapy for prostate cancer. Acta Medica Okayama 2009;63(3):129-35.

34. Kupelian PA, Potters L, Khuntia D, Ciezki JP, Reddy CA, Reuther AM, et al. Radical prostatectomy, external beam radiotherapy < $72 \mathrm{~Gy}$, external beam radiotherapy $\geq 72 \mathrm{~Gy}$, permanent seed implantation, or combined seeds/external beam radiotherapy for stage T1-T2 prostate cancer. International Journal of Radiation Oncology, Biology, Physics. 2004;58(1):25-33.

35. Lee WR, Hall MC, McQuellon RP, Case LD, McCullough DL. A prospective quality-of-life study in men with clinically localized prostate carcinoma treated with radical prostatectomy, external beam radiotherapy, or interstitial brachytherapy. International Journal of Radiation Oncology, Biology, Physics. 2001;51(3):614-23.

36. Malcolm JB, Fabrizio MD, Barone BB, Given RW, Lance RS, Lynch DF, et al. Quality of life after open or robotic prostatectomy, cryoablation or brachytherapy for localized prostate cancer. Journal of Urology. 2010;183(5):1822-8. 
37. Nieder AM, Porter MP, Soloway MS. Radiation therapy for prostate cancer increases subsequent risk of bladder and rectal cancer: a population based cohort study. Journal of Urology. 2008;180(5):2005-9.

38. Ojha RP, Fischbach LA, Zhou Y, Felini MJ, Singh KP, Thertulien R. Acute myeloid leukemia incidence following radiation therapy for localized or locally advanced prostate adenocarcinoma. Cancer Epidemiology. 2010;34(3):274-8.

39. Pe ML, Trabulsi EJ, Kedika R, Pequignot E, Dicker AP, Gomella LG, et al. Effect of percentage of positive prostate biopsy cores on biochemical outcome in low-risk PCa treated with brachytherapy or 3D-CRT. Urology. 2009;73(6):1328-34.

40. Pickles T, Keyes M, Morris WJ. Brachytherapy or conformal external radiotherapy for prostate cancer: a single-institution matched-pair analysis. International Journal of Radiation Oncology, Biology, Physics. 2010;76(1):43-9.

41. Pinkawa M, Piroth MD, Holy R, Fischedick K, Schaar S, Borchers $H$, et al. Prostate-specific antigen kinetics following external-beam radiotherapy and temporary (Ir-192) or permanent (I-125) brachytherapy for prostate cancer. Radiotherapy and Oncology. 2010;96(1):25-9.

42. Sharkey J, Cantor A, Solc Z, Huff W, Chovnick SD, Behar RJ, et al. 103Pd brachytherapy versus radical prostatectomy in patients with clinically localized prostate cancer: a 12-year experience from a single group practice. Brachytherapy. 2005;4(1):34-44.

43. Smith DP, King MT, Egger S, Berry MP, Stricker PD, Cozzi P, et al. Quality of life three years after diagnosis of localised prostate cancer: population based cohort study. BMJ. 2009;339:b4817.

44. Talcott JA, Manola J, Clark JA, Kaplan I, Beard CJ, Mitchell SP, et al. Time course and predictors of symptoms after primary prostate cancer therapy. Journal of Clinical Oncology. 2003;21(21):3979-86.

45. Vassil AD, Murphy ES, Reddy CA, Angermeier KW, Altman A, Chehade N, et al. Five year biochemical recurrence free survival for intermediate risk prostate cancer after radical prostatectomy, external beam radiation therapy or permanent seed implantation. Urology. 2010;76(5):1251-7.

46. Wong WW, Vora SA, Schild SE, Ezzell GA, Andrews PE, Ferrigni RG, et al. Radiation dose escalation for localized prostate cancer: intensity-modulated radiotherapy versus permanent transperineal brachytherapy. Cancer. 2009;115(23):5596-606.

47. Zelefsky MJ, Wallner KE, Ling CC, Raben A, Hollister T, Wolfe T, et al. Comparison of the 5-year outcome and morbidity of three-dimensional conformal radiotherapy versus transperineal permanent iodine-125 implantation for early-stage prostatic cancer. Journal of Clinical Oncology. 1999;17(2):517-22.

48. Zhou EH, Ellis RJ, Cherullo E, Colussi V, Xu F, Chen WD, et al. Radiotherapy and survival in prostate cancer patients: a population-based study. International Journal of Radiation Oncology, Biology, Physics. 2009;73(1):15-23.

49. Wilt TJ, Shamliyan T, Taylor B, MacDonald R, Tacklind J, Rutks I, et al. Comparative effectiveness of therapies for clinically localized prostate cancer. Executive summary. Rockville:Agency for Healthcare Research and Quality; 2008.

50. Ollendorf DA, Hayes J, McMahon P, Kuba M, Tramontano A, Pearson SD. Brachytherapy/proton beam therapy for clinically localized, low-risk prostate cancer: final appraisal document 22.12.2008. Boston: Institute for Clinical and Economic Review; 2008. Web site: http://www.icerreview.org/

51. Surveillance Epidemiology and End Results. Stat fact sheets: prostate. Bethesda: National Cancer Institute; 2010. Web site: http://seer. cancer.gov/

52. Crook JM, Gomez-Iturriaga A, Wallace K, Ma C, Fung S, Alibhai S, et al. Comparison of healthrelated quality of life 5 years after SPIRIT: Surgical Prostatectomy Versus Interstitial Radiation Intervention Trial. Journal of Clinical Oncology. 2011;29(4):362-8.

53. Higham-Kessler J, Kodner IJ, Keune JD. Ethical counseling of an indecisive patient with low-risk prostate carcinoma: a case study. Surgery 2010;148(5):1022-5.

54. Jang TL, Bekelman JE, Liu Y, Bach PB, Basch EM, Elkin EB, et al. Physician visits prior to treatment for clinically localized prostate cancer. Archives of Internal Medicine. 2010;170(5):440-50.

55. Gillitzer R, Hampel C, Thomas C, Schmidt F, Melchior SW, Pahernik S, et al. Bevorzugte Behandlungsoptionen des lokalisierten Prostatakarzinoms von deutschen Urologen und Radioonkologen bei eigener Erkrankung. Urologe A. 2009;48(4):399-407. 
56. Hayes JH, Ollendorf DA, Pearson SD, Barry MJ, Kantoff PW, Stewart ST, et al. Active surveillance compared with initial treatment for men with low-risk prostate cancer: a decision analysis. Journal of the American Medical Association. 2010;304(21):2373-80.

57. Taylor KM, Margolese RG, Soskolne CL. Physicians' reasons for not entering eligible patients in a randomized clinical trial of surgery for breast cancer. New England Journal of Medicine. 1984;310(21):1363-7.

58. Viani GA, Stefano EJ, Afonso SL. Higher-than-conventional radiation doses in localized prostate cancer treatment: a meta-analysis of randomized, controlled trials. International Journal of Radiation Oncology, Biology, Physics. 2009;74(5):1405-18.

59. Andriole GL. Serum prostate-specific antigen: the most useful tumor marker. Journal of Clinical Oncology. 1992;10(8):1205-7.

60. Roach M 3rd, Hanks G, Thames Jr H, Schellhammer P, Shipley WU, Sokol GH, et al. Defining biochemical failure following radiotherapy with or without hormonal therapy in men with clinically localized prostate cancer: recommendations of the RTOG-ASTRO Phoenix Consensus Conference. Int International Journal of Radiation Oncology, Biology, Physics. 2006;65(4):965-74.

61. Stephenson AJ, Kattan MW, Eastham JA, Dotan ZA, Bianco FJ Jr, Lilja H, et al. Defining biochemical recurrence of prostate cancer after radical prostatectomy: a proposal for a standardized definition. Journal of Clinical Oncology. 2006;24(24):3973-8.

62. Nielsen ME, Makarov DV, Humphreys E, Mangold L, Partin AW, Walsh PC. Is it possible to compare PSA recurrence-free survival after surgery and radiotherapy using revised ASTRO criterion - "nadir + 2"? Urology 2008;72(2):389-93.

63. Uchio EM, Aslan M, Wells CK, Calderone J, Concato J. Impact of biochemical recurrence in prostate cancer among US veterans. Archives of Internal Medicine. 2010;170(15):1390-5.

64. Thompson A, Keyes M, Pickles T, Palma D, Moravan V, Spadinger I, et al. Evaluating the Phoenix definition of biochemical failure after 1251 prostate brachytherapy: can PSA kinetics distinguish PSA failures from PSA bounces? International Journal of Radiation Oncology, Biology, Physics. 2010;78(2):415-21.

65. Caloglu M, Ciezki J. Prostate-specific antigen bounce after prostate brachytherapy: review of a confusing phenomenon. Urology. 2009;74(6):1183-90.

66. Medizinischer Dienst des Spitzenverbandes Bund der Krankenkassen, Kompetenz Centrum Onkologie, Institut fur Qualitat und Wirtschaftlichkeit im Gesundheitswesen, GKV-Spitzenverband. Praferenzbasierte Studie zur Evaluation der interstitiellen Brachytherapie beim lokal begrenzten Prostatakarzinom mit niedrigem Risiko; Studienkonzeption. Berlin: Gemeinsamer Bundesausschuss; 2009 Web site: http://www.g-ba.de/

67. Parulekar W. A phase III study of active surveillance therapy against radical treatment in patients diagnosed with favourable risk prostate cancer (START) [identifier NCT00499174]. Web site: http://clinicaltrials.gov/

68 Bottomley D. SABRE 1: Surgery Against Brachytherapy; a Randomised Evaluation. Randomised controlled trial of brachytherapy versus radical prostatectomy in good risk prostate cancer: a feasibility study. London: ISRCTN Registry; 2010. Web site: http://www.isrctn.com/

69. Brachman DG, Thomas T, Hilbe J, Beyer DC. Failure-free survival following brachytherapy alone or external beam irradiation alone for T1-2 prostate tumors in 2222 patients: results from a single practice. International Journal of Radiation Oncology, Biology, Physics. 2000;48(1):111-7.

70. Krupski T, Petroni GR, Bissonette EA, Theodorescu D. Quality-of-life comparison of radical prostatectomy and interstitial brachytherapy in the treatment of clinically localized prostate cancer. Urology. 2000;55(5):736-42.

71. Potters L, Klein EA, Kattan MW, Reddy CA, Ciezki JP, Reuther AM, et al. Monotherapy for stage T1-T2 prostate cancer: radical prostatectomy, external beam radiotherapy, or permanent seed implantation. Radiotherapy and Oncology. 2004;71(1):29-33.

72 Sharkey J, Cantor A, Solc Z, Huff W, Chovnick SD, Behar RJ, et al. Brachytherapy versus radical prostatectomy in patients with clinically localized prostate cancer. Current Urology Reports. 2002;3(3):250-7. 
73. Andres AM, Mato AS. Choosing the optimal unconditioned test for comparing two independent proportions. Comput Statistics and Data Analysis. 1994;17(5):555-74.

74. Tierney JF, Stewart LA, Ghersi D, Burdett S, Sydes MR. Practical methods for incorporating summary time-to-event data into metaanalysis. Trials. 2007;8:16.

Supplementary tables associated with this article can be found, in the online version, at doi: 10.1016/j.eururo.2011. 06.044. 


\section{Negative-pressure wound therapy:}

\section{Systematic review of randomized controlled}

\section{trials}

Peinemann F, Sauerland S. Negative-pressure wound therapy: systematic review of randomized controlled trials. Deutsches Arzteblatt International. 2011;108(22):381-9.

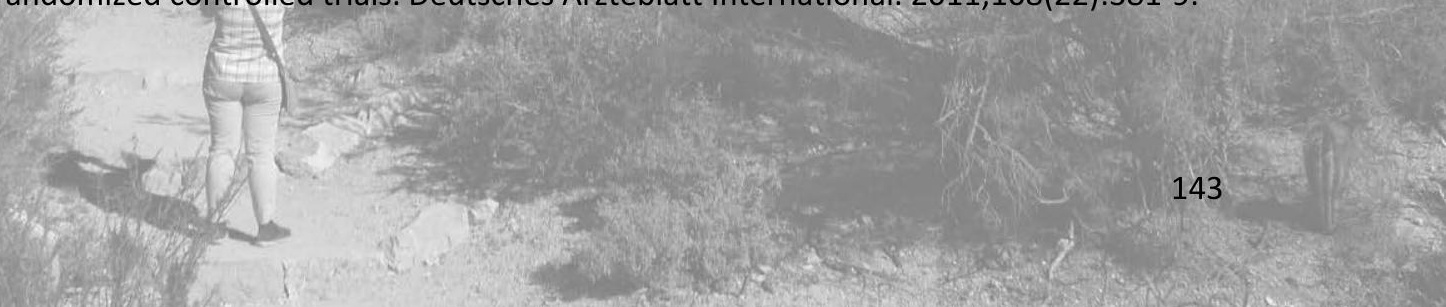




\section{Abstract}

Background In negative-pressure wound therapy (NPWT), a wound is covered with an airtight dressing, and negative pressure is applied. This is thought to promote healing. We evaluated NPWT with an updated, systematic review of the literature.

Methods We systematically searched the PubMed and Cochrane Library databases for randomized, controlled trials (RCTs) of NPWT for the treatment of acute or chronic wounds. The primary outcome was complete wound closure.

Results We found reports of 9 RCTs in addition to the 12 covered by earlier IQWiG reviews of this topic. Five of the 9 new trials involved NPWT systems that are not on the market. The frequency of complete wound closure is stated in only 5 of the 9 new reports; a statistically significant effect in favor of NPWT was found in only two trials. The results of 8 of the 9 new trials are hard to interpret, both because of apparent bias and because diverse types of wounds were treated.

Conclusion Although there may be a positive effect of NPWT, we did not find clear evidence that wounds heal any better or worse with NPWT than with conventional treatment. Good RCTs are still needed to evaluate NPWT. 


\section{Introduction}

Negative-pressure wound therapy (NPWT) is a sealed wound-care system and is particularly indicated for large chronic persistent wounds and acute complicated wounds $[1,2]$. The system consists of an electronically controlled pump and a foam dressing that drains the wound. An adjustable negative pressure is applied via an airtight adhesive film that covers the wound. NPWT drains wound exudate and is thought to promote blood circulation and healing.

This systematic review aims to update the systematic reviews on NPWT previously published by the Institute for Quality and Efficiency in Health Care (Institut für Qualität und Wirtschaftlichkeit im Gesundheitswesen, IQWiG) [3-5]. The aim of these reports was to evaluate wound healing and adverse events following NPWT in comparison to conventional treatment in patients with acute or chronic wounds.

\section{Methods}

The reports within this systematic review were compiled in accordance with the principles of the PRISMA statement [e1].

\section{Inclusion criteria}

The research included randomized controlled trials (RCTs) involving patients with acute and chronic wounds. Because of the increasing number of RCTs conducted in recent years, non-randomized trials were not included in the evaluation. The intervention under examination was NPWT. As in the previous reports, studies of systems not commercially available were included in addition to commercially available systems. In the systems that were not commercially available, negative pressure was generated by a suction pump for chest drainage, a central vacuum system or Redon bottles, for example. The comparator treatment was conventional dressings, generally saline-soaked gauze dressings. There was no minimum number of patients per trial. There was no restriction on language or year of publication. However, articles in languages other than English or German were only included in the review if there were translations available that made it possible to assess the trials concerned.

\section{Search strategy}

Unlike the earlier IQWiG reports, this review included only RCTs [3, 4]. The simplified search strategy used (eTable 1) identified all 12 RCTs already included in PubMed and the Cochrane Library's Clinical Trials on November 7, 2010. EMBASE and CINAHL were not searched, as they had not yielded any additional relevant results in previous 
searches [6]. The search results from the two included databases were imported into EndNote X3 (Thomson Reuters) and duplicates were deleted manually.

The electronic trial registers ClinicalTrials.gov (URL: http://clinicaltrials.gov/; registration numbers: NCT followed by eight digits) and the International Standard Randomised Controlled Trial Number Register (URL: www.controlled-trials.com/; registration numbers: ISRCTN followed by eight digits) were searched for completed and ongoing trials on January 15, 2011, using the following search terms: "vacuum assisted closure"; "vac"; "negative pressure wound therapy"; "npwt".

\section{Study selection}

First of all, articles were excluded on the basis of their title and abstract if these did not mention NPWT or it was clear that the trials were not randomized. The full text of the remaining articles was then examined. The reasons for excluding each individual study were recorded internally. All stages of study selection were performed independently by two separate individuals. Differences of opinion were discussed until a common decision could be made. Potential for bias

The risk of bias within trials was examined using the criteria stated in Table 1. A positive answer in all five categories was established at the outset as indicating a low potential for bias. The potential effect of publication bias was assessed by updating a previous study [6] identifying all the trials that were terminated early.

\section{Data collection and analysis}

All stages of data extraction were performed by one person and checked by another. Where there were differences of opinion, consensus was reached following discussion. The results were subjected to descriptive analysis. Study characteristics were extracted as shown in Table 2.

Complete wound closure, a variable used both as raw data and as a Kaplan-Meier estimator, was the primary endpoint. The U.S. Food and Drug Administration's (FDA) 2006 Guidance for Industry [7] defines complete wound closure as "skin closure without drainage or dressing requirements". No meta-analysis was performed, as the primary trials were highly heterogenous.

The following dependent variables were used as secondary endpoints:

- Adverse events, such as:

- Death

- Secondary amputations

- Fistula formation

- Wound infection

- Time to complete wound closure

- Reduction in wound size

- Health-related quality of life 


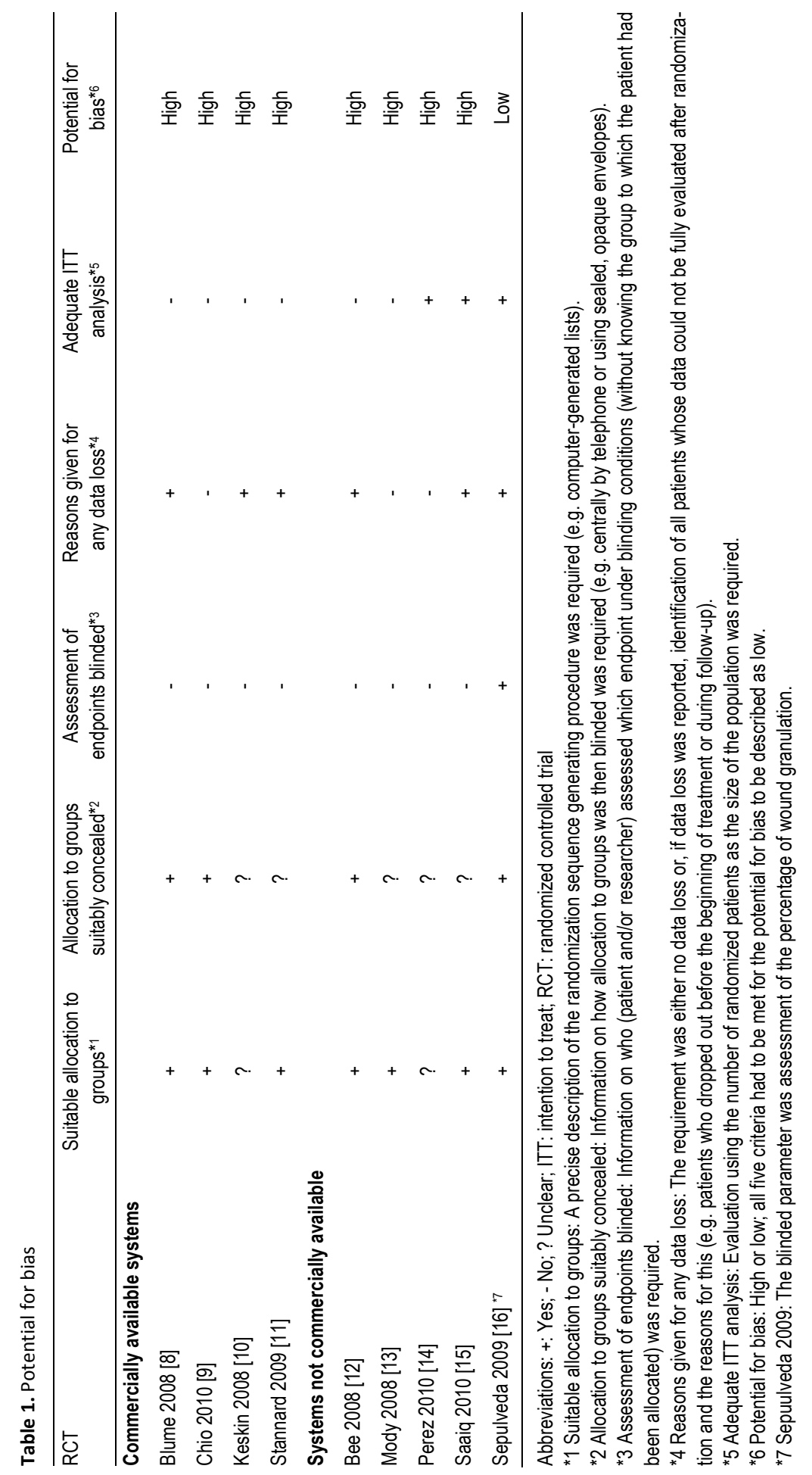




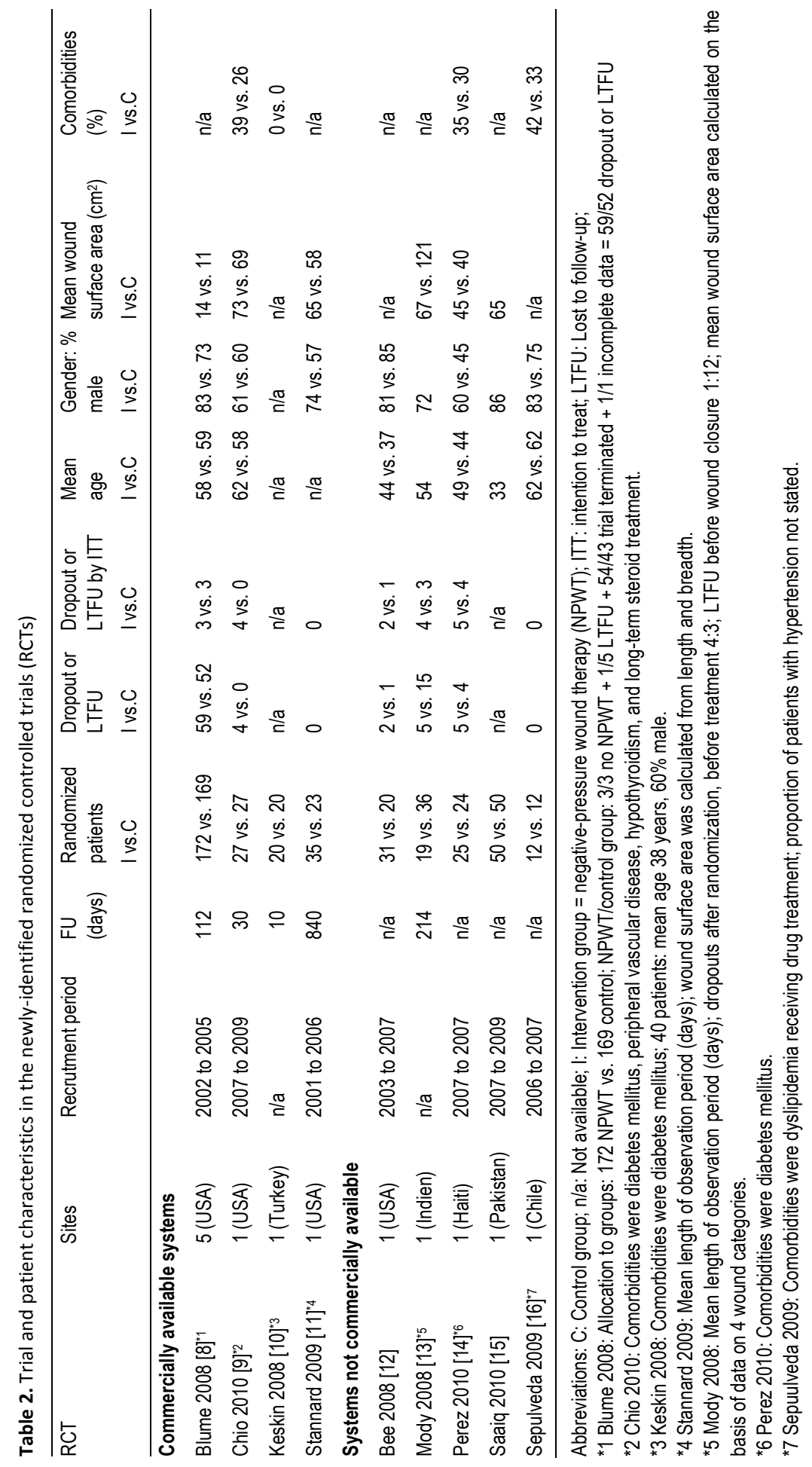




\section{Results}

\section{Search of the literature}

Of the 249 articles initially imported, 176 remained after duplicates had been deleted. In 137 cases it was clear from the title and/or abstract that the article did not meet the inclusion criteria (eFigure; online at doi: 10.3238/arztebl.2011.0381). A further 30 potentially relevant articles were excluded after they had been read in full. A total of nine new RCTs were identified in the updated search [8-16]. Five of the nine new RCTs examined systems that were not commercially available [12-16]. This left a total of 21 RCTs available for our research: seven [e2-e8] from IQWiG's Final Report N04-03 [3], five RCTs in four articles [e9-e12] from IQWiG's Rapid Report N06-02 [4], and nine RCTs from the updated search.

\section{Underlying data}

An overview of trial characteristics is provided in Table 2. The mean age of the participants, most of whom were male, was generally over 50 . The mean wound surface area was numerically slightly greater in intervention groups than in control groups in all trials in which this information was given separately. Detailed descriptions of inclusion and exclusion criteria, treatments under research, comparator treatments, analyzed endpoints, and their definitions can be found in eTables 2 and 3 (online at doi: 10.3238/arztebl.2011.0381). In most trials comorbidities were not reported. The trials examined many different types of acute and chronic wound (eTable 4; online at doi: 10.3238/arztebl.2011.0381).

\section{Potential for bias}

Eight of the nine trials had a high potential for bias (Table 1). The conditions for generating randomization sequences and treatment blinding were unclear in some trials, with the result that random allocation of patients to treatment groups was not traceable in these trials. In eight of the nine trials it was not reported or not clear that endpoints had been measured in blinded conditions, although this was feasible. It should be stressed that quality-of-life results from non-blinded trials are prone to a particularly high potential for bias. Only one of the trials met all five criteria for low potential for bias. In six of the nine new trials, up to $20 \%$ of the data from randomized patients were not included in the evaluation, and there was thus no appropriate intention-to-treat analysis.

Investigation of publication bias revealed a further four RCTs that had been terminated early, in addition to the five that had already been reported on: NCT00121537, NCT00691821, NCT00837096, and NCT01108276. 
The following reasons were given for terminating trials early:

- Inclusion criteria not met

- Patient withdrawal

- Low recruitment levels

- Changes in clinical practice

- Errors in study planning

Eight ongoing RCTs were also identified among the registered trials (NCT00582179, NCT00582998, NCT00635479, NCT01200563, NCT01191567, NCT00548314, and NCT00789659).

\section{Primary endpoint}

The proportion of patients with complete wound closure was reported in only five of the nine new trials $[8,12-15]$ (Table 3 ). In four trials the difference between groups was statistically insignificant. Only two trials showed a statistically significant effect in favor of NPWT [15].

\section{Secondary endpoints}

Time to wound closure was reported in four of the nine new trials $[8,13,14,16]$ (Table 4). Three trials showed a statistically significant difference between groups in favor of NPWT $[8,14,16]$, and in one trial the difference was statistically insignificant [13]. There was a statistically significant difference in reduction in wound size in favor of NPWT in one of the nine new trials [8].

Adverse events were investigated in eight of the nine new trials $[8,9,11,12]$. Statistically significant differences in favor of NPWT were reported in three trials. The adverse events concerned were secondary amputations [8], the proportion of patients with deep wound infections [11], and the secondary surgery rate [14].

Differences in mortality rates between treatment groups were statistically insignificant $[8,12,15,16]$. This was also the case for most of the wound complication rates in four trials $[8,9,12,13]$.

One trial investigated health-related quality of life, using questionnaires [11]. The results for the physical component (following treatment) were better in the NPWT group, and the difference was statistically significant. For the mental component, meanwhile, the results were comparable.

Another trial revealed more fear of treatment, e.g. due to possible pain, in the NPWT group than in the control group, and the difference was statistically significant [10]. 


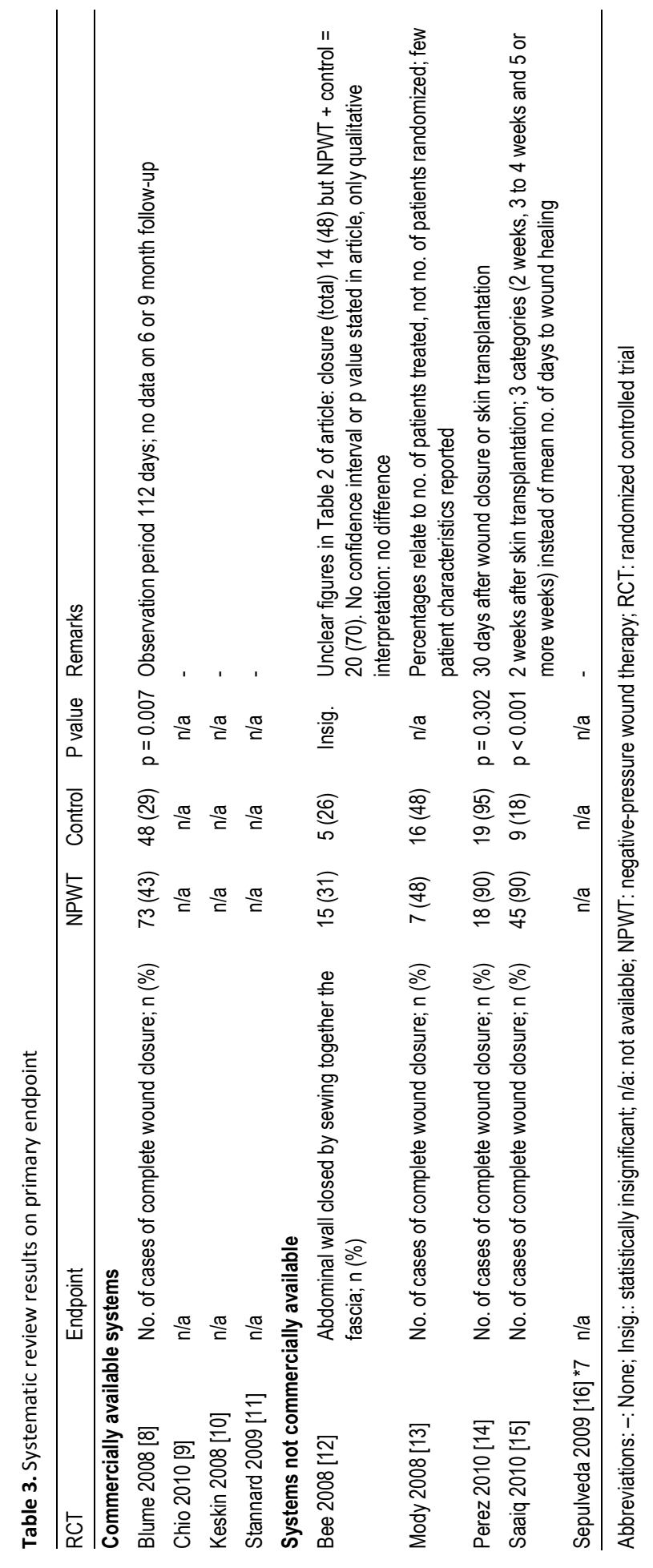




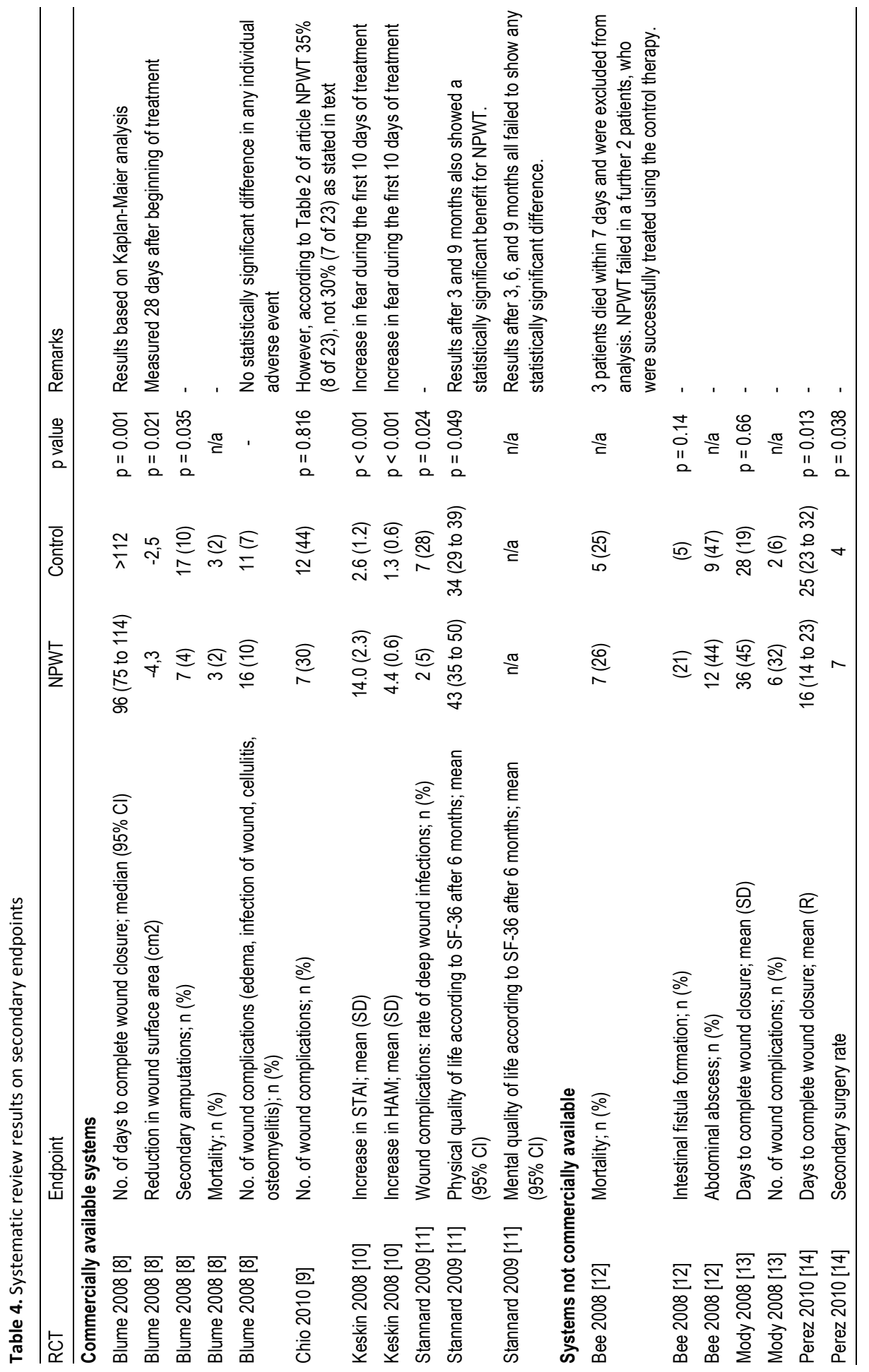




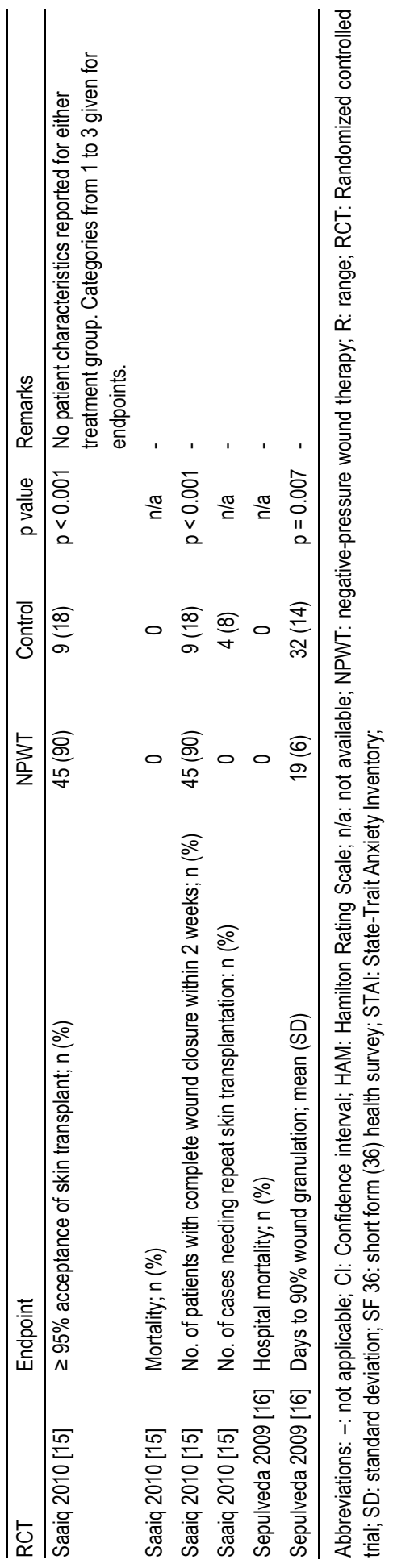




\section{Summary of results}

Table 5 shows the qualitative results of all 21 RCTs included in the present systematic review, in terms of the endpoints studied. The quantitative results of the 12 older RCTs covered in IQWiG reports can be found in the corresponding publications [3, 4], and the results of the nine new RCTs are shown in Tables 3 and 4.

Table 5. Summary of results of all 21 randomized controlled trials (RCTs) included to date

\begin{tabular}{|c|c|c|c|c|c|}
\hline \multirow[t]{2}{*}{$\overline{\mathrm{RCT}}$} & \multirow{2}{*}{$\begin{array}{l}\text { Primary endpoint } \\
\text { Complete } \\
\text { wound closure }\end{array}$} & \multicolumn{4}{|c|}{ Secundary endpoints } \\
\hline & & $\begin{array}{l}\text { Time to complete } \\
\text { wound closure }\end{array}$ & $\begin{array}{l}\text { Reduction in } \\
\text { wound size }{ }^{* 1}\end{array}$ & Mortality & $\begin{array}{l}\text { Other adverse } \\
\text { events }^{*} 2,3\end{array}$ \\
\hline Armstrong 2005 [e2] & +++ & +++ & $\mathrm{n} / \mathrm{a}$ & $(+)$ & $(+)$ \\
\hline Bee 2008 [12] & $(+)$ & $\mathrm{n} / \mathrm{a}$ & $\mathrm{n} / \mathrm{a}$ & $(-)$ & $(-)$ \\
\hline Blume 2008 [8] & +++ & +++ & +++ & $(+)$ & $(+)$ \\
\hline Braakenburg 2006 [e9] & n/a & $(+)$ & $(+)$ & $(+)$ & $(-)$ \\
\hline Chio 2010 [9] & $\mathrm{n} / \mathrm{a}$ & $\mathrm{n} / \mathrm{a}$ & $\mathrm{n} / \mathrm{a}$ & $\mathrm{n} / \mathrm{a}$ & $(+)$ \\
\hline Eginton 2003 [e3] & $\mathrm{n} / \mathrm{a}$ & $\mathrm{n} / \mathrm{a}$ & +++ & $\mathrm{n} / \mathrm{a}$ & $\mathrm{n} / \mathrm{a}$ \\
\hline Ford 2002 [e4] & $(-)$ & $\mathrm{n} / \mathrm{a}$ & $(+)$ & $\mathrm{n} / \mathrm{a}$ & $(-)$ \\
\hline Joseph 2000 [e5] & $\mathrm{n} / \mathrm{a}$ & +++ & +++ & $\mathrm{n} / \mathrm{a}$ & +++ \\
\hline Keskin $2008[10]^{* 4}$ & $\mathrm{n} / \mathrm{a}$ & $\mathrm{n} / \mathrm{a}$ & $\mathrm{n} / \mathrm{a}$ & $\mathrm{n} / \mathrm{a}$ & $\mathrm{n} / \mathrm{a}$ \\
\hline Llanos 2006 [e10] & $\mathrm{n} / \mathrm{a}$ & $\mathrm{n} / \mathrm{a}$ & +++ & $\mathrm{n} / \mathrm{a}$ & $\mathrm{n} / \mathrm{a}$ \\
\hline Mody 2008 [13] & $(-)$ & $(-)$ & $\mathrm{n} / \mathrm{a}$ & $\mathrm{n} / \mathrm{a}$ & $(-)$ \\
\hline Moisidis 2004 [e6] & $\mathrm{n} / \mathrm{a}$ & $\mathrm{n} / \mathrm{a}$ & $\mathrm{n} / \mathrm{a}$ & $\mathrm{n} / \mathrm{a}$ & $\mathrm{n} / \mathrm{a}$ \\
\hline Mouës 2004 [e6] & $\mathrm{n} / \mathrm{a}$ & $(+)$ & +++ & $\mathrm{n} / \mathrm{a}$ & $\mathrm{n} / \mathrm{a}$ \\
\hline Perez 2010 [14] & $(-)$ & +++ & $\mathrm{n} / \mathrm{a}$ & $\mathrm{n} / \mathrm{a}$ & -- \\
\hline Saaiq 2010 [15] & +++ & +++ & $\mathrm{n} / \mathrm{a}$ & 0 & $\mathrm{n} / \mathrm{a}$ \\
\hline Sepulveda 2009 [16] & $\mathrm{n} / \mathrm{a}$ & +++ & $\mathrm{n} / \mathrm{a}$ & 0 & $\mathrm{n} / \mathrm{a}$ \\
\hline Stannard 2006a $[\mathrm{e} 11]^{* 5}$ & $\mathrm{n} / \mathrm{a}$ & $\mathrm{n} / \mathrm{a}$ & $\mathrm{n} / \mathrm{a}$ & $\mathrm{n} / \mathrm{a}$ & $(-)$ \\
\hline Stannard 2006b [e11] & $\mathrm{n} / \mathrm{a}$ & $\mathrm{n} / \mathrm{a}$ & $\mathrm{n} / \mathrm{a}$ & $\mathrm{n} / \mathrm{a}$ & 0 \\
\hline Stannard $2009[11]^{* 6}$ & $\mathrm{n} / \mathrm{a}$ & $\mathrm{n} / \mathrm{a}$ & $\mathrm{n} / \mathrm{a}$ & $\mathrm{n} / \mathrm{a}$ & --- \\
\hline Vuerstaek 2006 [e12] & $\mathrm{n} / \mathrm{a}$ & +++ & +++ & $(-)$ & $(-)$ \\
\hline Wanner 2003 [e8] & $\mathrm{n} / \mathrm{a}$ & $(+)$ & $(+)$ & $\mathrm{n} / \mathrm{a}$ & $\mathrm{n} / \mathrm{a}$ \\
\hline
\end{tabular}

Abbreviations: +++: statistically significant difference in favor of negative-pressure wound therapy (NPWT); ---: statistically significant difference in favor of comparator treatment; (+): insignificant difference in favor of NPWT; $(-)$ : insignificant difference in favor of comparator treatment; 0 : no difference; n/a: not available

*1 Wound size: Surface area or volume, statistically significant results reported primarily

*2 Pain: Braakenburg 2006 referred to a study on pain but did not report its results; Vuerstaek 2006 reported a statistically significant benefit of NPWT, but there were already statistically significant differences in pain between the two groups initially (pain was lower at baseline in the NPWT group). This was not suitably taken into account in the evaluation.

*3 Further results that were only reported singly and were therefore not included in the table: amputations: Armstrong 2005: (+); Blume 2008: +++; Braakenburg 2006 (+). Quality of life: Keskin 2008: ---; Stannard 2009: +++; Vuerstaek 2006 :

-- (in the first week of treatment)

*4 Keskin 2008: fear during the first 10 days

*5 Stannard 2006a: trial on hematomas; Stannard 2006b: trial on incisions in fractures

${ }^{*} 6$ Stannard 2009: statistically significant difference after 3, 6 and 9 months 


\section{Discussion}

\section{Primary endpoint: complete wound closure}

The results on complete wound closure are not homogenous, and it is impossible to be sure that NPWT performs better than the control treatments. Effects in favor of NPWT were reported in some trials, and no opposing effects could be detected in other trials. As a result, other systematic reviews also currently conclude that an additional benefit of NPWT in comparison to other types of wound treatment has not been proved [17, 18].

\section{Secondary endpoints}

Time to wound closure: In terms of the endpoint "time to wound closure," effects in favor of NPWT groups were reported in most cases. However, there were considerable differences between trials in terms of the methods used to measure and evaluate wound closure; particularly problematic is the fact that no blinding was used when this endpoint was measured. In addition, most trials did not investigate whether wounds that had healed successfully actually remained closed in the longer term. The results thus cannot be interpreted as showing definitively that any one treatment is superior.

Adverse events: The results on adverse events were not homogenous. For some specific complications, such as secondary amputations, statistically significant effects in favor of NPWT groups were reported, but for a number of other adverse events no statistically significant difference was detected. No opposing results, i.e. statistically significant effects in favor of comparator groups, were recorded.

The difference between the number of patients included in trials and the number of patients treated worldwide is particularly striking when describing adverse effects. Data from the RCTs are of only limited use in evaluating the frequency of adverse events. It would be more appropriate if sufficiently large-scale RCTs were conducted.

The FDA recently issued a report on six deaths and 77 other complications that were reported within a two-year period in connection with NPWT [19]. All the deaths were caused by acute hemorrhages, and known contraindications for NPWT (e.g. a large blood vessel exposed) had clearly been overlooked. Many of the deaths occurred in outpatient care or care homes, which highlights the need to monitor therapy. In this regard, it should be noted that trials of NPWT were generally conducted in hospitals.

\section{Potential for bias}

Of the nine included RCTs, eight have a high potential for bias. This limits the value of the results on the endpoints reported on. The difficulties of conducting RCTs and the 
arguments for and against including non-randomized trials when assessing medical devices and surgeries have been extensively described [e13, e14].

\section{Heterogeneity}

Strikingly, almost all the trials of commercially available NPWT systems were conducted in the USA. It seems that in developing countries the commercially available systems are very difficult to afford, and as a result such countries have developed their own NPWT systems, sometimes from very simple materials. Trials of these are now being conducted. This wide variety of NPWT systems makes the data considerably more difficult to interpret, although it is still largely unclear whether or not there are genuine differences between commercially available NPWT systems and those that are not commercially available. Also, the treatments administered to comparator groups (conventional dressings) were defined in different ways in different trials, probably as a result of differences between patient populations. This too can cause heterogeneity between trials and so limit the comparability of trial results.

\section{Publication bias}

According to the website of manufacturer KCl (August 2010), NPWT has been prescribed to more than 3 million patients, and some 600 peer-reviewed articles have been published on the subject. This and the low total number of RCTs make it astonishing that despite the frequency of acute and chronic wounds and the widespread use of NPWT a considerable number of trials have apparently had to be terminated due to recruitment problems. Although it seems that some planned RCTs had not even been started or were terminated soon after they began, the fact that there are RCTs on which nothing has been published casts doubt on the completeness of the data available for assessment of the benefits of NPWT.

\section{Summary}

\section{Pool of trials}

As the wounds for which NPWT is used vary greatly in their etiology, chronicity, size, and location, there is considerable variation between trials in the selection and definition of endpoints. This alone makes a quantitative summary of all trials of questionable value. In trials that provide results on wound healing, these results are mostly favorable for NPWT. These results are partly supported by statistically significant effects regarding the primary endpoint "complete wound closure" and the secondary end- 
points "time to complete wound closure", "reduction in wound size", and "amputations".

The results on overall mortality and total adverse events are inconsistent. A considerable proportion of the total deaths were probably not caused by treatment. Individual adverse events are reported too infrequently and inconsistently for conclusions to be drawn. Also, the group of adverse events as a whole is highly heterogenous. Some of the few results on quality of life are limited to the endpoint "fear" alone. Only a few trials investigated pain (in particular when dressings were changed).

The available pool of only 21 RCTs remains too small to provide a clear answer to the question of whether or not NPWT is superior to conventional wound treatment. The difficulty of interpreting the RCTs is caused essentially by the heterogeneity of the various indications for NPWT on the one hand, and the considerable qualitative and quantitative shortcomings of the trials on the other.

\section{Outlook}

Germany's statutory health insurers jointly invited tenders for two RCTs on NPWT in July 2010 [20, e15]. Patients with diabetic foot ulcers or iatrogenic wounds must be randomized to receive NPWT or conventional wound treatment, and patient numbers must be sufficient in each treatment group and for each indication. It is hoped that these trials will provide the further evidence needed for a decision on NPWT to be made. Eight other ongoing registered RCTs were also identified.

\section{Conclusion}

Although NPWT may have a positive effect on wound healing, there is no proof that it is either superior or inferior to conventional wound treatment. Further RCTs of good methodological quality are required. 


\section{References}

1. Argenta LC, Morykwas MJ. Vacuum-assisted closure: a new method for wound control and treatment: clinical experience. Annals of Plastic Surgery. 1997;38(6):563-76.

2. Fleischmann W, Strecker W, Bombelli M, Kinzl L. Vakuumversiegelung zur Behandlung des Weichteilschadens bei offenen Frakturen. Unfallchirurg. 1993;96(9):488-92.

3. Institut für Qualitat und Wirtschaftlichkeit im Gesundheitswesen. Vakuumversiegelungstherapie von Wunden. Abschlussbericht N04-03. Koln: Institut für Qualitat und Wirtschaftlichkeit im Gesundheitswesen; 2006.

4. Institut für Qualitat und Wirtschaftlichkeit im Gesundheitswesen. Vakuumversiegelungstherapie von Wunden. Rapid Report N06-02. Koln: Institut für Qualitat und Wirtschaftlichkeit im Gesundheitswesen; 2007.

5. Gregor S, Maegele M, Sauerland S, Krahn JF, Peinemann F, Lange S. Negative pressure wound therapy: a vacuum of evidence? Archives of Surgery. 2008;143(2):189-96.

6. Peinemann F, McGauran N, Sauerland S, Lange S. Negative pressure wound therapy: potential publication bias caused by lack of access to unpublished study results data. BMC Medical Research Methodology. 2008;8:4.

7. Food and Drug Administration. Draft guidance for industry. Chronic cutaneous ulcer and burn wounds developing products for treatment. Silver Spring: U.S. Food and Drug Administration; 2006.

8. Blume PA, Walters J, Payne W, Ayala J, Lantis J. Comparison of negative pressure wound therapy using vacuum-assisted closure with advanced moist wound therapy in the treatment of diabetic foot ulcers: a multicenter randomized controlled trial. Diabetes Care. 2008;31(4):631-6.

9. Chio EG, Agrawal A. A randomized, prospective, controlled study of forearm donor site healing when using a vacuum dressing. Otolaryngology and Head and Neck Surgery. 2010;142(2):174-8.

10. Keskin M, Karabekmez FE, Yilmaz E, Tosun Z, Savaci N. Vacuum-assisted closure of wounds and anxiety. Scandinavian Journal of Plastic and Reconstructive Surgery and Hand Surgery. 2008;42(4):202-5.

11. Stannard JP, Volgas DA, Stewart R, McGwin G Jr, Alonso JE. Negative pressure wound therapy after severe open fractures: a prospective randomized study. Journal of Orthopaedic Trauma. 2009;23(8):552-7.

12. Bee TK, Croce MA, Magnotti L, Zarzaur BL, Maish GO 3rd, Minard G, et al. Temporary abdominal closure techniques: a prospective randomized trial comparing polyglactin 910 mesh and vacuum-assisted closure. The Journal of Trauma. 2008;65(2):337-42.

13. Mody GN, Nirmal IA, Duraisamy S, Perakath B. A blinded, prospective, randomized controlled trial of topical negative pressure wound closure in India. Ostomy/Wound Management. 2008;54(12):36-46.

14. Perez D, Bramkamp M, Exe C, von Ruden C, Ziegler A. Modern wound care for the poor: a randomized clinical trial comparing the vacuum system with conventional saline-soaked gauze dressings. American Journal of Surgergy. 2010;199(1):14-20.

15. Saaiq M, Hameed Ud D, Khan MI, Chaudhery SM. Vacuum-assisted closure therapy as a pretreatment for split thickness skin grafts. Journal of the College of Physicians and Surgeons - Pakistan. 2010;20(10):675-9.

16. Sepulveda G, Espindola M, Maureira M, Sepuulveda E, Ignacio Fernandez J, Oliva C, et al. Negativepressure wound therapy versus standard wound dressing in the treatment of diabetic foot amputation. A randomised controlled trial. Cirurgia Espaniola. 2009;86(3):171-7.

17. Agency for Healthcare Research and Quality. Negative pressure wound therapy devices. Technology assessment report, project ID: WNDT1108. Rockville: Agency for Healthcare Research and Quality; 2009.

18. Ubbink DT, Westerbos SJ, Evans D, Land L, Vermeulen H. Topical negative pressure for treating chronic wounds. Cochrane Database of Systematic Reviews. 2008;(3):CD001898.

19. Food and Drug Administration. Serious complications associated with negative pressure wound therapy systems. Silver Spring: U.S. Food and Drug Administration; 2009.

20. Tenders Electronic Daily. Vergabeverfahren Studie zur Vakuumversiegelungs-therapie. Luxembourg: European Union; 2010. 
Supplementary eReferences, eFigures, and eTables associated with this article can be found, in the online version, at doi: 10.3238/arztebl.2011.0381. 



\section{CHAPTER 7}

Development of an algorithm to provide awareness in choosing study designs for inclusion in systematic reviews of health care interventions - a method study

\section{Manuscript submitted}

Peinemann F, Kleijnen J. Development of an algorithm to provide awareness in choosing study designs for inclusion in systematic reviews of health care interventions - a method study. 


\begin{abstract}
Objectives We developed an algorithm that aims to provide guidance and awareness for various design characteristics suitable to answer distinct research questions in health care interventions.
\end{abstract}

Design In a method study, we tranferred information from electronic databases and major institutional handbooks into a non-systematic review. Based on the retrieved data, we developed an algorithm to provide guidance for allocating various study designs to specific research questions.

Setting There were no limits on the level of care and the geographical location.

Participants There were no limits on the type of diagnosis and the characteristics of patients.

Interventions There were no limits on the type of medical treatment or public health intervention.

Primary and secondary outcome measures The primary outcome was the development of an algorithm that incorporates the length of follow up (long, short), the frequency of events (rare, frequent), the types of outcome (death, disease, discomfort, disability, dissatisfaction), considers practical or ethical concerns, and unavailable best evidence. The secondary outcome was to show the usefulness of the algorithm while applying it to selected systematic reviews.

Results We developed a guidance-support tree and provided examples for explaining the critical guidance points and for testing the usefulness of the algorithm. We could follow and confirm the appropriateness of the pathways for all described examples of four selected systematic reviews. The algorithm cannot be applied without the consideration of disease-specific circumstances and aims of interventions.

Conclusions We are confident that the algorithm can assist to bring seminal features of a systematic review to the attention of anyone who is planning to conduct a systematic review. It aims to provide awareness not regulation. We think that it may reduce the time burden on review authors and may contribute to the production of a higher quality review.

\title{
Strengths and limitations of this study
}

- We developed an algorithm to provide guidance for allocating various study designs to specific research questions. This can be viewed as a response to the lack of comprehensive guidance in major published methods documents.

- The terms used for defining the critical decision points of the algorithm, such as short versus long follow-up and rare versus frequent events need to be interpreted in the context of the disease and may be unclear and not useful if used as general terms. 
- Disease-specific circumstances and aims of interventions always have to be taken into account during application of the algorithm.

- We could follow and confirm the appropriateness of the pathways during the application of the algorithm on four selected systematic reviews.

- The testing was conducted retrospectively with systematic reviews that were already completed. This approach is far from the everyday working condition and the approach may be considerably biased by the expectations of the authors.

\begin{tabular}{|c|c|}
\hline Abbreviation & Term \\
\hline $\mathrm{AE}$ & Adverse events \\
\hline СCT & Nonrandomised controlled clinical trial \\
\hline CEBM & Centre of Evidence-Based Medicine \\
\hline CRD & Centre for Reviews and Dissemination \\
\hline EBM & Evidence-based medicine \\
\hline EBRT & External beam radiotherapy \\
\hline $\mathrm{HDCT}$ & High-dose chemotherapy \\
\hline HRQL & Health-related quality of life \\
\hline HSCT & Haematopoietic stem cell transplantation \\
\hline IST & Immunosuppressive therapy \\
\hline LDR-BT & Permanent interstitial low-dose-rate brachytherapy \\
\hline MSD & Human leukocyte antigen matched sibling donors \\
\hline NICE & National Institute for Health and Care Excellence \\
\hline NPT & No primary therapy \\
\hline NPWT & Negative pressure wound therapy \\
\hline NRSTS & Nonrhabdomyosarcoma soft tissue sarcomas \\
\hline ORDR & Office of Rare Diseases Research \\
\hline OS & Overall survival \\
\hline $\mathrm{PCa}$ & Prostate cancer \\
\hline PICOTS-SD & Population - Intervention - Comparator - Outcome - Time - Setting - Study design \\
\hline RCT & Randomised controlled trial \\
\hline $\mathrm{RP}$ & Radical prostatectomy \\
\hline SAA & Acquired severe aplastic anaemia \\
\hline SDCT & Standard-dose chemotherapy \\
\hline
\end{tabular}




\section{Introduction}

When evaluating health care interventions, different categories of intervention such as medicinal versus non-medicinal therapy, and different categories of outcomes such as intended effects, adverse events, or health-related quality of life may sometimes be best answered by multiple study designs. Some designs have features, which preferably match the requirements of specific parts of a research question. Exclusively using data from randomised trials (RCTs) to evaluate whether an intervention might work has a number of limitations [1]. For example, RCTs may not be appopropriate to estimate the incidence of rare (adverse) events. Study designs that incorporate the data of a large number of participants of interest such as case control studies, case series, registry analyses, or cross-sectional analyses may complement the information on such rare, but important events. We have gathered some examples of research questions that cannot or only with great difficulty be investigated in RCTs (Table S1). A practical concern may arise with low numbers of patients with a rare disease. It might be difficult to conduct an RCT to evaluate patients with acquired severe aplastic anaemia. An ethical concern may arise with the treatment of severe diseases or life-threatening treatments. It might be obsolete to conduct an RCT to evaluate a new experimental treatment of patients with pancreatic cancer.

The methods of conducting systematic reviews of health care interventions are major components of 'evidence-based' medicine (EBM). In 2000, Sackett et al. defined EBM as the integration of 'best' research evidence with individual clinical expertise, patient values and expectations, and 'best' external research evidence [2]. This definition may be visualized by three overlapping circles in a Venn diagram [3]. The area of intersection, where all three different resources meet, should represent the EBM. To classify more valid and less valid information, the 'levels of evidence' specify a hierarchical order for various research designs based on their internal validity. The highest level of valid data, that is, the 'best' evidence, however, is not always available. In Table S2, we present the classification of some of the major study designs for intended effects of therapy. There appears to be some variation in the hierarchy among some authors and institutions issuing 'evidence-based' guidelines or systematic reviews. All authors agree that RCTs have the highest 'level of evidence' with respect to minimising the risk of bias. The prospective nonrandomised controlled clinical trial (CCT) has an experimental design and its internal validity should be regarded lower than a randomised trial but higher than an observational study. Prospective cohort studies have a potential for a lower risk of bias than retrospective cohort studies because they have lower risk of recall bias and confounding [4]. In cohort studies groups are defined by exposure whereas in case-control studies groups are defined by outcome status. Both points are acknowledged in the 'hiearchy of evidence' by some but not all authors. Case series and case reports are descriptions of one or more individual cases. Some authors combine both designs in one category while others place case series a higher level. 


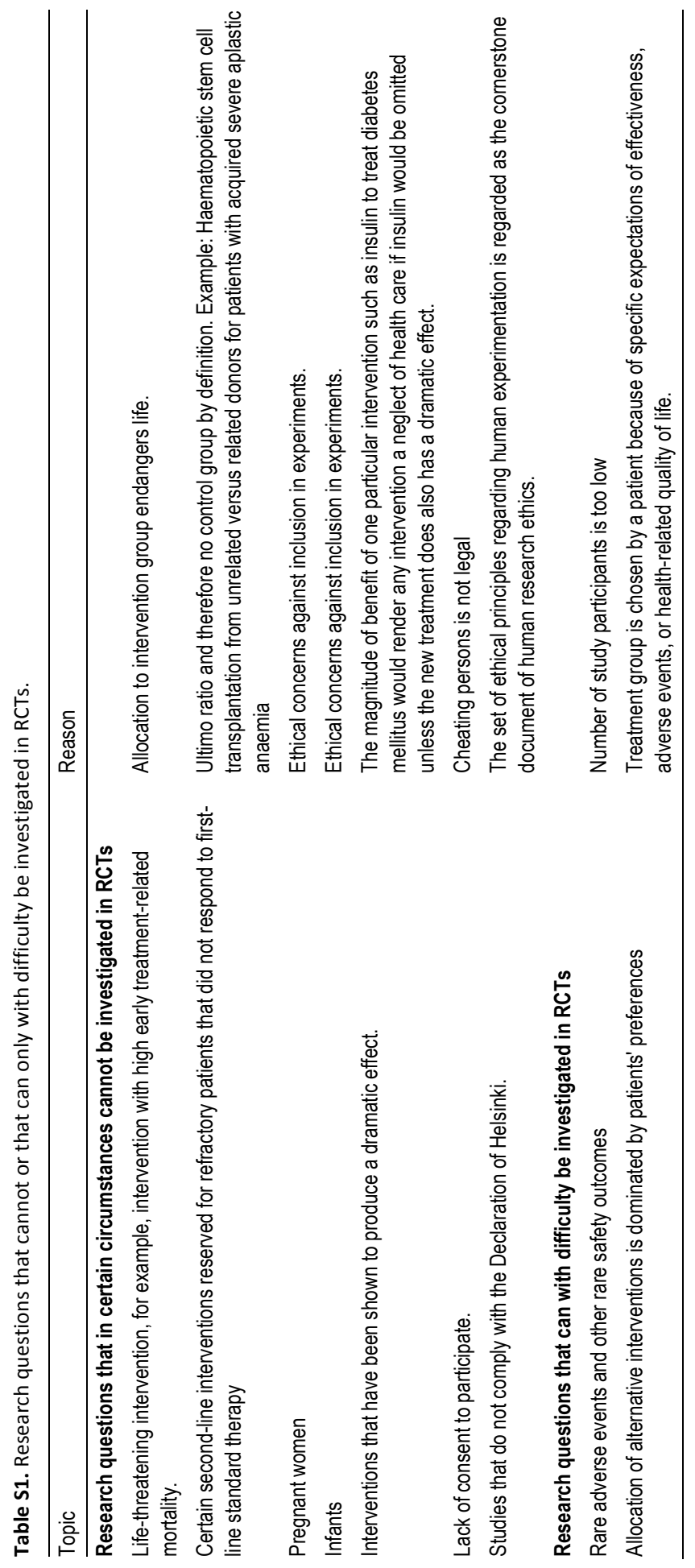




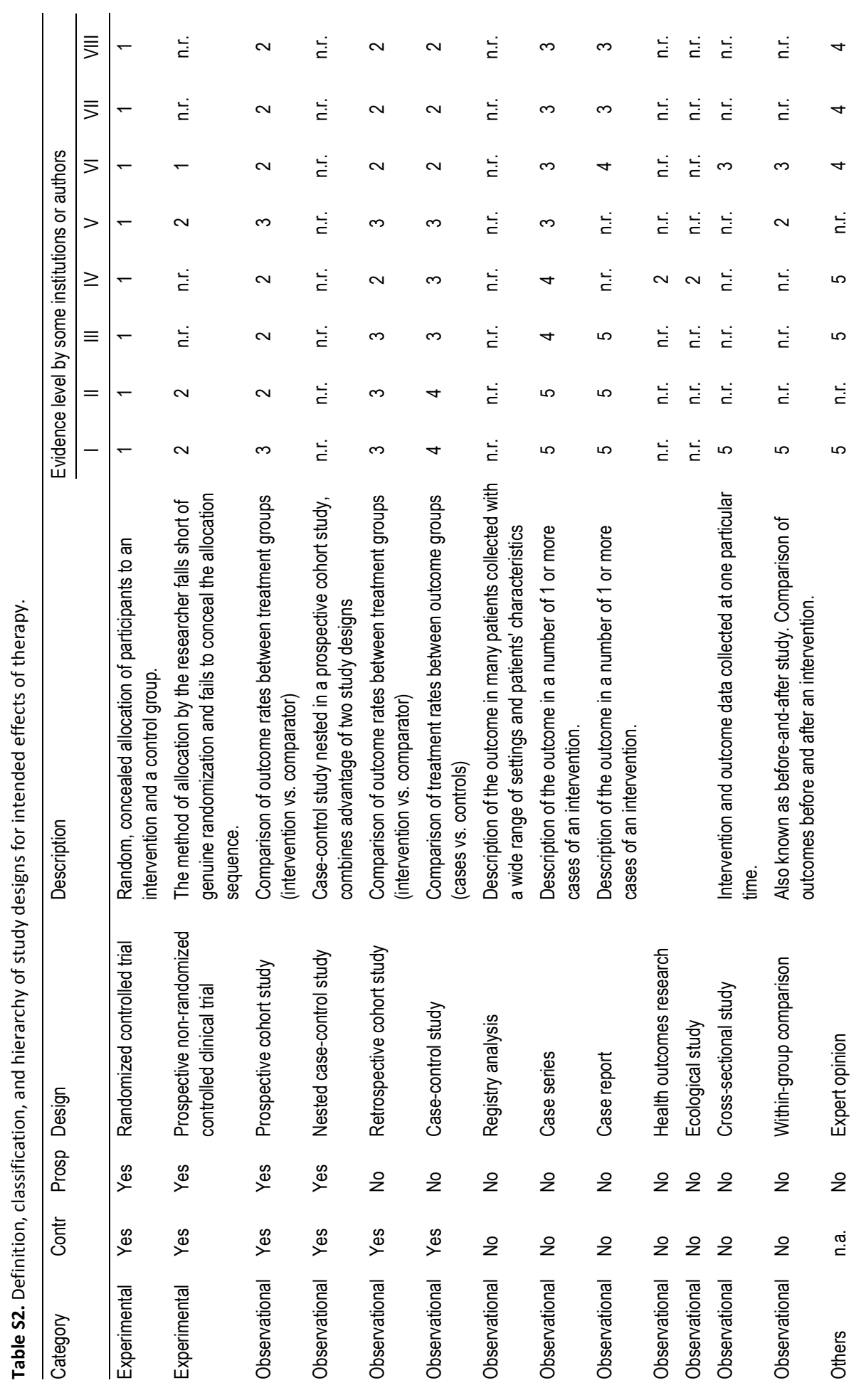




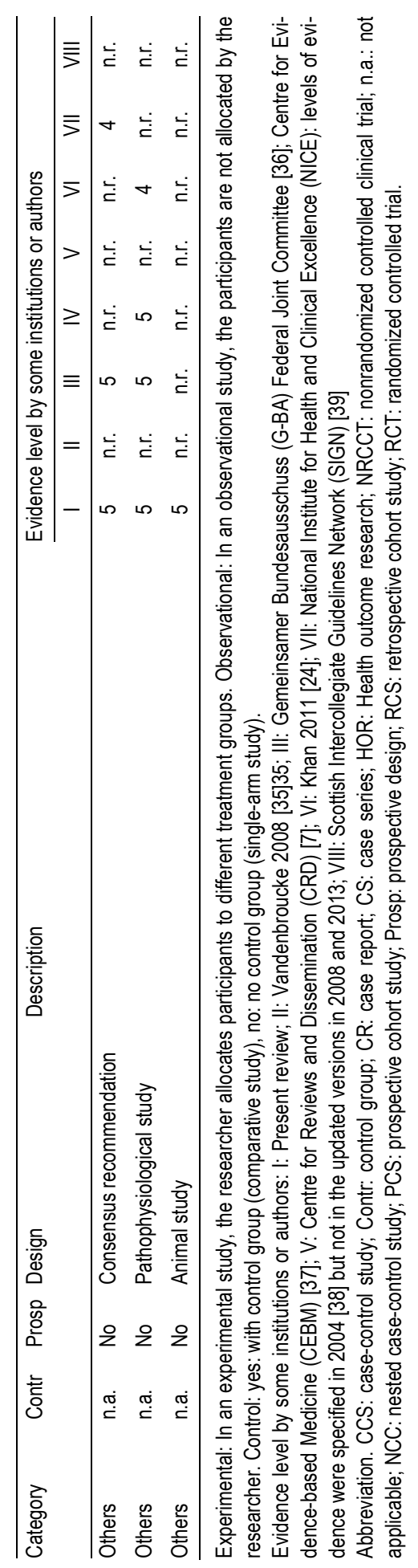


In Figure 1 we show a study design classification tree including the main features of study designs that makes them distinct from others conforming with the reports of the Centre for Evidence-Based Medicine (CEBM), the National Institute for Health and Care Excellence (NICE), and the Centre for Reviews and Dissemination (CRD) [5-7]. Examples of distinguishing study characteristics are the concurrent vs. the historical control group or the participants being or not being allocated to the treatment groups by the investigator. Within group comparison has also been referred to as a before and after study in a previous CRD report.

\section{Methods}

The aim of this paper is to develop an algorithm as a guidance to choose study designs that are most appropriate to answer various health care questions and to guide systematic reviewers in considering multiple study designs for evaluation of the many facets of health care interventions. We searched the internet sites of not-for-profit publishers of systematic reviews and health technology assessments of health care interventions to identify published guidelines on the topic. We developed an algorithm as a guidance for choosing appropriate study design using the following decision points (Figure 2): length of follow up (long, short), frequency of events (rare, frequent), types of outcome (death, disease, discomfort, disability, dissatisfaction), and practical or ethical concerns. These decision points follow implicitly when considering the main characteristics of frequently used different study designs. E.g. cohort studies are done when randomisation is not practical or ethical, case-control studies are done when cohort studies are not practical due to low frequency of outcomes. Studies without control groups may be done when a disease is extremely rare, or for certain outcomes such as dissatisfaction or for assessing compliance. 


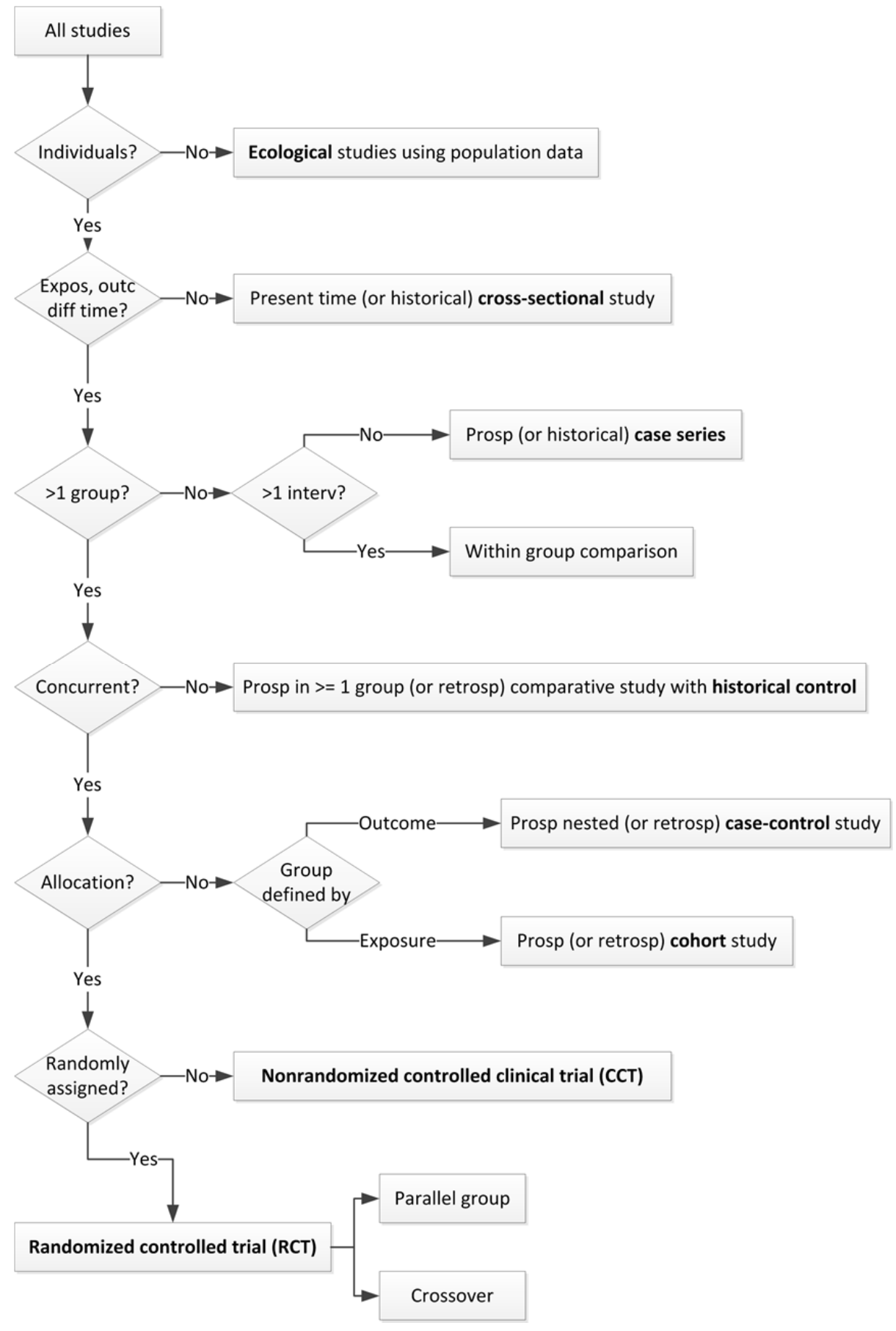

Figure 1. Decision algorithm to help define study designs. 


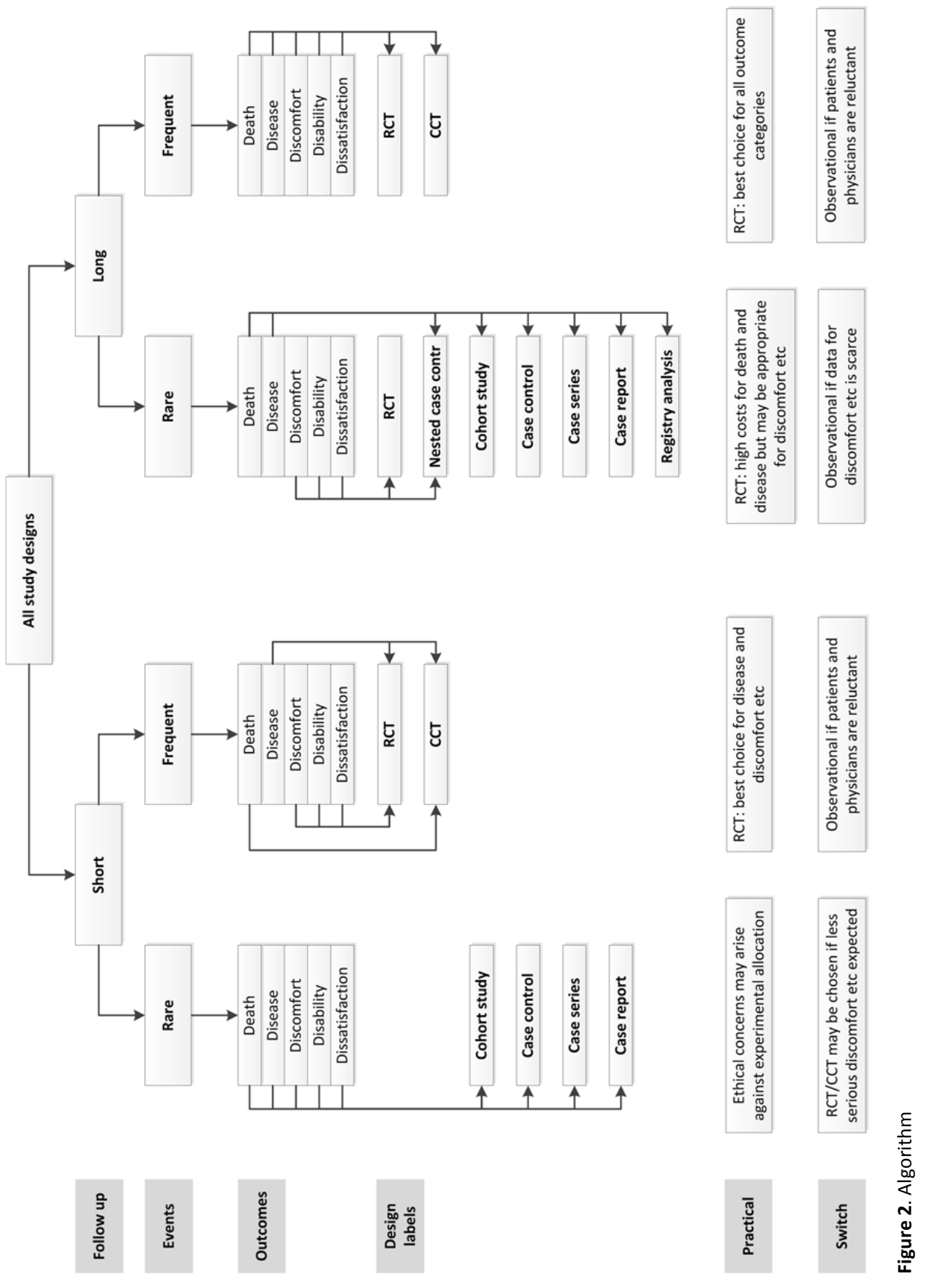




\section{Explanation.}

RCT: prospective randomized controlled trial, allocating experimental units via random assignment to a treatment or control condition with concealment of the allocation procedure

CCT: prospective nonrandomized controlled clinical trial, allocating experimental units via nonrandom assignment to a treatment or control condition; discomfort etc: discomfort, disability, and dissatisfaction

Nested case-control study: case-control study nested within a prospective, observational cohort study

Cohort study: prospective, observational cohort study

Case series: retrospective, observational tabulation of data from participants without consecutive enrolment

Case report: retrospective, observational report of data from one participants up to 3 patients

Registry analysis: retrospective, observational analysis of participants data from various sources transfered to and collected in a database

Abbreviation. СCT: controlled clinical trial; nested case contr: nested case-control study within a prospective cohort study; RCT: prospective randomized controlled trial, allocating experimental units via random assignment to a treatment or control condition with concealment of the allocation procedure

\section{Length of follow up}

The outcomes can be evaluated early or at a late time point after start of treatment. The terms short vs. long are relative depending on the disease, intervention and outcome of interest. We list some examples with a cut-off between short and long follow up that ranges from 30 days to 5 years (Table S3). The disease may be invasive, severe and fast progressing and a short follow up may capture the majority of the events of interest. Symptoms may aggravate a long time period after the onset of some diseases and a long follow-up is necessary to observe events. A long follow-up is also required if events occur distributed over a wide time range. The intervention of interest might have an instantaneous impact on the patients' well-being such as dextrose given to a patient in hypoglycemic coma or acute cardioversion and defibrillation in a patient with malignant arrhythmia that can occur after a heart attack. The effects of these events can be detected within a short observation period. Some patients receive lifelong medicinal therapies that are intended to prevent the appearance of lifethreatening symptoms of an underlying disease. In this situation, a long observation will be required to detect a number of beneficial or adverse events sufficient for comparing a test with a control intervention.

\section{Frequency of events}

The condition of interest may be rare and hard to encounter at all and may require specific study designs that allow to observing patients with these rare diseases to collect sufficient data for analysis and to draw conclusions supported by the data. A rare disease may be defined according to the Office of Rare Diseases Research (ORDR): "In the United States, a rare disease is generally considered to be a disease that affects fewer than 200,000 people. There are more than 6,800 rare diseases. Altogether, rare diseases affect an estimated 25 million to 30 million Americans." [8]. Disease-specific 
registration of patients may provide information about the number and characteristics of patients that are in need of health care. Multicentre studies may need the information gathered by these registers and may arrange a treatment regimen of interest applicable to all participants. An example might be the German neuroblastoma study group [9]. A total of $96 \%$ of all German patients registered at the German childhood cancer registry with a specific type of neuroblastoma entered one of the trials. Randomization may be possible to compare two different chemotherapeutic substances but may not be feasible to investigate some other questions. In a retrospective analysis, the investigators found that spontaneous regression is regularly seen in infants with localized neuroblastoma and is not limited to the first year of life and that a waitand-see strategy is justified in those patients [10]. Adverse events after the start of treatment may be rare and can be serious. The number of observed randomized patients may not be sufficient to detect a representative number of events. An observation of a large number of patients in single-arm studies or the recognition of selected case reports may provide information about serious drawbacks of a promising treatment. The terms rare vs. frequent events are relative depending on the disease, intervention and outcome of interest. We list some examples with a cut-off between rare and frequent events in Table S4.

\section{Types of outcomes}

We classified the outcomes according to Fletcher 2005 into the 5 groups of death, disease, discomfort, disability, and dissatisfaction (Table S5) [11]. In case of short follow-up and rare events and regarding all types of outcome, data of a large number of participants may be needed to estimate a realistic event rate (Figure 1; Table 1). Thus, prospectively designed RCT or CCT may not be appropriate because they usually recruit a limited number of participants. In case of long follow-up and rare events, this might similarly be true for the outcomes death and disease, which might be studied in observational studies that include large numbers of participants including registry analyses (Figure 1; Table 1). Discomfort, disability, and dissatisfaction may be subjective outcomes and may be reported only by participants. These outcomes should be measured with the highest possible validity and should be studied in RCTs to prevent a potential high risk of confounding. Alternatively, they might be studied in case control studies nested within prospective cohort studies to retrieve data from a large population. In case of short follow-up and frequent events, disease should be evaluated in trials with a high internal validity including prospectively design randomised and nonrandomised controlled trials (Figure 1; Table 1). Due to the frequent number of events, a realistic event rate can be achieved, though the number of participants may be limited. It might not be appropriate to randomly allocate participants to treatment groups if death occurs frequently primarily in one of the groups. Again, discomfort, disability, and dissatisfaction should be measured with the highest possible validity and should 
be studied only in RCTs. In case of long follow-up and frequent events regarding all outcomes, there is no reason to include other study designs than RCTs or alternatively CCTs, if RCTs are not available (Figure 1; Table 1). The RCT is appropriate because of its highest possible validity and a number of events, which can be expected to be sufficient high to enable a realistic rate.

\section{Study design labels}

After deciding whether the follow-up is short or long and after deciding whether the event is rare or frequent, one or several appropriate study designs are recommended. We used the following study design labels: RCT, CCT, nested case-control study, cohort study, case-control study, case series, case report, and registry analysis. We provided a description and classification of these and other possible study design labels in Table S2. The prospective design may be considered on two separate levels. This first level concerns the prospective direction of studying the exposure and outcome relationship, which can be call prospective in any RCT, CCT or cohort study (and retrospective in a case control study). The second level of prospective design of any study predefines the timing of the data collection. If data were collected in the past or from the past, the study would be considered retrospective (e.g. a retrospective cohort study), if data are collected in the present or future, the study would be considered prospective. It is always important to be explicit which level is meant when talking about prospective or retrospective study features to avoid confusions. Some health interventions are difficult to randomize because they are implemented at a regional-level rather than a facility- or patient-level. Therefore, it is important to consider multiple study designs including CCT or other nonrandomized study designs for these types of interventions [12].

\section{Practical or ethical concerns}

Practical or ethical concerns may emerge as reasons to override the earlier decisions or to switch to a more appropriate study design. Therefore, we remind the reader at the bottom of the Figure 2 to reconsider the chosen path. Some study designs may be more suited for answering specific research questions than others. However, availability of high-quality evidence can only be determined by searching for it. It does not seem like a sound strategy to apply an algorithm that excludes RCTs from consideration because of ex ante assumptions that relevant RCTs may not exist. Therefore, the practical and ethical concerns provide a flexible handling of the algorithm if required. We provide some examples that follow the outlined structure of the algorithm in Table S6. 


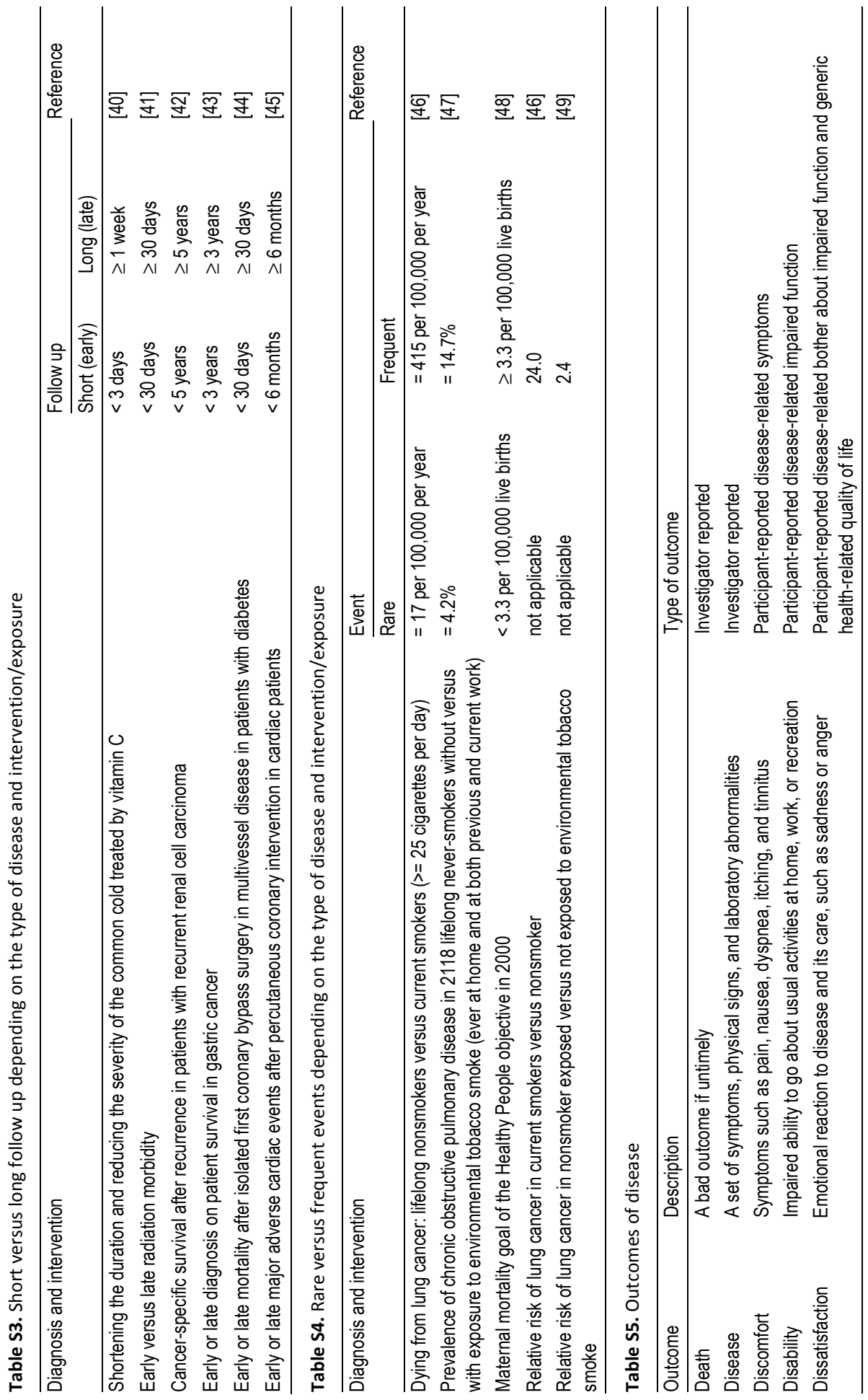




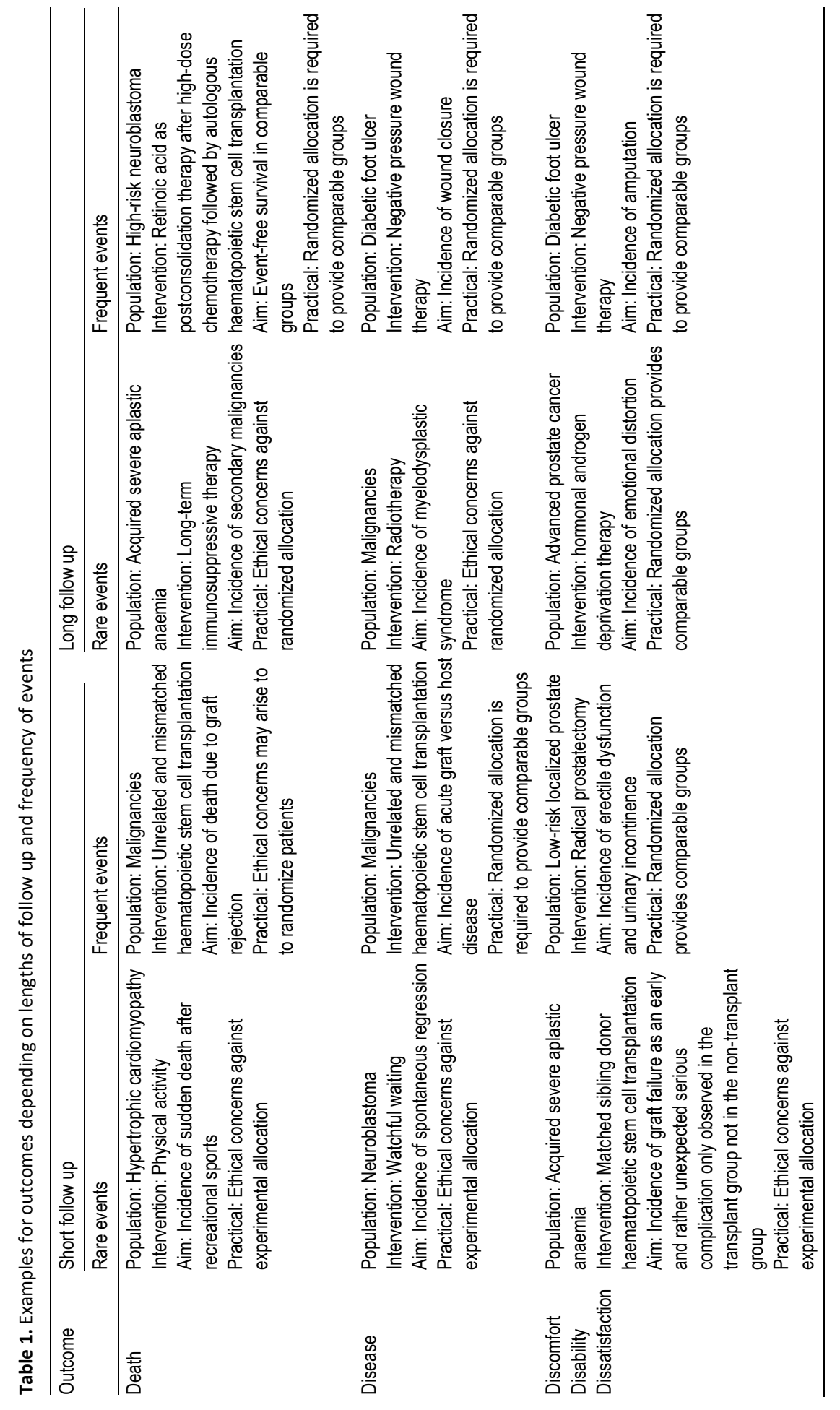




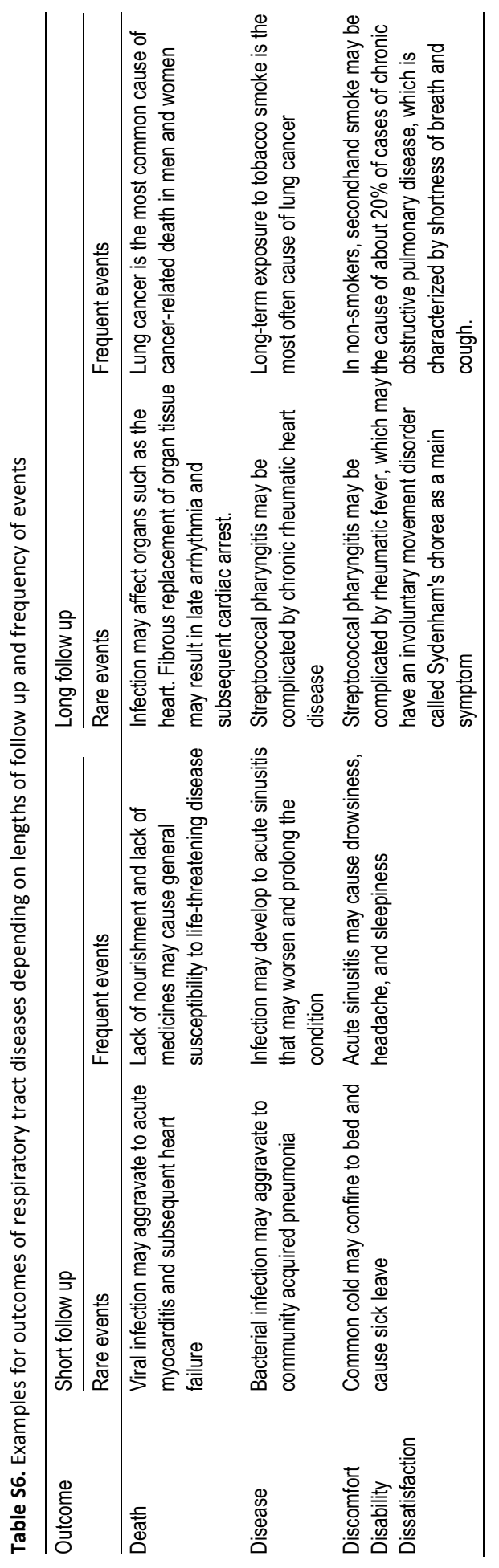




\section{Testing the usefulness of the algorithm}

We have conducted four systematic reviews on various diseases, interventions, and outcomes. We wanted to reproduce the process of deciding what study design would best fit the respective conditions, treatments, and patient centered endpoints. We wanted to practice the pathways of the algorithm and to test whether it works for the selected systematic reviews. Thus, the algorithm has been tested on them. The information on the PICOTS-SD frame regarding each systematic review is shown in Table 2. We introduced the main topics of each systematic review and discussed whether the algorithm was helpful in choosing the best study designs. We reflected on potential advantages and disadvantages of various study designs in each example. Figure 3 is modified from Figure 2 to delineate the pathways of 6 examples described in detail in the results chapter without altering the basic structure of the algorithm.

\section{Results}

\section{Statements on research design}

We looked at a sample of 12 high profile not-for-profit publishers of systematic reviews and health technology assessments of health care interventions, detailed in Table 3. Of those, 10 have published guidance about their methodological procedure for preparing the systematic reviews [5-7,13-19]. A range of other books or guidance documents on systematic reviews exist [20-25]. We extracted the major statements of their methods guidance with respect to choosing the appropriate research design in Table S7. We did not identify an algorithm or a comprehensive guidance focussing on finding the appropriate research design in any of these methods guidance documents.

\section{Algorithm to find the appropriate research design}

We propose an algorithm, which is shown in Figure 2. The algorithm has four decision points. First, it should be decided whether the follow-up is regarded as short or long. Second, it should be decided whether the events of interest are regarded as rare or frequent. Third, the outcome of interest needs to be considered. Fourth, the appropriate study design will be assigned. In addition, it should be considered whether it is justified to stay with the chosen study designs or whether it is warranted to switch the study design depending on possible practical and/or ethical reasons. We provide various specific examples for all outcome categories and want to show in detail in what way these outcomes depend on the length of follow up and the frequency of events (Table 1). 


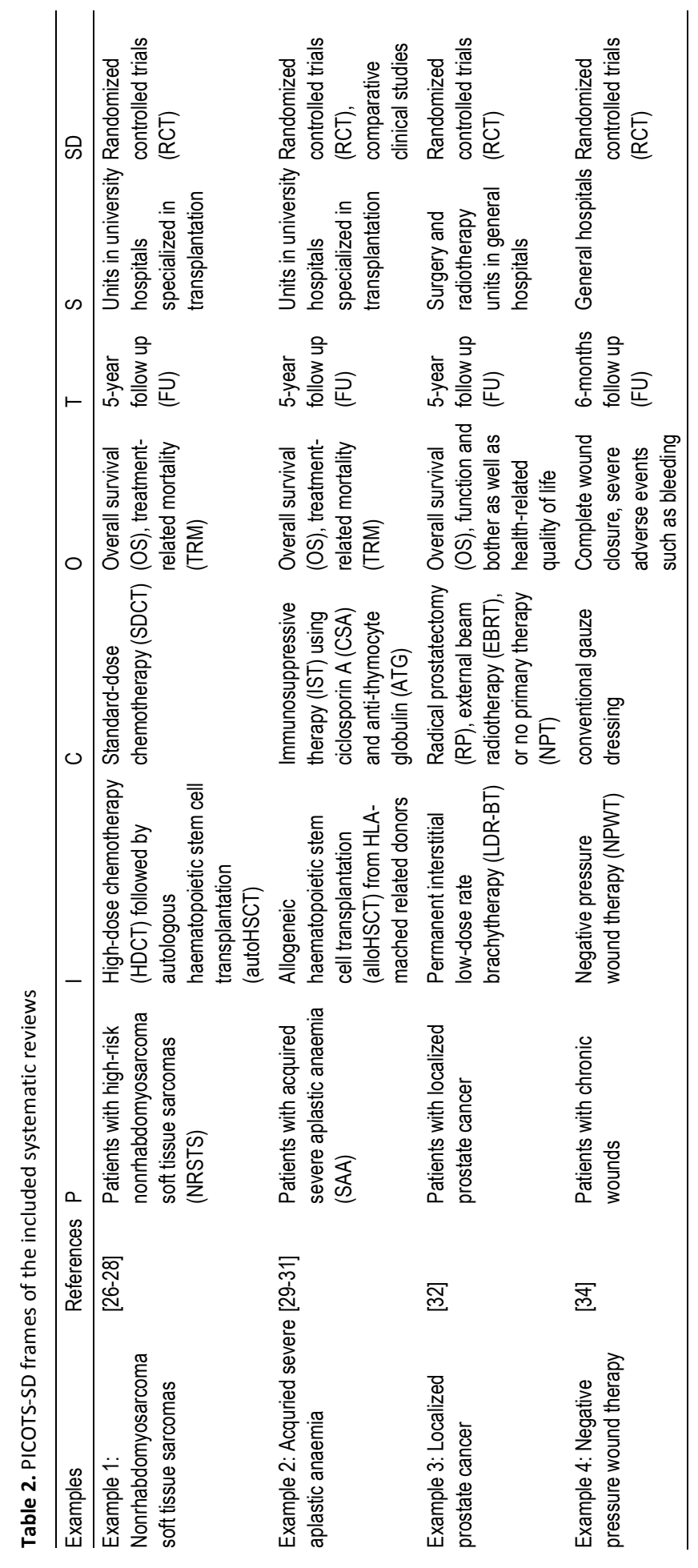



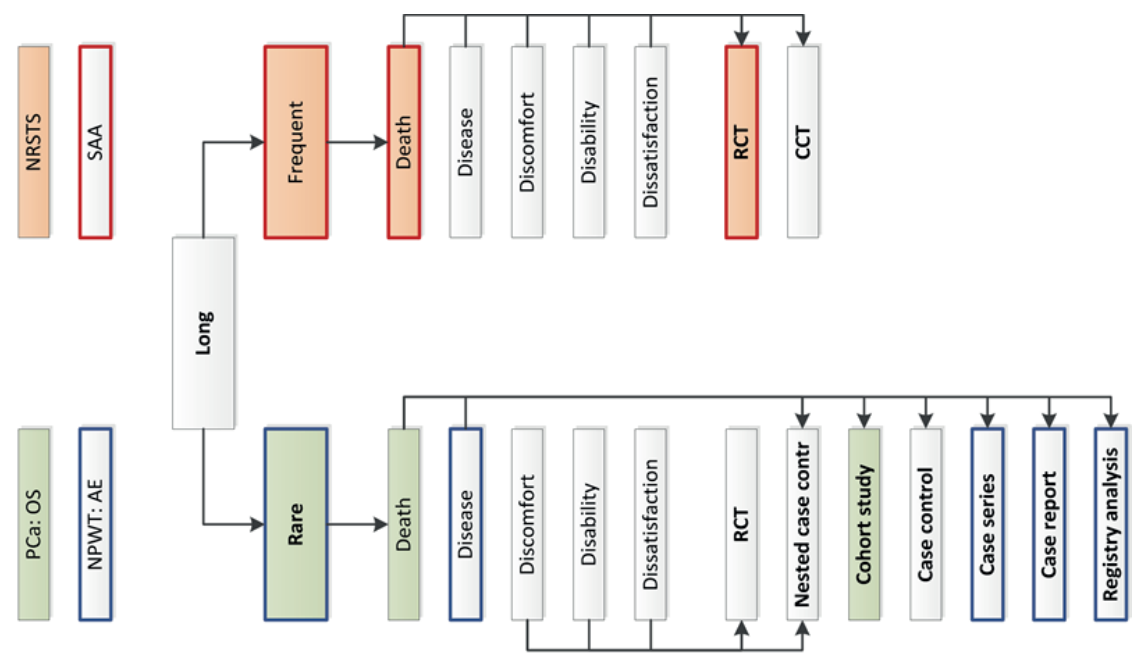

量
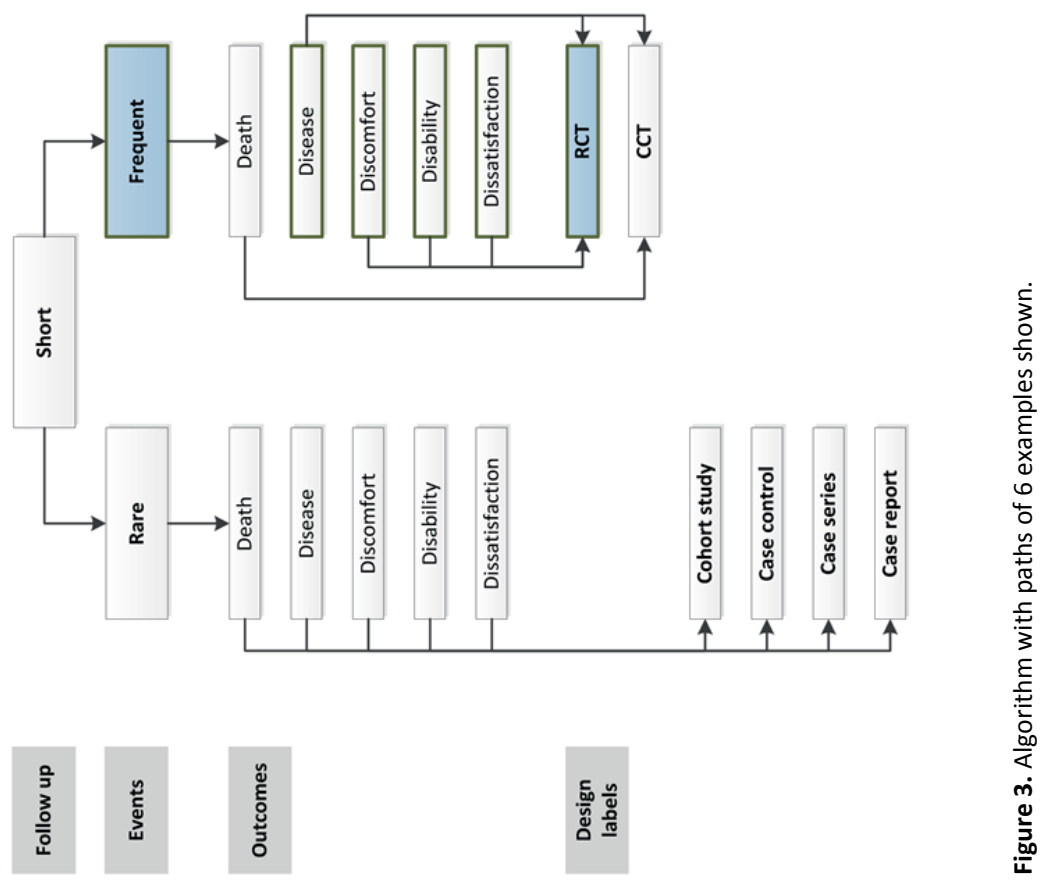


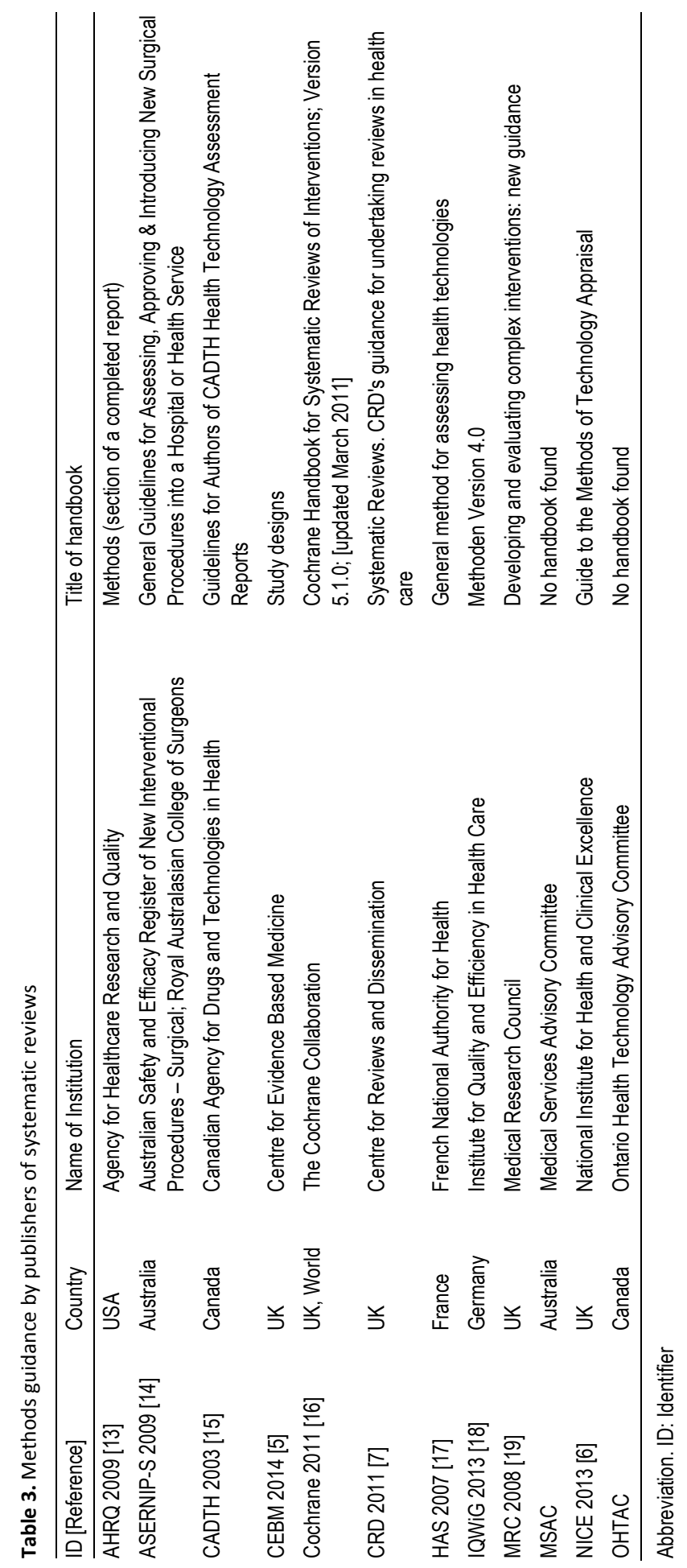




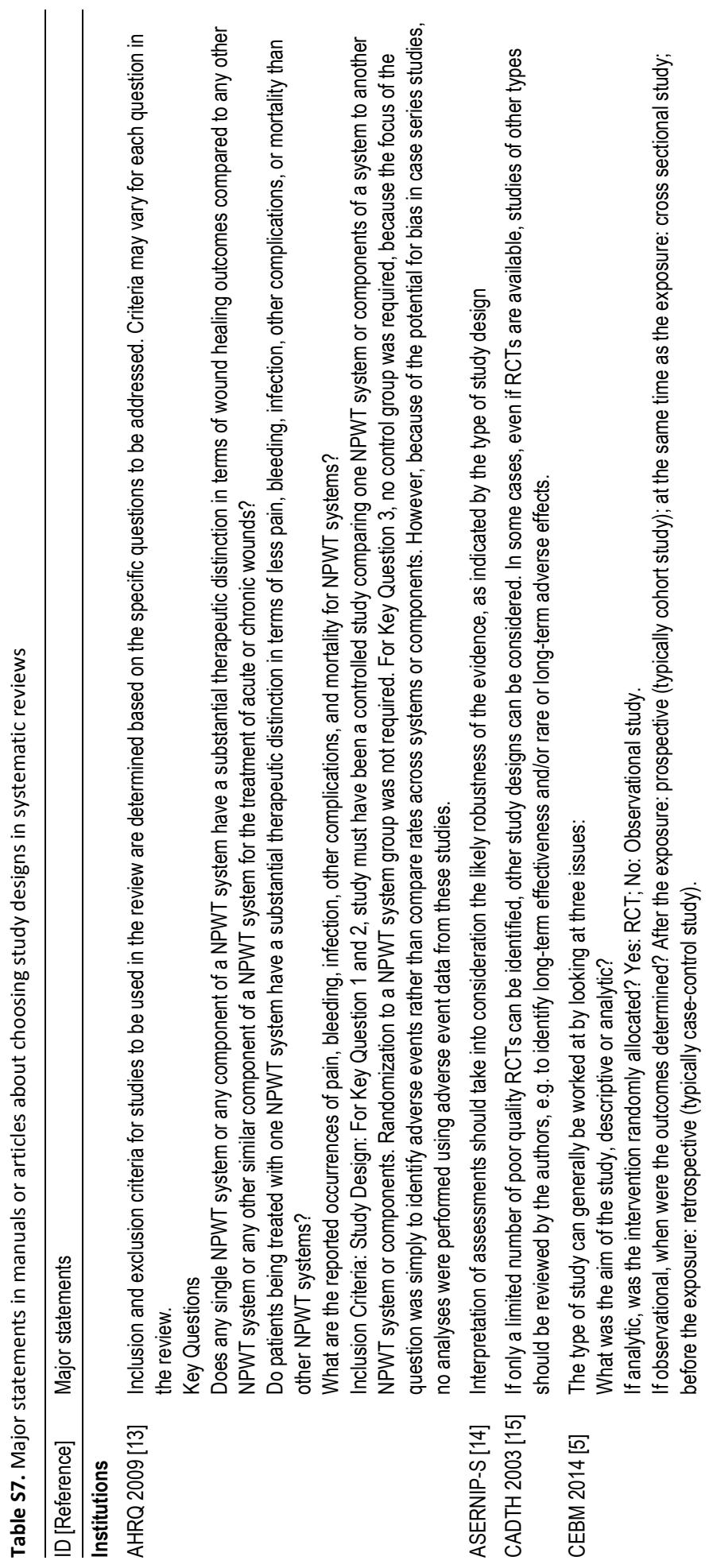




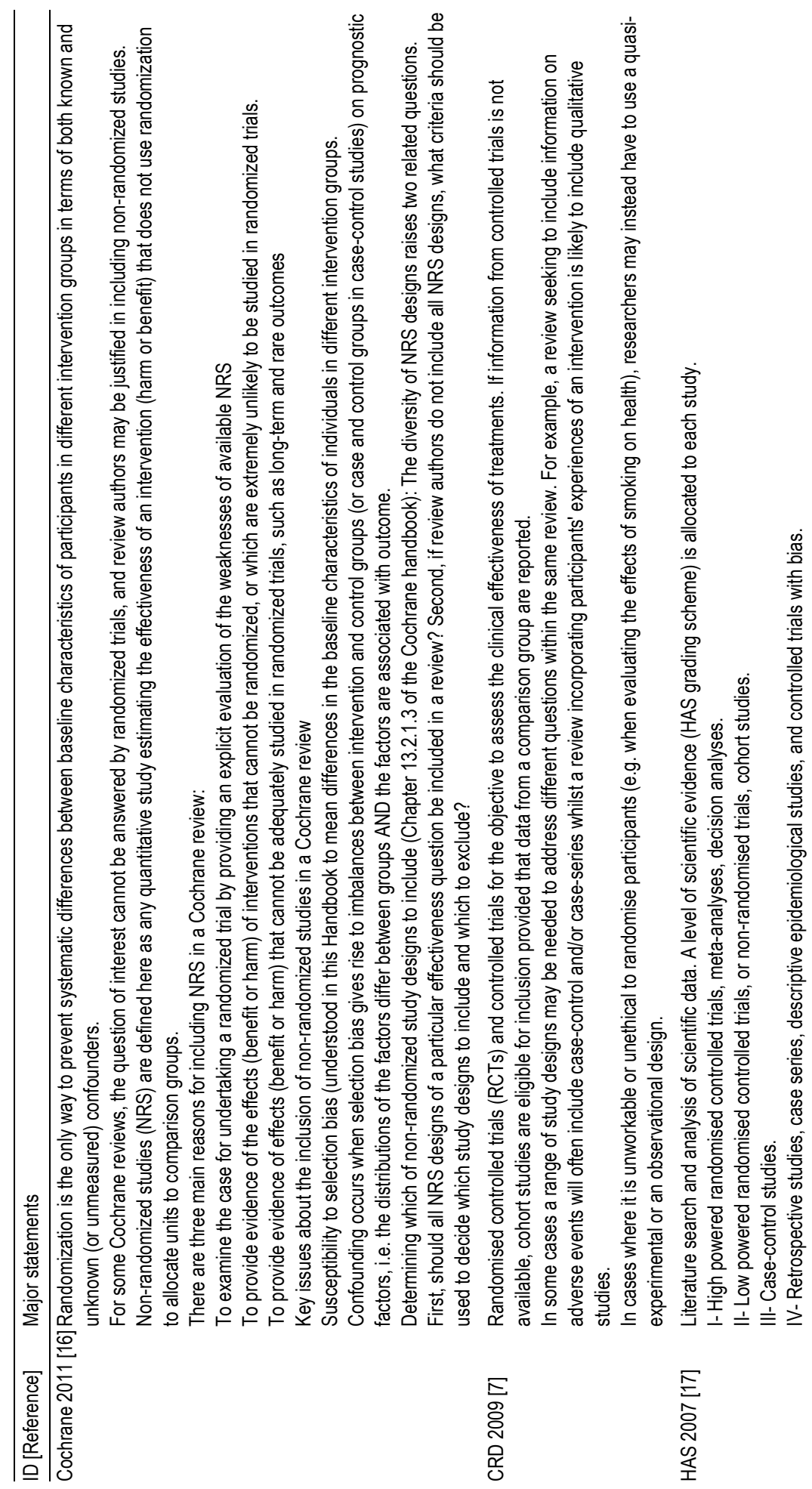




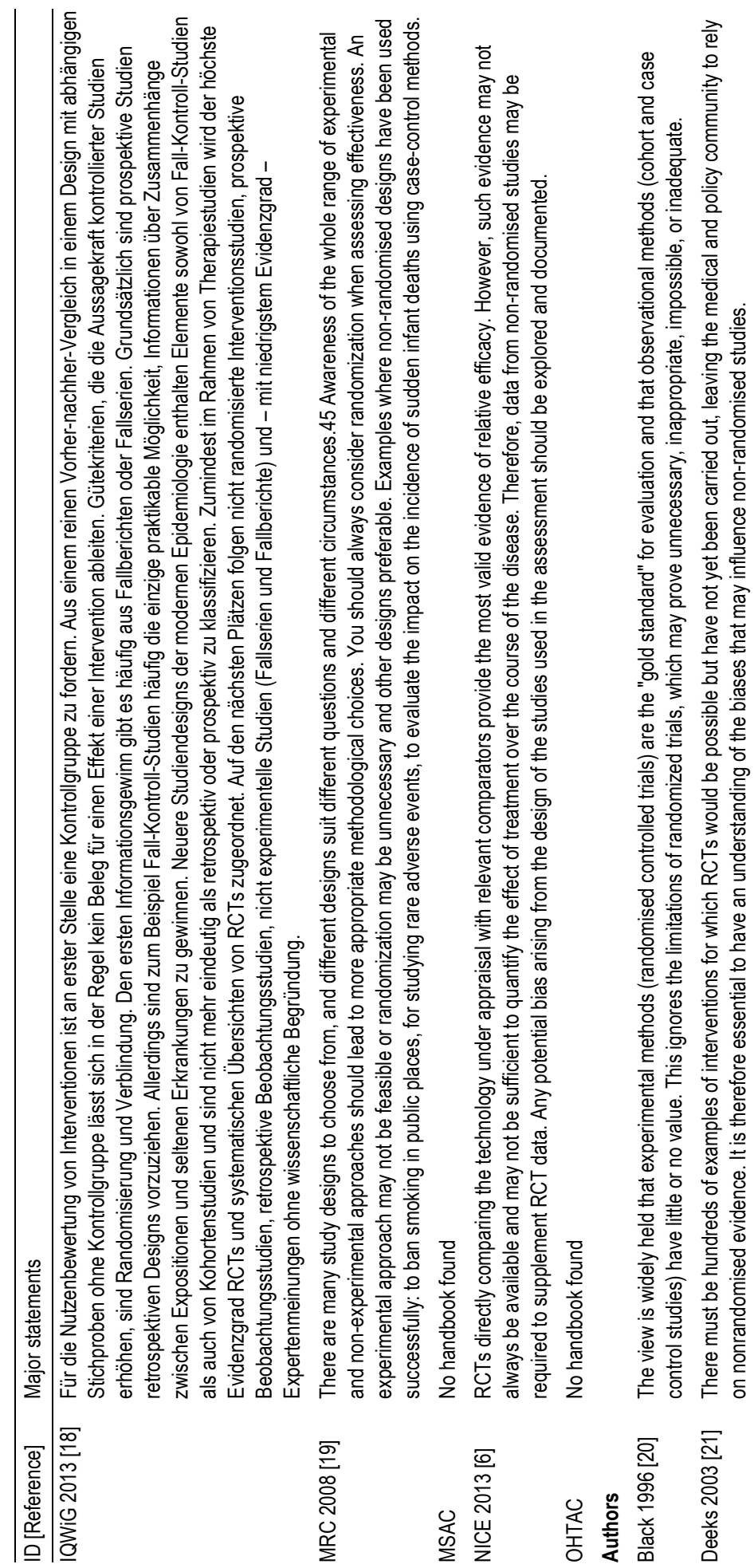




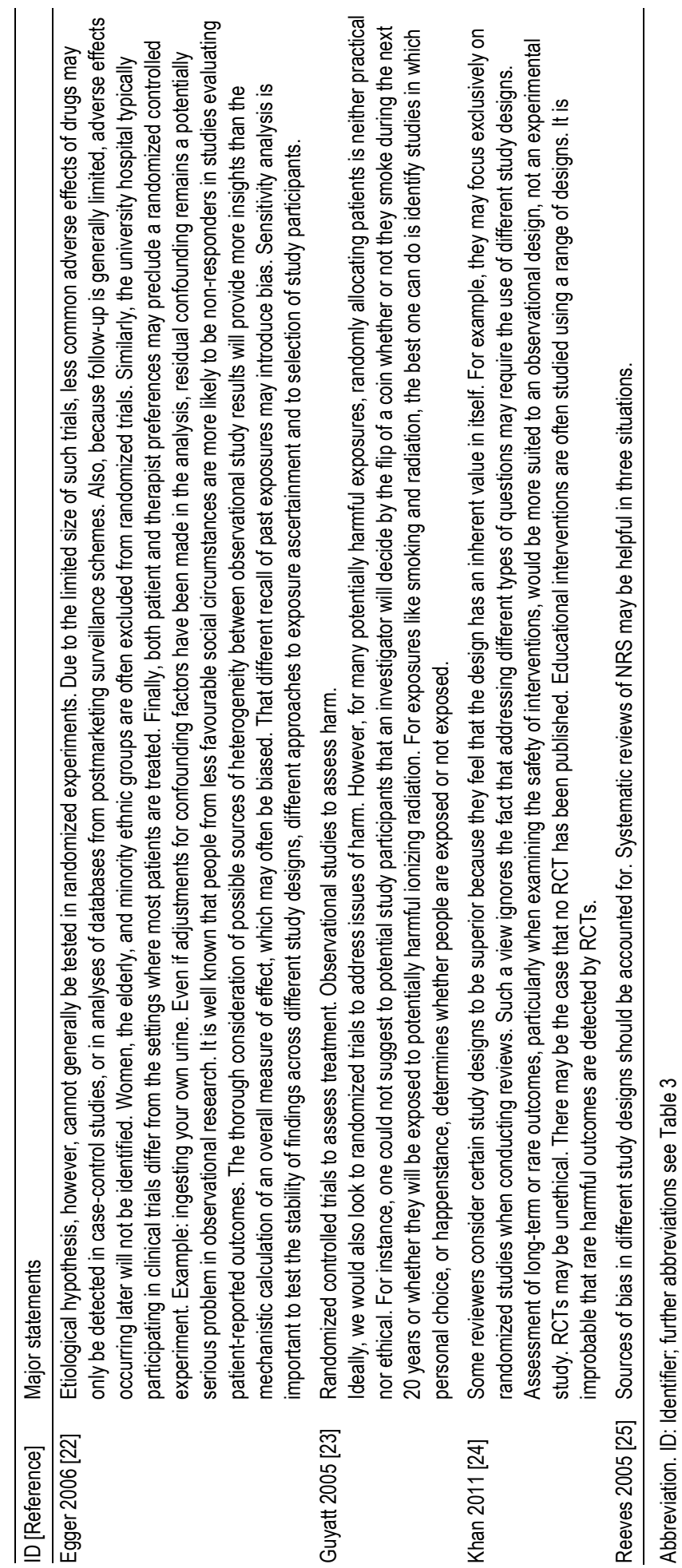




\section{Testing the usefulness of the algorithm}

\section{Example 1: Non-rhabdomyosarcoma soft tissue sarcomas}

The PICOTS-SD frame and the respective references associated with the systematic review on autologous haematopoietic stem cell transplantation (autoHSCT) following high-dose chemotherapy (HDCT) versus standard-dose chemotherapy (SDCT) in patients with nonrhabdomyosarcoma soft tissue sarcomas (NRSTS) are shown in Table 2. In the first version of this systematic review, we assumed a long follow-up and frequent events regarding death by disease or complication: NRSTS in Figure 3 [26]. Thus, an RCT would be the best choice for all outcomes. We evaluated patients with a rare disease of interest that are treated rarely with the intervention of interest. The disease is a malignant tumor and treatment of cancer may frequently be followed up to allow estimation of the 5-year overall survival. Many authors recommended the conducting of RCTs as a requirement for the decision whether HDCT followed by autoHSCT results in a better survival than standard-dose chemotherapy (SDCT). In the first version of the Cochrane review, we did not find any RCT and we did not find any comparative study [26]. We identified only single-arm studies including a few case series and a lot of individual case data. We decided to include any study design with primary patient data to provide an overview of the available evidence. We were able to estimate overall survival and to describe adverse events. We were unable to draw conclusions on the benefit of the intervention of interest. We conducted an update 2.5 years after the first version was published and identified a single RCT [27]. There was consensus among the reviewers that we should restrict the study design to RCTs only in a future update under the condition that at least two RCTs are available for evaluation. Although the algorithm would have guided us to initially use RCTs, we switched to include observational data in the first version because RCTs were lacking completely. This represents an example of the principle of 'best' available evidence that we described in the preceding section. We had to downgrade the 'levels of evidence' to find and include data matching the prespecified PICOTS-SD frame. Using different study types provided advantages such as the presention of data from other sources on overall survival after realizing that RCTs were not available in the first version. The update showed that we could present data on adverse events beyond the scope of an RCT. We brought to public attention that RCTs were requested for a long time and by many authors and we published the message that a meaningful decision on the usefulness of the intervention of interest might be impeded until RCTs are available. We were astounded when we identified an RCT during the search for the update. Thus, the presentation of a lack of quality studies might have fostered the conduction of a long desired study. Otherwise, it was not possible to estimate the effect of the intervention of interest because single-arm studies do not provide data that allow comparison between two different interventions. We tried to estimate overall survival from pooled individual data, which created a considerable heterogeneity not to mention the very 
high risk of bias. We pooled different subtypes, which may have diverse courses of disease. The pooled cases were treated in different hospitals and countries and the variation in treatment condition was presumably very large. We think that the absence of study data was the cause for the inability to draw conclusions but not the use of different study types. We conducted another systematic review addressing the similar PICOTS-SD items but concentrated on metastatic rhabdomyosarcoma, the single soft tissue sarcoma entity excluded by the NRSTS review [28]. Again, the algorithm would have guided us to initially use RCTs but we switched to include observational data because RCTs were again lacking completely.

\section{Example 2: Acquried severe aplastic anaemia}

The PICOTS-SD frame and the respective references associated with the systematic review on allogeneic haematopoietic stem cell transplantation (alloHSCT) from matched sibling donors (MSD) versus immunosuppressive therapy (IST) in patients with acquired severe aplastic anaemia (SAA) are shown in Table 2. In this systematic review, we assumed a long follow-up and frequent events regarding death by disease or complication: SAA in Figure 3 [29]. Thus, an RCT would be the best choice for all outcomes. We evaluated patients with a rare disease of interest that are treated frequently with the intervention of interest. The disease is acquired severe aplastic anaemia caused by an autodestructive action against bone marrow stem cells. Immunosuppressive therapy interferes with selfdestruction but some patients may be refractory and long-term treatment may result in secondary malignancies. Allogeneic stem cell transplants from HLA-matched sibling donors is potentially curative opposed to IST and may have a favorable survival compared to IST. We did not find any RCT. We subsequently included any comparative study. We tried to lower the risk of bias by restricting the inclusion criteria to studies that were prospective, that met the requirements of 'Mendelian randomization', and that were confined to HLA-mached sibling donors [30]. Three studies were left for the evaluation. Unfortunately, the extracted data were generated more than 10 years ago and hardly applicable to the current medical care status. Although the algorithm would have guided us to initially use RCTs, we switched to include prospective nonrandomized controlled trials that met the criteria for 'Mendelian randomization' because RCTs were lacking completely. A consideral proportion of patients with acquired severe aplastic anaemia do not respond to immunosuppressive therapy and they have neither an HLA-matched sibling donor nor an HLA-matched related donor. The only treatment alternative left is to offer transplantation from an unrelated donor, preferably with a matched HLA status. The inherent practical concern may limit expectations of a control treatment. In our systematic review, we identified, as expected, only single-arm studies [31]. Nevertheless, we were able to quantitatively pool the data and specify estimated survival and adverse effects. Using different study types provided advantages such as the presention of data from a lot of other comparative studies on overall survival after realizing 
that RCTs were not available in the first version. These studies presented a large number of factors that may have influenced the course of the disease, for example age of participants and year of transplantation. We analysed the data qualitatively. The variety of those factors and also the data on adverse events may have been beyond the scope of an RCT. It was possible to estimate the effect of the intervention of interest and put them in context to reports published by others. However, high risk of bias due to the nonrandomized study design limited validity and high level of heterogeneity limited applicability of the study results considerably.

\section{Example 3: Localized prostate cancer}

The PICOTS-SD frame and the respective references associated with the systematic review on permanent interstitial low-dose-rate brachytherapy (LDR-BT) versus radical prostatectomy (RP) versus external beam radiotherapy (EBRT) and no primary therapy (NPT) in patients with localised prostate cancer are shown in Table 2. In this systematic review, we assumed a long follow-up and rare events concerning death: PCa: OS in Figure 3 [32]. Localized prostate cancer as opposed to advanced prostate cancer is believed to be associated with a very good overall survival regardless of the intervention. According to the algorithm, a cohort study would be appropriate to estimate long-term overall survival. Concerning patient-reported outcomes such as discomfort, disability and dissatisfaction, we assume that we have short follow-up and frequent events: PCa: HRQL in Figure 3. According to the algorithm, an RCT would be the best choice. The different treatment options might result in non-relevant differences of overall survival, too small to be detected. However, they are believed to have considerably different impact on physical and psychological well-being. For example, radical prostatectomy may promise to completely remove the malignant tumor but may also disrupt erectile function in a considerable proportion of patients. Loss of function, increase of bother, and constrained quality of life may be perceived by many men shortly after the intervention. We found that physician-reported urogenital late toxicity grade 2 to 3 was more common in the LDR-BT group when compared to the EBRT group. With respect to patient-reported outcomes, better scores for sexual and urinary function as well as urinary incontinence were reported for LDR-BT compared to RP. Better scores for bowel function were reported for LDR-BT compared to EBRT. We think that the algorithm matches well with the study design requirements generated by the research question. Restricting the study design to RCTs only resulted in a systematic review reporting the results of only a single study because only one RCT was available [33]. The information about discomfort, disability and dissatisfaction reported in numerous studies, though, with limited validity, was consequently ignored. Using different study types provided the main advantage to address two different research questions inherent in the systematic review. Evaluating overall survival needed a different approach than evaluating patient-reported outcomes. The obvious reluctance of 
patients and physicians alike to participate in RCTs corroborated the consideration of other study designs such as nonrandomized controlled clinical trials and/or cohort studies with a set of inclusion criteria prospectively designed to request a minimal level of quality to meet potential high risk of bias. The single included RCT provided valuable information but was limited to some issues and did not cover all relevant questions. The nonrandomised studies had a high risk of bias due to study design and various additional flaws such as the lack of reporting of a consecutive enrollment, a retrospective design, and no adequate confounder control.

\section{Example 4: Negative pressure wound therapy}

The PICOTS-SD frame and the respective references associated with the systematic review on negative pressure wound therapy (NPWT) versus standard wound dressing in patients with wounds are shown in Table 2 . In this systematic review, we assumed a short follow-up and frequent events concerning complete wound closure: NPWT: Closure in Figure 3 and we assumed a long follow-up and rare events concerning the outcome of severe adverse events NPWT: AE in Figure 3 [34]. NPWT is believed to facilitate wound closure faster than other treatment options and enable closure of chronic wounds that have failed to heal after other treatments. According to the algorithm, an RCT or a CCT would have been appropriate to evaluate the successful treatment of the disease. Serious adverse events may be detected in study designs of lower hierarchy such as registry analyses or case reports. For instance, in the year 2009, the US Food and Drug Administration issued a report on six deaths and 77 other complications that were reported within a two-year period in connection with NPWT. All the deaths were caused by acute hemorrhages, and known contraindications for NPWT (e.g. a large blood vessel exposed) had clearly been overlooked. Many of the deaths occurred in outpatient care or care homes, which highlights the need to monitor therapy. In this regard, it should be noted that trials of NPWT were generally conducted in hospitals. Using different study types provided the main advantage to address different research questions inherent in the systematic review. Evaluating complete wound closure needed a different approach than evaluating adverse events. The consideration of registry analyses and case reports were very helpful to draw attention to possible dangerous and life-threatening events and to point the finger at home care where indeed a considerable number of deaths were reported. A decision whether the intervention of interest can close wounds better than other alternative treatments apparently relies on the presence of high quality data from RCTs. 


\section{Discussion}

We did not identify an existing algorithm or comprehensive guidance focussing on finding the appropriate research design. Therefore, we developed an algorithm as a guidance, which aims to guide the reasonable inclusion of various study designs in systematic reviews of health care interventions. The proposed algorithm cannot be applied without considering disease-specific circumstances and aims of interventions, in other words, it is not intended to be an absolute guide that in all cases will lead to appropriate study designs. The terms used for defining the critical decision points of the algorithm such as short versus long follow-up need to be interpreted in the context of the disease and may be unclear and not useful if used as general terms. We provided examples to show that short versus long follow-up can vary considerably depending on the disease. Similarly, we provided examples to show that the definition of rare versus frequent events has to be interpreted in the context of the type of intervention or exposure as well as the type of event. For some research questions, the algorithm may recommend the use of studies with the highest possible validity. For alternative research questions, the algorithm may recommend the use of studies with qualities other than methodological validity. The recommended study design may not be reported in the identified studies and, thus, may not be available. In this case, a study design of the next lower level of validity may be used as a replacement.

We tested the constructed algorithm in four systematic reviews to evaluate whether our reasoning in theory concerning the algorithm may solidify in practice. Each work clearly explained why it was necessary to include multiple study designs. The number of our systematic reviews was limited. However, we could cover most of the pathways. We judged in a retrospective view, whether the pathways of the algorithm could have been useful at the time of designing the review. We could follow and confirm the appropriateness of the pathways for all described examples of systematic reviews. In one example, the algorithm selected RCTs as the best choice but due to the lack of RCTs it was decided to rely on nonrandomized studies. This example showed that it is important to build a flexibility into the algorithm, which enables the systematic reviewer to extend or change the inclusion criteria to other study designs in case that certain unexpected conditions may emerge or practical concerns exists. We are confident that the algorithm is a tool helping to bring seminal features of a systematic review to the attention of anyone who is planning to conduct a systematic review. It has the potential to help to reorientate oneself to major features of the studies eligible for an evaluation of a health care intervention. The benefit is the provision of awareness, and it is not a new regulation. The intention is to provide a guide and a decision support that might be used fully or partially by persons who are going to prepare a systematic review. While preparing a systematic review, it may be important at an early time point to identify the relevant and the most appropriate study designs necessary to find answers for a variety of prespecified outcomes. It might also be of interest for persons 
who evaluate the quality of systematic reviews and might want to check whether the all study designs have been considered that should have been considered. Therefore, we think that it may reduce the time burden on review authors and contribute to the production of a higher quality review.

Although it appeared that the algorithm is proper for projection of various research questions on the delineated pathways, we want to draw the attention to some limitations of this study. Disease-specific circumstances and aims of interventions always have to be taken into account during application of the algorithm. It is not intended to be an absolute guide always leading to appropriate study designs but meant to support systematic reviewers in their decisions. The testing was conducted retrospectively with systematic reviews that were already completed. This approach may have the advantage that potential pitfalls and a complicated matter are already known. However, this situation is far from the everyday working condition and the approach may be considerably biased by the expectations of the authors, to name just one potential cause. A testing more adapt to the real world should be included prospectively and should start while a systematic review is planned. Testing the algorithm prospectively and applying it at the start of a systematic review may have other results than those reported in the present study. Nevertheless, the results of this testing certainly need to be confirmed by other systematic reviewers, in other PICOTS-SD frames, and in a higher number of applications.

\section{Conclusions}

We are confident that the algorithm can assist to bring seminal features of a systematic review to the attention of anyone who is planning to conduct a systematic review. It aims to provide awareness not regulation. We think that it may reduce the time burden on review authors and may contribute to the production of a higher quality review. 


\section{References}

1. Victora CG, Habicht JP, Bryce J. Evidence-based public health: moving beyond randomized trials. American Journal of Public Health. 2004;94(3):400-5.

2. Sackett DL, Straus SE, Richardson WS, Rosenberg W, Haynes RB. Evidence-based medicine. How to practice and teach EBM. Second ed. Edinburgh: Churchill Livingstone; 2000.

3. Clarke N. Evidence-based medicine tutorial. Tallahassee: Medical Informatics, College of Medicine, Florida State University; 2014.

4. Campbell PG, Malone J, Yadla S, et al. Comparison of ICD-9-based, retrospective, and prospective assessments of perioperative complications: assessment of accuracy in reporting. Journal of Neurosurgery: Spine. 2011;14(1):16-22.

5. Centre of Evidence-Based Medicine. Study designs. Oxford: Centre of Evidence-Based Medicine, University of Oxford; 2014.

6. National Institute for Health and Care Excellence. Guide to the methods of technology appraisal. London: National Institute for Health and Care Excellence; 2013.

7. Centre for Reviews and Dissemination. Systematic reviews. CRD's guidance for undertaking reviews in health care. York: Centre for Reviews and Dissemination, University of York; 2009.

8. Office of Rare Diseases Research. What is a rare disease? Bethesda: Office of Rare Diseases Research, National Institutes of Health; 2014.

9. Berthold F, Hero B, Kremens B, Handgretinger R, Henze G, Schilling FH, et al. Long-term results and risk profiles of patients in five consecutive trials (1979-1997) with stage 4 neuroblastoma over 1 year of age. Cancer Letters. 2003;197(1-2):11-7.

10. Hero B, Simon T, Spitz R, Ernestus K, Gnekow AK, Scheel-Walter HG, et al. Localized infant neuroblastomas often show spontaneous regression: results of the prospective trials NB95-S and NB97. Journal of Clinical Oncology. 2008;26(9):1504-10.

11. Fletcher RH, Fletcher SW. Clinical epidemiology. The essentials. Fourth edition Philadelphia: Lippincott Williams and Wilkins; 2005.

12. Peinemann F, Tushabe DA, Kleijnen J. Using multiple types of studies in systematic reviews of health care interventions - a systematic review. PLoS One 2013;8(12):e85035.

13. Agency for Healthcare Research and Quality. Negative pressure wound therapy devices. Rockville: Agency for Healthcare Research and Quality; 2009.

14. Australian Safety and Efficacy Register of New Interventional Procedures - Surgical. General guidelines for assessing, approving \& introducing new surgical procedures into a hospital or health service. Stepney: Australian Safety and Efficacy Register of New Interventional Procedures - Surgical, Royal Australasian College of Surgeons; 2009.

15. Canadian Agency for Drugs and Technologies in Health. Guidelines for authors of CADTH health technology assessment reports. Ottawa: Canadian Agency for Drugs and Technologies in Health; 2003.

16. Reeves BC, Deeks JJ, Higgins JPT, Wells GA. Chapter 13. Including non-randomized studies. In: Higgins JPT, Green S (editors). Cochrane Handbook for Systematic Reviews of Interventions Version 5.1.0 [updated March 2011]. The Cochrane Collaboration; 2011.

17. Haute Autorite de Sante. General method for assessing health technologies. Paris: Haute Autorite de Sante, French National Authority for Health; 2007.

18. Institut fur Qualitat und Wirtschaftlichkeit im Gesundheitswesen. Methoden Version 4.1 [in German]. Koln: Institut fur Qualitat und Wirtschaftlichkeit im Gesundheitswesen; 2013.

19. Medical Research Council. Developing and evaluating complex interventions: new guidance. London: Medical Research Council; 2008.

20. Black $N$. Why we need observational studies to evaluate the effectiveness of health care. BMJ. 1996;312(7040):1215-8.

21. Deeks JJ, Dinnes J, D'Amico R, Sowden AJ, Sakarovitch C, Song F, et al. Evaluating non-randomised intervention studies. Health Technology Assessment. 2003;7(27):1-173. 
22. Egger M, Davey Smith G, Altman DG. Systematic reviews in health care. Meta-analysis in context. 2nd ed. London: B.M.J. Publishing Group; 2006.

23. Guyatt $\mathrm{GH}$, Rennie D, editors. Users' guides to the medical literature. A manual for evidence-based clinical practice. 5th ed. Chicago: A.M.A. Press; 2005.

24. Khan KS, Kunz R, Kleijnen J, Antes G. Systematic reviews to support evidence-based medicine. How to review and apply findings of healthcare research. London: Hodder Arnold; 2011.

25. Reeves BC, van Binsbergen J, van Weel C. Systematic reviews incorporating evidence from nonrandomized study designs: reasons for caution when estimating health effects. European Journal of Clinical Nutrition. 2005;59 Suppl 1:S155-61.

26. Peinemann F, Smith LA, Kromp M, Bartel C, Kroger N, Kulig M. Autologous hematopoietic stem cell transplantation following high-dose chemotherapy for non-rhabdomyosarcoma soft tissue sarcomas. Cochrane Database of Systematic Reviews. 2011;(2):CD008216.

27. Peinemann F, Smith LA, Bartel C. Autologous hematopoietic stem cell transplantation following high dose chemotherapy for non-rhabdomyosarcoma soft tissue sarcomas. Cochrane Database of Systematic Reviews. 2013;(8):CD008216.

28. Peinemann F, Kroger N, Bartel C, Grouven U, Pittler M, Erttmann R, et al. High-dose chemotherapy followed by autologous stem cell transplantation for metastatic rhabdomyosarcoma--a systematic review. PLoS One. 2011;6(2):e17127.

29. Peinemann F, Grouven U, Kroger N, Bartel C, Pittler MH, Lange S. First-line matched related donor hematopoietic stem cell transplantation compared to immunosuppressive therapy in acquired severe aplastic anemia. PLoS One. 2011;6(4):e18572.

30. Peinemann F, Bartel C, Grouven U. First-line allogeneic hematopoietic stem cell transplantation of HLAmatched sibling donors compared with first-line ciclosporin and/or antithymocyte or antilymphocyte globulin for acquired severe aplastic anemia. Cochrane Database of Systematic Reviews. 2013;7:CD006407.

31. Peinemann F, Grouven U, Kroger N, Pittler M, Zschorlich B, Lange S. Unrelated donor stem cell transplantation in acquired severe aplastic anemia: a systematic review. Haematologica. 2009;94(12):1732-42.

32. Peinemann F, Grouven U, Bartel C, Sauerland S, Borchers H, Pinkawa M, et al. Permanent interstitial low-dose-rate brachytherapy for patients with localised prostate cancer: a systematic review of randomised and nonrandomised controlled clinical trials. European Urolology. 2011;60(5):881-93.

33. Peinemann F, Grouven U, Hemkens LG, Bartel C, Borchers H, Pinkawa M. Low-dose rate brachytherapy for men with localized prostate cancer. Cochrane Database of Systematic Reviews. 2011;(7):CD008871.

34. Peinemann F, Sauerland S. Negative-pressure wound therapy: systematic review of randomized controlled trials. Deutsches Arzteblatt International. 2011;108(22):381-9.

35. Vandenbroucke JP. Observational research, randomised trials, and two views of medical science. PLoS Medicine. 2008;5(3):e67.

36. Gemeinsamer Bundesausschuss. Verfahrensordnung Stand: 21. Februar 2013 [in German]. Berlin: Gemeinsamer Bundesausschuss; 2013.

37. Centre of Evidence-Based Medicine. Levels of evidence. Oxford: Centre of Evidence-Based Medicine, University of Oxford; 2009.

38. National Institute for Health and Care Excellence. Guide to the methods of technology appraisal. London: National Institute for Health and Care Excellence; 2004.

39. Scottish Intercollegiate Guidelines Network. SIGN 50. A guideline developer's handbook. Revised November 2011. Annex B page 51. Edinburgh: Scottish Intercollegiate Guidelines Network; 2011.

40. Hemila $\mathrm{H}$, Chalker E. Vitamin C for preventing and treating the common cold. Cochrane Database of Systematic Reviews. 2013;1:CD000980.

41. Radiation Therapy Oncology Group. Guidance for routine adverse event reporting on RTOG protocols (initial 4.11.2013). Philadelphia: Radiation Therapy Oncology Group; 2013. 
42. Brookman-May SD, May M, Shariat SF, Novara G, Zigeuner R, Cindolo L, et al. Time to recurrence is a significant predictor of cancer-specific survival after recurrence in patients with recurrent renal cell carcinoma--results from a comprehensive multi-centre database (CORONA/SATURN-Project). BJU International. 2013;112(7):909-16.

43. Arvanitakis C, Nikopoulos A, Giannoulis E, Theoharidis A, Georgilas V, Fotiou $H$, et al. The impact of early or late diagnosis on patient survival in gastric cancer in Greece. Hepatogastroenterology 1992;39(4):355-7.

44. Calafiore AM, Di Mauro M, Di Giammarco G, Contini M, Vitolla G, laco AL, et al. Effect of diabetes on early and late survival after isolated first coronary bypass surgery in multivessel disease. The Journal of Thoracic and Cardiovascular Surgery. 2003;125(1):144-54.

45. Pedersen SS, Martens EJ, Denollet J, Appels A. Poor health-related quality of life is a predictor of early, but not late, cardiac events after percutaneous coronary intervention. Psychosomatics. 2007;48(4):331-7.

46. Doll R, Peto R, Boreham J, Sutherland I. Mortality from cancer in relation to smoking: 50 years observations on British doctors. Britisch Journal of Cancer. 2005;92(3):426-9.

47. Hagstad S, Bjerg A, Ekerljung L, Backman H, Lindberg A, Ronmark E, et al. Passive Smoking Exposure Is Associated With Increased Risk of COPD in Never Smokers. Chest. 2014;145(6):1298-304.

48. National Center for Health Statistics. Healthy People 2000 Final Review. Hyattsville: National Center for Health Statistics, Public Health Service; 2001.

49. Hackshaw AK, Law MR, Wald NJ. The accumulated evidence on lung cancer and environmental tobacco smoke. BMJ. 1997;315(7114):980-8. 



\section{CHAPTER 8}

\section{General discussion}





\section{Summary of main findings}

A review of 42 articles about the use of multiple study designs in systematic reviews of health care interventions showed a tendency that nonrandomized studies should be conducted and integrated in systematic reviews to complement available RCTs or replace lacking RCTs in 85\% (36 of 42) of these articles. Most papers acknowledged the advantages and the disadvantages of RCTs and nonrandomized studies with regard to specific methodologic topics or specific clinical outcomes. In general, it was acknowledged that only RCTs can achieve the lowest risk of bias. Many papers highlighted that results of RCTs may not be applicable to a considerable number of the acual target population. Alternative study designs may be needed to confirm that the intervention of interest does work under real everyday conditions. Some papers addressed the problem that RCTs are not possible for assessing certain questions and that case reports may have a considerable impact on safety issues.

In a Cochrane Review on 'Autologous hematopoietic stem cell transplantation following high dose chemotherapy for non-rhabdomyosarcoma soft tissue sarcomas', several single-arm studies were included with aggregate data, and many single arm studies with individual data to complement the results of a single available RCT. A time-to-event analysis was conducted on overall survival to incorporate individual data from non-comparative single-arm studies. The required follow-up information was incomplete or missing in a considerable number of participants. Neither the individual data, which were used in a time-to-event analysis on overall survival, nor the aggregagte data from single-arm studies could contribute to the decision-making whether the text intervention was associated with a longer overall survival than the control intervention. The number of participants in the RCT was low and the individual data contributed to address serious adverse events associated with the test intervention. Some treatments were performed 10 to 20 years ago. Thus, the results may not be applicable to patients who are treated today.

In a systematic review on 'First-line matched related donor hematopoietic stem cell transplantation compared to immunosuppressive therapy in acquired severe aplastic anemia', nonrandomized controlled trials with a prospective design were included because RCTs on the topic were not identified. The available data enabled a pooled estimate of overall survival for the test and the control intervention. Potential duplicate publication bias was identified due to identical data that may have been reported in a hospital-based study and in a registry analysis. Considerable outcome reporting bias, which is defined as the selection of a subset of the originally recorded outcome variables for publication, was also identified. A high risk of bias was identified within almost all non-randomized controlled trials limiting any meaningful inferences.

In a systematic review on 'Permanent interstitial low-dose-rate brachytherapy for patients with localised prostate cancer: a systematic review of randomised and nonrandomised controlled clinical trials', 30 comparative nonrandomized studies were 
included in addition to a single RCT because data on health-related quality of life was limited in the RCT. Due to the stage of the condition of interest, health-related quality of life rather than overall survival was the preeminent outcome of interest. The comparative nonrandomized studies provided useful information for decision-making. Individual preferences by patients and physicians may have played a central role in the decision whether to treat or to pursue active surveillance.

In a systematic review on 'Negative-pressure wound therapy: systematic review of randomized controlled trials', only RCTs were included because a large number of RCTs were identified. RCTs provided sufficient data on the primary outcome 'complete wound closure'. However, data on treatment-related complications were limited due to a low number of participants. A postmarketing surveillance system was consulted to complement data on a considerable number of serious complications connected with the test intervention. These data changed the overall picture of the possible benefits and harms of the intervention of interest.

The inclusion of various study designs may be required if a systematic review aims to answer different research questions. A decision tree was constructed that may guide systematic reviewers to choose a single design or multiple study designs appropriate to answer these research questions. For some research questions, the algorithm may recommend the use of studies with the highest possible validity. For alternative research questions, the algorithm may recommend the use of studies with qualities other than methodological validity. The recommended study design may not be reported in the identified studies and, thus, may not be available. In this case, a study design of the next lower level of validity may be used as a replacement. The usefulness and functionality of the algorithm was evaluated by applying it to four systematic reviews. These systematic reviews were conducted to evaluate the prospects of using multiple study designs. The systematic reviews provided short and long follow-ups, rare and frequent events, and various outcomes, that all suited well for a projection on the various pathways offered by the algorithm. The theoretical algorithm proved to be useful in various practical situations and helped to choose the appropriate study designs for inclusion in each systematic review.

\section{Strengths and limitations}

The search for published information on the advantages and disadvantages of various study designs, the corresponding data extraction, and data synthesis were performed systematically. For example, the definition of the search strategies, the inclusion criteria and study selection, the data analyses and result interpretation were independently done by at least two authors. The PRISMA statement were endorsed, adhered to its principles and conformed to its checklist. As in any systematic review, the limitations in 
drawing conclusions are directly dependent on the quality and homogeneity of the primary studies.

One strength of the thesis lies in the broad search strategy. The retrieved information was designated to provide an objective view on the possible merits of every individual study design to support decision-making in health care. However, different authors and readers may have varying preconceptions about the way, how the term 'objective' should be conceived. It was tried to provide a comprehensive view of the published knowledge concerning the topic of this thesis. The comprehensiveness of the process of data collection required to include not only systematic reviews and meta-analyses but also nonsystematic reviews, method studies and opinions. The qualitative data were summarised by extracting the major identified contents. Thus, in every step of acquisition and judgement of data, personal preferences may have influenced the results.

The documentation of the applied methods enables others to repeat the work. It is possible that another person might come to different results. While reading through hundreds of papers, I perceived a polarized dispute on randomized versus nonrandomized and on experimental versus observational study designs among some authors. Some put RCTs on a pedestal and claimed that results are only valid and trustworthy if derived from high quality RCTs regarding all possible research questions. Others demanded that only data from observational studies are able to answer some research questions especially in the context of proving that an intervention might work under real world conditions. Thus, the inferences made in many included papers may be influenced by the authors' preoccupations. While building the algorithm, I aligned the decision points and paths according to seminal published information. The algorithm follows strict binary decision points and it retains sufficient flexibility to consider certain conditions such as ethical or practical issues or to react if the best possible evidence is not available.

The proposed algorithm cannot be applied without considering disease-specific circumstances and aims of interventions. The information base included nonsystematic reviews, which some may dislike as invalid opinions. The terms used for defining the critical decision points of the algorithm such as short versus long follow-up need to be interpreted in the context of the disease and may be unclear and not useful if used as general terms. We provided examples to show that short versus longterm follow-up can vary considerably depending on the disease. Similarly, we provided examples to show that the definition of rare versus frequent events has to be interpreted in the context of the type of intervention or exposure as well as the type of event.

The prospects of using multiple study designs were evaluated in four systematic reviews. The various characteristics of follow-up, frequency of adverse events, and type of outcomes of the included systematic reviews qualified to test almost every pathway of the algorithm. Although it appeared that the algorithm is proper for projection of various research questions on the delineated pathways, we wanted to draw 
the attention to some limitations of this study. Disease-specific circumstances and aims of interventions always have to be taken into account during application of the algorithm. It is not intended to be an absolute guide always leading to appropriate study designs. The testing was conducted retrospectively with systematic reviews that were already completed. This approach may have the advantage that potential pitfalls and a complicated matter are already known. However, this situation is far from the everyday working condition and the approach may be considerably biased by the expectations of the authors, to name just one potential cause. A testing more adapt to the real world should be included prospectively and should start while a systematic review is planned. Testing the algorithm prospectively and applying it at the start of a systematic review may have other results than those reported in the present study. Nevertheless, the results of this testing certainly need to be confirmed by other systematic reviewers, in other PICOTS-SD frames, and in a higher number of applications.

\section{Agreements and disagreements with other studies or reviews}

We have not identified another algorithm published by other authors. It appears that our algorithm may be the first comprehensive decision tree available. Thus, we cannot compare our guidance tool for systematic reviewers with a similar one. Nevertheless, there are numerous papers reporting about issues concerning including multiple study designs. We want to address some salient aspects of this topic reported by some renowned authors.

The view of RCTs as the sole means of finding reliable answers to clinical research questions was perpetuated only by a minority of the evaluated reviews [1]. For example, McCarthy 2008 recommended to perform more RCTs in surgery because they provide the most rigorous way of determining a cause-effect relationship between treatment and outcome [2]. Mitchell 1995 stated that rigorous and large RCTs are required for valid estimations of rare and serious adverse events [3]. Reeves 2005 refered to the drawbacks of nonrandomized designs and pointed out that they are associated with selection bias, performing bias, detection bias, and attrition bias [4]. It is conceivable that a high level of evidence associated with RCTs certainly prevents a number of major biases considering effects of interventions [5-6]. Therefore, RCTs should be used if feasible.

We found that the majority of trials and systematic reviews reported effects that did not differ considerably between randomized and nonrandomized controlled trials [7]. About one third of the trials showed a different direction or a statistically significant difference of the magnitude of effect between those two designs. The estimated treatment effect may underestimate or overestimate the real effect. For example, Hernan 2012 noticed that the intention-to-treat analyses may underestimate the treatment effect in placebo-controlled randomized clinical trials [8]. A Cochrane review 
compared RCTs versus historically or concurrently controlled nonrandomized trials in 2007 [10]. The authors concluded that, on average, the nonrandomized controlled trials tend to result in larger estimates of effect than RCTs. The latest update of this Cochrane review in 2011 amended the research question and compared RCTs versus concurrently controlled nonrandomized trials and excluded historically controlled ones [11]. The authors concluded that the results of randomized and nonrandomized controlled trials sometimes differed, namely, in some instances nonrandomized studies yielded larger estimates of effect and in other instances vice versa. It appears that the early firm statement expressing larger estimates in the nonrandomized controlled trials changed to a less decided message. Systematic biases can arise from time trends of changing outcomes in historically controlled studies in contrast to concurrently controlled studies [12]. Thus, the change was probably caused by the exclusion of studies with a historically controlled group and thereby removing a source of additional risk of bias. A new Cochrane review is on the way to assess the impact of study design on the effect measures estimated in RCTs compared to various observational study designs such as prospective or retrospective cohorts [13]. However, nonrandomized controlled trials may presumably not be included. We want to emphasize the important difference between observational comparative studies (no assignment by study investigator to treatment groups) and nonrandomized controlled trials (experimental design with assignment).

We found that the majority, at least three quarters of relevant identified reviews, inferred that nonrandomized studies should be included in systematic reviews [1]. In a landmark paper, Black 1998 explained that RCTs can be unnecessary (e.g. dramatic effect such as instant healing by insulin), inappropriate (e.g. act of random allocation may reduce the effectiveness), impossible (e.g. some interventions cannot be allocated on a random basis), or inadequate (e.g. limited applicability) [14]. Lewsey 2000 provided an example that an RCT is not possible to study early versus late surgery for subarachnoid haemorrhage [15]. Hartling 2005 addressed the issue of applicability and noticed that RCTs tend to enroll younger and healthier patients [16] and Hodgson 2007 further added that older patients, women, and patients with comorbid disorders are underrepresented in RCTs [17]. Olivier 2006 stressed the importance of case reports and postmarket monitoring of adverse events and described that case reports lead to the withdrawal of 19 of 21 drugs for safety reasons in a specific time period in France [18]. Concato 2010 noticed that contradictions among RCTs themselves are well described [19]. Britton 1998 concluded that a well-designed nonrandomized study may be preferable to a small, poorly designed and exclusive RCT [20]. Studies of lower levels may be necessary when RCTs are not feasible. For example, a considerable number of eligible individuals may be excluded from an RCT that have characteristics different from those of the included ones [20]. Eligible patients excluded from an RCT are usually not observed further, which may cause important limitations to jugdements about applicability [21]. 
We concluded that the risk of presenting uncertain results without knowing for sure the direction and magnitude of the effect holds true for both nonrandomized and randomized controlled trials. Vandenbroucke 2009 elucidated that conflicting results between observational studies and RCTs with respect to hormone replacement therapy (HRT) finally fell in line mainly by adjusting different time intervals [22]. He concluded that the discrepancies between RCTs and observational studies cannot be automatically attributed to randomization itself but may be related to systematic differences in charateristics of participants. Conflict \#1 concerns the question whether HRT increases coronary heart disease. HRT caused an initial increased risk, which waned in later years. RCTs truely identified an increased risk because the data were observed since the start of HRT. The time lag caused the difference in risk not the study design. Observational studies falsely showed a reduced risk for coronary heart disease because the users were observed beyond a time interval since start HRT and were in a phase of decreased incidence. Conflict \#2 concerns the question whether HRT increases breast cancer. Observational studies truely identified an increased risk after combined oestrogen-progestin. RCTs falsely did not identify this risk because the users were observed beyond a longer time interval after menopause than in the observational studies. The varying time interval between menopause and start of HRT caused the difference in risk not the study design. Hoppe 2009 acknowledged that RCTs are the most objective design but admitted that RCTs may not provide all of the information a clinician might need [23]. We concluded that the integration of multiple study designs in systematic reviews is required if patients should be informed on the many facets of patient relevant issues of health care interventions such as survival, cure of disease, improvement of symptoms, treatment-related complications, other adverse events, health-related quality of life. In a recent methods paper written under contract of the Agency for Healthcare Research and Quality, Seida 2013 found a considerable diversity across the comparative effectiveness reviews with respect to methods used to search for, select, appraise, and analyze observational studies [24]. The authors inferred that it was not always clear whether the inclusion of observational studies added value. As mentioned in the introduction chapter of the present thesis, ljaz 2014 concluded that reporting of nonrandomized studies in Cochrane reviews requires an improved guidance [25].

\section{Best available evidence}

Evidence-based medicine (EBM) was defined as the integration of best research evidence with individual clinical expertise, patient values and expectations, and best external research evidence [26]. This definition of EBM may be appropriately illustrated by the Venn diagram in Figure 1 [27]. 


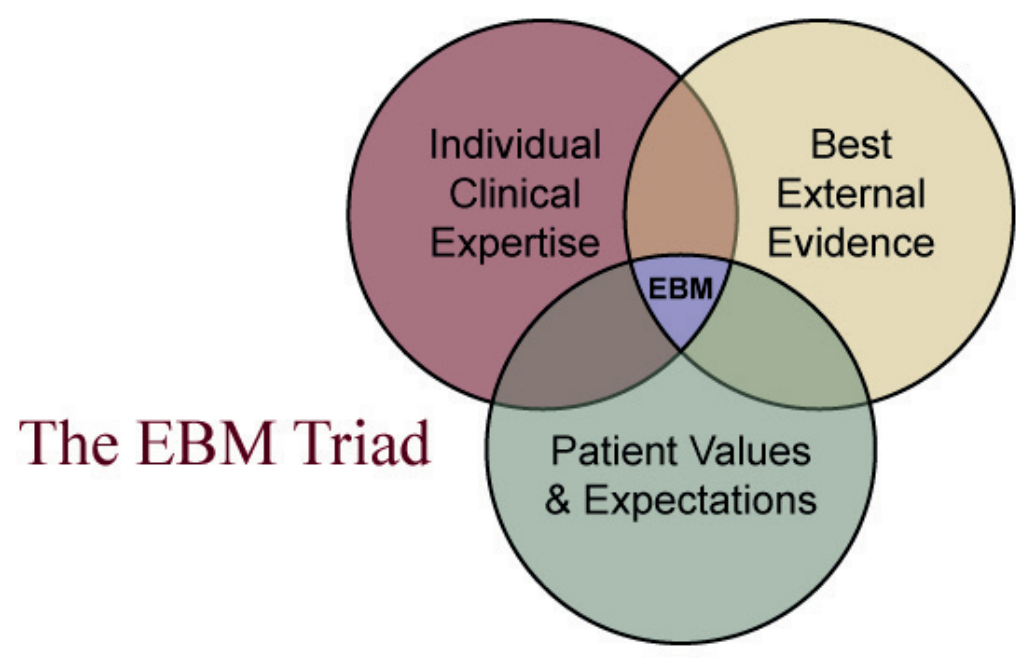

Figure 1. Definition of Evidence-Based Medicine [27].

Sackett 1996 judged: "Without current best evidence, practice risks becoming rapidly out of date, to the detriment of patients." [28]. The term 'best external evidence' may be described as a rigorous analysis of published study data primarily from RCT and quantitative (meta-analysis) and/or qualitative summary of these data within a systematic review. The term 'evidence' means information and the term 'best evidence' means the most valid and reliable information [29]. To classify more valid and less valid information, the 'levels of evidence' specify a hierarchical order for various research designs based on their internal validity. The highest level of valid data, that is, the 'best' evidence, however, is not always available. For instance, if RCTs are lacking and only case reports are available, then, case reports may constitute the best available evidence.

EBM proponents who might be inclined to narrow the view down to statistics may always demand RCTs. A spoof systematic review evaluated whether the imposition of a parachute versus no parachute results in a better survival when jumping out of a plane [30]. The article's effect was probably to contest idealization of RCTs. It is very important to keep the other circles of EBM always in mind. Many aspects of health care depend on individual circumstances and preferences and it may not be possible to evaluate those important issues. The term evidence-based medicine may imply that health care decisions are based solely on the best external evidence circle and not on the individual clinical expertise circle and not on the patient value and expectations circle. Therefore, the term evidence informed healthcare may be more appropriate [31]. Sacket 1996 warned: "Without clinical expertise, practice risks becoming tyrannised by evidence, for even excellent external evidence may be inapplicable to or inappropriate 
for an individual patient." [28]. Berguer 2004 criticized that the name 'evidence-based medicine' is self-righteous in that it singles out one approach to the analysis of clinical data as the one embodying scientific truth [32]. He further pointed out that results from RCT are average numbers referable to an average individual. However, the 'average' risk may be meaningless when you are the patient. Feinstein and Horwitz 1997 [33] apprehended: "The laudable goal of making clinical decisions based on evidence can be impaired by the restricted quality and scope of what is collected as 'best available evidence'. The authoritative aura given to the collection, however, may lead to major abuses that produce inappropriate guidelines or doctrinaire dogmas for clinical practice." There may be perceivable hints that dogma and ideology prevail at least in some areas. It is certainly not a scientific characteristic to oppress other opinions including those by experts in various fields. Spence 2014 [34] criticized: "Today EBM is a loaded gun at clinicians' heads and that you better do as the evidence says, leaving no room for discretion or judgment. The current incarnation of EBM is corrupted, let down by academics and regulators alike." The letters by Hicks 2012 [35] and Hicks 2013 [36] may serve as an example for a heated dispute including the accusation that the authors of an EBM article did not take the clinical and the patient part sufficiently into account. They noted that the work "lacks appropriate clinical perspective", that the authors have "apparent misunderstanding of the values and principles of EBM", that the authors "have presented an analysis that is so lacking in scientific rigor that it can be fairly judged to have provided a prejudiced appraisal of the evidence pertaining to the patient benefits", and that the authors "potentially misguide policymakers and individuals about appropriate use of this technology. In our view, this is a disservice to our patients that must be strenuously resisted and hence the tone of our prior letter."

In summary, the term 'evidence-informed healthcare' mounts on three different equally important foundations. These three cornerstones comprise the patients and their values and expectations, the clinicians and their expertise and experience, and the epidemiologists and statisticians and their interpretation of study data. Subsequently, the term 'best available evidence' should not be confined to medical biometrical views but should include all three aspects.

\section{Conclusions}

The use of multiple study designs in systematic reviews clearly showed that various study designs increased the information that should be considered in decision-making. The impact of the extra information may not be foreseen very well. The extra information may complement the best available evidence adding new important data and may open the horizon to bring attention to issues that may be overlooked but are nevertheless pertinent to health care. Sometimes information from multiple study designs can induce prudence in those who decide about an acclaimed new interven- 
tion. RCTs may not be the typical study design to provide sufficient evidence for market withdrawals.

\section{Recommendations for decision makers}

We recommend decision makers to avoid building their decisions only on data emerging from a single study design. Methods groups are on their way to improve the bias control and the reporting standards of nonrandomized controlled clinical trials. Other groups bring out suggestions to better search for and find studies on adverse events. Some Cochrane Groups demand two primary outcomes, one associated with the most wanted treatment effect and one associated with a serious unwanted effect. Patientreported outcomes are important in evaluations that apply patient-centered outcomes and invite consumers to participate in conducting systematic reviews. We recommend considering multiple study designs to enable Cochrane Reviews and other systematic reviews accomplishing these goals more effectively. The algorithm is foreseen to function as a tool helping to bring seminal features of a systematic review to the attention of anyone who is planning to conduct a systematic review. It helps to reorientate oneself to major features of the studies eligible for an evaluation of a health care intervention. The benefit is the provision of awareness not a new regulation. The intention is to provide a guide that might be used fully or partially by persons who are going to prepare a systematic review. While conducting a systematic review, it may be important at an early time point to identify the relevant and the most appropriate study designs necessary to find answers for a variety of prespecified outcomes. It might also be of interest for persons who evaluate the quality of systematic reviews and might want to check whether the all study designs have been considered that should have been. The algorithm should be embedded in an article, which provides introduction and explanation of its target population, aims purposes, and its optimal use. The article should be published in an open access journal, a scholarly journal that is available online worldwide to all potential readers who can use the internet. The article will have a particular internet site, which contains tools for instant feedback to the authors, general comments, recommendations passed on to others, and links to social networks such as twitter.

\section{Recommendations for further research}

First, we recommend continuing the refinement of requirements for nonrandomized controlled clinical trials. Second, we recommend evaluating whether all Cochrane Reviews should include multiple study designs to cover the various main objectives. Third, we recommend elaborating whether the implementation of an algorithm can support the quality and scope of a systematic review. The algorithm should be applied prospectively and used as a tool for the process of choosing appropriate study designs 
for inclusion in a systematic review of health-care interventions. We imagine a trial with random allocation of using versus not using the algorithm. The satisfaction of convenience of the users might be evaluated by a questionnaire and may be used as the effect measure. At least, the algorithm should be tried by more than just one person to allow any conclusions on its usefulness. Experience with the algorithm should be collected with 10 or more author groups. The systematic reviews conducted with the use of the algorithm should have other types of population, intervention, comparator, and outcome than those contained in the systematic reviews of this thesis.

\section{Recommendations for instructing the algorithm}

There might be an educational challenge of instructing end users of the algorithm. Persons who are planning to conduct a systematic review and use the algorithm should make themselves acquainted with the scope of possible study designs, their purposes, advantages, and drawbacks. Many pathways might lead to choose only RCTs for the evaluation of the efficacy of a health care intervention. Nevertheless, other study designs should be kept in mind and considered for additional inclusion depending on the particular disease and intervention of interest. We recommend a flexible and pragmatic approach without the obligation to rigidly exclude study designs. In the case that, for example, the RCT should be chosen, we have already implemented a strategy of considering ethical and practical issues. These issues should not be overlooked and might be reasons to replace RCT with another study design. If available publications do not report the study design of interest, then the hierarchical structure of study designs should be considered and the next lower level of evidence might be considered. The algorithm will be published preferably in an open accesss journal. Beginners might find it helpful to find a framework that offers already some potential study designs and objective reasons to favor specific study designs for inclusion. The algorithm is supposed to assist a group of experienced scientists while gaining a consensus about choosing study designs for inclusion in systematic reviews. It is not intended to replace the dialog among those experts. Knowledge and application of general rules and experience in methodological issues relevant for the conduct of systematic reviews described comprehensively in particular in the Cochrane Handbook for Systematic Reviews of Interventions is mandatory. 


\section{References}

1. Peinemann F, Tushabe DA, Kleijnen J. Using multiple types of studies in systematic reviews of health care interventions--a systematic review. PLoS One. 2013;8(12):e85035.

2. McCarthy CM, Collins ED, Pusic AL. Where do we find the best evidence? Plastic and Reconstructive Surgery. 2008;122(6):1942-7.

3. Mitchell AA, Lesko SM. When a randomised controlled trial is needed to assess drug safety. The case of paediatric ibuprofen. Drug Safety. 1995;13(1):15-24.

4. Reeves BC, van Binsbergen J, van Weel C. Systematic reviews incorporating evidence from nonrandomized study designs: reasons for caution when estimating health effects. European Journal of Clinical Nutrition. 2005;59 Suppl 1:S155-61.

5. Reeves BC, Deeks JJ, Higgins JPT, Wells GA. Chapter 13. Including non-randomized studies. In: Higgins JPT, Green S (editors). Cochrane Handbook for Systematic Reviews of Interventions Version 5.1.0 [updated March 2011]. The Cochrane Collaboration; 2011.

6. Kunz R, Oxman AD. The unpredictability paradox: review of empirical comparisons of randomised and non-randomised clinical trials. BMJ. 1998;317(7167):1185-90.

7. Peinemann F, Kleijnen J. Development of an algorithm to provide awareness in choosing study designs for inclusion in systematic reviews of health care interventions - a method study. Submitted 2014.

8. Hernan MA, Hernandez-Diaz S. Beyond the intention-to-treat in comparative effectiveness research. Clinical Trials. 2012;9(1):48-55.

9. Kunz R, Vist G, Oxman AD. Randomisation to protect against selection bias in healthcare trials. Cochrane Database of Systematic Reviews. 2002;(4):MR000012.

10. Kunz R, Vist G, Oxman AD. Randomisation to protect against selection bias in healthcare trials. Cochrane Database of Systematic Reviews. 2007;(2):MR000012.

11. Odgaard-Jensen J, Vist GE, Timmer A, Kunz R, Akl EA, Schunemann H, et al. Randomisation to protect against selection bias in healthcare trials. Cochrane Database of Systematic Reviews. 2011;(4):MR000012.

12. Deeks JJ, Dinnes J, D'Amico R, Sowden AJ, Sakarovitch C, Song F, et al. Evaluating non-randomised intervention studies. Health Technology Assessment. 2003;7(27): iii-x, 1-173.

13. Bero L, Anglemyer A, Horvath T. Healthcare outcomes assessed with non-experimental designs compared with those assessed in randomised trials (Protocol). Cochrane Database of Systematic Reviews 2012;(2):MR000034.

14. Black N. Why we need observational studies to evaluate the effectiveness of health care. BMJ. 1996;312(7040):1215-8.

15. Lewsey JD, Leyland AH, Murray GD, Boddy FA. Using routine data to complement and enhance the results of randomised controlled trials. Health Technology Assessment. 2000;4(22):1-55.

16. Hartling L, McAlister FA, Rowe BH, Ezekowitz J, Friesen C, Klassen TP. Challenges in systematic reviews of therapeutic devices and procedures. Annals of Internal Medicine. 2005;142(12 Pt 2):1100-11.

17. Hodgson R, Bushe C, Hunter R. Measurement of long-term outcomes in observational and randomised controlled trials. British Journal of Psychiatry: Supplement. 2007;50:s78-84.

18. Olivier $\mathrm{P}$, Montastruc JL. The nature of the scientific evidence leading to drug withdrawals for pharmacovigilance reasons in France. Pharmacoepidemiology and Drug Safety. 2006;15(11):808-12.

19. Concato J, Lawler EV, Lew RA, Gaziano JM, Aslan M, Huang GD. Observational methods in comparative effectiveness research. American Journal of Medicine. 2010;123(12 Suppl 1):e16-23.

20. Britton A, McKee M, Black N, McPherson K, Sanderson C, Bain C. Choosing between randomised and non-randomised studies: a systematic review. Health Technology Assessment. 1998;2(13):i-iv, 1-124.

21. Schmoor C, Olschewski M, Schumacher M. Randomized and non-randomized patients in clinical trials: experiences with comprehensive cohort studies. Statistics in Medicine. 1996;15(3):263-71.

22. Vandenbroucke JP. The HRT controversy: observational studies and RCTs fall in line. The Lancet. 2009;373(9671):1233-5. 
23. Hoppe DJ, Schemitsch EH, Morshed S, Tornetta P, 3rd, Bhandari M. Hierarchy of evidence: where observational studies fit in and why we need them. The Journal of Bone and Joint Surgery: American Volume. 2009;91 Suppl 3:2-9.

24. Seida JC, Dryden DM, Hartling L. In: Observational Studies: Empirical evidence of their contributions to comparative effectiveness reviews. Rockville: Agency for Healthcare Research and Quality; 2013.

25. Ijaz S, Verbeek JH, Mischke C, Ruotsalainen J. Inclusion of nonrandomized studies in Cochrane systematic reviews was found to be in need of improvement. Journal of Clinical Epidemiology. 2014;67(6):645-53.

26. Sackett DL, Straus SE, Richardson WS, Rosenberg W, Haynes RB. Evidence-based medicine. How to practice and teach EBM. Edinburgh: Churchill Livingstone; 2000.

27. Evidence-Based Medicine Tutorial. Tallahassee: Florida State University; 2014.

28. Sackett DL, Rosenberg WM, Gray JA, Haynes RB, Richardson WS. Evidence based medicine: what it is and what it isn't. BMJ. 1996;312(7023):71-2.

29. What is Meant By The 'Best Available' Evidence? Amsterdam: Center for Evidence-Based Management; 2014.

30. Lexchin J, Bero LA, Djulbegovic B, Clark O. Pharmaceutical industry sponsorship and research outcome and quality: systematic review. BMJ. 2003;326(7400):1167-70.

31. Evidence-based medicine. Wikipedia; 2014.

32. Berguer R. The evidence thing. Annals of Vascular Surgery. 2004;18(3):265-70.

33. Feinstein AR, Horwitz RI. Problems in the "evidence" of "evidence-based medicine". American Journal of Medicine. 1997;103(6):529-35.

34. Spence D. Evidence based medicine is broken. BMJ. 2014;348:g22.

35. Hicks RJ, Ware RE, Hofman MS. Not-so-random errors: randomized controlled trials are not the only evidence of the value of PET. Journal of Nuclear Medicine. 2012;53(11):1820-2.

36. Hicks RJ, Hofman MS, Ware RE. Not-so-random errors: randomized controlled trials are not the only evidence of the value of PET--rebuttal. Journal of Nuclear Medicine. 2013;54(3):492. 


\section{Summary}

\section{Background and rationale}

A systematic review attempts to collate all empirical evidence that fits pre-specified eligibility criteria in order to answer a specific research question. The most distinctive characteristics that are present in a systematic review and that are not present in a nonsystematic review may be a study protocol, an analysis plan, a literature search strategy, and a description of the selection of suitable studies in accordance with prospectively defined inclusion and exclusion criteria. The starting point and fundamental component of a systematic review of health care interventions is a structured clinical question.

A systematic review may evaluate benefit and harm of a health care intervention and may include a specific set of studies. Explanatory study designs address the question whether the intervention of interest can work in principle in the ideal study setting and typically provide a conclusion for an average patient only. The intervention and the control group may differ only with respect to the intervention of interest. Known and unknown characteristics are equally distributed among the two treatment groups. The resulting structural equality facilitates a decision whether an observed effect was actually caused by the intervention. Randomization may be the best approach to provide this structural equality and may provide a low risk of bias. However, in some situations, randomization is not feasible, not appropriate, or the results may not be applicable to everyday practice. Pragmatic study designs aim to show that interventions will work under every day circumstances but may have a high risk of bias. To accommodate the evaluation of various research questions, the inclusion of more than one study design appears to be necessary.

\section{Research questions and answers}

The aim of this thesis is to investigate the advantages and disadvantages of using various study designs to answer specific clinical research questions within systematic reviews and to develop and pilot test an algorithm to guide systematic reviewers in their 
decision to choose appropriate study designs. The following research questions are discussed in the present thesis:

What is known in the published literature about the pros and cons of integration of multiple study types in systematic reviews?

A review of 42 articles about the use of multiple study designs in systematic reviews of health care interventions showed a tendency that nonrandomized studies should be conducted and integrated in systematic reviews to complement available randomized controlled trials or replace lacking trials in $85 \%$ (36 of 42) of these articles. It was acknowledged that only randomized controlled trials can achieve the lowest risk of bias. Many papers highlighted that results of randomized trials may not be applicable to a considerable number of the actual target population. The risk of presenting uncertain results without knowing for sure the direction and magnitude of the effect holds true for both nonrandomized and randomized controlled trials.

What can be learnt from conducting systematic reviews about topics that may require the inclusion of multiple study designs, assuming that more than one study design may be essential to gather sufficient data for answering the objectives of the review.

If no comparative study is available, then the data of single-arm studies might provide, for example, an estimation of overall survival. Data on adverse events can be presented beyond the scope of a randomized controlled trial. Discussing the limitations of the results may bring the public attention to a lack of certain data, which might foster the conduction of a long desired trial. In another example, the test but not the control intervention may cure patients, however, the test intervention might be associated with a higher early treatment-related mortality than the control intervention. This situation might create a conflict. Ethical concerns may prevent trials with a random allocation of patients to the treatment groups. The principles of 'Mendelian randomization' could be applied for evaluating transplantation by restricting transplant donors to siblings. Another example shows that patients with a localized as opposed to an advanced cancer might have a very good overall survival regardless of the type of intervention. Though, the health-related quality of life as measured by patient-reported outcomes may vary considerably among the treatment options, which is caused by the varying degrees of their invasiveness. Reluctance of patients and physicians alike to participate in randomization corroborates the consideration of alternative approaches. A report on deaths was issued in connection with a particular medical device. It showed that the consideration of registry analyses and case reports can be very helpful to draw attention to possible dangerous and life-threatening events. It was also helpful to point at the home setting where a considerable number of deaths happened. 
What is the preferred content and format of a straightforward algorithm for integration of various study designs in a systematic review that incorporates major study characteristics as decision points and that allows consideration of practical concerns?

A decision tree was constructed using length of follow-up, frequency of events, and type of outcomes as main decision points. It was ensured that the preset pathways retain sufficient flexibility to consider ethical and practical issues as well as unavailable best evidence. The outcomes may be evaluated after a short or long follow-up. The events of interest may be rare or frequent. The outcomes can be classified into the five major groups of death, disease, discomfort, disability, and dissatisfaction. Then, appropriate study designs are recommended with respect to the type of outcome. Practical or ethical concerns or lack of recommended study designs may emerge as reasons to override the earlier decisions or to switch to a more appropriate study design. Therefore, the reader is reminded to reconsider the chosen path.

Can the algorithm hold its promise as a useful guide for choosing appropriate study designs by testing its feasibility and applying it to existing systematic reviews?

The appropriateness of the pathways of the decision tree was confirmed during the application of the algorithm on four selected systematic reviews. These systematic reviews were conducted to evaluate the prospects of using multiple study designs and were well suited for a projection on the various pathways offered by the algorithm. The theory-based algorithm proved to be useful in various practical situations and helped to choose the appropriate study designs for inclusion in each tested systematic review.

\section{Strengths and limitations}

One strength of the thesis lies in the broad search strategy. The retrieved information was designated to provide an objective view on the possible merits of every individual study design to support decision-making in health care. Nevertheless, personal preferences may have influenced the results in every step of acquisition and judgement of data. While reading through hundreds of papers, I perceived a polarized dispute on randomized versus nonrandomized and on experimental versus observational study designs among some authors. Thus, the inferences made in many included papers may be influenced by the authors' preoccupations.

The testing of the algorithm was conducted retrospectively by backtracing systematic reviews that were already completed. This approach is far from the everyday working condition. It may be considerably biased by my expectations that the algorithm should have been worked if applied prospectively. Thus, the results of this testing need to be confirmed by other systematic reviewers who plan to use the algorithm 
from the start. The algorithm is not intended to be an absolute guide always leading to appropriate study designs. Disease-specific circumstances and aims of interventions always have to be taken into account during application of the algorithm.

\section{Recommendations}

The algorithm is foreseen to function as a guide helping to bring seminal features of a systematic review to the attention of anyone who is planning to conduct a systematic review. It is recommended to confirm this assumption by its prospective application, possibly within a trial. It is also recommended to test its usefulness with respect to other types of population, intervention, comparator, and outcome than those contained in the systematic reviews of this thesis. The algorithm may help to reorientate oneself to major features of the studies eligible for an evaluation of a health care intervention. There might be an educational challenge of instructing end users of the algorithm. Persons who are planning to conduct a systematic review and use the algorithm should make themselves acquainted with the scope of possible study designs, their purposes, advantages, and drawbacks. Persons without extensive practice in conducting systematic reviews might be asked to share their opinion concerning its usefulness for beginners. In general, a flexible and pragmatic approach without the obligation to rigidly exclude study designs is recommended. 


\section{Valorisation}

The work of the thesis gained extensive insight into the using of evidence of multiple study designs in systematic reviews. A review of a comprehensive literature showed a tendency that nonrandomized studies should be conducted and integrated in systematic reviews to complement available randomized controlled trials or replace lacking those trials. The risk of presenting uncertain results without knowing for sure the direction and magnitude of the effect holds true for both nonrandomized and randomized controlled trials. The consideration of registry analyses and case reports can be very helpful to draw attention to possible dangerous and life-threatening events beyond the scope of a randomized controlled trial. Ethical concerns may prevent trials with a random allocation of patients to treatment groups. Health-related quality of life may vary considerably if the treatment options are characterized by varying degrees of invasiveness. In this case, reluctance of patients and physicians alike to participate in randomization corroborates the consideration of alternative approaches. The work showed the importance of using multiple study designs in systematic reviews and provided many examples. A decision tree was constructed to facilitate the choosing of study designs for particular research questions, as shown below. Length of follow-up, frequency of events, and type of outcomes were the main decision points. It was ensured that the preset pathways retain sufficient flexibility to consider ethical and practical issues as well as unavailable best evidence. The appropriateness of the pathways of the decision tree was confirmed by backtracing four systematic reviews. The theorybased algorithm proved to be useful in various practical situations and helped to choose the appropriate study designs for inclusion in each tested systematic review. 


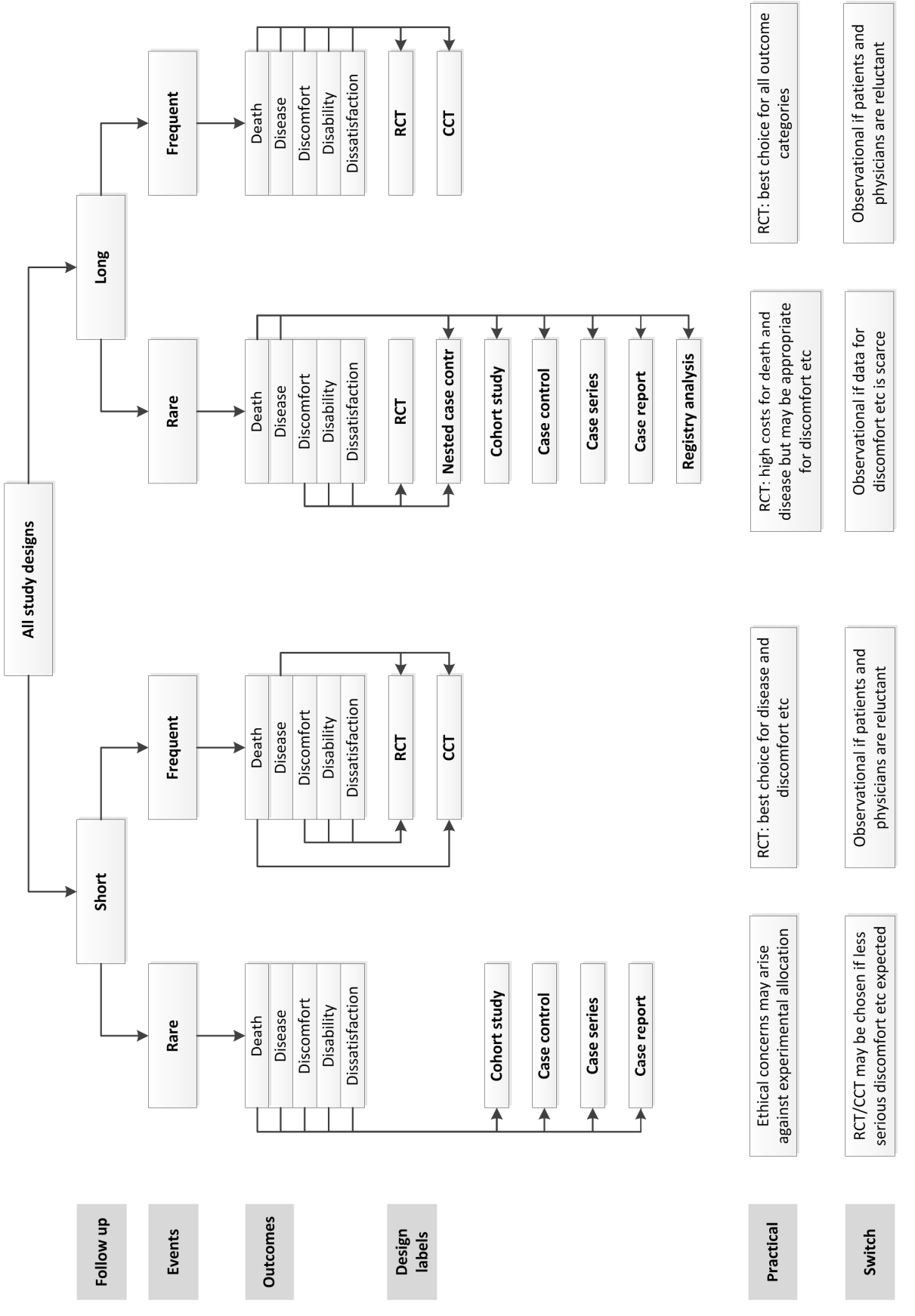




\section{Relevance}

The use of multiple study designs in systematic reviews clearly showed that various study designs increased the information that should be considered in decision-making. The impact of the extra information may not be foreseen very well. The extra information may complement the best available evidence based on randomized controlled trials by adding new important data and by opening the horizon to bring attention to issues that may be overlooked but are nevertheless pertinent to health care. Sometimes information from multiple study designs can induce prudence in those who decide about an acclaimed new intervention. For example, randomized controlled trials may not be the typical study design to provide sufficient evidence for market withdrawals.

\section{Target groups}

The algorithm is foreseen to function as a tool helping to bring seminal features of a systematic review to the attention of anyone who is planning to conduct a systematic review. This includes persons working in organizations or institutes that prepare health technology assessment reports, evidence reports, or systematic reviews on health care interventions. It helps to reorientate oneself to major features of the studies eligible for an evaluation of a health care intervention. This is not meant to add a new regulation, but the benefit is the provision of awareness of the value of different study designs in systematic reviews. The intention is to provide a guide that might be used fully or partially by persons who are going to prepare a systematic review. While conducting a systematic review, it may be important at an early time point to identify the relevant and the most appropriate study designs necessary to find answers for a variety of prespecified outcomes. It might also be of interest for persons who evaluate the quality of systematic reviews and might want to check whether all study relevant designs have indeed been considered. This may include individual physicians who intend to make evidence-based decisions on the treatment of their patients, although it will not be easy for busy clinicans to do so. It should also include persons with positions on a more collective level of evidence synthesis, such as scientists of academic institutions and members of guideline committees who critically assess the published evidence on various health care interventions, and staff of governmental administrations that make political decisions on the reimbursement of public health care services. 


\section{Activities/Products}

Five of the six results chapters have been published in article format. The results of one remaining chapter are submitted to a journal and the manuscript will hopefully be accepted for publication in the near future. The publication will provide introduction and explanation of its target population, aims purposes, and its optimal use. The article is planned to published in an open access journal, a scholarly journal that is available online worldwide to all potential readers who can use the internet. In general, an article published in this way will have a particular internet site, which contains tools for instant feedback to the authors, general comments, recommendations passed on to others, and links to social networks such as Twitter. The algorithm is embedded in a manuscript and, as mentioned earlier, is submitted to an open access journal. It is also planned to submit the work to the Cochrane Colloquium, a meeting of persons who are international experts in the field of conducting and assessing systematic reviews.

\section{Innovation}

I looked at the methods guidance documents of high profile not-for-profit publishers of systematic reviews and health technology assessments of health care interventions. I did not find an existing algorithm providing guidance for systematic reviewers to choose the most appropriate study designs. It appears that the algorithm may be the first comprehensive decision tree available. Subsequently, I developed a decision support tree using length of follow-up, frequency of events, and type of outcomes as main decision points. It was ensured that the preset pathways retain sufficient flexibility to consider ethical and practical issues as well as unavailable best evidence. The constructed algorithm was tested in four systematic reviews to evaluate whether our reasoning based on theory is applicable in practice. Although it appeared that the algorithm is proper for projection of various research questions on the delineated pathways, disease-specific circumstances and aims of interventions have always to be taken into account during application of the algorithm.

\section{Schedule \& Implementation}

The algorithm should be tried by more than just one person to allow any conclusions on its usefulness. The systematic reviews conducted with the use of the algorithm should have other types of population, intervention, comparator, and outcome than those contained in the systematic reviews of this thesis. First, it is recommend to continue the refinement of requirements for nonrandomized controlled clinical trials. Second, it is recommended to evaluate whether all Cochrane Reviews should include 
multiple study designs to cover the various main objectives. Third, it is recommended to elaborate whether the implementation of an algorithm can support the quality and scope of a systematic review. Persons who are willing to use the algorithm should be provided with an instruction manual that includes further interpretations and explanations. Training needs should be predicted and addressed. Educational seminars should be offered to elucidate the various pathways of the algorithm and the process of choosing the most appropriate study designs required to answer the important research questions of a systematic review. 



\section{Curriculum vitae}

Frank Peinemann was born on 27 December 1959 in Northeim, Germany. In 1987, he graduated from Medical School and in 1989 he was promoted Dr. med. for his dissertation in the field of molecular genetics at the University of Gottingen, Germany (unigoettingen.de). He is recipient of two grants from the DFG German Research Foundation (dfg.de), a 2-year fellowship grant to conduct molecular genetic research at Emory University, Atlanta, USA (emory.edu), and a financial support for laboratory equipment in Gottingen (humangenetik.gwdg.de). During his stay in the USA, he passed the exams of the ECFMG Educational Commission of Foreign Medical Graduates, Philadelphia, Pennsylvania, USA (ecfmg.org).

After various employments in medical care of infants, children, and adolescents (uniklinik-duesseldorf; klinikumfrankfurt.de; herzzentrum.uk-koeln.de/de/kinderkardiologie), and after continuing medical education, the medical board authorities awarded him certificates in pediatrics, medical genetics, pediatric cardiology, neonatology, medical informatics, and medical quality management. During his employment with the BQS German National Institute for Quality Measurement in Health Care, Dusseldorf, Germany (bqs-institut.de), he participated in the development of quality indicators in various fields to conduct external quality assurance and benchmarking of German hospitals. Then he started his current employment with the IQWiG Institute for Quality and Efficiency in Health Care, Koln, Germany (iqwig.de). His main job is to conduct systematic reviews on interventions in health care in various fields, which are commissioned by the G-BA Federal Joint Committee, Berlin, Germany (g-ba.de).

He was promoted Master of Science in Epidemiology after completing his studies and master thesis at the universities in Mainz and Essen, Germany (unimedizinmainz.de/imbei; imibe.de). He is lecturer in Pediatrics at the Children's Hospital of the University of Cologne, Germany (kinderklinik.uk-koeln.de). He is also lecturer in Public Health on a freelance basis at FOM University of Applied Science for Economics \& Management, Essen, Germany (fom.de). He works with several Cochrane Review Groups to conduct Cochrane systematic reviews on interventions in health care. He publishes articles in international peer-reviewed journals (pubmed.gov), presentations at international meetings, and provides peer reviews for prestigious scholarly journals (publons.com). 



\section{Publications}

\section{Chapters 2 to 6 are based on the following published articles}

Peinemann F, Tushabe DA, Kleijnen J. Using multiple types of studies in systematic reviews of health care interventions - a systematic review. PLoS One. 2013;8(12): e85035.

Peinemann F, Smith LA, Bartel C. Autologous hematopoietic stem cell transplantation following high dose chemotherapy for non-rhabdomyosarcoma soft tissue sarcomas. Cochrane Database of Systematic Reviews. 2013;8:CD008216.

Peinemann F, Grouven U, Kroger N, Bartel C, Pittler MH, Lange S. First-line matched related donor hematopoietic stem cell transplantation compared to immunosuppressive therapy in acquired severe aplastic anemia. PLoS One. 2011;6(4):e18572.

Peinemann F, Grouven U, Bartel C, Sauerland S, Borchers H, Pinkawa M, Heidenreich $A$, Lange $S$. Permanent interstitial low-dose-rate brachytherapy for patients with localised prostate cancer: a systematic review of randomised and nonrandomised controlled clinical trials. European Urology. 2011;60(5):881-93.

Peinemann F, Sauerland S. Negative-pressure wound therapy: systematic review of randomized controlled trials. Deutsches Arzteblatt International. 2011;108(22):381-9.

\section{Chapter 7 is based on the following submitted manuscript}

Peinemann F, Kleijnen J. Development of an algorithm to provide awareness in choosing study designs for inclusion in systematic reviews of health care interventions - a method study. 


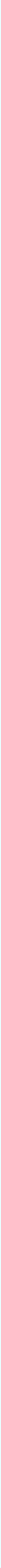

